\title{
The Role of the P2X7 Nucleotide Receptor in Salivary Gland Inflammation
}

\author{
A Dissertation \\ presented to \\ the Faculty of the Graduate School \\ at the University of Missouri-Columbia \\ In Partial Fulfillment \\ of the Requirements for the Degree \\ Doctor of Philosophy \\ By: Mahmoud G. Khalafalla \\ Dissertation Supervisor: Dr. Gary A. Weisman \\ December 2017
}


The undersigned, appointed by the dean of the Graduate School, have examined the dissertation entitled:

The Role of the P2X7 Nucleotide Receptor in Salivary Gland Inflammation

presented by Mahmoud Khalafalla, a candidate for the degree of doctor of philosophy, and hereby certify that, in their opinion, it is worthy of acceptance.

Professor Dr. William Durante

Professor Dr. Michael J. Petris

Professor Dr. Laurie Erb

Professor Dr. Gary A. Weisman 


\section{Acknowledgements}

Firstly, I would like to express my sincere gratitude to my advisor Prof. Dr.

Gary A. Weisman who provided me a great opportunity to join his research team. I am extremely grateful for his invaluable insights, suggestions, guidance and all the useful discussions and brainstorming sessions which helped me at various stages of my research. Being mentored by a worldwide known scientist has always inspired me to follow his footsteps in my research career. Thank you for inspiring me, encouraging me and being always very patient and understanding. Without your precious support it would not be possible to conduct this research.

I would also like to thank the members of my committee: Drs. Michael Petris, Laurie Erb and William Durante, for their insightful discussions and suggestions that helped me proceed steadily in my Ph.D. career.

My sincere gratitude also goes to Mrs. Jean Camden for the continuous support of my Ph.D. study and related research and for her patience, motivation, and immense knowledge. Her guidance helped me in the research and writing of this thesis.

Also, I would like to thank my labmate Lucas Woods for the stimulating discussions, suggestions, encouragement and motivation at various stages of my research.

I am also grateful to my current and former labmates, Drs. Adam Martin, Kimberly Jasmer, Chen Cao (Cheery) and Deepa Viswanathan who greatly helped enhance my graduate career. 
I consider myself blessed to be in such a wonderful environment on the fifth floor of the Life Sciences Center (Weisman and Petris labs) surrounded by experienced and knowledgeable lab mates that I now call family. I would like to express my sincere gratitude to my friends, Dr. Aslam Khan, Vinit Shanbhag and Nikita Gudekar for the great time, helpful comments and suggestions, encouragement and motivation throughout my Ph.D.

My thanks also go to my friends whom I was blessed with since I landed in the U.S., especially, Dr. Chady Hakeem and his beautiful family, Dr. Saif Khayrat and Dr. Bassem Shebl.

My sincere thanks are reserved for my wife Dr. Marwa Elnahas and my kids Khadija and Yahya. I would like to express my deepest gratitude and appreciation to my wonderful wife Marwa who was always my support in the moments when there was no one to answer my queries. Thank you for being extremely wise and understanding no matter how busy and overwhelmed I was. Thank you for being a constant source of strength, inspiration, encouragement and motivation. To Marwa, Khadija and Yahya, thank you for bringing such happiness and joy with your smiles to my life.

I am also very thankful to my beloved parents-in-law, General Omar Elnahas and Mrs. Nagwa Eldeqeeny, who provided me with constant emotional support, encouragment and motivation. Without their precious support it would not be possible to conduct this research. I would also like to thank my brother in-law and sisters in-law for their kindness, love, encouragement, thoughtfulness, unconditional support and prayers which supported me spiritually throughout my $\mathrm{Ph} . \mathrm{D}$. journey. 
Last but definitely not least, there are not enough words to express how thankful and grateful I am to my great parents, Prof. Dr. Galal Khalafalla and Mrs. Soad Barakat, who provided me with unconditional love and care and taught me about hard work and selfrespect, about persistence and about how to be independent. Thank you for being a great role model of resilience, strength and character. I would also like to thank my brother Farid Khalafalla and his wife Emily Nation for their kindness, love, encouragement, thoughtfulness, unconditional support and prayers which supported me spiritually throughout my Ph.D. journey.

Thank you for my family and friends for sharing with me all the beautiful moments in my life and making these memories much more valuable by having you around. Thank you for helping me get over every challenge I've faced throughout my life until I reached this level, defending my Ph.D. thesis. Without your love and support definitely I would not have made it this far. I love you most and I will forever be thankful and grateful to you. 


\section{Table of Contents}

\begin{tabular}{|c|c|}
\hline Acknowledgements & ii \\
\hline List of Abbreviations & viii \\
\hline List of Figures & $\mathrm{xi}$ \\
\hline Abstract & xiii \\
\hline Chapter I. Introduction & 1 \\
\hline 1.1 Sjögren's syndrome & 1 \\
\hline 1.1.1 Etiology of SS & 2 \\
\hline 1.1.1.1 Genetic factors & 2 \\
\hline 1.1.1.2 Epigenetics & 3 \\
\hline 1.1.1.3 Hormonal factors & 3 \\
\hline 1.1.1.4 Environmental factors & 4 \\
\hline 1.1.2 Current treatments for SS & 4 \\
\hline 1.2. Epithelial cells as antigen-presenting cells & 4 \\
\hline 1.3. P2X7 nucleotide receptor & 6 \\
\hline 1.4 P2X7R and inflammation & 8 \\
\hline 1.5 P2X7R and the inflammasome & 11 \\
\hline 1.6 P2X7R and apoptosis & 15 \\
\hline 1.7 $\quad$ P2X7R and autoimmune diseases & 16 \\
\hline $\begin{array}{ll}1.8 & \text { P2X7R and clinical studies }\end{array}$ & 18 \\
\hline 1.9 P2X7R and salivary gland function & 18 \\
\hline $1.10 \mathrm{P}_{2} \mathrm{Y}_{2}$ nucleotide receptor & 19 \\
\hline 1.11 Mouse models of salivary gland inflammation & 19 \\
\hline $\begin{array}{l}\text { 1.11.1 } \mathrm{CD}^{-8^{-1}} \text {, IFN } \gamma^{-1-} \text {, NOD.H-2 } 2^{\mathrm{h} 4} \text {, a murine model of salivary } \\
\text { gland autoimmune exocrinopathy }\end{array}$ & 19 \\
\hline 1.11.2 Salivary gland duct ligation/deligation mouse model & 20 \\
\hline 1.12 Research goals and experimental approaches & 21 \\
\hline $\begin{array}{l}\text { Chapter II. P2X7 receptor antagonism prevents IL-1ß release from } \\
\text { salivary epithelial cells and reduces inflammation in a mouse } \\
\text { model of autoimmune exocrinopathy }\end{array}$ & 23 \\
\hline Abstract & 23 \\
\hline 2.1 Introduction & 24 \\
\hline 2.2 Results & 27 \\
\hline
\end{tabular}




\begin{tabular}{|c|c|}
\hline $\begin{array}{l}\text { 2.2.1 P2X7R activation induces the release of IL-1 } \beta \text { in primary } \\
\text { SMG epithelial cell aggregates from wild type, but not } \\
\text { P2X7R } \mathrm{R}^{-1-} \text {, mice }\end{array}$ & 27 \\
\hline $\begin{array}{l}\text { 2.2.2 NLRP3 inflammasome activation is required for P2X7R- } \\
\text { mediated IL-1 } \beta \text { release in primary SMG epithelial cell } \\
\text { aggregates }\end{array}$ & 28 \\
\hline $\begin{array}{l}\text { 2.2.3 Ionic dependence of P2X7R-mediated IL-1 } \beta \text { release in } \\
\text { primary SMG epithelial cell aggregates }\end{array}$ & 29 \\
\hline $\begin{array}{l}\text { 2.2.4 Inhibition of ROS production significantly reduces P2X7R- } \\
\text { mediated IL-1 } \beta \text { release in primary SMG epithelial cell } \\
\text { aggregates }\end{array}$ & 30 \\
\hline $\begin{array}{l}\text { 2.2.5 Functional Heat Shock Protein } 90 \text { (HSP90) is required for } \\
\text { P2X7R-mediated IL-1 } \beta \text { release in primary SMG epithelial cell } \\
\text { aggregates }\end{array}$ & 31 \\
\hline $\begin{array}{l}\text { 2.2.6 In vivo administration of the P2X7R antagonist A438079 } \\
\text { reduces salivary gland inflammation and improves saliva flow } \\
\text { in the CD } 28^{-1-} \text {, IFN } \gamma^{-1-} \text {, NOD.H- } 2^{\mathrm{h} 4} \text { mouse model of salivary } \\
\text { gland exocrinopathy }\end{array}$ & 31 \\
\hline 2.3 Discussion & 33 \\
\hline 2.4 Experimental procedures & 39 \\
\hline $\begin{array}{l}\text { Chapter III. Alternative therapeutic approaches for salivary gland } \\
\text { inflammation and fibrosis }\end{array}$ & 59 \\
\hline $\begin{array}{l}\text { 3.1 } \mathrm{P}_{2} \mathrm{Y}_{2} \text { nucleotide receptor activation enhances the aggregation and } \\
\text { self-organization of dispersed salivary epithelial cells }\end{array}$ & 59 \\
\hline $\begin{array}{l}\text { 3.2 Increased expression of TGF- } \beta \text { signaling components in a mouse } \\
\text { model of fibrosis induced by submandibular gland duct ligation }\end{array}$ & 60 \\
\hline Chapter IV. Summary and future directions & 62 \\
\hline 4.1 Summary & 62 \\
\hline 4.2 Future directions & 65 \\
\hline $\begin{array}{l}\text { 4.2.1 Investigating the role of the P2X7R in salivary gland } \\
\text { epithelial cells (SGECs) as nonprofessional antigen- } \\
\text { presenting cells. }\end{array}$ & 65 \\
\hline 4.2.2 Investigating the genetics of $\mathrm{P} 2 \mathrm{X} 7 \mathrm{R}$ in SS & 66 \\
\hline References & 68 \\
\hline $\begin{array}{l}\text { Appendix I } \mathrm{P2Y}_{2} \text { nucleotide receptor activation enhances the } \\
\text { aggregation and self- organization of dispersed salivary } \\
\text { epithelial cells }\end{array}$ & 99 \\
\hline
\end{tabular}




\begin{tabular}{|l|c|}
\hline $\begin{array}{c}\text { Appendix II Increased expression of TGF- } \beta \text { signaling components in a } \\
\text { mouse model of fibrosis induced by submandibular gland } \\
\text { duct ligation }\end{array}$ & 153 \\
\hline Vita & 209 \\
\hline
\end{tabular}




\section{List of Abbreviations}

\begin{tabular}{|c|c|}
\hline ADAM10/17 & a disintegrin and metalloproteinases $10 / 17$ \\
\hline ASC & apoptosis-associated speck like protein containing a CARD \\
\hline ATP & adenosine 5 '-triphosphate \\
\hline BAFF & $\mathrm{B}$ cell activating factor \\
\hline CARD & carboxy terminal caspase recruiting domain \\
\hline DAMP & damage-associated molecular pattern \\
\hline eATP & extracellular ATP \\
\hline EGFR & epidermal growth factor receptor \\
\hline ER & endoplasmic reticulum \\
\hline ERK1/2 & extracellular signal-regulated kinases $1 / 2$ \\
\hline GA & geldanamycin \\
\hline HSP90 & heat shock protein 90 \\
\hline ICAM-1 & intracellular cell adhesion molecule \\
\hline ICP-OES & inductively coupled plasma optical emission spectrometer \\
\hline IFN- $\alpha$ & interferon- $\alpha$ \\
\hline
\end{tabular}




\begin{tabular}{|c|c|}
\hline IFN- $\gamma$ & interferon- $\gamma$ \\
\hline IL-18 & interleukin-18 \\
\hline IL-1 $\beta$ & interleukin-1 $\beta$ \\
\hline IL-6 & interleukin-6 \\
\hline LRR & leucine rich domain \\
\hline MAPK & mitogen-activated protein kinase \\
\hline MHC II & major histocompatibility complex class II \\
\hline NAC & $N$-acetyl cysteine \\
\hline NLRP3 & NLR family pyrin domain containing protein 3 \\
\hline NOD & nucleotide-binding oligomerization domain \\
\hline NOD.H-2 ${ }^{\mathrm{h} 4}$ mouse & non-obese diabetic $\mathrm{H}-2^{\mathrm{h} 4}$ mouse \\
\hline NOX & NADPH oxidase \\
\hline PAMP & pathogen-associated molecular pattern \\
\hline PYD & pyrin domain \\
\hline RA & rheumatoid arthritis \\
\hline ROS & reactive oxygen species \\
\hline
\end{tabular}




\begin{tabular}{|c|c|}
\hline SGECs & salivary gland epithelial cells \\
\hline SLE & systemic lupus erythematosus \\
\hline SMG & submandibular gland \\
\hline SS & Sjögren's syndrome \\
\hline TAB1 & TAK binding protein-1 \\
\hline TAK1 & transforming growth factor- $\beta$-activated kinase \\
\hline TNF- $\alpha$ & tumor necrosis factor- $\alpha$ \\
\hline Type 1 IFN & Type 1 interferone \\
\hline UTP & uridine 5'-triphosphate \\
\hline VCAM & vascular cell adhesion molecule \\
\hline
\end{tabular}




\section{List of Figures}

\begin{tabular}{|c|c|c|}
\hline Figure & Title & Page \\
\hline I-1 & The structure of P2X7R & 8 \\
\hline I-2 & The NLRP3 inflammasome & 13 \\
\hline II-1 & $\begin{array}{l}\text { P2X7R activation induces the release of IL-1 } \beta \text { in primary mouse } \\
\text { SMG cell aggregates }\end{array}$ & 47 \\
\hline II-2 & $\begin{array}{c}\text { The NLRP3 inflammasome mediates P2X7R-induced IL-1 } \beta \\
\text { release }\end{array}$ & 49 \\
\hline III-3 & $\mathrm{Na}^{+}$and/or $\mathrm{K}^{+}$flux is required for P2X7R induced IL- $1 \beta$ release & 50 \\
\hline II-4 & Mitochondrial ROS contribute to P2X7R-induced IL- $1 \beta$ release & 51 \\
\hline II-5 & HSP90 is crucial for P2X7R-induced IL- $1 \beta$ release & 52 \\
\hline II-6 & $\begin{array}{l}\text { P2X7R antagonism ameliorates salivary gland inflammation in } \\
\qquad \mathrm{CD} 28^{-/-}, \mathrm{IFN}^{-/-}, \mathrm{NOD} \cdot \mathrm{H}-2^{\mathrm{h} 4} \text { mice }\end{array}$ & 53 \\
\hline II-7 & $\begin{array}{l}\text { P2X7R antagonism reduces } I L-1 B \text { expression in } \mathrm{CD} 28^{-1-}, \mathrm{IFN} \gamma^{-1-} \text {, } \\
\text { NOD.H- } 2^{\mathrm{h} 4} \text { mice. }\end{array}$ & 54 \\
\hline II-8 & $\begin{array}{l}\text { P2X7R antagonism reduces expression of immunoactive molecules } \\
\text { in } \mathrm{CD} 28^{--_{-}}, \mathrm{IFN} \gamma^{--}, \mathrm{NOD} \cdot \mathrm{H}-2^{\mathrm{h} 4} \text { mice }\end{array}$ & 55 \\
\hline II-9 & $\begin{array}{l}\text { P2X7R antagonism improves saliva flow rate in } \mathrm{CD} 28^{-1-}, \mathrm{IFN}^{-1-} \text {, } \\
\text { NOD.H- } 2^{\mathrm{h} 4} \text { mice }\end{array}$ & 56 \\
\hline II-10 & $\begin{array}{l}\text { Schematic diagram illustrating the proposed role of the P2X7R in } \\
\text { salivary gland inflammation. }\end{array}$ & 58 \\
\hline Appendix I-1 & $\begin{array}{l}\text { UTP enhances Par-C10 cell aggregation and the formation of } \\
\text { acinar-like spheres on growth factor reduced (GFR) Matrigel }\end{array}$ & 122 \\
\hline Appendix I-2 & $\begin{array}{l}\text { Inhibition of epidermal growth factor (EGF) receptor (EGFR) } \\
\text { activation decreases UTP-induced enhancement of Par-C10 cell } \\
\text { aggregation }\end{array}$ & 124 \\
\hline Appendix I-3 & $\begin{array}{l}\text { Inhibition of metalloproteases ADAM10/ADAM17 decreases } \\
\text { UTP-induced enhancement of Par-C10 cell aggregation and EGFR } \\
\text { phosphorylation }\end{array}$ & 126 \\
\hline
\end{tabular}




\begin{tabular}{|c|c|c|}
\hline Appendix I-4 & $\begin{array}{l}\text { Inhibition of the } \alpha_{5} \beta_{1} / \mathrm{Cdc} 42 \text { signaling pathway decreases UTP- } \\
\text { induced Par-C10 cell aggregation and EGFR phosphorylation }\end{array}$ & 128 \\
\hline Appendix I-5 & $\begin{array}{l}\text { UTP-induced enhancement of Par-C10 cell aggregation is } \\
\text { dependent on the activation of JNK and ERK1/2 by the EGFR }\end{array}$ & 130 \\
\hline Appendix I-6 & $\begin{array}{l}\mathrm{P}^{2} \mathrm{Y}_{2} \text { receptor }\left(\mathrm{P} 2 \mathrm{Y}_{2} \mathrm{R}\right) \text { mediates UTP-induced migration of } \\
\text { primary submandibular gland }(\mathrm{SMG}) \text { cell aggregates }\end{array}$ & 132 \\
\hline Appendix I-7 & $\begin{array}{l}\mathrm{P}_{2} \mathrm{Y}_{2} \mathrm{R} \text {-induced migration of primary SMG cell aggregates is } \\
\text { dependent on EGFR. }\end{array}$ & 133 \\
\hline Appendix I-8 & $\begin{array}{c}\text { Proposed mechanisms for } \mathrm{P}_{2} \mathrm{Y}_{2} \mathrm{R}-\text { mediated enhancement of } \\
\text { salivary epithelial cell aggregation and formation of acinar-like } \\
\text { spheres }\end{array}$ & 135 \\
\hline Appendix II-1 & $\begin{array}{l}\text { Submandibular gland ductal ligation followed by deligation results } \\
\text { in reversible acinar cell atrophy, immune cell infiltration and } \\
\text { glandular fibrosis }\end{array}$ & 177 \\
\hline Appendix II-2 & $\begin{array}{l}\text { Upregulation of TGF- } \beta 1 \text {, TGF- } \beta 3 \text { and TGF- } \beta \text { R1 in response to } \\
\text { SMG duct ligation is reversible upon deligation }\end{array}$ & 179 \\
\hline Appendix II-3 & $\begin{array}{l}\text { Upregulation of Smad2/3, TAK1 and TAB1 in response to SMG } \\
\text { duct ligation is reversible upon duct deligation }\end{array}$ & 181 \\
\hline Appendix II-4 & $\begin{array}{l}\text { Upregulation of Snail and Slug in response to SMG duct ligation is } \\
\text { reversible upon duct deligation }\end{array}$ & 183 \\
\hline Appendix II-5 & $\begin{array}{l}\text { E-cadherin upregulation in response to SMG duct ligation is } \\
\text { reversible after duct deligation. }\end{array}$ & 185 \\
\hline Appendix II-6 & $\begin{array}{l}\text { Glandular fibrosis following SMG duct ligation is resolved } \\
\text { following deligation }\end{array}$ & 187 \\
\hline Appendix II-7 & $\begin{array}{l}\text { TGF- } \beta \text { R1 inhibitors SB431542 and GW788388 attenuate duct } \\
\text { ligation-induced upregulation of fibrosis markers }\end{array}$ & 188 \\
\hline
\end{tabular}




\section{ABSTRACT}

Salivary gland inflammation is a hallmark of Sjögren's syndrome (SS), a common autoimmune disease characterized by lymphocytic infiltration and the consequent impairment of the salivary gland and loss of saliva secretion, predominantly in women. The current therapeutic management of SS is relatively ineffective and does not address the underlying inflammatory processes contributing to the pathology of SS. In this study, two novel therapeutic approaches were evaluated to limit salivary gland inflammation and improve secretory function, i.e., antagonism of the $\mathrm{P} 2 \mathrm{X} 7$ nucleotide receptor (P2X7R), which prevents salivary gland inflammation and activation of the $\mathrm{P} 2 \mathrm{Y}_{2}$ nucleotide receptor $\left(\mathrm{P} 2 \mathrm{Y}_{2} \mathrm{R}\right)$ which stimulates the regeneration of damaged salivary glands. The P2X7R is an ATP-gated non-selective cation channel that regulates inflammatory responses in cells and tissues, including salivary gland epithelium. The $\mathrm{P} 2 \mathrm{X} 7 \mathrm{R}$ contributes to the pathology of a variety of inflammatory diseases, including rheumatoid arthritis and inflammatory bowel disease. In immune cells, P2X7R activation induces the production of pro-inflammatory cytokines, including IL-1 $\beta$ and IL-18, by inducing the oligomerization of the multiprotein complex NLRP3-type inflammasome. This study (Chapter II) sheds light on the role of the P2X7R in salivary gland inflammation and hyposalivation. Our results show that in primary mouse submandibular gland (SMG) epithelial cells, P2X7R activation induces the assembly of the NLRP3 inflammasome and the maturation and release of IL-1 $\beta$, responses that are absent in SMG cells isolated from mice devoid of P2X7Rs $\left(\mathrm{P} 2 \mathrm{X} 7 \mathrm{R}^{-/-}\right)$. P2X7R-mediated IL-1 $\beta$ release in SMG epithelial cells is dependent on downhill transmembrane $\mathrm{Na}^{+}$and/or $\mathrm{K}^{+}$fluxes, the activation of heat shock protein 90 (HSP90), a protein required for the activation and 
stabilization of the NLRP3 inflammasome, and the generation of mitochondrial ROS. In vivo administration of the P2X7R antagonist $\mathrm{A} 438079$ in the $\mathrm{CD} 28^{-/}$, IFN $\gamma^{-/-}$, NOD.H-2 ${ }^{\mathrm{h} 4}$ mouse model of salivary gland exocrinopathy ameliorated salivary gland inflammation and enhanced carbachol-induced saliva secretion. These findings demonstrate that P2X7R antagonism in vivo represents a promising therapeutic strategy to limit salivary gland inflammation and improve secretory function. The $\mathrm{P} 2 \mathrm{Y}_{2} \mathrm{R}$, a G protein-coupled receptor equipotently activated by ATP and UTP, is upregulated in a variety of tissues, including salivary gland epithelium, in response to injury or stress and is proposed to play a role in tissue regeneration. The results indicated that $\mathrm{P} 2 \mathrm{Y}_{2} \mathrm{R}$ activation with UTP enhances the migration, aggregation and self-organization of dispersed salivary epithelial cells forming spheres that display characteristics similar to differentiated acini in salivary glands.

One of the consequences of the chronic inflammatory disease SS is the fibrosis of the salivary gland. The role of transforming growth factor- $\beta$ (TGF- $\beta$ ) is well established in the fibrosis and regeneration of various organs, including the liver, lung and kidney. In this study, results with a submandibular gland (SMG) duct ligation-induced mouse model of fibrosis indicated that 7 days of SMG duct ligation resulted in upregulation of TGF- $\beta$ signaling components which correlated with the upregulation of the fibrosis markers collagen 1 and fibronectin, responses that were inhibited by administration of the TGF- $\beta$ receptor 1 inhibitors. These results suggest that TGF- $\beta$ signaling contributes to duct ligation-induced changes in salivary epithelium that correlate with glandular fibrosis. 


\section{Chapter I}

\section{Introduction}

Salivary gland is an exocrine gland whose function is to produce saliva ${ }^{l}$. Salivary glands are classified into major and minor salivary glands according to their size. There are three pairs of major salivary glands, namely the parotid, submandibular and sublingual glands. Also, there are many minor salivary glands lining the oral cavity $^{l}$. Saliva plays a very important role in helping gustatory buds perceive taste, and help protect and lubricate oral tissues, thereby maintaining the integrity of tooth enamel in addition to its roles in digestion and as a bactericide ${ }^{2}$. Accordingly, salivary gland dysfunction greatly diminishes the quality of life of patients causing hyposalivation, dry mouth, oral bacterial and yeast infections and speech problems ${ }^{2}$. One of the major causes of salivary gland dysfunction and hyposalivation is Sjögren’s syndrome (SS), the major focus of this study, which is an autoimmune inflammatory disease that affects exocrine glands, particularly salivary and lacrimal glands ${ }^{3}$. Another cause of salivary gland dysfunction is the unintended secondary effect of radiotherapy in head and neck cancer patients ${ }^{4}$

\subsection{Sjögren's syndrome}

Sjögren's syndrome (SS) is a chronic autoimmune inflammatory disorder that affects exocrine glands, particularly lacrimal and salivary glands ${ }^{3}$. One of the hallmarks of (SS) is the mononuclear cell infiltration of salivary glands, mainly T- and B-cells ${ }^{3}$, dendritic cells ${ }^{5}$ and macrophages ${ }^{6}$. The infiltrating cells produce pro-inflammatory 
cytokines, e.g., IL-18, IL-22 and IFN- $\gamma$ in addition to IL-1 $\beta$ and IL-6 produced by immune cells or salivary gland epithelial cells ${ }^{3,7,8}$. Another characteristic of (SS) is the production of high levels of immunoglobulins and the autoantibodies anti-Ro and antiLa (against ribonucleoprotein complexes) ${ }^{9}$, anti- $\alpha$-fodrin ${ }^{10-12}$ (against a membrane associated cytoskeletal protein), anti-muscarinic receptor-3, that inhibits saliva production and aquaporin translocation to the plasma membrane ${ }^{13,14}$, and anti-RF (rheumatoid factor) $^{15}$. It has been reported that autoantibodies purified from the serum of SS patients activate the intrinsic and extrinsic apoptotic pathways in the A-253 salivary gland cell line ${ }^{16}$. The inflammatory responses together with apoptosis activation lead to destruction of the salivary gland and consequently salivary gland dysfunction and hyposalivation ${ }^{17}$.

\subsubsection{Etiology of SS}

The etiology of SS is currently unclear, although some potential contributing factors are described below.

\subsubsection{Genetic factors}

A genetic predisposition was suggested to influence the susceptibility and initiation of SS. The prevalence of some major histocompatibility complex (HLA) alleles, e.g., HLA-DR3, was reported and correlated with the production of the autoantibodies anti-Ro and anti-La ${ }^{18}$. Also, in SS patients, single nucleotide polymorphisms were seen in the genes for IFN- $\gamma$ regulating factor- $5^{19}$, required for IFN- $\gamma$ synthesis, and $\mathrm{BAFF}^{20}$, a transcription factor responsible for B-cell differentiation and activation. Moreover, the low serotonin levels in SS patients were 
shown to result from polymorphisms in the serotonin reporter gene (5-HTT), where certain variants of the 5-HTT are repeatedly seen in SS patients ${ }^{21}$.

\subsubsection{Epigenetics}

In addition to genetic factors, epigenetic factors, including defective DNA methylation, also contribute to SS etiology. The dysregulation of methylation of IFNinduced genes was linked to seropositive SS patients ${ }^{22}$. Also, screening of genome wide alterations in DNA methylation in SS patients showed that changes occur mainly in blood B-cells rather than blood T-cells ${ }^{23}$. Similarly, in systemic lupus erythematous, a systemic autoimmune rheumatic disease, dysregulation of T-cell methylation patterns was reported $^{24}$. Interestingly, in salivary glands of SS patients, methylating enzymes were upregulated as compared to healthy controls which could be a defense mechanism to counteract the deleterious increased expression of other inflammatory genes, such as the long interspersed nuclear element 1 (LINE-1) gene that activates the type I IFN pathway, a key inflammatory response in both SS and systemic lupus erythematous ${ }^{25}$. Additionally, it was recently reported that variants of the methylene-tetrahydrofolate reductase (MTHFR) gene contribute to the development of non-Hodgkin lymphoma in SS patients as a result of the dysregulation of DNA methylation ${ }^{26}$.

\subsubsection{Hormonal factors}

The prevalence ratio of SS in females to males is 10:1, and development of the disease in females occurs around the menopause phase, suggesting a role for hormonal factors in the etiology of SS. This was addressed in different studies showing that SS patients acquire reduced expression of androgens, in particular dihydrotestosterone, which is required for the synthesis of estrogen ${ }^{27}$. In addition, mouse models lacking 
aromatase that converts androgen to estrogen or those undergoing ovariectomy showed extensive lymphocytic infiltrates, in both lacrimal and salivary glands ${ }^{28}$.

\subsubsection{Environmental factors}

Among the environmental factors, viruses and stress are reported to contribute to SS pathology. Several viruses, including Epstein-Barr virus, human herpes virus 6 and hepatitis $\mathrm{C}$ virus, were found to induce type 1 IFN inflammatory responses, but no

clear cut relationship with SS has been identified ${ }^{29,30}$. On the other hand, a stressful life has been suggested to trigger SS in susceptible patients ${ }^{31}$.

\subsubsection{Current treatments for SS}

The current therapeutic management of SS is through the stimulation of saliva or tear flow in residual salivary or lacrimal epithelium by administration of muscarinic receptor agonists (i.e., pilocarpine or cevimeline) $)^{32}$, INF- $\alpha^{33}$ or artificial tears ${ }^{34}$. The need for alternative treatments that address the underlying inflammatory processes in $\mathrm{SS}$ is a necessity and could be achieved through antagonizing the $\mathrm{P} 2 \mathrm{X} 7$ purinergic receptor for ATP, which is a putative anti-inflammatory treatment for a variety of inflammatory diseases ${ }^{35,36}$.

\subsection{Epithelial cells as antigen-presenting cells}

There are increasing lines of evidence that epithelial cells play a crucial immunological role in addition to being the physical barrier against infections. Different types of epithelial cells are reported to act as nonprofessional antigenpresenting cells under pathological conditions. For example, esophageal epithelial cells 
contribute to the pathology of eosinophilic esophagitis by acting as nonprofessional antigen-presenting cells that present antigens via major histocompatibility complex class II (MHC II) to activate $\mathrm{T}_{\text {Helper }}\left(\mathrm{T}_{\mathrm{H}}\right)$ cells ${ }^{37}$. Also, primary colon epithelial cells isolated from colitic IL-2 $2^{-/-}$mice showed higher levels of uptake and presentation of antigens by MHC II to $\mathrm{CD}^{+} \mathrm{T}$ cells compared to normal non-inflamed mice ${ }^{38}$.

Furthermore, intestinal epithelial cells induce $\mathrm{T}$ cell activation upon presentation of ovalbumin (OVA) antigen by MHC $11^{39}$.

The inflammatory conditions surrounding salivary gland epithelial cells (SGECs) in SS are believed to result in their activation, inducing "autoimmune epithelitis", where SGECs attract lymphocytes and modulate immune responses, hence, participating actively in the pathogenesis of $\mathrm{SS}^{40-42}$. The epithelial cells from SS patients were reported to have higher constitutive expression (compared to non-disease controls) of several immunoactive molecules, e.g., major histocompatibility complex $(\mathrm{MHC} \text { I and II })^{43}$, costimulatory molecules $(\mathrm{CD} 80 \text { and CD86 })^{43}$, which are ligands for $\mathrm{CD} 28$ required for $\mathrm{T}$ cell activation ${ }^{44,45}$, adhesion molecules (e.g., E-selectin, ICAM-1 and VCAM) required for immune cell homing and apoptotic molecules (e.g., Fas and Fas L) ${ }^{41}$. Activated SGECs also produce B cell activating factor (BAFF) ${ }^{46}$ responsible for B cell survival, maturation and differentiation, and chemokines and proinflammatory cytokines (e.g., IL-1, IL-18, IL-6 and TNF- $\alpha)^{7}$. The aberrant expression and release of these molecules in SS salivary glands suggests that SGECs possibly act as nonprofessional antigen-presenting cells for activating $\mathrm{T}$ cells and modulating innate and adaptive immune responses leading to the pathogenic features of $(\mathrm{SS})^{40,42,43}$.

\subsection{P2X7 nucleotide receptor}


In addition to its role as a source of energy in intracellular metabolism and signaling, ATP is well established as an extracellular signaling molecule that regulates various physiological processes, including immune cell recruitment, neurotransmission and pain perception ${ }^{47-50}$. Under normal conditions, the levels of extracellular ATP (eATP) are tightly regulated by ecto-ATPases ${ }^{51}$, however, in the microenvironment of injured, inflamed or stressed cells, eATP is known to be present at high concentrations $^{52}$. Extracellular ATP is the natural agonist for most members of the purinergic receptor family, which includes the ionotropic P2X (P2X1-7) and the G protein-coupled P2Y $\left(\mathrm{P} 2 \mathrm{Y}_{1,2,4,6,11-15}\right)$ receptors ${ }^{53}$. The $\mathrm{P} 2 \mathrm{X} 7$ receptor $(\mathrm{P} 2 \mathrm{X} 7 \mathrm{R})$ is of particular interest as its activation is linked to a number of inflammatory diseases, e.g., glomerulonephritis, neuroinflammation and rheumatoid arthritis ${ }^{54-57}$. P2X7R is a 595 amino acid protein that includes 2 transmembrane domains, intracellular carboxy and amino termini and a bulky hydrophilic extracellular loop with a cysteine rich region that forms disulfide bridges ${ }^{53,58}$ (Fig. I-1). P2X7R is an ionotropic ligand-gated cation channel $^{53}$ and is activated by high eATP concentration $(100 \mu \mathrm{M})$; mainly present at sites of cell injury or inflammation ${ }^{53}$. Accordingly, the P2X7R is viewed as a detector of high levels of eATP that initiates inflammatory and apoptotic responses ${ }^{58,59}$. The ligand for activation of the $\mathrm{P} 2 \mathrm{X} 7 \mathrm{R}$ is extracellular $\mathrm{ATP}^{4-}$, not ATP, as the activity of the receptor increases when divalent cation concentrations decrease ${ }^{60}$. Brief stimulation of the P2X7R with ATP will cause the depolarization of the plasma membrane due to the opening of a membrane cation channel that promotes the influx of $\mathrm{Na}^{+}$and $\mathrm{Ca}^{2+}$ and the efflux of $\mathrm{K}^{+}$. On the other hand, sustained P2X7R activation by ATP can induce the opening of a pore permeable to hydrophilic molecules up to $900 \mathrm{Da}^{53,61}$. 
Proteomic analysis showed that the P2X7R forms a multiprotein complex with 11 proteins, including laminin $\alpha 3$, integrin $\beta 2, \beta$-actin, $\alpha$-actinin, supervillin, matrix activated MAGuK (membrane-associated guanylate kinase P55), heat shock proteins 70 and 90 (Hsp70, Hsp90), heat shock cognate protein 71 (Hsc71), phosphatidylinositol 4kinase (PI4K) and receptor protein tyrosine phosphatase-beta (RPTP $\beta)$, facilitating the interaction between the extracellular matrix and the intracellular actin cytoskeleton and signaling cascades ${ }^{62}$. More than 500 single nucleotide polymorphisms are known to occur in the $P 2 X 7 R$ which are accompanied by an increase or decrease in receptor function $^{63}$. There are ten known P2X7R isoforms namely P2X7R-B through K, five of which are truncated variants lacking a C-terminus ${ }^{64,65}$. These isoforms tend to heterooligomerize with the full length P2X7R and hence regulate its function ${ }^{64,65}$. For example, P2X7J binds to the full length P2X7R and negatively regulates the receptor's function by blocking P2X7R-induced apoptosis ${ }^{66}$. Several studies investigated the relationship between the expression of the P2X7R variants and the development of diseases $^{67-69}$ but there were no definitive conclusions drawn. 


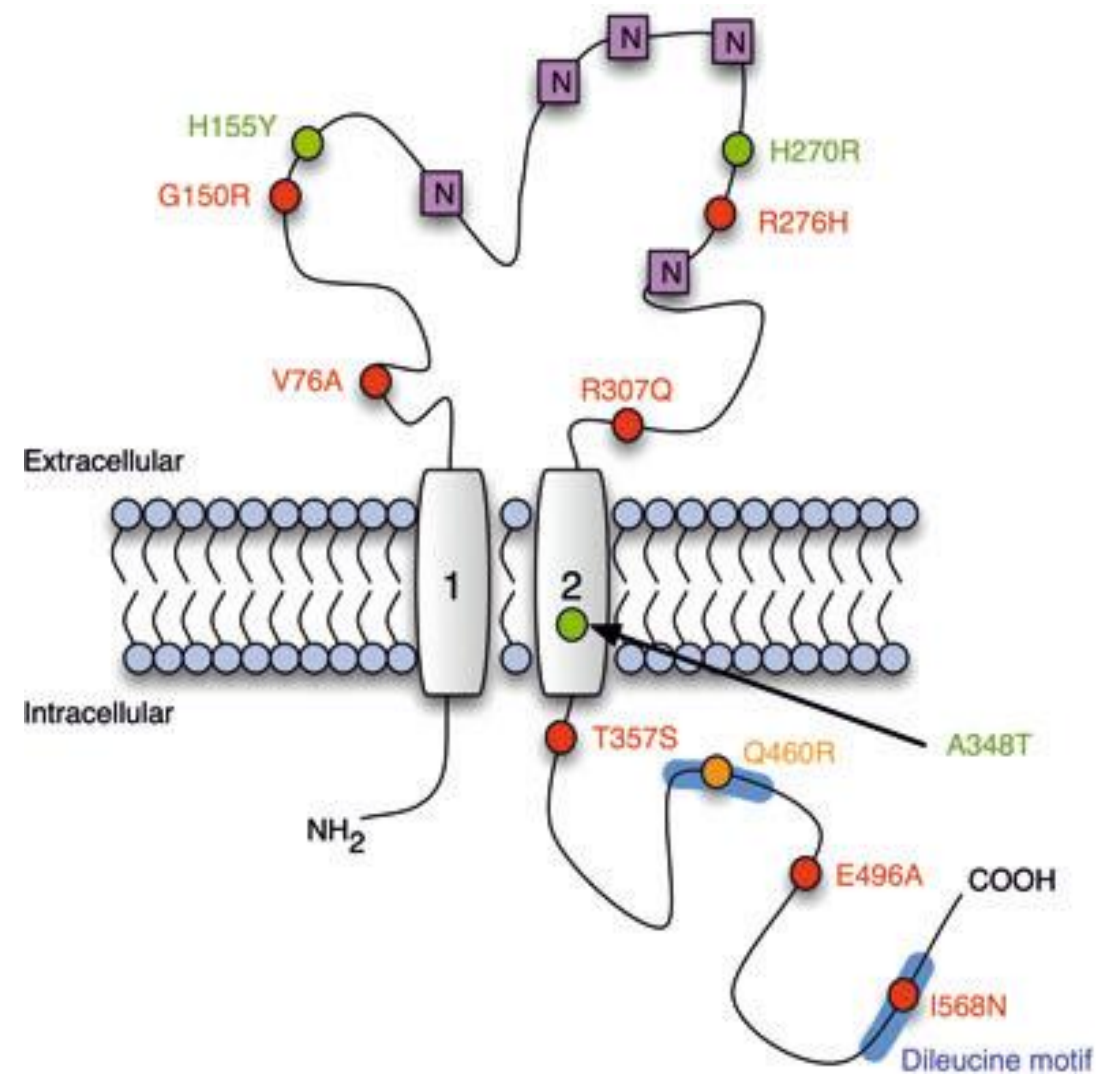

Human P2X7 receptor and innate immunity. J. S. Wiley et al. 2011

Figure I-1 The structure of P2X7R. P2X7R is composed of two transmembrane domains and a bulky extracellular loop. Both the amino (N-) and carboxy (C-) termini reside in the cytoplasm. More than 500 single nucleotide polymorphisms (SNP's) are known in P2X7R, some are gain of function (green circles) and some are loss of function (red circles) mutations and some have no effect (orange). The blue oval clouds are dileucine motifs required for trafficking and protein sorting from the ER to the plasma membrane. The purple boxes are asparagine residues necessary for glycosylation required for proper folding in the ER.

\subsection{P2X7R and inflammation}

The P2X7R is widely expressed in diverse tissues, including hematopoietic cells, neurons, glial cells, bone, muscle, endothelial cells and epithelial cells ${ }^{53}$. High concentrations of eATP act as a "danger signal", which activates the P2X7R to initiate signaling cascades that produce pro-inflammatory cytokines, e.g., IL-1 $\beta$, IL-18, IL-6, IL-8 and TNF- $\alpha$, to enable antigen-presenting cells (APCs) to initiate innate immune responses $^{59,70-74}$. IL-1 $\beta$ is a leaderless pro-inflammatory cytokine whose production stimulates $\mathrm{T}$ cell and macrophage activation, in addition to the expression of cyclic 
oxygenase type $2(\mathrm{COX}-2)^{59}$. The P2X7R plays a key role in the release of IL- $1 \beta$ in monocytes, macrophages and microglia ${ }^{70,75}$. The efficient release of IL- $1 \beta$ requires two consecutive stimuli. The first is an inflammatory insult, e.g., lipopolysaccharide $(\mathrm{LPS})^{76}$, which acts on toll-like receptors (TLRs) to activate the classical nuclear factor $\kappa \mathrm{B}(\mathrm{NF}-\mathrm{\kappa B})$ cascade and produce the immature $31 \mathrm{kDa}$ pro-IL- $1 \beta^{61,63}$. The pro-IL-1 $\beta$ accumulates in the cytoplasm whereupon a second stimulus, eATP, activates the $\mathrm{P} 2 \mathrm{X} 7 \mathrm{R}$ to stimulate the cleavage of immature pro-caspase- 1 to active, mature caspase-1 upon oligomerization of the multiprotein complex NLRP3 type inflammasome $e^{59,77,78}$. Caspase-1 within the inflammasome cleaves immature pro-IL-1 $13(31 \mathrm{kDa})$ to mature IL-1 $\beta(17 \mathrm{kDa})$, which is released to the extracellular milieu ${ }^{77-80}$ (Figure I-2).

In addition to IL-1 $\beta$, the P2X7R is involved in the production of IL-18, i.e., interferon- $\gamma($ IFN- $\gamma)$-inducing factor, in monocytes ${ }^{74,81}$. Immature pro-IL-18 is also cleaved by caspase- 1 to produce mature IL-18 through inflammasome activation ${ }^{82}$. IL18 consequently will modulate the production of other cytokines (e.g., IL-1 $\beta$, IL-6, TNF- $\alpha$ and IFN- $\gamma$ ) and chemokines in addition to increasing the expression of adhesion molecules such as ICAM-1 and VCAM-1 ${ }^{61,81}$. In mast cells, P2X7R stimulation promotes the expression of IL-4, IL-6 and TNF- $\alpha^{71}$. Fibroblasts were also reported to release IL-6 in rheumatoid arthritis and atherosclerosis due to P2X7R activation by ATP present in synovial fluid or released from platelets ${ }^{59,72}$. Moreover, in cultured primary mouse microglial cells, treatment with ATP or the high affinity P2X7R agonist BzATP caused an increase in the release of IL- 6 and the chemokines CCL2 and TNF- $\alpha$, which regulate neurotoxic and neuroprotective responses that are absent in mice devoid of the $\mathrm{P} 2 \mathrm{X} 7 \mathrm{R}\left(\mathrm{P} 2 \mathrm{X} 7 \mathrm{R}^{-1-}\right)^{73,83}$. It is noteworthy to mention that the $\mathrm{P} 2 \mathrm{X} 7 \mathrm{R}$ is 
upregulated in microglial cells surrounding $\beta$-amyloid plaques in the brains of a transgenic Alzheimer's disease mouse model (i.e., $\mathrm{Tg} 2576$ ), where it is responsible for the release of superoxide ions and other pro-inflammatory cytokines that cause neurotoxicity ${ }^{84}$. Also, it was reported that the simultaneous treatment with TNF- $\alpha$ and IFN-y upregulated P2X7R expression in the THP-1 monocytic cell line ${ }^{85}$.

The P2X7R mediates inflammatory responses in various cells, and several different diseases, although the majority of P2X7R studies have been done in immune cells. The P2X7R is responsible for the generation of lung inflammation associated with cigarette smoke in mice, a response that is significantly reduced in $\mathrm{P} 2 \mathrm{X} 7 \mathrm{R}^{-/-}$mice ${ }^{86}$. Similarly, in a neuropathic pain mouse model lacking the P2X7R $\left(\mathrm{P} 2 X 7 \mathrm{R}^{-1-}\right)$, chronic inflammation and hypersensitivity to pain resulting from mechanical or thermal stimuli are completely absent ${ }^{87}$. Also, the P2X7R is involved in inflammatory responses in epithelial cells. In salivary gland epithelial cells (SGECs), stimulation of the P2X7R with ATP or BzATP increased caspase-1 activity and immune cell infiltration in wild type but not the $\mathrm{P} 2 \mathrm{X} \mathrm{R}^{-/-}$mice ${ }^{88}$. In intestinal epithelia in inflammatory bowel disease, $\mathrm{P} 2 \mathrm{X} 7 \mathrm{R}$ activation is accompanied by an increase in caspase- 1 activity and IL-1 $\beta$ release in response to ATP released by infiltrating polymorphonuclear leukocytes ${ }^{89}$.

The role of the P2X7R in the development and progression of different cancer types is well established. The P2X7R is activated by concentrations of ATP present in the inflammatory microenvironment of tumors. In prostate cancer, P2X7R activation results in increased invasion and metastasis of cancer cells due to the increased expression of genes regulating epithelial mesenchymal transition, including matrix metalloproteinase-3, Ecadherin and Snail ${ }^{90}$. In pancreatic ductal adenocarcinoma, inhibition of the P2X7R 
prevents the proliferation of these cancer cells ${ }^{91}$. Importantly, the P2X7R together with components of the NLRP3 inflammasome were found to be upregulated in head and neck cancer patients ${ }^{92}$. The co-activation of the P2X7R with the NLRP3 inflammasome was correlated with invasiveness of the tumor, whereas their inhibition causes cancer cell death $^{92}$. Interestingly, several studies demonstrate that the ability of the P2X7R to induce apoptosis of cancer cells, making P2X7R activation a potential therapeutic approach for the treatment of various cancer types. For example, acute myeloid leukemia and leukemic stem cells express high levels of the P2X7R whose activation with ATP results in cytotoxicity and apoptosis, a response not seen in normal stem cell populations ${ }^{93}$. The dual role of the P2X7R in the regulation of inflammation and apoptosis, particularly in cancerous tissues, highlights the difficulties of understanding these complex mechanisms in an intact organism, but clearly warrants further investigation.

\subsection{P2X7R and the inflammasome}

The inflammasome is a multiprotein complex and a molecular platform responsible for the activation of caspase- 1 and caspase- 5 with the subsequent maturation of pro-inflammatory cytokines, i.e., IL-1 $\beta$ and IL- $18^{78}$. There are several types of inflammasomes, including NLRP3 (also called NALP3), IPAF and AIM2. The NLRP3 inflammasome is of particular importance in this study because of its role in SS where recently, Baldini et al. reported that all of the NLRP3 components and the P2X7R are upregulated in salivary gland biopsies from SS patients compared to non-disease controls $^{94}$. The NLRP3 inflammasome is composed of NLRP3 protein, ASC protein and pro-caspase-1 (Figure I-2). The NLRP3 protein includes a central NACHT domain for 
oligomerization and nucleotide binding, an amino terminal leucine rich domain (LRR) and a carboxy terminal caspase recruiting domain (CARD) or pyrin domain (PYD) ${ }^{78}$ (Figure I2). The NLRP3 inflammasome is activated and oligomerizes in response to several hostderived molecules, e.g., amyloid- $\beta$ peptides of $\beta$-amyloid plaques in Alzheimer's disease $^{95}$, monosodium urate crystals (MSU) in gout ${ }^{96}$ and extracellular ATP ${ }^{97}$. The mechanism of activation and assembly of the NLRP3 inflammasome by different activators is still unclear. It was suggested that some activators, such as bacterial peptidoglycans, will directly bind to the LRR domain of the inflammasome triggering its assembly. On the other hand, Petrilli et al. ${ }^{80}$ and others reported that $\mathrm{K}^{+}$efflux and reactive oxygen species (ROS) are required for inflammasome assembly and activation in mouse macrophages and human THP-1 monocytes ${ }^{80,98,99}$. Also, in contrast to the key role of ROS in activation of the inflammasome, it was found in THP-1 macrophages that thioredoxin interacting protein (TXNIP) at high ROS levels is released from oxidized thioredoxin (TRX) and binds to the inflammasome leading to its activation ${ }^{100}$. Moreover, it was reported that $\mathrm{CD} 4^{+}$effector $\mathrm{T}$ cells suppress inflammasome 


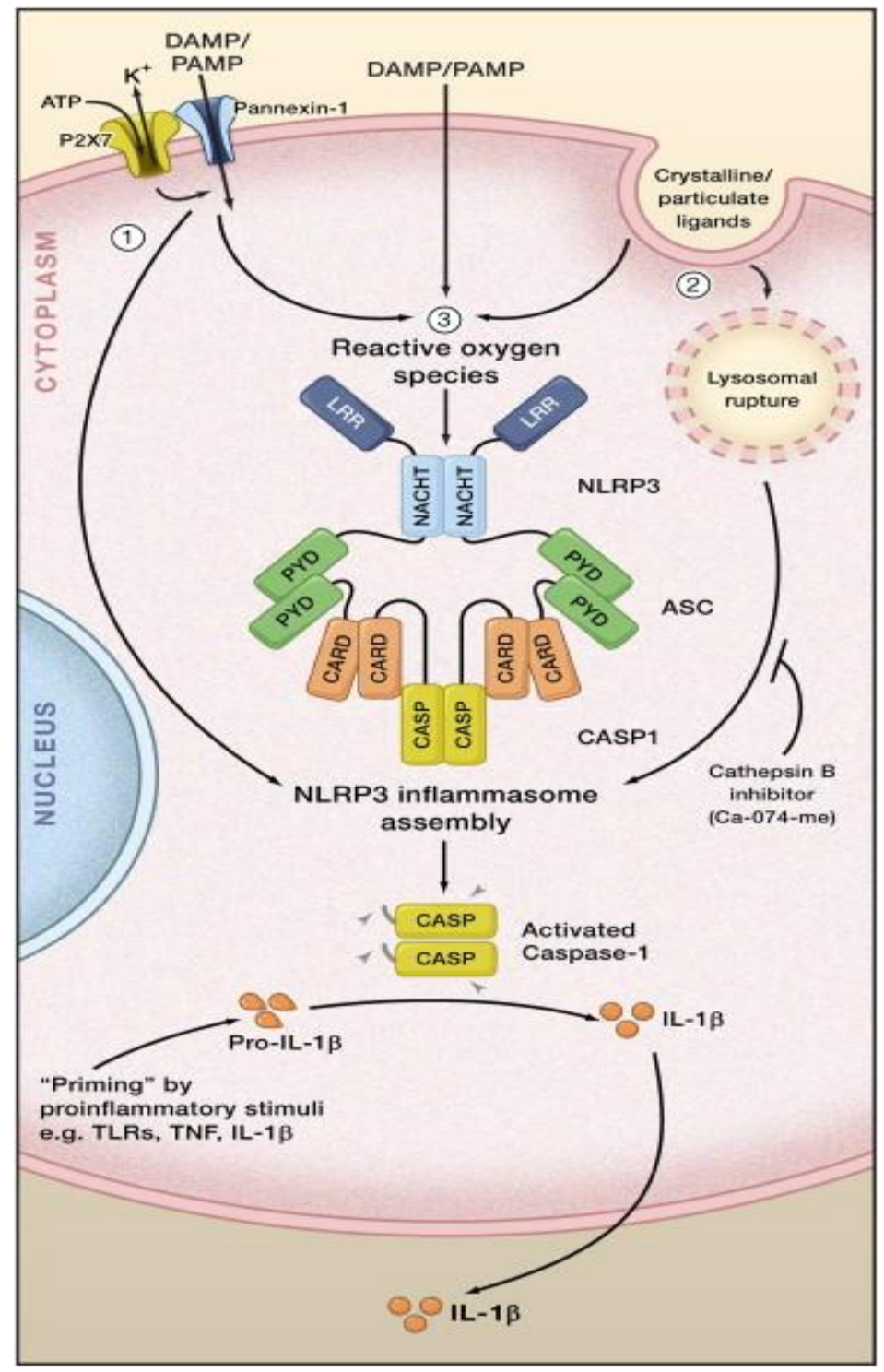

The Inflammasomes. Kate Schroder, Jurg Tschopp. Cell, Volume 140, Issue 6, 2010, 821-832

Figure I-2. The NLRP3 inflammasome. The release of mature IL-1 $\beta$ requires 2 consecutive stimuli. The first stimulus is an inflammatory insult, e.g., LPS that induces the production of pro-IL-1 $\beta$ which accumulates in the cytoplasm. The second stimulus, e.g. ATP, upon inflammasome assembly, activates caspase- 1 and promotes the maturation and release of IL-1 $\beta$. Three models are shown for inflammasome activation: 1 . eATP activates the P2X7R which induces $\mathbf{K}^{+}$efflux and recruitment of the pannexin-1 hemichannel to induce pore formation through which NLRP3 agonists enter the cell to activate the inflammasome; 2 . crystalline or particulate NLRP3 agonists are engulfed by the cells causing the rupture of the lysosome, thereby releasing its contents, some of which act as inflammasome agonists and 3. reactive oxygen species (ROS) produced by NLRP3 agonists.

activation in bone marrow derived macrophages (BMDMs), depending on cell to cell contact through TNF ligands ${ }^{101}$. This is viewed as a way to control innate immunity by 
regulating the production of the leaderless pro-inflammatory cytokines IL-1 $\beta$ and IL- $18^{101}$. Furthermore, Mayor et al. ${ }^{102}$ showed in THP-1 cells that both heat shock protein 90 (HSP90) and SGT-1 chaperones are essential for NLRP3 inflammasome activity. Also, they showed that the absence of HSP90 reduced NLRP3-dependent gout inflammation in mice after injection with monosodium urate crystals ${ }^{102}$.

There are several models proposed for the mechanism of NLRP3 inflammasome activation (Figure I-2), one of which is through P2X7R activation by eATP that induces $\mathrm{K}^{+}$efflux and recruitment of the pannexin- 1 hemichannel to form pores through which NLRP3 agonists enter the cells ${ }^{103}$. In a second model, crystalline or particulate NLRP3 agonists are engulfed by the cells causing rupture of the lysosome, which releases its contents, some of which act as inflammasome agonists ${ }^{95,104}$. A third model is through reactive oxygen species (ROS) produced by all NLRP3 agonists, and inhibition of ROS production has been shown to suppress inflammasome activity ${ }^{80,98}$. The major sources of ROS are NADPH oxidase (NOX) (a family of seven homologs) and the mitochondrial electron transport chain. The contribution of NOX as a source of inflammasome-activating ROS is controversial. Some research indicates that knockout of the P22 ${ }^{\text {PHOX }}$ subunit of NOX abolishes IL- $1 \beta$ secretion $^{99}$, whereas other studies show that loss of NOX function or knockout of NOX1, NOX2 and NOX4 did not affect inflammasome activity ${ }^{105,106}$. Furthermore, a hyperinflammatory response was still seen in the lungs of NOX-deficient mice ${ }^{107}$. The mitochondria is another potential source of ROS, mainly generated through the electron transport chain at complex I and the Q cycle in complex $\mathrm{III}^{108,109}$. Mitochondrial ROS are triggers for the activation of the NLRP3 inflammasome in murine and human macrophages upon ATP or nigericin 
treatment, a response that was abolished in presence of the mitochondrial specific ROS scavenger Mito-Tempo ${ }^{110,111}$. In bronchial epithelial cells, mitochondrial ROS are also responsible for airway inflammation in bronchial asthma ${ }^{112}$. The of this study is to elucidate the role of the P2X7R in salivary gland inflammation and its dependence on the activation and assembly of the NLRP3 inflammasome multiprotein complex.

\subsection{P2X7R and apoptosis}

Apoptosis or programmed cell death is defined as the physiological process leading to cell death where cells undergo several morphological changes including cell shrinkage and plasma and nuclear membrane blebbing, biological changes such as chromatin condensation and nuclear fragmentation and biochemical changes including activation of various caspases (cysteine dependent proteases specific for aspartic acid residues) and endonucleases ${ }^{113}$. ATP stimulation of cells can cause cell death depending on the dose of ATP, the exposure time and the cell type ${ }^{114}$. The P2X7R is responsible for the ATP-induced apoptosis in T-cells, where P2X7R-mediated cell death occurs through two independent pathways, C-terminal-dependent apoptosis which involves pore formation and influx of extracellular chloride ions ${ }^{115,116}$, and N-terminal-dependent necrosis which involves ERK1/2 phosphorylation ${ }^{116}$. Verhoef et al. reported that stimulation of the P2X7R with ATP activates Rho A and ROCK-1 which induces membrane blebbing (a hallmark of apoptosis) in both HEK-293 and BAC1 macrophage cell lines $^{117}$. In the RAW 264.7 macrophage cell line, P2X7R activation stimulates NOX2 to generate ROS that induce the activation of caspase-3 (a principal regulator of apoptosis) through the ASK1-P38-MAPK pathway ${ }^{118}$. Moreover, in Par C5 parotid salivary gland 
epithelial cells, P2X7R activation causes $\mathrm{Ca}^{2+}$-dependent ROCK1 activation and myosin light chain (MLC) phosphorylation that leads to membrane blebbing and apoptosis ${ }^{119}$. The $\mathrm{P} 2 \mathrm{X} 7 \mathrm{R}$ was reported to mediate apoptosis in cervical epithelial cells ${ }^{120}$ and rat primary cortical neurons through caspase-8/9/3 activity $^{121}$. On the other hand, the P2X7R in the absence of ATP activates phagocytosis of apoptotic cells by mononuclear phagocytes ${ }^{122}$. These results suggest that blocking P2X7R activity should prevent apoptosis, thereby reducing tissue damage to maintain normal cell functions.

Interestingly, P2X7R activation can enhance cell growth. Endogenous ATP release from cells induces proliferation of neighboring cells by an autocrine/paracrine mechanism. In T lymphocytes, P2X7R activation by ATP acts as a costimulator of proliferation in cells treated with mitogen-like phytohemagglutinin ${ }^{123}$. The same result was obtained in the K562 and LG14 lymphoid cell lines, where P2X7R activation by endogenous ATP release maintained proliferation in the absence of serum, a response absent in cells lacking the P2X7R and treated with an ecto-ATPase inhibitor ${ }^{124}$. The role of P2X7R in cell death and survival is seemingly contradictory, but depends on the level of P2X7R activation. There is a dose-dependent relationship between eATP and the cellular response to $\mathrm{P} 2 \mathrm{X} 7 \mathrm{R}$ activation that is affected by the rate of extracellular ATP hydrolysis and is difficult to evaluate in vivo. In general, stimulation of the P2X7R by low levels of eATP induces cell proliferation, whereas high eATP concentrations promote cell death.

\subsection{P2X7R and autoimmune diseases}

The P2X7R plays a key role in inflammatory and immune responses in various cell types. Hence, the P2X7R has emerged as an interesting therapeutic target for several 
autoimmune inflammatory diseases. Rheumatoid arthritis (RA) is an autoimmune disease characterized by chronic inflammation and deformation of bones and cartilage of diarthroidal joints ${ }^{125}$. High levels of purine and pyrimidine nucleotides have been found in the synovial fluid of RA patients which stimulates P2X7R-mediated IL-6 release from synovial fluid fibroblasts, a key inflammatory event that contributes to the pathology of $\mathrm{RA}^{35,126,127}$. In addition, the P2X7R is responsible for the release of the pro-inflammatory cytokines IL-1 $\beta$ and IL-18 that are implicated in chronic joint inflammation seen in RA ${ }^{128}$. Systemic lupus erythematosus (SLE) is another autoimmune disease characterized by disturbances in innate and adaptive immune responses that result in the destruction of several organs, including lung, kidney, skin and bone marrow ${ }^{129}$. In humans, the P2X7R is upregulated in patients with autoimmune disease-related glomerulonephritis ${ }^{130}$. Also, the P2X7R and NLRP3 inflammasome components are upregulated in the kidneys of SLE rodent models ${ }^{131}$. Activation of the P2X7R in splenocytes and bone marrow cells induces the assembly of the inflammasome multiprotein complex and the release of proinflammatory cytokines, including IL- $1 \beta$ and IFN- $\gamma$, the signature of SLE ${ }^{132}$. Antagonizing the P2X7R in the MLR/lpr SLE mouse model ${ }^{131}$ or the pristane-induced lupus nephritis mouse model ${ }^{132}$ significantly reduces levels of circulating autoantibodies, a hallmark of SLE, and diminishes lupus nephritis, respectively ${ }^{131,132}$. In this study, the contribution of the P2X7R to the autoimmune inflammatory disease SS was determined for the first time and results indicate that P2X7R antagonism is a promising therapeutic strategy to limit salivary gland inflammation and associated hypofunction. 


\subsection{P2X7R and clinical studies}

Based on the significant contribution of the P2X7R to inflammatory responses in several diseases, particularly autoimmune diseases, ${ }^{133} \mathrm{P} 2 \mathrm{X} 7 \mathrm{R}$ antagonists were investigated in phase I and phase II clinical trials for the treatment of inflammatory bowel syndrome, spinal cord injury and rheumatoid arthritis ${ }^{35,134,135}$. P2X7R antagonists have shown promising clinical efficacy and proven to be safe in patients ${ }^{35,134,135}$. Future studies are still required to improve the clinical efficacy of P2X7R antagonists and to further investigate the precise role of the P2X7R in each disease context to develop more specific P2X7R-based therapies.

\subsection{P2X7R and salivary gland function}

Salivation is a calcium $\left(\mathrm{Ca}^{2+}\right)$ dependent process ${ }^{136}$ and is induced by activation of the muscarinic (cholinergic) and $\alpha$-adrenergic receptors by their ligands acetylcholine and nor-epinephrine, respectively. This results in a sustained increase in the intracellular calcium concentration $\left[\mathrm{Ca}^{2+}\right]_{\mathrm{i}}$ and the generation of primary isotonic saliva by salivary acinar cells, which is then modified to its final hypotonic form by salivary ductal cells ${ }^{136}$. P2X7R activation by eATP is accompanied by a sustained elevation in intracellular calcium levels, which also promotes salivation, a response abolished in $\mathrm{P} 2 \mathrm{X} 7 \mathrm{R}^{-1-}$ mice $\mathrm{e}^{136 \text {, }}$ 137-138, 139. Nakamoto et al. reported that costimulation of SMG cells with ATP and a muscarinic agonist has an inhibitory effect on saliva production ${ }^{137}$, demonstrating that P2X7R activation regulates excretory function of the salivary gland ${ }^{85}$. Thus, blocking the P2X7R should improve secretory function of the salivary gland, whereas increased expression and activation of the P2X7R, particularly during inflammation, should reduce 
muscarinic receptor-induced salivation. Contrary to Nakamoto's findings, Novak et al. concluded that muscarinic receptors act synergistically with P2X7R to enhance saliva secretion ${ }^{138}$. Therefore, the role of P2X7R in regulating the salivary gland excretory function needs further investigation.

\subsection{0 ${\mathrm{P} 2 \mathrm{Y}_{2}}_{2}$ nucleotide receptor}

The $\mathrm{P}_{2} \mathrm{Y}_{2}$ nucleotide receptor $\left(\mathrm{P} 2 \mathrm{Y}_{2} \mathrm{R}\right)$ is a member of the $\mathrm{P} 2$ nucleotide receptor family and is activated equipotently by eATP and uridine 5'-triphosphate (UTP). The $\mathrm{P} 2 \mathrm{Y}_{2} \mathrm{R}$ is upregulated in the epithelium of inflamed and/or damaged salivary glands ${ }^{140-144}$. The role of the $\mathrm{P}_{2} \mathrm{Y}_{2} \mathrm{R}$ is well established in tissue repair; it induces wound healing in corneal epithelium by triggering cell migration ${ }^{145}$, liver regeneration by stimulating hepatocyte proliferation ${ }^{146}$ and enhances epithelial cell repair in inflammatory bowel syndrome ${ }^{147}$. Additional studies have shown that $\mathrm{P} 2 \mathrm{Y}_{2} \mathrm{Rs}$ regulate localized immune responses, induce immune cell infiltration ${ }^{148}$ and upregulate VCAM-1 expression ${ }^{142}$. Notably, our previous studies showed that IL-1 $\beta$ increases NF- $\mathrm{kB}$-dependent expression of the $\mathrm{P} 2 \mathrm{Y}_{2} \mathrm{R}^{147,149}$. Thus, $\mathrm{P} 2 \mathrm{X} 7 \mathrm{R}$ and $\mathrm{P} 2 \mathrm{Y}_{2} \mathrm{R}$ may partner in the initiation of an inflammatory response and epithelial tissue repair during inflammation.

\subsection{Mouse models of salivary gland inflammation}

\subsubsection{CD28 ${ }^{-/}$, IFN $\gamma^{-/}$, NOD.H-2 ${ }^{\mathrm{h} 4}$, a murine model of salivary gland autoimmune exocrinopathy}

The CD $28^{-{ }_{-}}$, IFN $\gamma^{-{ }_{-}}$, NOD.H-2 $2^{\mathrm{h} 4}$ mouse model was developed to study autoimmune thyroid disease $\mathrm{e}^{150}$. The lack of IFN- $\gamma$ results in increased hyperplasia and proliferation of thyroid epithelial cells ${ }^{151}$, whereas the lack of CD28 results in the depletion of Treg cells ${ }^{152}$ and extensive immune cell infiltration of the thyroid gland, a hallmark of 
autoimmune thyroiditis ${ }^{150}$. Interestingly, female CD $28^{-/-}$, IFN $\gamma^{-/-}$, NOD.H-2 ${ }^{\mathrm{h} 4}$ mice develop hypofunction and immune cell infiltration of the salivary gland by 4 months of age, which become more pronounced by 6 months of age, clinical manifestations of SS. The male CD28 ${ }^{-{ }^{-}}$, IFN $\gamma^{-/-}$, NOD.H-2 ${ }^{\text {h4 }}$ mice showed fewer and smaller lymphocytic foci than female mice at 4 months of age that is unchanged at 6 months, and this diminished response compared to female mice is consistent with the 9:1 female to male prevalence of SS in humans ${ }^{153}$. The autoantibodies anti-Ro and anti-La that are elevated in human SS were undetectable in the $\mathrm{CD} 28^{-/}$, IFN $\gamma^{-{ }^{-}}$, NOD.H- $2{ }^{\mathrm{h} 4}$ mice $^{150}$. Nonetheless, the CD28 ${ }^{-{ }^{-}}$, IFN $\gamma^{-1-}$, NOD.H-2 $2^{\mathrm{h} 4}$ is an excellent mouse model to study the role of the P2X7R in salivary gland autoimmune exocrinopathy associated with SS.

\subsubsection{Salivary gland duct ligation/deligation mouse model}

Salivary gland duct ligation and subsequent deligation is a well-studied animal model of salivary gland inflammation (ligation) and regeneration (deligation) ${ }^{144,154}$. In this model, the main excretory duct of the submandibular gland (SMG) is surgically occluded and after a set period of time ( 1-30 days) the process is reversed. Within 24 hours of duct ligation, immune cells begin to infiltrate the gland and acinar cells begin to atrophy, lose expression of acinar proteins and eventually undergo apoptosis ${ }^{155}$. Ductal cells, subsets of which have been proposed to be salivary progenitor cells that can regenerate the gland, remain intact and proliferative during duct ligation ${ }^{156-158}$. Additionally, ligation causes salivary glands to become fibrotic ${ }^{159}$. 


\subsection{Research goals and experimental approaches}

The role of P2X7R activation by eATP in inflammasome assembly and activation has been extensively studied in immune cells, but not in salivary gland epithelial cells. P2X7R activation by eATP opens a plasma membrane cation channel that mediates the downhill influx of $\mathrm{Na}^{+}$and $\mathrm{Ca}^{2+}$ and the efflux of $\mathrm{K}^{+53}$. P2X7R activation is also implicated in the production of ROS through the stimulation of NADPH oxidase $(\mathrm{NOX} 2)^{118}$. Deplano et al. found that macrophages infiltrating WKY rat nephritic glomeruli showed higher expression of the P2X7R and enhanced production of caspase-1, IL-1 $\beta$ and IL-18 after induction of nephrotoxic nephritis ${ }^{54}$. They concluded that P2X7Rmediated inflammasome activation regulates susceptibility to macrophage-dependent crescentic glomerulonephritis ${ }^{54}$. In alveolar macrophages, hyperoxia-induced inflammasome activation is dependent on P2X7R activation and the accompanying $\mathrm{K}^{+}$ efflux and ROS production ${ }^{160}$. The P2X7R antagonist (oxidizedATP), a high extracellular $\left[\mathrm{K}^{+}\right]$(to inhibit $\mathrm{K}^{+}$efflux) or a ROS inhibitor, prevented hyperoxia-induced inflammasome activation ${ }^{160}$. Pelegrin and Surprenant co-immunopreciptated the hemichannel protein pannexin-1 with the P2X7R in J-774 macrophages, and determined that pannexin-1 inhibition with siRNA or mimetic inhibitory peptides abrogated ATP-induced caspase-1 and IL-1 $\beta$ production and activation but did not affect ATP-, nigericin- or maitotoxininduced $\mathrm{K}^{+}$efflux, leading to the conclusion that pannexin-1 acts downstream of $\mathrm{K}^{+}$efflux and upstream of caspase- 1 cleavage in the regulation of inflammasome activity ${ }^{161,162}$. In contrast, Riteau et al. reported that pannexin-1 is required for the release of endogenous intracellular ATP with subsequent P2X7R stimulation by eATP, leading to NLRP3 inflammasome activation and IL-1 $\beta$ production in macrophages upon internalization of 
uric acid, silica or alum crystals ${ }^{163}$. Finally, HSP90 which is essential for activation of the NLRP3 inflammasome ${ }^{102}$, is a constituent of the P2X7R multiprotein complex ${ }^{62}$ and acts as a negative regulator of the assembly and function of P2X7R within the complex ${ }^{164}$. HSP90 when bound to the P2X7R (but not in the cytosol) is tyrosine phosphorylated, and its phosphorylation level increases when P2X7R function decreases (i.e., when P2X7Rinduced membrane blebbing and ionic currents decrease) ${ }^{164}$. The dependence of inflammasome activation on P2X7R stimulation by eATP has been studied in immune cells, where it is well established that P2X7R activation plays a crucial role in the assembly and activation of the inflammasome. Hence, we hypothesized that P2X7R activation by eATP would result in the activation and assembly of the NLRP3 inflammasome together with the enhanced maturation and release of the pro-inflammatory cytokine IL-1 $\beta$ in salivary gland epithelial cells. This hypothesis was addressed using primary SMG epithelial cell aggregates isolated from P2X7R and P2X7R ${ }^{-/-} \mathrm{C} 57 / \mathrm{B} 6$ mice. The mechanism of P2X7R-induced NLRP3 inflammasome activation and IL-1 $\beta$ release was determined. Finally, P2X7R antagonism was examined as a therapeutic approach in vivo in the $\mathrm{CD} 28^{-{ }^{-}}$, IFN $\gamma^{-{ }^{-}}$, NOD.H-2 ${ }^{\mathrm{h} 4}$ mouse model of autoimmune exocrinopathy ${ }^{150}$. 


\section{Chapter II}

\section{P2X7 receptor antagonism prevents IL-1ß release from salivary epithelial cells and reduces inflammation in a mouse model of autoimmune exocrinopathy}

As found in: Khalafalla, M.G., Woods, L.T., Camden, J.M., Khan, A.A., Limesand, K.H., Petris, M.J., Erb, L. and Weisman, G.A., 2017. P2X7 receptor antagonism prevents IL-1 $\beta$ release from salivary epithelial cells and reduces inflammation in a mouse model of autoimmune exocrinopathy. Journal of Biological Chemistry, 292(40), pp.1662616637.

\section{ABSTRACT}

Salivary gland inflammation is a hallmark of Sjögren's syndrome (SS), a common autoimmune disease characterized by lymphocytic infiltration of the salivary gland and loss of saliva secretion, predominantly in women. The $\mathrm{P} 2 \mathrm{X} 7$ receptor $(\mathrm{P} 2 \mathrm{X} 7 \mathrm{R})$ is an ATP-gated non-selective cation channel that induces inflammatory responses in cells and tissues, including salivary gland epithelium. In immune cells, P2X7R activation induces the production of proinflammatory cytokines, including IL-1 $\beta$ and IL-18, by inducing the oligomerization of the multiprotein complex NLRP3-type inflammasome. Here, our results show that in primary mouse submandibular gland (SMG) epithelial cells, P2X7R activation also induces the assembly of the NLRP3 inflammasome and the maturation and release of IL-1 $\beta$, a response that is absent in SMG cells isolated from mice deficient in P2X7Rs (P2X7R $\left.{ }^{-/-}\right)$. P2X7R-mediated IL-1 $\beta$ release in SMG epithelial cells is dependent on transmembrane $\mathrm{Na}^{+}$and/or $\mathrm{K}^{+}$flux and the activation of heat shock protein 90 (HSP90), a protein required for the activation and stabilization of the NLRP3 inflammasome. Also, using the reactive oxygen species (ROS) scavengers $\mathrm{N}$-acetyl 
cysteine and Mito-TEMPO, we determined that mitochondrial ROS are required for P2X7R-mediated IL-1 $\beta$ release. Lastly, in vivo administration of the P2X7R antagonist A438079 in the CD28 $8^{-/-}$, IFN $\gamma^{-/-}$, NOD.H- $2^{\text {h4 }}$ mouse model of salivary gland exocrinopathy ameliorated salivary gland inflammation and enhanced carbachol-induced saliva secretion. These findings demonstrate that P2X7R antagonism in vivo represents a promising therapeutic strategy to limit salivary gland inflammation and improve secretory function.

\subsection{INTRODUCTION}

Salivary gland inflammation and dysfunction are serious clinical problems that affect millions of people whose quality of life is severely impacted due to dry mouth, periodontitis, oral bacterial and yeast infections and speech problems ${ }^{2}$. Major causes of salivary gland degeneration leading to hyposalivation in humans are the autoimmune inflammatory disease Sjögren's syndrome (SS) and the unintended side effects of radiotherapies for head and neck cancers ${ }^{2}$. A hallmark of salivary gland inflammation in $\mathrm{SS}$ is mononuclear cell infiltration, mainly $\mathrm{T}$ and B lymphocytes, dendritic cells and macrophages, which produce proinflammatory cytokines and chemokines and ultimately promote salivary gland degeneration in addition to extraglandular manifestations including skin vasculitis, glomerulonephritis, peripheral neuropathy and malignant lymphomas ${ }^{3,153}$. There is increasing evidence that salivary gland epithelial cells contribute to immunological responses associated with salivary gland inflammation ${ }^{42,43}$, hence, understanding the mechanism of initiation of inflammatory events in salivary epithelium is crucial to developing more effective and localized treatments for salivary gland disorders than are currently available. To date, relatively ineffective therapies for 
salivary hypofunction include stimulation of salivary flow in residual salivary acinar cells of SS patients using muscarinic receptor agonists (e.g., pilocarpine or cevimeline), oral administration of anti-inflammatory agents (e.g., interferon- $\alpha$ ) or utilization of artificial saliva $^{165}$.

In addition to its role as a source of energy in intracellular metabolism and signaling, ATP is well established as an extracellular signaling molecule that regulates various physiological processes, including immune cell recruitment, neurotransmission and pain perception ${ }^{47-50}$. Under normal conditions, the levels of extracellular ATP (eATP) are tightly regulated by ecto-ATPases, however, in the microenvironment of injured, inflamed or stressed cells, eATP is known to be present at high concentrations ${ }^{52}$. Extracellular ATP is the natural agonist for most members of the purinergic receptor family, which includes the ionotropic P2X (P2X1-7) and the G protein-coupled P2Y $\left(\mathrm{P} \mathrm{Y}_{1,2,4,6,11-15}\right)$ receptors ${ }^{53}$. The $\mathrm{P} 2 \mathrm{X} 7$ receptor (P2X7R) is of particular interest as its activation is linked to a number of inflammatory diseases, e.g., glomerulonephritis, neuroinflammation and rheumatoid arthritis ${ }^{54-57}$. P2X7R is widely expressed in hematopoietic cells, neurons, glial cells, osteoblasts, endothelial cells and epithelial cells ${ }^{53}$. Brief stimulation of the ionotropic P2X7R with ATP causes plasma membrane depolarization due to $\mathrm{Na}^{+}, \mathrm{Ca}^{2+}$ and $\mathrm{K}^{+}$flux down their electrochemical gradients ${ }^{53,166}$. Sustained activation of the P2X7R by high ATP concentrations in some cell types, including macrophages, astrocytes and epithelial cells, can lead to the increased permeability of hydrophilic molecules up to $900 \mathrm{Da}^{167}$, membrane blebbing ${ }^{88,168}$, reactive oxygen species (ROS) production and intracellular nucleotide release resulting in cell death ${ }^{53}$. P2X7R activation plays a key role in the maturation and release of the 
leaderless proinflammatory cytokine IL- $1 \beta$ in immune cells by inducing the oligomerization of the multiprotein complex NLRP3-type inflammasome ${ }^{59,169}$. Notably, IL-1 $\beta$ and the components of the NLRP3 inflammasome, including a scaffold NOD-like receptor (NLR) protein, NLR family pyrin domain containing protein 3 (NLRP3), apoptosis associated speck-like protein containing a CARD (ASC) and pro-caspase-1 ${ }^{169}$, along with P2X7Rs, are upregulated in salivary gland biopsies from SS patients, as compared to normal controls ${ }^{94}$. Although widely studied in immune cells, P2X7Rmediated NLRP3 inflammasome activation in salivary epithelial cells has not been investigated.

P2X7Rs are highly expressed in salivary epithelium ${ }^{88,119}$ and have been implicated in the regulation of ATP-induced saliva secretion, probably through calcium influx ${ }^{137}$, but their role in salivary gland inflammation is not well understood. Our previous studies showed that $\mathrm{P} 2 \mathrm{X} 7 \mathrm{R}$ activation by ATP induces inflammatory responses, e.g., increases in caspase-1 activity and membrane blebbing, in freshly prepared mouse submandibular gland (SMG) cells from wild type mice, but not from P2X7R-deficient $\left(\mathrm{P} \mathrm{X} 7 \mathrm{R}^{-1}\right)$ mice ${ }^{88}$. In addition, duct-ligation after ATP perfusion in wild type mouse SMG increases lymphocytic infiltration, a response that is absent in $\mathrm{P} 2 \mathrm{X} 7 \mathrm{R}^{-/-}$mouse $\mathrm{SMG}^{88}$. Studies have shown that $\mathrm{P} 2 \mathrm{X} 7 \mathrm{R}^{-/-}$mice exhibit reduced lung inflammation and neuropathic pain as compared to wild type mice ${ }^{86,87}$ and systemic administration of selective P2X7R antagonists, e.g., A438079, attenuates inflammatory responses in rodent models of lung inflammation, nephritis, nociception and intracerebral hemorrhage ${ }^{131,170-}$ 172. Taken together, the P2X7R represents a novel therapeutic target for reducing inflammation ${ }^{56,173}$ as further indicated by previous Phase I and II clinical trials with 
P2X7R antagonists for treatment of rheumatoid arthritis and spinal cord injury ${ }^{35,135}$. To date, there have been no clinical studies investigating the P2X7R as a therapeutic target to prevent salivary gland inflammation.

Here, we demonstrate for the first time in salivary gland epithelial cells that P2X7R activation promotes NLRP3 inflammasome activation and assembly and IL-1 $\beta$ release through a mechanism involving transmembrane $\mathrm{Na}^{+}$and $\mathrm{K}^{+}$flux, $\mathrm{ROS}$ production and HSP90 protein function. Moreover, our in vivo results show that administration of the P2X7R antagonist, A438079, in the CD28 $8^{-/-}$, IFN $\gamma^{-/-}$, NOD.H- $2^{\text {h4 }}$ mouse model of autoimmune exocrinopathy ${ }^{150}$, reduced salivary gland lymphocytic infiltrates and enhanced saliva secretion, suggesting that antagonism of the $\mathrm{P} 2 \mathrm{X} 7 \mathrm{R}$ is a promising approach to prevent salivary gland inflammation and associated hyposalivation in the autoimmune disease SS.

\subsection{RESULTS}

\subsubsection{P2X7R activation induces the release of IL-1 $\beta$ in primary SMG epithelial cell aggregates from wild type, but not $P 2 X 7 R^{-/-}$, mice}

Activation of the P2X7R in immune cells is well known to play a role in the maturation and release of the proinflammatory cytokine, IL-1 $\beta^{59,174,175}$. We have previously shown that $\mathrm{P} 2 \mathrm{X} 7 \mathrm{R}$ activation in primary mouse SMG epithelial cell aggregates increases the activity of caspase-1, the protease responsible for IL- $1 \beta$ processing ${ }^{88}$, however, it is unclear how P2X7R activation in salivary glands regulates IL-1 $\beta$ maturation and release. Here, we show that IL-1 $\beta$ release is significantly increased in wild type primary SMG cell aggregates (97-99\% epithelial cells, Fig. II-1C) stimulated 
with ATP (3 mM), as compared to untreated controls (Fig. II-1A). This response is abolished by pretreating aggregates with the P2X7R antagonist A438079 (25 $\mu \mathrm{M})$, whereas IL-1 $\beta$ release induced by the $\mathrm{K}^{+}$ionophore nigericin $(10 \mu \mathrm{M})$ is unaffected (Fig. II-1A). Moreover, ATP-induced IL-1 $\beta$ release is absent in SMG cell aggregates from $\mathrm{P} 2 \mathrm{X} 7 \mathrm{R}^{-/-}$mice (Fig. II-1B). To further validate that SMG epithelial cells are the source of IL-1 $\beta$, rather than immune cells contaminating the SMG cell preparations, epithelial cell purity was enriched using the magnetic bead-based EasySep Mouse Epithelial Cell Enrichment Kit to remove hematopoietic and endothelial cells and fibroblasts. ATPinduced IL- $1 \beta$ release was equally robust in the enriched SMG epithelial cells (Fig. II1D) and the standard SMG cell preparations (Fig. II-1A), suggesting that SMG epithelial cells are the primary source of ATP-induced IL-1 $\beta$ release in our in vitro experiments.

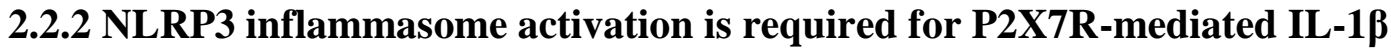 release in primary SMG epithelial cell aggregates}

Activation of the multiprotein complex NLRP3 inflammasome is responsible for the maturation and release of the proinflammatory cytokine IL-1 $\beta$ in a variety of cell types including intestinal epithelial cells, monocytes and macrophages ${ }^{103,169,176}$. To investigate whether NLRP3 inflammasome activation is required for P2X7R-mediated IL-1 $\beta$ release in salivary epithelium, primary SMG cell aggregates from wild type mice were pre-treated with the selective NLRP3 inflammasome inhibitors Bay 11-7082 (15 $\mu \mathrm{M}){ }^{177}$ or MCC-950 $(10 \mu \mathrm{M}){ }^{178}$ and then stimulated with ATP $(3 \mathrm{mM})$. Results show that inhibition of NLRP3 inflammasome activity abolishes ATP-induced IL-1 $\beta$ release (Fig. II-2A). Furthermore, immunoprecipitation of NLRP3 was used to demonstrate that ATP (3 mM) potentiates co-precipitation of ASC and pro-caspase-1 proteins, components 
of the NLRP3 inflammasome, in SMG cell aggregates from wild type but not P2X7R ${ }^{-/-}$ mice (Fig. II-2B). These results indicate that P2X7R-mediated IL-1 $\beta$ release in salivary epithelial cells is mediated by activation and assembly of the NLRP3 inflammasome.

\subsubsection{Ionic dependence of P2X7R-mediated IL-1 $\beta$ release in primary SMG epithelial cell aggregates}

$\mathrm{P} 2 \mathrm{X} 7 \mathrm{R}$ is an ATP-gated non-selective cation channel whose stimulation induces the efflux of $\mathrm{K}^{+}$and influx of $\mathrm{Na}^{+}$and $\mathrm{Ca}^{2+}$ ions ${ }^{53,166} . \mathrm{K}^{+}$efflux and $\mathrm{Na}^{+}$influx are necessary for the activation of the NLRP3 inflammasome complex in immune cells ${ }^{80,179}$. Therefore, we sought to evaluate the role of transmembrane ion flux in ATP-induced IL$1 \beta$ release in salivary epithelial cells. $\mathrm{K}^{+}$efflux is a necessary response in immune cells to various NLRP3 inflammasome activators, including ATP, monosodium urate crystals and bacterial lipopolysaccharide ${ }^{80,99,180}$. As mentioned above, the $\mathrm{H}^{+} / \mathrm{K}^{+}$ionophore nigericin induces IL- $1 \beta$ release in primary SMG cell aggregates from wild type and $\mathrm{P} 2 \mathrm{X} 7 \mathrm{R}^{-/-}$mice (Fig. II-1), suggesting that $\mathrm{K}^{+}$efflux is required for inflammasome activation in salivary epithelium. To determine whether ATP treatment perturbs intracellular $\mathrm{K}^{+}$homeostasis in salivary epithelial cells, primary SMG cell aggregates from wild type and P2X7R ${ }^{-/-}$mice were treated with ATP $(3 \mathrm{mM})$ and the intracellular $\left[\mathrm{K}^{+}\right]$was quantified with an inductively coupled plasma optical emission spectrometer (ICP-OES). ATP induced a significant decrease in the intracellular $\left[\mathrm{K}^{+}\right]$after 10 and $30 \mathrm{~min}$, a response that was absent in $\mathrm{P} 2 \mathrm{X} \mathrm{R}^{-1-} \mathrm{SMG}$ cell aggregates (Fig. II-3A). To determine whether the transmembrane $\left[\mathrm{Na}^{+}\right]$and $\left[\mathrm{K}^{+}\right]$gradients are required for NLRP3 inflammasome activation, primary SMG cell aggregates were assayed for IL-1 $\beta$ release in a buffer containing the physiological extracellular $\left[\mathrm{Na}^{+}\right]$and $\left[\mathrm{K}^{+}\right](145 \mathrm{mM}$ and $5 \mathrm{mM}$, 
respectively) or in a buffer where the $\mathrm{NaCl}(145 \mathrm{mM})$ was substituted with $\mathrm{KCl}(145$ $\mathrm{mM}$ ) or choline chloride (145 mM). Replacement of extracellular $\mathrm{NaCl}$ with either $\mathrm{KCl}$ or choline chloride inhibited ATP-induced IL-1 $\beta$ release (Fig. II-3B), indicating that P2X7R-mediated IL-1 $\beta$ release in salivary epithelial cells is dependent on physiological transmembrane $\mathrm{Na}^{+}$and $\mathrm{K}^{+}$gradients.

\subsubsection{Inhibition of ROS production significantly reduces P2X7R-mediated IL-1ß release in primary SMG epithelial cell aggregates}

ROS are generated by all known inflammasome activators at times of inflammation and infection, where they play crucial roles in innate immune responses, including wound healing ${ }^{181}$, and act as anti-microbial agents ${ }^{182}$. ROS scavengers, e.g., $\mathrm{N}$-acetylcysteine (NAC), are known to block inflammasome activity, caspase-1 activation

and IL- $1 \beta$ release in immune cells ${ }^{98}$. To examine whether generation of cytosolic ROS is required for ATP-induced IL-1 $\beta$ maturation and subsequent release in salivary epithelial cells, primary SMG cell aggregates were pre-treated with the ROS scavenger NAC (25 $\mathrm{mM})$ and then stimulated with ATP (3 mM). NAC significantly inhibited P2X7Rmediated IL-1 $\beta$ release (Fig. II-4A). Since the mitochondria is one of the major sources of cellular ROS under stress conditions ${ }^{111,183}$, the contribution of mitochondrial ROS to P2X7R-mediated IL-1 $\beta$ release was evaluated by pre-treating primary SMG cell aggregates with the mitochondrial-targeted anti-oxidant Mito-TEMPO (1 mM), before stimulation with ATP (3 mM). Mito-TEMPO partially blocked ATP-induced IL-1 $\beta$ release demonstrating that ROS generated in the mitochondria are partially required for P2X7R-mediated IL-1 $\beta$ release in mouse SMG epithelial cells (Fig. II-4B) and that other sources of ROS (e.g., NADPH oxidase) contribute to inflammasome activation. 


\subsubsection{Functional Heat Shock Protein 90 (HSP90) is required for P2X7R-mediated IL-1ß release in primary SMG epithelial cell aggregates}

HSP90 is a molecular chaperone whose function is to maintain the proper folding of proteins required for their stability and activity, including proteins of the NLRP3

inflammasome ${ }^{102,184}$. In monocytes, HSP90 is a member of the P2X7R multiprotein complex and is required for NLRP3 inflammasome activity ${ }^{102}$. To determine whether HSP90 contributes to P2X7R-mediated IL-1 $\beta$ release in salivary epithelial cells, primary SMG cell aggregates were pretreated with the HSP90 inhibitor geldanamycin (GA, 5 $\mu \mathrm{M})$, then stimulated with ATP $(3 \mathrm{mM})$. GA abolished ATP-induced IL-1 $\beta$ release in salivary epithelial cells (Fig. II-5A), indicating that HSP90 is required for P2X7Rmediated IL-1 $\beta$ release. Furthermore, GA $(5 \mu \mathrm{M})$ pre-treatment significantly reduced the endogenous expression of NLRP3 protein, suggesting that functional HSP90 contributes to inflammasome activity in salivary epithelial cells by maintaining the stability of the NLRP3 protein (Fig. II-5B).

\subsubsection{In vivo administration of the P2X7R antagonist $A 438079$ reduces salivary gland inflammation and improves saliva flow in the $\mathrm{CD}^{-/-}, \mathrm{IFN} \gamma^{-/-}, \mathrm{NOD} . \mathrm{H}-2^{\mathrm{h} 4}$ mouse model of salivary gland exocrinopathy}

P2X7R antagonists, including A438079, have been shown to reduce inflammation in a number of inflammatory diseases including glomerulonephritis, pulmonary fibrosis and rheumatoid arthritis ${ }^{35,135}$. Hence, we sought to determine if in vivo antagonism of the $\mathrm{P} 2 \mathrm{X} 7 \mathrm{R}$ in a mouse model of salivary gland exocrinopathy would reduce salivary gland inflammation. Recently, we showed that the CD28 $8^{-/-}$, IFN $\gamma^{-/-}$, 
NOD.H-2 ${ }^{\mathrm{h} 4}$ mouse exhibits extensive lymphocytic infiltrates in salivary glands that correlate with diminished saliva flow by 4-6 months of age, as compared to the NOD.H$2^{\mathrm{h} 4}$ mouse control ${ }^{150}$. Therefore, the P2X7R antagonist A438079 (34.2 mg/kg/day) or saline was injected intraperitoneally for 10 days in $\mathrm{CD} 28^{-/-}, \mathrm{IFN} \gamma^{-/-}, \mathrm{NOD} \cdot \mathrm{H}-2^{\mathrm{h} 4}$ mice. Histochemical analysis by hematoxylin and eosin $(\mathrm{H} \& \mathrm{E})$ staining revealed a decrease in lymphocytic infiltrates in SMGs from A438079-injected CD $28^{-/-}$, IFN $\gamma^{-/-}$, NOD.H-2 ${ }^{\text {h4 }}$ mice, as compared to saline-injected control mice (Fig. II-6A). This result was further confirmed by RT-PCR analysis where the expression of the pan-immune cell antigen CD45 was significantly reduced in response to A438079 treatment (Fig. II-6B), as compared to mice injected with saline alone.

Since ATP-induced inflammasome activation is responsible for the maturation and release of the leaderless proinflammatory cytokine IL-1 $\beta$ in mouse SMG cells (Figs. II-1 and II-2), we evaluated the role of the P2X7R on the expression of $I L-1 \beta$ in whole SMGs isolated from $\mathrm{CD} 28^{-/-}, \mathrm{IFN} \gamma^{-/-}$, NOD.H-2 ${ }^{\mathrm{h} 4}$ mice injected with the P2X7R antagonist A438079 or saline alone. Results indicated that A438079 significantly decreased the expression of $I L-1 \beta$ in $\mathrm{CD} 28^{-/-}$, IFN $\gamma^{-/-}$, NOD.H- $2^{\mathrm{h} 4}$ mice, as compared to saline alone (Fig. II-7).

During inflammation, as in SS, salivary gland epithelial cells exhibit aberrant expression of immunoactive molecules ${ }^{40,43}$ that mediate innate immune responses and induce chronic inflammation known as "autoimmune epithelitis" 40 . These immunoactive molecules include co-stimulatory molecules (e.g., CD80 and CD86) ${ }^{43}$ that are required for T-cell activation ${ }^{185}$, and adhesion molecules (e.g., E-selectin, ICAM-1 and VCAM) that are required for immune cell homing ${ }^{43}$. Using RT-PCR analysis, the expression of 
these molecules was assessed in whole SMGs isolated from CD2 $8^{-{ }^{-}}$, IFN $\gamma^{-/-}$, NOD.H-2 $2^{\mathrm{h} 4}$ mice following treatment for 10 days with the P2X7R antagonist A438079 or saline alone. The results show that expression levels of the adhesion molecules E-selectin, ICAM-1 and VCAM (Fig. II-8A) and the co-stimulatory molecules CD80 and CD86 (Fig. II-8B) were significantly reduced in CD28 $8^{-/-}$, IFN $\gamma^{-/-}$, NOD.H- $2^{\text {h4 }}$ mice treated with A438079, as compared to saline alone.

Hyposalivation is associated with SS and although its cause is not fully understood, inflammation is likely a contributing factor ${ }^{186}$. Since the CD $28^{-/-}$, IFN $\gamma^{-/-}$, NOD.H- $2^{\text {h4 }}$ mouse model of autoimmune exocrinopathy exhibits diminished saliva flow as compared to the NOD.H- $2^{\mathrm{h} 4}$ control ${ }^{150}$, the effects of a 10 day treatment with A438079 or saline alone on carbachol-induced saliva flow were compared in CD28 ${ }^{-/-}$, IFN $\gamma^{-/-}$, NOD.H- $2^{\mathrm{h} 4}$ mice. Importantly, there was a significant improvement in saliva flow in A438079-injected CD28 $8^{-/-}$, IFN $\gamma^{-/-}$, NOD.H-2 ${ }^{\mathrm{h} 4}$ mice (Fig. II-9), as compared to salineinjected controls.

\subsection{DISCUSSION}

The lack of an understanding of inflammatory processes that predispose the salivary gland to degeneration and dysfunction is a major obstacle hindering the development of effective therapies to prevent or reverse hyposalivation caused by Sjögren's syndrome (SS) or inadvertent radiation-induced damage from head and neck cancer treatments. Epithelial cells have emerged as active players in immune responses that underlie inflammation, in addition to their well-accepted role in the formation of a physical barrier to the outside environment in a wide variety of tissues. Inflammatory disorders of the epithelium besides SS include inflammatory bowel disease ${ }^{187}$, primary 
biliary cirrhosis ${ }^{188}$, pulmonary fibrosis ${ }^{189}$ and psoriasis ${ }^{190}$. In these diseases, changes in the morphology and ionic and molecular permeabilities of the plasma membrane of epithelial cells initiate interactions with immune cells resulting in tissue inflammation ${ }^{42}$. In SS, salivary epithelial cells participate in inflammatory responses by releasing proinflammatory cytokines and chemokines ${ }^{42}$ and expressing immunoactive molecules that modulate early innate immune responses preceding hyposalivation or autoimmune exocrinopathy ${ }^{40,43}$. While there are multiple reports of inflammatory responses in immune cells that are associated with SS, very few studies have focused on salivary epithelial cells in the initiation of inflammatory disease despite the critical role played by the epithelium in homeostasis required for normal gland functions ${ }^{191}$. In this study, we show that P2X7R activation by eATP in freshly isolated primary mouse SMG epithelial cells increases the activity of the multiprotein NLRP3 inflammasome required for the subsequent release of the proinflammatory cytokine IL-1 $\beta$ (Figs. II- 1 and II-2). These data are consistent with reports that the P2X7R stimulates inflammasome activity in intestinal epithelial cells ${ }^{89}$ and immune cells, e.g., monocytes and macrophages ${ }^{103,} 176$.

Mechanisms have been proposed in immune cells to define how eATP enhances NLRP3 inflammasome activity, including by alteration of the ionic composition of the inflammasome's microenvironment through transmembrane $\mathrm{Na}^{+}$influx and $\mathrm{K}^{+}$efflux ${ }^{80,}$ ${ }^{179,180}$. Besides eATP, other activators of the NLRP3 inflammasome in immune cells promote $\mathrm{K}^{+}$efflux, including monosodium ureate, peptidoglycan and silica, leading to the secretion of mature IL-1 $\beta^{80,99,180}$. It was reported that in neutrophils following Streptococcus pneumoniae infection of the cornea, a low intracellular $\left[\mathrm{K}^{+}\right]$enhanced P2X7R-mediated inflammasome activation and IL-1 $\beta$ maturation and release ${ }^{174}$. Also, 
pro-caspase-1 was not recruited to the inflammasome complex in monocytes in the presence of a high extracellular $\left[\mathrm{K}^{+}\right]^{80}$. However, media devoid of $\mathrm{Na}^{+}$also impaired inflammasome activation in human monocytes ${ }^{179,180}$. Here, we show that the $\mathrm{H}^{+} / \mathrm{K}^{+}$ ionophore nigericin induced IL-1 $\beta$ release in SMG cell aggregates prepared from either wild type or P2X7R ${ }^{-/-}$mice (Fig. II-1). Stimulation of the P2X7R with ATP for 10 or 30 min in wild type salivary epithelial cells resulted in a significant reduction in the intracellular $\left[\mathrm{K}^{+}\right]$that did not occur with SMG cells from $\mathrm{P} 2 \mathrm{X} 7 \mathrm{R}^{-/-}$mice (Fig. II-3A). Moreover, P2X7R-mediated IL-1 $\beta$ release was diminished when cells were incubated in a high extracellular $\left[\mathrm{K}^{+}\right]$or in absence of extracellular $\mathrm{Na}^{+}$(Fig. II-3B). These results suggest that disruption of the normal transmembrane $\mathrm{Na}^{+}$and $\mathrm{K}^{+}$gradients inhibits P2X7R-dependent NLRP3 inflammasome activation and the release of IL-1 $\beta$.

In addition to ionic dependence, the generation of ROS is a common response to various inflammasome activators, including ATP ${ }^{98,192}$, and ROS have been shown to enhance inflammasome activity ${ }^{80,98}$. Mitochondria are a major source of ROS, hence, abnormal mitochondria and uncontrolled ROS production are known to contribute to inflammatory diseases, including neurodegenerative diseases and sepsis ${ }^{193,194}$. Mitochondrial ROS are generated by the electron transport chain in complex I and the Q cycle in complex III ${ }^{108,109}$. Accumulation of mitochondrial ROS, as a consequence of mitochondrial dysfunction, is a trigger for the activation of the NLRP3 inflammasome in murine and human macrophages upon ATP or nigericin treatment, a response that was abolished in the presence of the mitochondrial-specific ROS scavenger Mito-Tempo ${ }^{110}$, 111. In bronchial epithelial cells, mitochondrial ROS induce the co-localization of NLRP3 and ASC inflammasome proteins in the mitochondria and are responsible for airway 
inflammation in bronchial asthma ${ }^{112}$. Consistent with these data, our results show that in salivary epithelial cells NAC or Mito-Tempo reduce P2X7R-mediated inflammasome activation indicated by a significant decrease in the ATP-induced release of mature IL-1 $\beta$ (Figs. II-4A and II-4B). The molecular chaperone HSP90 is also required for NLRP3 inflammasome stability in monocytes, since it prevents the degradation of the NLRP3 protein in the absence of inflammation ${ }^{102}$, a homeostatic mechanism that likely prepares cells to respond to inflammasome activators, including ATP. We found that inhibition of HSP90 activity in mouse SMG epithelial cells abolishes P2X7R-mediated IL-1 $\beta$ release (Fig. II-5A) and significantly reduces the endogenous levels of NLRP3 protein (Fig. II5B), consistent with a role for this chaperone in inflammasome stability in salivary epithelium. Taken together, these findings demonstrate for the first time that P2X7R activation in salivary gland epithelial cells induces the assembly of an active NLRP3 inflammasome that regulates the maturation and release of the proinflammatory cytokine IL-1 $\beta$, a pathway that requires physological transmembrane $\mathrm{Na}^{+}$and $\mathrm{K}^{+}$gradients, the production of mitochondrial ROS and the presence of a functional HSP90 protein.

P2X7R antagonists have been explored as inhibitors of inflammation in several mouse models of inflammatory diseases, including lung inflammation, nephritis, nociception and intracerebral hemorrhage $35,36,89,131,170-172$, and P2X7R antagonists have shown promise in phase I and phase II clinical trials for the treatment of inflammatory bowel syndrome, spinal cord injury and rheumatoid arthritis $35,134,135$. In this study, the selective P2X7R antagonist A438079 was administered in vivo to CD28 ${ }^{-/-}$, IFN $\gamma^{-/-}$, NOD.H- $2^{\text {h4 }}$ mice that we recently demonstrated develop extensive immune cell infiltrates of salivary glands and hyposalivation ${ }^{150}$. The results revealed that P2X7R antagonism dramatically reduced infiltration of CD45-expressing lymphocytes in the SMG of this mouse 
model of inflammation (Figs. II-6A and II-6B). In addition, A438079 reduced the expression of the proinflammatory cytokine IL-1 $\beta$ in SMG (Fig. II-7). The role of IL-1 $\beta$ in promoting tissue inflammation and recruiting systemic immune cells is well established in several inflammatory diseases, including myocardial infarction, gout and rheumatoid arthritis ${ }^{195}$. Also, IL-1 $\beta$ is known to be upregulated in salivary glands isolated from SS patients, as compared to normal controls ${ }^{8}$. IL- $1 \beta$ activates the NF- $\kappa B$ transcription factor in cells, thereby inducing the expression of several proinflammatory genes, including cyclooxygenase- 2 and inducible nitric oxide synthase ${ }^{196}$, which in turn increase the production of the proinflammatory factors prostaglandin E2 and nitric oxide that are responsible for vasodilation and the recruitment of immune cells to sites of inflammation ${ }^{196-198}$. In addition, IL-1 $\beta$ enhances the expression of cell adhesion molecules, including ICAM-1 and VCAM to promote immune cell homing to inflamed tissue ${ }^{196}$. Notably, our previous studies showed that IL-1 $\beta$ increases NF-kB-dependent expression of the $\mathrm{G}$ protein-coupled $\mathrm{P}_{2} \mathrm{Y}_{2}$ receptor $\left(\mathrm{P} 2 \mathrm{Y}_{2} \mathrm{R}\right){ }^{147,149}$, a member of the purinergic receptor family. The $\mathrm{P} 2 \mathrm{Y}_{2} \mathrm{R}$ is upregulated in the epithelium of inflamed and/or damaged salivary glands ${ }^{140-144}$ and upon activation, mediates integrin-dependent cell migration and enhances acinar formation ${ }^{143}$. Additional studies have shown that $\mathrm{P}_{2} \mathrm{Y}_{2} \mathrm{Rs}$ regulate localized immune responses, induce immune cell infiltration ${ }^{148}$ and upregulate VCAM-1 expression ${ }^{142}$. Thus, $\mathrm{P} 2 \mathrm{X} 7 \mathrm{R}$ and $\mathrm{P} 2 \mathrm{Y}_{2} \mathrm{R}$ may partner together in the initiation of an inflammatory response and in epithelial tissue repair during inflammation. Nonetheless, the reduced expression of IL-1 $\beta$ seen in SMGs of CD2 ${ }^{-/}$, IFN $\gamma^{-/}$, NOD.H$2^{\mathrm{h} 4}$ mice treated with the P2X7R antagonist A438079 (Fig. II-7) could explain, at least in 
part, the diminution of lymphocytic infiltrates in the SMGs of this mouse model of salivary gland inflammation upon A438079 administration (Figs. II-6A and II-6B).

Salivary glands of SS patients exhibit immune cell infiltrates, primarily comprised of B- and T-cells ${ }^{186}$ and increased expression of immunoactive proteins, including the co-stimulatory molecules, CD80 and CD86, and the cell adhesion molecules, VCAM, ICAM-1 and E-selectin ${ }^{43}$. The increased expression of immunoactive proteins propagates inflammatory responses and enhances the interaction between immune and salivary epithelial cells. Here, we show that P2X7R antagonism in $\mathrm{CD} 28^{-/-}, \mathrm{IFN} \gamma^{-1}$, NOD.H- $2^{\text {h4 }}$ mice induces a dramatic decrease in the expression of the adhesion molecules VCAM, ICAM-1 and E-selectin (Figs. II-8A) and the co-stimulatory molecules CD80 and CD86 (Fig. II-8B), suggesting that P2X7R antagonism could be used to prevent chronic inflammation that ultimately results in the loss of salivary gland function ${ }^{2}$.

Current treatments for hyposalivation, including muscarinic receptor agonists ${ }^{2}$, do not address the underlying salivary gland inflammation, which is a well-appreciated factor in salivary gland dysfunction ${ }^{186}$, particularly in the autoimmune disease SS. In the NOD mouse model of SS, increased expression of proinflammatory cytokines has been shown to precede a decrease in saliva flow ${ }^{199}$. In addition, a recent proteomic analysis of saliva from SS patients demonstrated that hyposalivation is associated with increased expression and activity of the IL-1 family of proinflammatory cytokines (i.e., IL-1 $\beta$ and IL-18) ${ }^{186}$ and adiponectin, a metabolic regulatory protein that promotes IL-1 cytokine interaction with downstream targets ${ }^{200}$. Some anti-inflammatory drugs such as interferon- $\alpha$, have undergone clinical trials for treatment of salivary gland dysfunction ${ }^{2}$. Similarly, our results encourage attempts to use P2X7R antagonists to treat 
hyposalivation in humans, based on the ability of A438079 to enhance the saliva flow

rate in the $\mathrm{CD} 28^{-/-}$, IFN $\gamma^{-/-}$, NOD.H- $2^{\mathrm{h} 4}$ mouse model of salivary gland inflammation (Fig. II-9).

In conclusion, we propose a role for the P2X7R in salivary gland inflammation, where stimulation of the P2X7R with eATP in salivary epithelial cells induces the assembly and activation of the NLRP3 inflammasome and consequently the maturation and release of the proinflammatory cytokine IL- $1 \beta$. This process requires a transmembrane $\mathrm{Na}^{+}$and/or $\mathrm{K}^{+}$flux, mitochondrial ROS production and a functional HSP90 protein (Fig. II-10). In addition, P2X7R activation is associated with increased immune cell infiltration of the salivary gland that eventually results in tissue degeneration (Fig. II-10). Hence, this study suggests that P2X7R antagonism represents a novel therapeutic strategy to prevent chronic inflammation in human salivary gland inflammatory disorders.

\subsection{EXPERIMENTAL PROCEDURES}

\subsubsection{Materials}

DMEM/F12 medium and penicillin-streptomycin 100X solution were obtained from Life Technologies (Grand Island, NY). All other reagents were purchased from Sigma-Aldrich (St. Louis, MO), unless stated otherwise.

\subsubsection{Mice}

Male C57/BL6 (Stock No: 000664) and P2X7R ${ }^{-/-}$(Stock No: 005576) mice (6-8 weeks old) were purchased from Jackson Laboratory (Bar Harbor, ME) where the 
P2X7R ${ }^{-1-}$ mice (stock No: 005576) were originally donated by Pfizer Pharmaceuticals. The NOD.H-2 ${ }^{\mathrm{h} 4}$ and CD28 $8^{--}$, IFN $\gamma^{-/-}$, NOD.H-2 ${ }^{\mathrm{h} 4}$ mice were provided by Dr. Helen Braley-Mullen, Department of Molecular Microbiology and Immunology, University of Missouri (Columbia, MO). The mice were bred in the Christopher S. Bond Life Sciences Center Animal Facility of the University of Missouri and housed in vented cages with 12 $\mathrm{h}$ light-dark cycles and free access to standard laboratory diet and water. For P2X7R antagonism, A438079 (34.2 mg/kg/day) or saline was injected intraperitoneally for 10 days in $\mathrm{CD} 28^{-{ }^{--}}$, IFN $\gamma^{-1-}$, NOD.H- $2^{\mathrm{h} 4}$ mice. The mice were treated under the guidelines and approval of the University of Missouri Institutional Animal Care and Use Committee (IACUC).

\subsubsection{Preparation of dispersed cell aggregates from mouse SMG}

Dispersed SMG cell aggregates were prepared as previously described ${ }^{88}$. Briefly, mice were anesthetized with isoflurane in a chamber and euthanized by cervical dislocation. SMGs were isolated, minced and incubated at $37^{\circ} \mathrm{C}$ in a shaking water bath for $1 \mathrm{~h}$ in dispersion media [1:1 DMEM:Ham's F-12 media containing $50 \mathrm{U} / \mathrm{ml}$ collagenase (Worthington Biochemical, Lakewood, NJ), $400 \mathrm{U} / \mathrm{ml}$ hyaluronidase, $1 \%$ $(\mathrm{w} / \mathrm{v}) \mathrm{BSA}$ and $\left.0.2 \mathrm{mM} \mathrm{CaCl}_{2}\right]$ in an atmosphere of $5 \% \mathrm{CO}_{2}$ and $95 \% \mathrm{O}_{2}$. For further dispersion, the minced SMGs were passed through a $10 \mathrm{ml}$ pipette after 20,30 and 40 min of incubation. Finally, the dispersed cell aggregates were filtered through a nylon mesh and incubated for an additional hour at $37^{\circ} \mathrm{C}$ in 1:1 DMEM:Ham's F-12 media containing $100 \mathrm{U} / \mathrm{ml}$ penicillin and $100 \mu \mathrm{g} / \mathrm{ml}$ streptomycin in an atmosphere of $5 \% \mathrm{CO}_{2}$ and $95 \% \mathrm{O}_{2}$, before further use. For further SMG epithelial cell purification, the EasySep 
Mouse Epithelial Cell Enrichment Kit (Stemcell Technologies, Cambridge, MA) was used according to the manufacturer's protocol.

\subsubsection{IL-1 $\beta$ enzyme linked immunosorbent assay (ELISA)}

Dispersed SMG cells in fresh 1:1 DMEM:Ham's F-12 media containing $100 \mathrm{U} / \mathrm{ml}$ penicillin and $100 \mu \mathrm{g} / \mathrm{ml}$ streptomycin were incubated with ATP (pH 7.4), nigericin (Tocris, Minneapolis, MN), A438079 (Tocris), Bay11-7082 (Tocris), MCC-950 (catalog no. AG-CR1-3615, Adipogen, San Diego, CA), geldanamycin (GA) (Tocris, catalog no. 1368) or the ROS scavengers, N-acetyl cysteine (NAC) or Mito-TEMPO for the indicated time periods. Cell supernatants were collected and concentrated using Amicon Ultra- $0.5 \mathrm{ml}$ centrifugal filter devices. IL- $1 \beta$ was measured in the supernatant using the Quantikine IL-1 $\beta$ ELISA kit (R\&D Systems, Minneapolis, MN), according to the manufacturer's protocol. To measure the effect of ionic gradient alterations, dispersed SMG cells were incubated for 90 min with ATP $(3 \mathrm{mM})$ in a buffer with physiological $\left[\mathrm{Na}^{+}\right]$and $\left[\mathrm{K}^{+}\right]\left(145 \mathrm{mM} \mathrm{NaCl}, 5 \mathrm{mM} \mathrm{KH}{ }_{2} \mathrm{PO}_{4}, 10 \mathrm{mM}\right.$ HEPES, $1 \mathrm{mM} \mathrm{MgCl} 2,1 \mathrm{mM}$ $\mathrm{CaCl}_{2}$ and $1 \%(\mathrm{w} / \mathrm{v})$ bovine serum albumin (BSA)), $\mathrm{pH}$ adjusted to 7.4 with $\mathrm{NaOH}$, a buffer with high $\left[\mathrm{K}^{+}\right]\left(145 \mathrm{mM} \mathrm{KCl}, 5 \mathrm{mM} \mathrm{NaH}_{2} \mathrm{PO}_{4}, 10 \mathrm{mM}\right.$ HEPES, $1 \mathrm{mM} \mathrm{MgCl} 2,1$ $\mathrm{mM} \mathrm{CaCl}_{2}$ and $1 \%(\mathrm{w} / \mathrm{v}) \mathrm{BSA}$ ), $\mathrm{pH}$ adjusted to 7.4 with $\mathrm{KOH}$, or a buffer with low $\left[\mathrm{Na}^{+}\right]$ in which $\mathrm{NaCl}$ is substituted with choline chloride $(145 \mathrm{mM}$ choline chloride, $5 \mathrm{mM}$ $\mathrm{KH}_{2} \mathrm{PO}_{4}, 10 \mathrm{mM}$ HEPES, $1 \mathrm{mM} \mathrm{MgCl} 2,1 \mathrm{mM} \mathrm{CaCl}_{2}$ and $1 \%$ (w/v) BSA), $\mathrm{pH}$ adjusted to 7.4 with $\mathrm{KOH}$. 


\subsubsection{NLRP3 inflammasome immunoprecipitation}

Dispersed SMG cells from wild type or P2X7R ${ }^{-/-}$mice were incubated with ATP $(3 \mathrm{mM})$ for $15 \mathrm{~min}$. The cells were then collected by centrifugation and incubated in $\mathrm{T}$ PER lysis buffer (ThermoFisher Scientific, Waltham, MA) with 1X SigmaFast serine, cysteine and metalloprotease inhibitors ( $2 \mathrm{mM}$ AEBSF, $1 \mathrm{mM}$ EDTA, $130 \mu \mathrm{M}$ bestatin, $14 \mu \mathrm{M}$ E-64, $1 \mu \mathrm{M}$ leupeptin, $0.3 \mu \mathrm{M}$ aprotinin). NLRP3 in SMG cell lysates (500-1,000 $\mu \mathrm{g}$ protein/ml) was immunoprecipitated with protein A MagBeads (GenScript, Piscataway, NJ) pre-coated with mouse anti-mouse NLRP3 antibody (1:200 dilution; Cryo-2, Cat. No. AG-20B-0014-C100, Adipogen, San Diego, CA) by incubation for $1 \mathrm{~h}$ at room temperature. Immunoprecipitated proteins were solubilized using $40 \mu \mathrm{l}$ of $1 \mathrm{X}$ SDS sample buffer (62.5 mM Tris- $\mathrm{HCl}$ at pH 6.8, 2\% (w/v) SDS, 10\% (v/v) glycerol, 50 $\mathrm{mM}$ DL-DTT and $0.01 \%(\mathrm{w} / \mathrm{v})$ bromophenol blue) followed by heating at $95^{\circ} \mathrm{C}$ for 5 min. The samples were then subjected to SDS-PAGE on a $12 \%(\mathrm{w} / \mathrm{v})$ gel (GenScript, Piscataway, NJ) and then transferred to nitrocellulose membranes for Western blot analysis.

\subsubsection{Western blot analysis}

Nitrocellulose membranes were blocked for $1 \mathrm{~h}$ with $5 \%(\mathrm{w} / \mathrm{v})$ nonfat dry milk in TBS containing $0.1 \%(\mathrm{v} / \mathrm{v})$ Tween-20 (TBST) and incubated overnight at $4^{\circ} \mathrm{C}$ with mouse anti-mouse NLRP3 antibody $(1: 1,000$ dilution in 5\% (w/v) nonfat dry milk in TBST, Cryo-2, Cat. No. AG-20B-0014-C100, Adipogen, San Diego, CA), rabbit antimouse ASC antibody (1:1,000 dilution in 5\% (w/v) nonfat dry milk in TBST, Catalog no. AG-25B-0006, Adipogen, San Diego, CA),rabbit anti-mouse pro-caspase-1 antibody 
(1:1,000 dilution in 5\% (w/v) nonfat dry milk in TBST, Catalog no. ab108362, Abcam, Cambridge, MA) or mouse anti-mouse $\beta$-tubulin antibody (1:5,000 dilution in 5\% (w/v) nonfat dry milk in TBST). Membranes were washed three times in TBST and incubated with horseradish peroxidase-conjugated goat anti-rabbit $\operatorname{IgG}$ or goat anti-mouse $\operatorname{IgG}$ antibody (1:1,000 dilution in 5\% (w/v) nonfat dry milk in TBST, Santa Cruz, Dallas, TX) at room temperature for $1 \mathrm{~h}$. Then, blots were washed three times in TBST and incubated in enhanced chemiluminescence reagent (ThermoFisher Scientific, Waltham, MA) for 1 min. Protein bands were detected on X-ray film and quantified using Image Studio Lite software (Li-Cor, Lincoln, NE).

\subsubsection{Intracellular $\left[\mathrm{K}^{+}\right]$quantification}

Dispersed SMG cells from wild type or P2X7R ${ }^{-1-}$ mice were incubated with ATP $(3 \mathrm{mM})$ for 0,10 or $30 \mathrm{~min}$. Cells were then collected by centrifugation and extracted with $10 \%(\mathrm{v} / \mathrm{v})$ ultrapure $\mathrm{HNO}_{3}$. Intracellular $\left[\mathrm{K}^{+}\right]$was then quantified using an ICP-OES (PerkinElmer, Optima 8000) at wavelength $769.9 \mathrm{~nm}$ using manganese as the internal standard.

\subsubsection{Immunohistochemistry}

Whole SMGs were isolated from CD28 $8^{-{ }_{-}}$, IFN $\gamma^{-{ }_{-}}$, NOD.H- $2^{\mathrm{h} 4}$ mice, placed in $4 \%$ (v/v) paraformaldehyde in PBS at $4^{\circ} \mathrm{C}$ for $24 \mathrm{~h}$, followed by $70 \%(\mathrm{v} / \mathrm{v})$ ethanol for $24 \mathrm{~h}$ at $4^{\circ} \mathrm{C}$. Samples were then sent to IDEXX RADIL (Columbia, MO) where glands were embedded in paraffin, cut into $5 \mu \mathrm{m}$ sections and subjected to hematoxylin and eosin staining. 


\subsubsection{RT-PCR}

Whole SMGs were excised, homogenized in TRIzol reagent (Life Technologies, Grand Island, NY) and incubated for $5 \mathrm{~min}$ at room temperature, followed by incubation with chloroform $(0.2 \mathrm{ml} / \mathrm{ml} \mathrm{TRIzol})$ for $5 \mathrm{~min}$ at room temperature. Following centrifugation at $12,000 \mathrm{~g}$ for $15 \mathrm{~min}$ at $4^{\circ} \mathrm{C}$, the resulting aqueous phase containing RNA was collected and DNA-free RNA was isolated using the RNeasy Plus Mini kit (Qiagen, Valencia, CA). cDNA was prepared from purified RNA using RNA to cDNA EcoDry Premix (Clontech Laboratories, Mountain View, CA). TaqMan probes for CD45 (also known as protein tyrosine phosphatase receptor type $\mathrm{C}$, a pan-immune cell marker), $I L$ 1 $\beta, C D 80, C D 86, I C A M-1, V C A M$ and E-selectin were obtained from Applied Biosystems (Foster City, CA) and used for RT-PCR with an Applied Biosystems 7500 real-time PCR machine. The mRNA expression of target genes was normalized to $18 \mathrm{~S}$ ribosomal RNA as an internal control and data were analyzed using Applied Biosystems software.

\subsubsection{Saliva collection}

Mice were anesthetized with tribromoethanol (Avertin; $0.75 \mathrm{mg} / \mathrm{g}$ mouse weight) and an endotracheal tube (PE50 polyethylene tubing) was inserted through a $2 \mathrm{~cm}$ midventral incision to prevent aspiration. Saliva secretion was induced by intraperitoneal injection of $0.25 \mathrm{mg} / \mathrm{kg}$ carbachol. Saliva was collected from the oral cavity for $15 \mathrm{~min}$ using a pipette tip and placed in a pre-weighed Eppendorf tube. Results are presented as microliters of saliva produced per $15 \mathrm{~min}$. 


\subsubsection{Statistical analysis}

The statistical analyses were performed using Student's $t$-test on Graphpad Prism software where significant differences were considered to be $P<0.05$

\section{Author contributions}

M. G. K. contributed to the experimental design, performed most of the experiments, and drafted the manuscript. L. T. W. performed the immunohistochemistry experiment, provided technical assistance, and participated in the critical review of the manuscript. J. M. C. supervised the experiments and performed the mouse studies. A. A. K. measured the $\left[\mathrm{K}^{+}\right]$using ICP-OES and participated in the critical review of the manuscript. K. H. L., M. J. P., and L. E. contributed to the experimental design and the critical review of the results and manuscript. G. A. W. designed and supervised the project and edited the manuscript.

\section{Footnotes}

This work was supported by National Institute of Dental and Craniofacial Research, National Institutes of Health Grant DE023342. The authors declare that they have no conflicts of interest with the contents of this article. The content is solely the responsibility of the authors and does not necessarily represent the official views of the National Institutes of Health. 


\section{FIGURES}

Figure II-1. P2X7R activation induces the release of IL-1 in primary mouse SMG cell aggregates. (A) Dispersed SMG cell aggregates from wild type mice were cultured in the presence or absence of $\mathrm{A} 438079(25 \mu \mathrm{M})$ for 30 min and then incubated with ATP (3 $\mathrm{mM})$ or nigericin $(10 \mu \mathrm{M})$ for $90 \mathrm{~min}(n=4)$. (B) Dispersed SMG cell aggregates isolated from P2X7R $\mathrm{R}^{-/-}$mice were incubated with ATP $(3 \mathrm{mM})$ or nigericin $(10 \mu \mathrm{M})$ for $90 \min (n=3)$. Cells were collected by centrifugation and IL-1 $\beta$ was quantified in the supernatant using the IL-1 $\beta$ Quantikine ELISA kit. Data represent means \pm S.E., where ${ }^{* *} P<0.01$ indicates a significant increase over basal levels, whereas ${ }^{\# \#} P<0.01$ indicates a significant decrease compared to ATP-treated cells. (C) Wild type dispersed SMG cell aggregates were suspended in PBS buffer and non-specific antibody binding was blocked by incubation for $10 \mathrm{~min}$ at $4{ }^{\circ} \mathrm{C}$ with anti-mouse CD16/32 antibody $\left(1 \mu \mathrm{g} / 10^{6}\right.$ cells in $100 \mu \mathrm{l}$, Mouse $\mathrm{F}_{\mathrm{C}}$ block, Cat. No. 553142, BD Biosciences, San Jose, CA). SMG cells were incubated for 20 min at $4{ }^{\circ} \mathrm{C}$ with Alexa Fluor 594-conjugated anti-mouse CD45 antibody (1:50 dilution, clone 30-F11, Biolegend, San Diego, CA) and then washed 3 times in PBS buffer. Stained cells were placed on a 8-well coverslip and fluorescence was visualized using a Nikon TI-E inverted microscope equipped with appropriate filters. Images from 3 independent SMG preparations were analyzed for immune cell contamination by counting the number of $\mathrm{CD} 45^{+}$cells and total number of cells. Epithelial cell purity of SMG cell preparations was 97-99\%. (D) SMG epithelial cells were enriched using the magnetic bead-based EasySep Mouse Epithelial Cell Enrichment Kit to remove hematopoietic, endothelial and fibroblast cells. The isolated epithelial cells were stimulated with ATP (3 mM) for 90 min and then cells were collected by centrifugation and IL$1 \beta$ was quantified in the supernatant using the IL-1 $\beta$ Quantikine ELISA kit. Data represent means \pm S.E., where $* P<0.05$ indicate a significant increase over basal levels. 
(A)

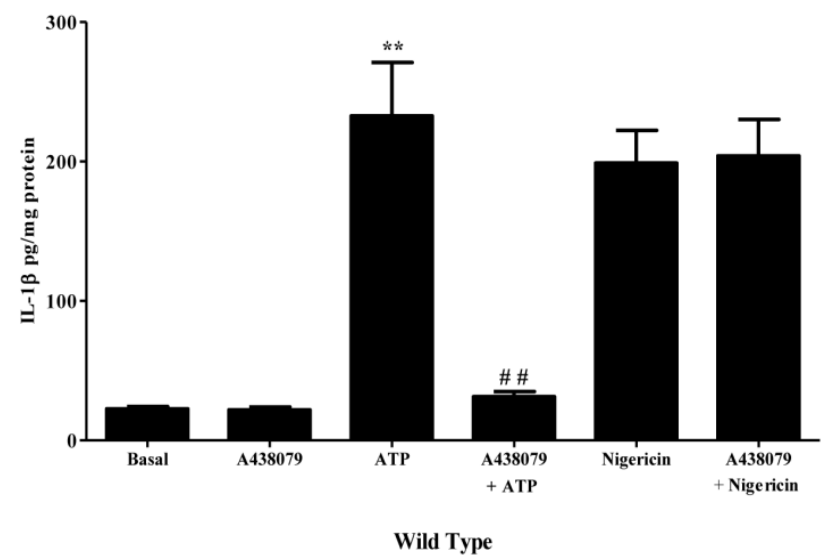

(C)

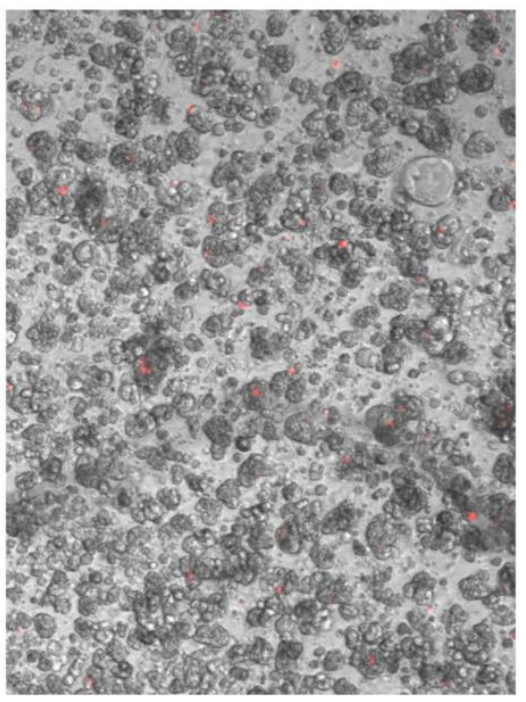

(B)

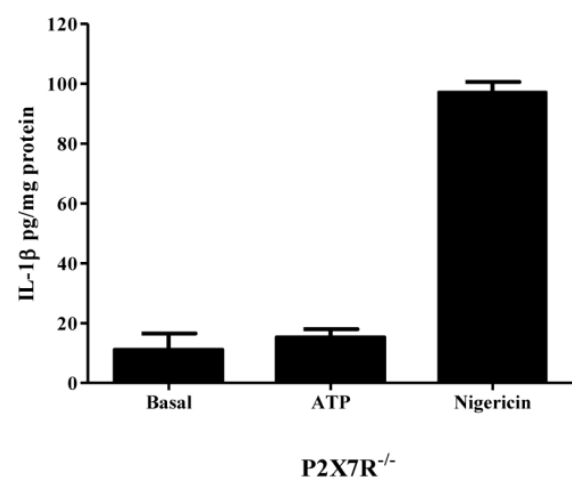

(D)

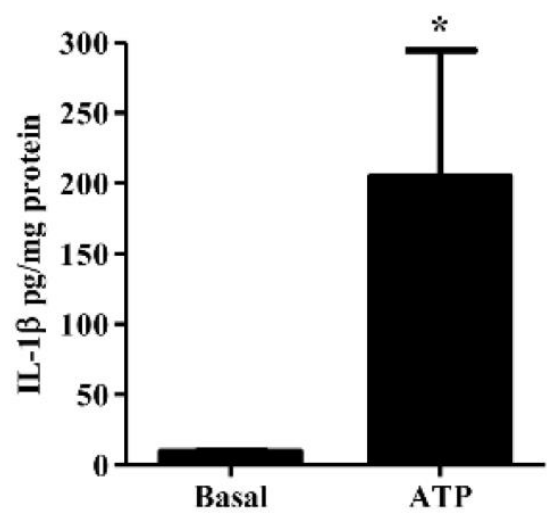


Figure II-2. The NLRP3 inflammasome mediates P2X7R-induced IL-1ß release. (A) Dispersed SMG cell aggregates from wild type mice were cultured in the presence or absence of Bay 11-7082 (15 $\mu \mathrm{M})$ for $1 \mathrm{~h}$ or MCC-950 $(10 \mu \mathrm{M})$ for $30 \mathrm{~min}$ and then stimulated with ATP $(3 \mathrm{mM})$ for $90 \mathrm{~min}(n=3)$. Cells were collected by centrifugation and IL-1 $\beta$ was quantified in the supernatant using the IL-1 $\beta$ Quantikine ELISA kit. Data represent means \pm S.E., where $* * P<0.01$ and $* * * P<0.001$ indicate significant decreases from ATP-treated only. (B) Upper panel-Cell lysates from dispersed wild type or P2X7R ${ }^{-/}$SMG cell aggregates treated with or without ATP (3 mM) for 15 min, were subjected to immunoprecipitation (IP) with anti-NLRP3 antibody, followed by immunoblotting (IB) with anti-NLRP3, anti-ASC or anti-pro-caspase-1 antibodies. Images represent results from 3 independent experiments. Lower panel-Quantification of the co-immunoprecipitated proteins in wild type SMG cells $(n=3)$. Data represent means \pm S.E., where $* P<0.05$ and $* * P<0.01$ indicate significant increases in relative band intensities as compared to basal conditions. 
(A)

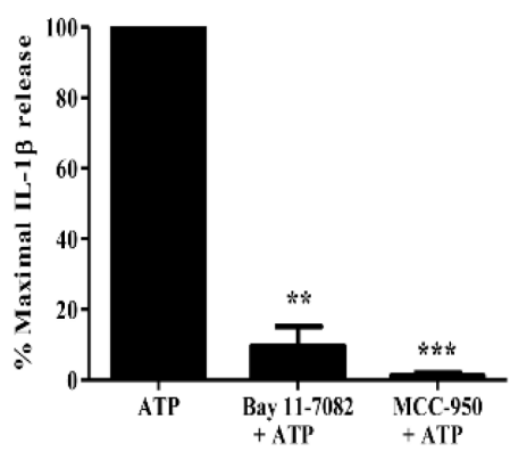

(B)

Wild Type

P2X7R *

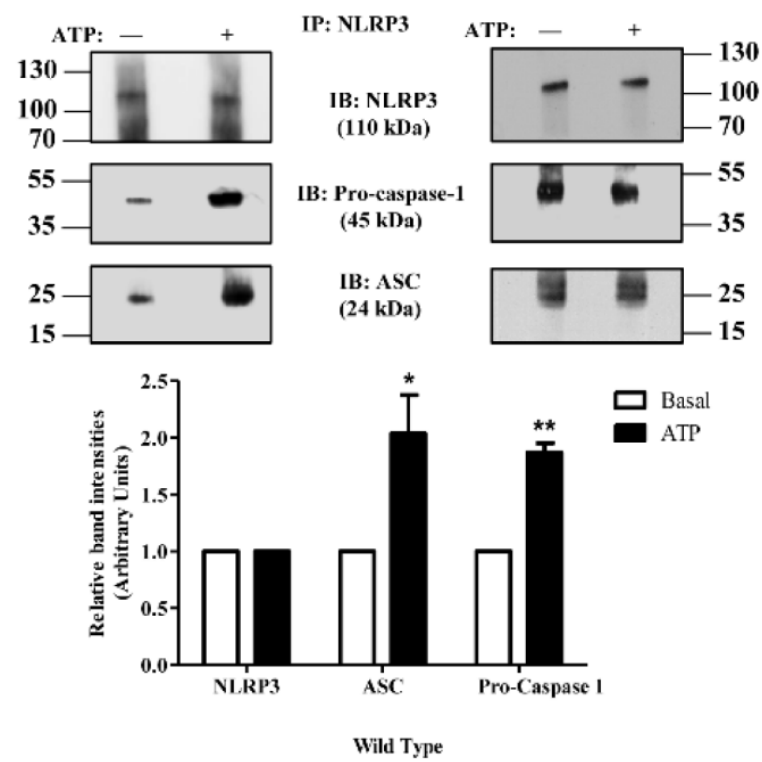


Figure II-3 $\mathrm{Na}^{+}$and/or $\mathrm{K}^{+}$efflux is required for P2X7R induced IL-1ß release. (A)

Dispersed SMG cell aggregates from wild type and P2X7R ${ }^{-/-}$mice were stimulated with ATP (3 $\mathrm{mM}$ ) for 0,10 or $30 \mathrm{~min}$. Then, the intracellular $\left[\mathrm{K}^{+}\right]$was quantified using ICP-OES and expressed as a percentage of the intracellular $\left[\mathrm{K}^{+}\right]$at 0 min of ATP treatment $(n=3)$. Data represent means \pm S.E. where $* P<0.05$ indicates a significant decrease from ATP-treated cells at 0 min. (B) Dispersed SMG cell aggregates from wild type mice were stimulated with ATP (3 $\mathrm{mM}$ ) for $90 \mathrm{~min}$ in the presence of the specified concentrations of $\mathrm{NaCl}, \mathrm{KCl}$ or choline chloride $(n=4)$. Cells were collected by centrifugation and IL-1 $\beta$ was quantified in the supernatant using the IL-1 $\beta$ Quantikine ELISA kit. Data represent means \pm S.E., where $* * P<0.01$ and $* * * P<$ 0.001 indicate significant decreases from ATP-treated cells in $145 \mathrm{mM} \mathrm{Na}^{+}$.

(A)

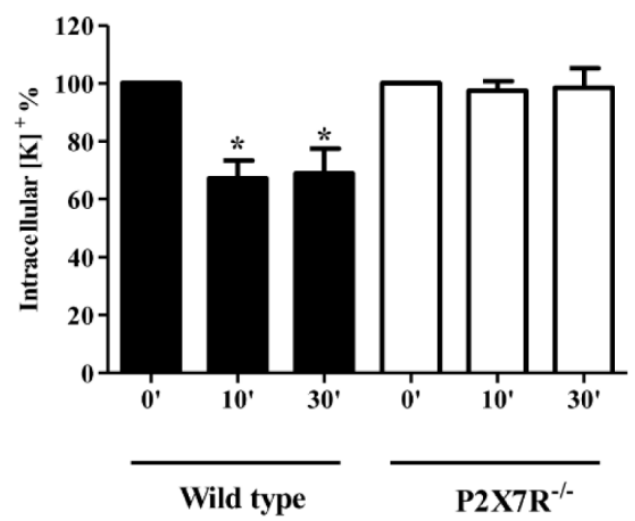

(B)

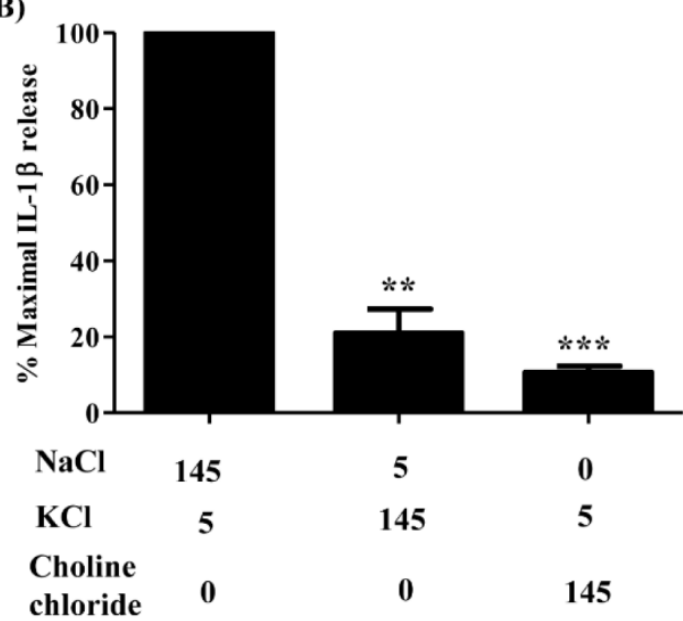




\section{Figure II-4 Mitochondrial ROS contribute to P2X7R-induced IL-1ß release}

Dispersed SMG cell aggregates from wild-type mice were treated at $\mathrm{pH} 7$ with $3 \mathrm{mM}$ ATP for 90 min at $37^{\circ} \mathrm{C}$ with or without pretreatment with the ROS inhibitor (a) NAC (25 mM) or (b) mitochondrial ROS inhibitor Mito-Tempo (1mM) for $1 \mathrm{~h}$. Cells were collected by centrifugation and IL- $1 \beta$ release was quantified in the supernatant using the IL-1 $\beta$ Quantikine ELISA kit. Data with ATP, NAC/Mito-Tempo-treated wild-type SMG cells represent means $\pm \mathrm{SE}(n=3) . * P<0.05$, significant decrease from ATP-treated only.

(A)

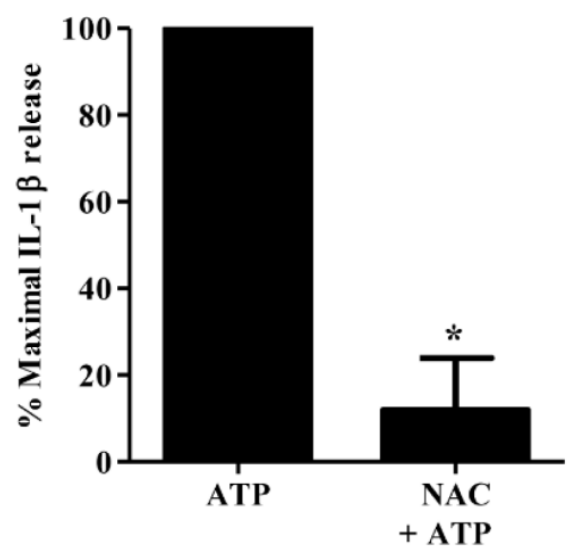

(B)

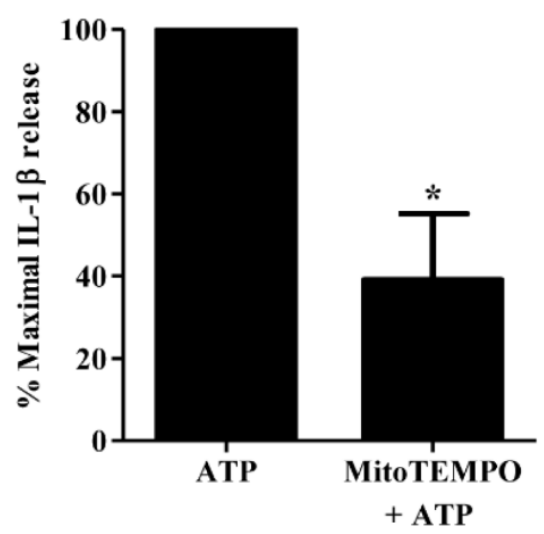


Figure II-5 HSP 90 is crucial for P2X7R-induced IL-1ß release (A) Dispersed SMG cell aggregates from wild-type C57BL/6 mice were treated at $\mathrm{pH} 7$ with 3 mM ATP for 90 min at $37^{\circ} \mathrm{C}$ with or without pretreatment with the HSP90 inhibitor geldanamycin (GA, $5 \mu \mathrm{M}$ ), for $1 \mathrm{~h}$. Cells were collected by centrifugation and IL-1 $\beta$ release was quantified in the supernatant using the IL-1 $\beta$ Quantikine ELISA kit. Data with ATP, GAtreated SMG cells represent means $\pm \mathrm{SE}(n=3) .{ }^{* *} P<0.01$, significant decrease from ATP-treated only. (B) Upper panel-Cell lysates from dispersed wild type SMG cell aggregates were treated with or without GA $(5 \mu \mathrm{M})$ for $1 \mathrm{~h}$ and subjected to immunoblotting (IB) with anti-NLRP3 or anti- $\beta$-tubulin antibodies. Images represent results from 3 independent experiments. Lower panel- Quantification of NLRP3 expression in wild type SMG cells $(n=3)$. Data represent means \pm S.E., where $* P<0.05$ indicates a significant decrease in relative band intensity as compared to basal conditions.

(A)

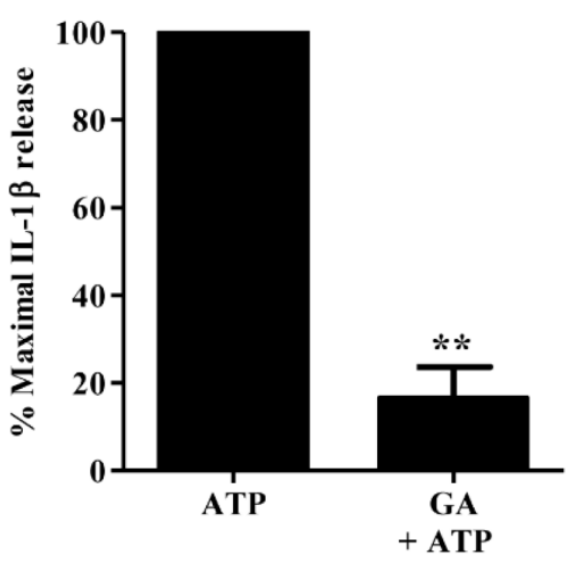

(B)
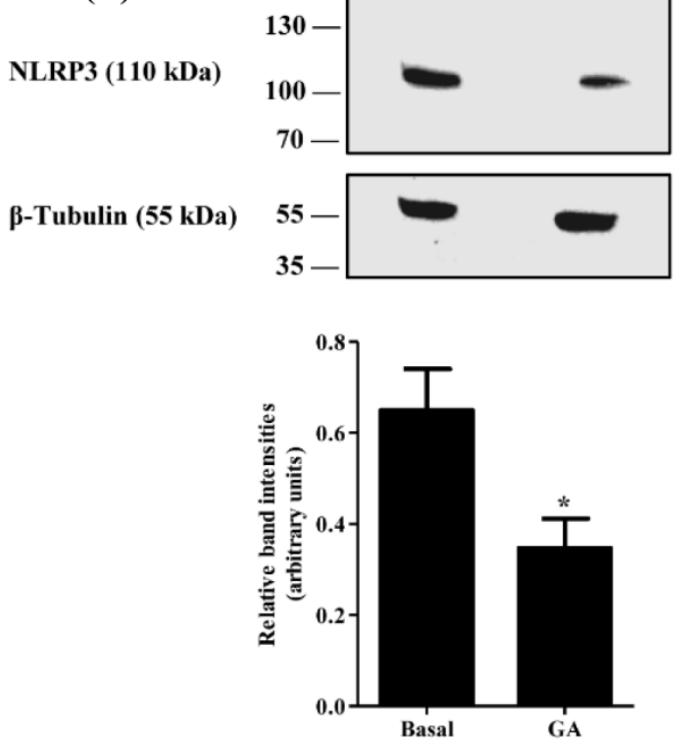
Figure II-6. P2X7R antagonism ameliorates salivary gland inflammation in $\mathrm{CD}^{-8^{-/}}{ }^{-}$, IFN $\gamma^{-/-}$, NOD.H-2 ${ }^{\text {h4 }}$ mice. (A) H \& E staining of SMG sections isolated from NOD.H-2 $2^{\text {h4 }}$ or CD28 ${ }^{-/-}$, IFN $\gamma^{-/-}$, NOD.H-2 $2^{\mathrm{h} 4}$ mice (5 months old) injected intraperitoneally with saline alone or the P2X7R antagonist A438079 (34.2 mg/kg/day) for 10 days. Images are representative of $n=10$ mice per each group. (B) cDNA was prepared from SMGs of NOD.H-2 $2^{\mathrm{h} 4}$ and CD28 $8^{-/-}$, IFN $\gamma^{-/-}$, NOD.H-2 $2^{\mathrm{h} 4}$ mice injected with saline alone or A438079, as above, then analyzed by RT-PCR using specific primers for the pan-immune cell marker CD45 ( $n=5$ for NOD.H- $2^{\mathrm{h} 4}$ mice, $n=9$ for saline-injected and $n=10$ for A438079-injected $\mathrm{CD} 28^{-/-}, \mathrm{IFN} \gamma^{-/-}$, NOD.H-2 ${ }^{\mathrm{h} 4}$ mice). Data represent means \pm S.E., where $* P<0.05$ indicates a significant difference from saline-injected CD28 ${ }^{-/-}$, IFN $\gamma^{-/-}$, NOD.H- $2^{\mathrm{h} 4}$ mice.

(A)

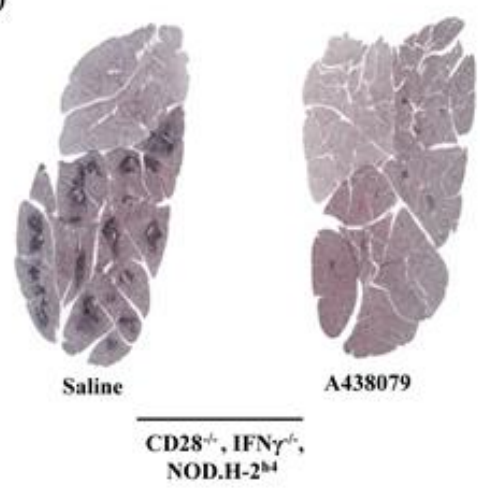

(B)

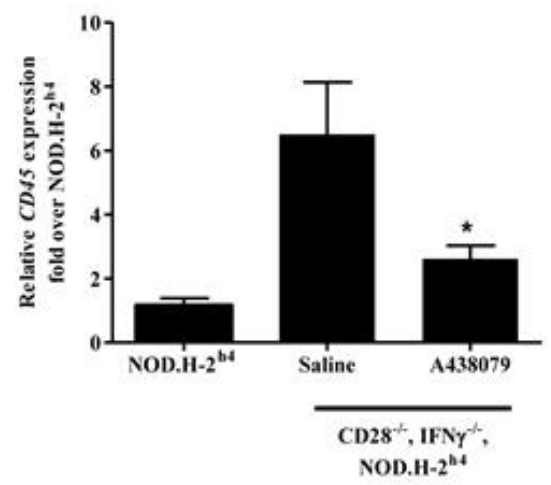


Figure II-7. P2X7R antagonism reduces $I L-1 B$ expression in $\mathrm{CD}^{-8^{-/}}$, IFN $\gamma^{-/ \text {, }}$ NOD.H-2 ${ }^{\text {h4 }}$ mice. cDNA was prepared from SMGs of NOD.H-2 ${ }^{\text {h4 }}$ and CD28 $8^{-1}$, IFN $\gamma^{-1-}$, NOD.H- ${ }^{\text {h4 }}$ mice (5 months old) injected with saline alone or the P2X7R antagonist A438079 (34.2 mg/kg/day) for 10 days, then analyzed by RT-PCR using specific primers for $I L-1 B\left(n=4\right.$ for NOD.H- $2^{\mathrm{h} 4}$ mice, $n=9$ for saline-injected and $n=10$ for A438079injected CD28 $8^{-{ }_{-}}$, IFN $\gamma^{-{ }^{-}}$, NOD.H-2 ${ }^{\text {h4 }}$ mice). Data represent means \pm S.E., where $* P<$ 0.05 indicates a significant difference from saline-injected CD28 $8^{-/-}$IFN $\gamma^{-/-}$, NOD.H- $2^{\text {h4 }}$ mice.

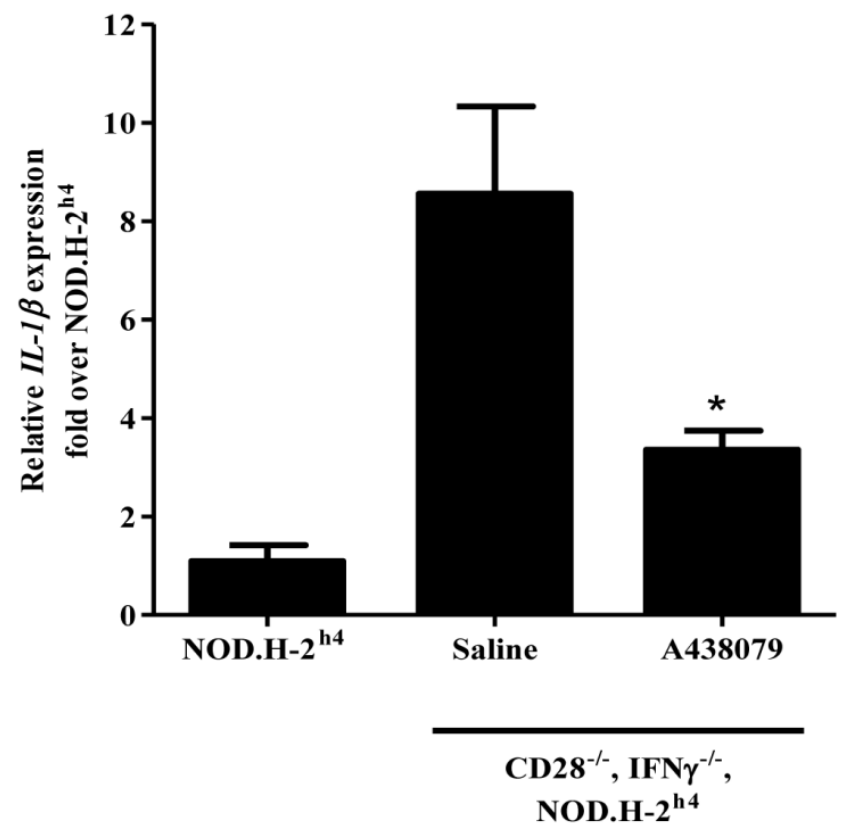


Figure II-8. P2X7R antagonism reduces expression of immunoactive molecules in CD28 $^{-/-}$, IFN $\gamma^{-/-}$, NOD.H-2 ${ }^{\text {h4 }}$ mice. cDNA was prepared from SMGs of NOD.H- $2^{\text {h4 }}$ and $\mathrm{CD} 28^{-/-}$, IFN $\gamma^{-/-}$, NOD.H- $2^{\mathrm{h} 4}$ mice (5 months old) injected with saline alone or the P2X7R antagonist A438079 (34.2 mg/kg/day) for 10 days, then analyzed by RT-PCR using specific primers for (A) ICAM-1, VCAM or E-Selectin or (B) CD80 or CD86 $(n=4$ for NOD.H-2 $2^{\text {h4 }}$ mice, $n=9$ for saline-injected and $n=10$ for A438079-injected CD28 $8^{-/-}$, IFN $\gamma^{-/-}$, NOD.H-2 $2^{\mathrm{h} 4}$ mice). Data represent means \pm S.E., where $* P<0.05$ and $* * P<0.01$ indicate significant differences from saline-injected CD $28^{-/-}, \mathrm{IFN} \gamma^{-/-}, \mathrm{NOD} \cdot \mathrm{H}-2^{\mathrm{h} 4}$ mice.

(A)

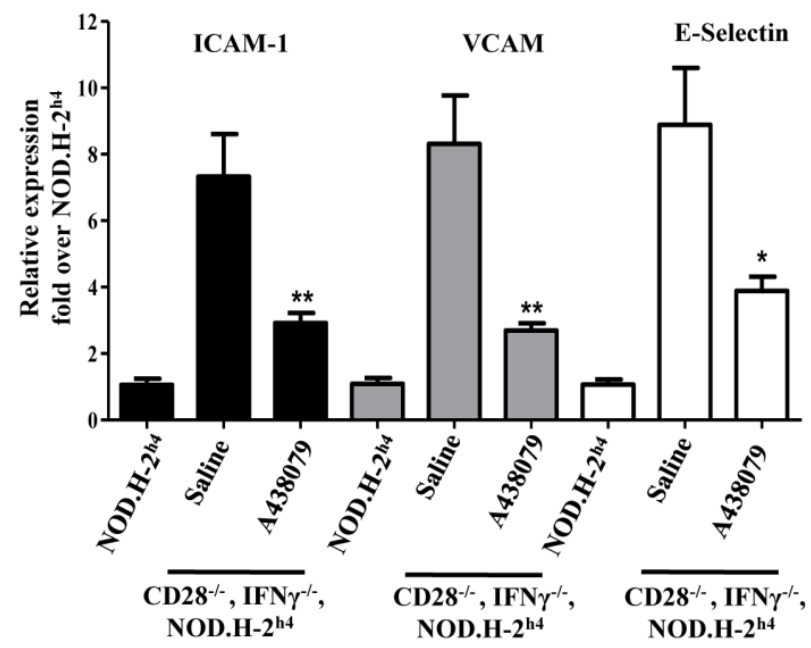

(B)

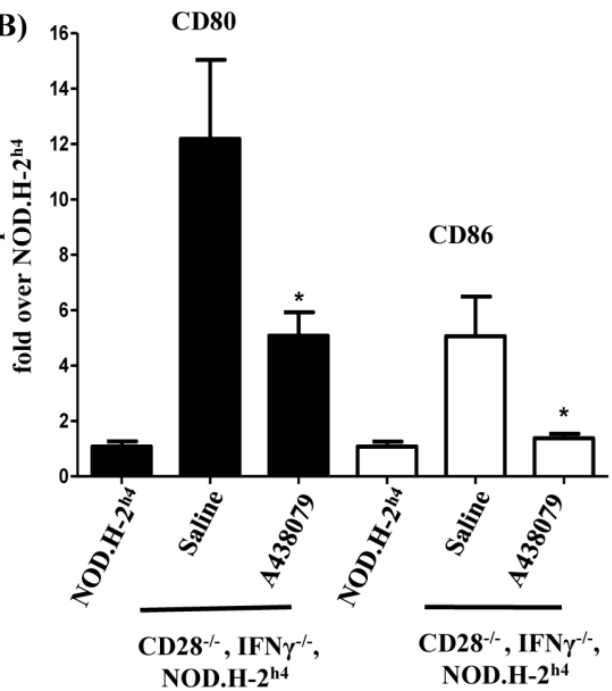


Figure II-9. P2X7R antagonism improves saliva flow rate in $\mathrm{CD28}^{-/}$, IFN $\gamma^{-/ \text {, }}$ NOD.H-2 ${ }^{\text {h4 }}$ mice. Carbachol-induced saliva flow rate in $\mathrm{CD} 28^{-/-}, \mathrm{IFN} \gamma^{-/-}$, NOD.H-2 ${ }^{\text {h4 }}$ mice (5 months old) injected with saline alone or the P2X7R antagonist A438079 (34.2 $\mathrm{mg} / \mathrm{kg} / \mathrm{day}$ ) for 10 days ( $n=9$ for saline-injected and $n=10$ for A438079-injected CD28${ }^{\text {- }}$, IFN $\gamma^{-/-}$, NOD.H- $2^{\text {h4 }}$ mice). Data represent means \pm S.E., where $* * P<0.01$ indicates a significant difference from saline-injected $\mathrm{CD} 28^{-/-}$, IFN $\gamma^{-/-}$, NOD.H-2 ${ }^{\mathrm{h} 4}$ mice.

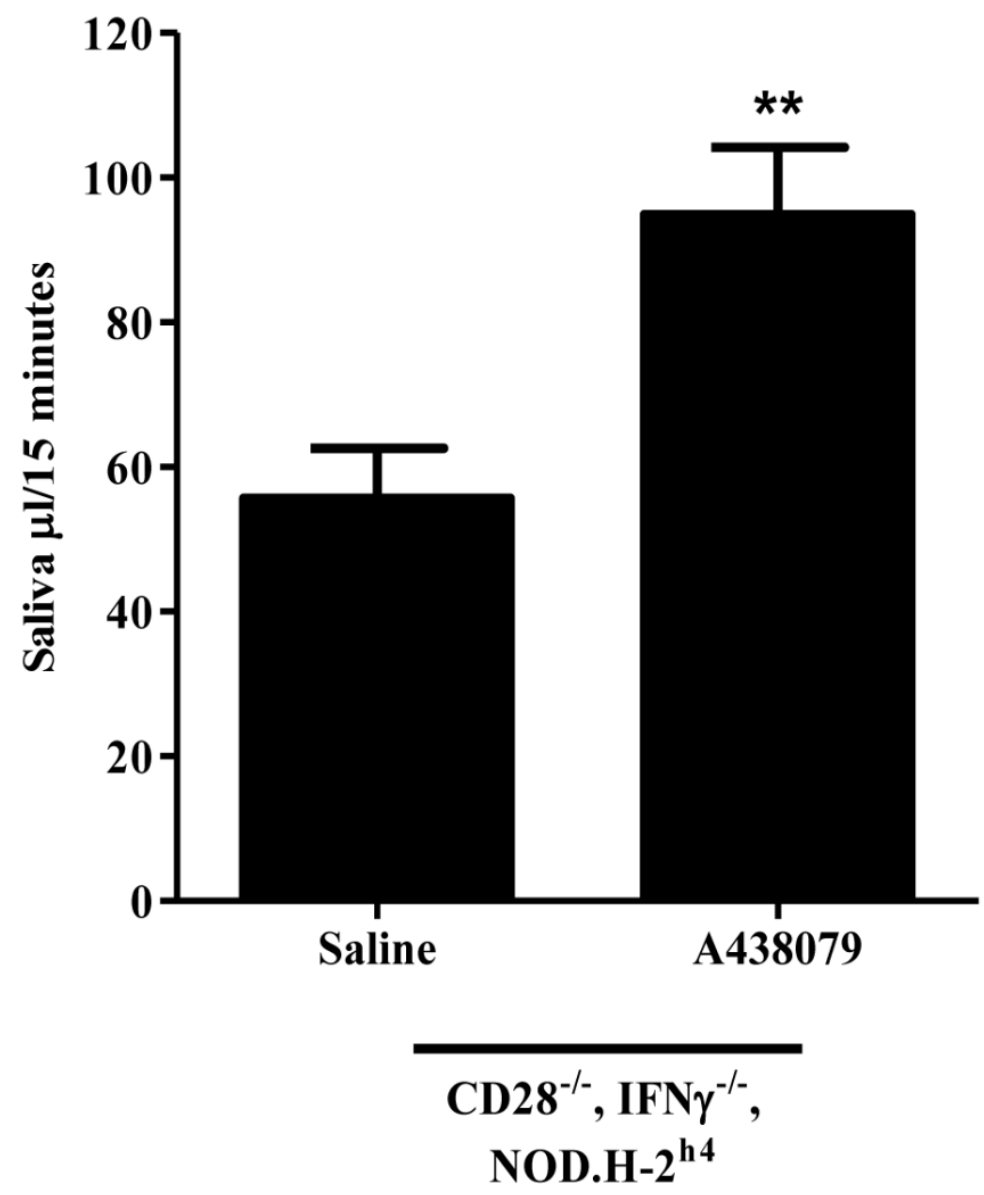


Figure II-10. Schematic diagram illustrating the proposed role of the P2X7R in salivary gland inflammation. In salivary epithelial cells, P2X7R activation by eATP induces the assembly and activation of the NLRP3 inflammasome and the subsequent release of mature IL-1 $\beta$. This process involves efflux of $\mathrm{K}^{+}$ions, production of ROS and the presence of an active HSP90 protein. P2X7R antagonism reduces immune cell infiltration and salivary gland expression of $I L-1 \beta, I C A M-1, V C A M$, E-Selectin, CD80 and $C D 86$ and enhances carbachol-induced saliva secretion in the CD28 ${ }^{--_{-}}$, IFN- $\gamma^{-{ }^{-}}$, NOD.H-2 $2^{\mathrm{h} 4}$ mouse model of salivary gland inflammation. 


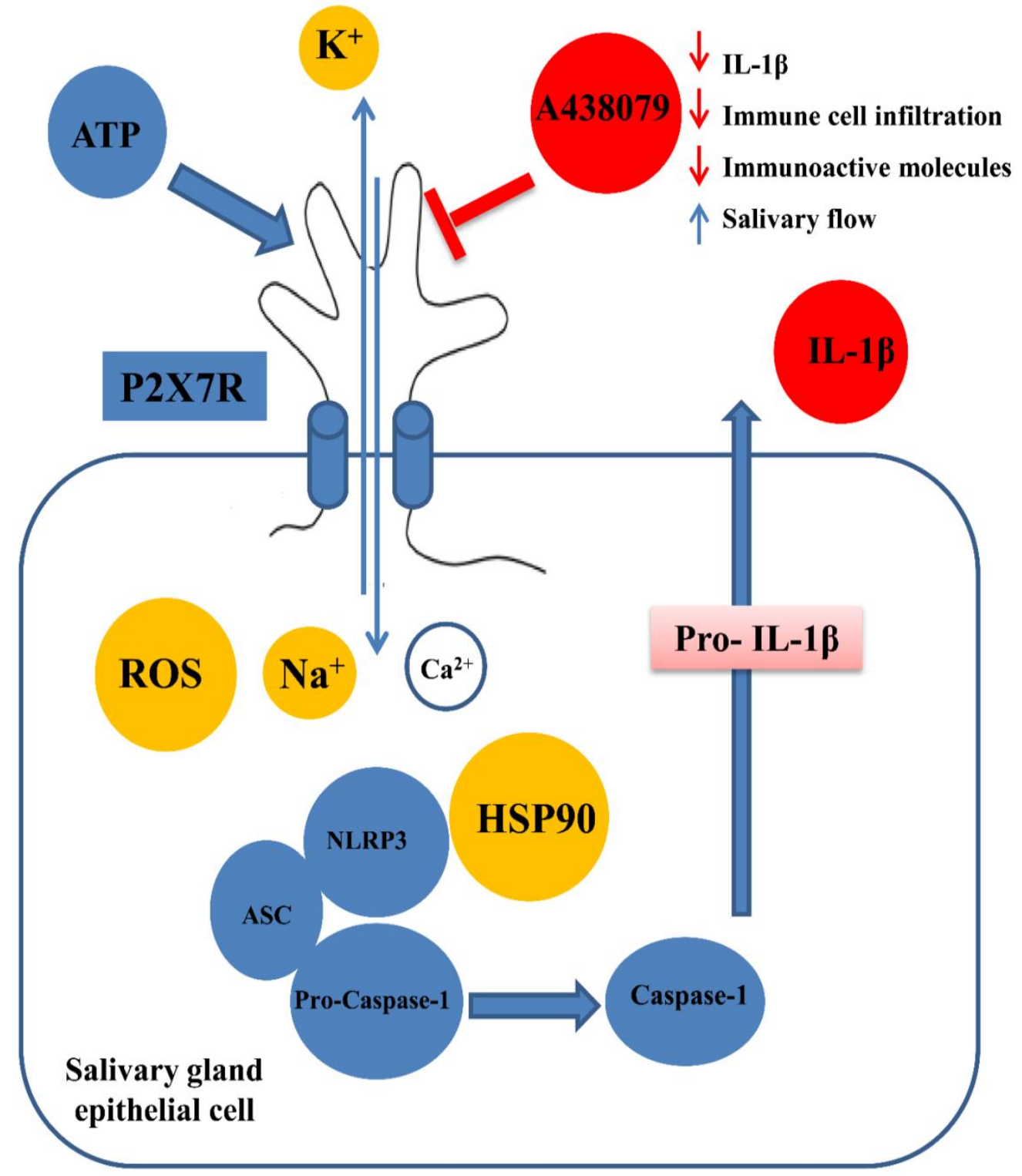




\section{Chapter III}

\section{Alternative therapeutic approaches for salivary gland inflammation and fibrosis}

\section{1 $\mathrm{P}_{2} \mathrm{Y}_{2}$ nucleotide receptor activation enhances the aggregation and self- organization of dispersed salivary epithelial cells}

Hyposalivation resulting from salivary gland dysfunction leads to poor oral health and greatly reduces the quality of life of patients ${ }^{2}$. Current treatments for hyposalivation are limited ${ }^{2}$. Regenerative medicine represents a revolutionary approach to replace dysfunctional salivary glands. Over the past decade, progress has been made in cell-based reconstitution strategies for salivary glands. The ability of dispersed salivary epithelial cells or salivary gland-derived progenitor cells to selforganize into acinar-like spheres or branching structures that mimic the native tissue holds promise for cell-based reconstitution of a functional salivary gland ${ }^{201}$. However, the mechanisms involved in salivary epithelial cell aggregation and tissue reconstitution are not fully understood. This study investigated the role of the $\mathrm{P} 2 \mathrm{Y}_{2}$ nucleotide receptor $\left(\mathrm{P} 2 \mathrm{Y}_{2} \mathrm{R}\right)$, a $\mathrm{G}$ protein-coupled receptor that is upregulated following salivary gland damage and disease ${ }^{140,141}$, in salivary gland reconstitution. In vitro results with the rat parotid acinar Par-C10 cell line indicate that $\mathrm{P} 2 \mathrm{Y}_{2} \mathrm{R}$ activation with the selective agonist UTP enhances the self-organization of dispersed salivary epithelial cells into acinar-like spheres. Other results indicate that the $\mathrm{P} 2 \mathrm{Y}_{2} \mathrm{R}$ mediated response is dependent on epidermal growth factor receptor activation via the metalloproteases ADAM10/ADAM17 or the $\alpha_{5} \beta_{1}$ integrin/Cdc42 signaling pathway, which leads to activation of the MAPKs JNK and ERK1/2. Ex vivo data 
using primary submandibular gland cells from wild-type and $P 2 Y_{2} R^{-/}$mice confirmed that UTP-induced migratory responses required for acinar cell selforganization are mediated by the $\mathrm{P} 2 \mathrm{Y}_{2} \mathrm{R}$. Overall, this study suggests that the $\mathrm{P} 2 \mathrm{Y}_{2} \mathrm{R}$ is a promising target for salivary gland reconstitution and identifies the involvement of two novel components of the $\mathrm{P} 2 \mathrm{Y}_{2} \mathrm{R}$ signaling cascade in salivary epithelial cells, the $\alpha_{5} \beta_{1}$ integrin and the Rho GTPase Cdc42 (see Appendix 1).

\subsection{Increased expression of TGF- $\beta$ signaling components in a mouse model of fibrosis induced by submandibular gland duct ligation}

One of the consequences of the chronic inflammatory disease SS is the fibrosis of the salivary gland and its subsequent hypofunctioning ${ }^{202}$. Transforming growth factor- $\beta$ (TGF- $\beta$ ) is a multi-functional cytokine with a well-described role in the regulation of tissue fibrosis and regeneration in the liver, kidney and lung ${ }^{203-205}$. Submandibular gland (SMG) duct ligation and subsequent deligation in rodents is a classical model for studying salivary gland damage and regeneration ${ }^{88,144}$. While previous studies suggest that TGF- $\beta$ may contribute to salivary gland fibrosis, the expression of TGF- $\beta$ signaling components has not been investigated in relation to mouse SMG duct ligation-induced fibrosis and regeneration following ductal deligation. Following a 7-day SMG duct ligation, TGF- $\beta 1$ and TGF- $\beta 3$ were significantly upregulated in the SMG, as were TGF- $\beta$ receptor 1 and downstream Smad family transcription factors in salivary acinar cells, but not in ductal cells. In acinar cells, duct ligation also led to upregulation of Snail, a Smad-activated Ecadherin repressor and regulator of epithelial-mesenchymal transition, whereas in ductal cells upregulation of E-cadherin was observed while Snail expression was 
unchanged. Upregulation of these TGF- $\beta$ signaling components correlated with upregulation of fibrosis markers collagen 1 and fibronectin, responses that were inhibited by administration of the TGF- $\beta$ receptor 1 inhibitors SB431542 or GW788388. After SMG regeneration following a 28-day duct deligation, TGF- $\beta$ signaling components and epithelial-mesenchymal transition markers returned to levels similar to non-ligated controls. The results from this study indicate that increased TGF- $\beta$ signaling contributes to duct ligation-induced changes in salivary epithelium that correlate with glandular fibrosis. Furthermore, the reversibility of enhanced TGF- $\beta$ signaling in acinar cells of duct-ligated mouse SMG after deligation indicates that this is an ideal model for studying TGF- $\beta$ signaling mechanisms in salivary epithelium as well as mechanisms of fibrosis initiation and resolution (see Appendix 2). 


\section{Chapter IV}

\section{Summary and future directions}

\subsection{Summary}

Salivary gland inflammation and the associated hyposalivation is a serious clinical problem that greatly affects the quality of life of patients resulting in several health problems, including oral speech difficulties, oral bacterial infections and digestion deficits. The major causes of salivary gland inflammation include the autoimmune inflammatory disease SS and radiotherapy for head and neck cancer patients that causes salivary gland degradation as a secondary unintended side effect. The current treatments for hyposalivation are symptomatic and relatively ineffective, including stimulation of salivary flow in residual salivary acinar cells of SS patients using muscarinic receptor agonists (e.g., pilocarpine or cevimeline), oral administration of anti-inflammatory agents (e.g., interferon- $\alpha$ ) or utilization of artificial saliva. The $\mathrm{P} 2 \mathrm{X} 7 \mathrm{R}$ is a purinergic receptor whose natural agonist is extracellular ATP. The P2X7R is of particular interest as its activation is linked to a number of inflammatory diseases, e.g., glomerulonephritis, neuroinflammation and rheumatoid arthritis ${ }^{54-57}$. In this study, we investigated the contribution of the P2X7R to salivary gland inflammation and examined the possibility that P2X7R antagonists can reduce inflammation and restore salivary gland excretory function in a mouse model of autoimmune exocrinopathy.

In summary, the results of this study include the following novel findings: 
1- The P2X7R contributes to salivary gland inflammation where its stimulation promotes NLRP3 inflammasome assembly and activation leading to IL-1 $\beta$ release through a mechanism involving downhill transmembrane $\mathrm{Na}^{+}$and $\mathrm{K}^{+}$fluxes, $\mathrm{ROS}$ production and HSP90 protein function.

2- In vivo administration of the $\mathrm{P} 2 \mathrm{X} 7 \mathrm{R}$ antagonist $\mathrm{A} 438079$ in the $\mathrm{CD} 28^{-/-}, \mathrm{IFN} \gamma^{-/-}$, NOD.H- ${ }^{\mathrm{h} 4}$ mouse model of autoimmune exocrinopathy reduced salivary gland lymphocytic infiltration, a hallmark of SS.

3- In vivo administration of the P2X7R antagonist $\mathrm{A} 438079$ in the $\mathrm{CD} 28^{-/-}, \mathrm{IFN} \gamma^{-/-}$, NOD.H- $2^{\text {h4 }}$ mouse model of autoimmune exocrinopathy reduced the expression of the pro-inflammatory cytokine IL-1 $\beta$ which explains, at least in part, the diminution of lymphocytic infiltrates in the SMGs of this mouse model of salivary gland inflammation.

4- In vivo administration of the $\mathrm{P} 2 \mathrm{X} 7 \mathrm{R}$ antagonist $\mathrm{A} 438079$ in the $\mathrm{CD} 28^{-{ }^{-}}, \mathrm{IFN} \gamma^{-/-}$, NOD.H- $2^{\text {h4 }}$ mouse model of autoimmune exocrinopathy reduced the expression of immunoactive proteins, e.g., CD80, CD86, ICAM, VCAM and E-selectin, that are responsible for the propagation of inflammatory and immune responses seen in SS. This result suggests that P2X7R antagonism can be utilized to limit innate immune responses, reduce the interaction between immune and salivary epithelial cells and prevent chronic inflammation that ultimately results in the loss of salivary gland function.

5- Amelioration of salivary gland inflammation by P2X7R antagonism in the CD28${ }^{\text {/- }}$ IFN $\gamma^{-/-}$, NOD.H-2 ${ }^{\mathrm{h} 4}$ mouse model was associated with a significant 
improvement in saliva flow, which demonstrates the clinical utility of this approach.

In conclusion, this study suggests that P2X7R antagonism represents a novel therapeutic strategy to prevent chronic inflammation and improve hyposalivation in human salivary gland inflammatory disorders, including the autoimmune disease SS .

In other studies, it was shown that $\mathrm{P} 2 \mathrm{Y}_{2} \mathrm{R}$ activation with the selective agonist UTP enhances the self-organization of dispersed salivary epithelial cells into acinarlike spheres. The $\mathrm{P} 2 \mathrm{Y}_{2} \mathrm{R}$-mediated response is dependent on epidermal growth factor receptor activation via the metalloproteases ADAM10/ADAM17 or the $\alpha_{5} \beta_{1}$ integrin/Cdc42 signaling pathway, which leads to activation of the MAPKs, JNK and ERK1/2. These findings introduce $\mathrm{P} 2 \mathrm{Y}_{2} \mathrm{R}$-targeted regenerative medicine as an alternative therapeutic approach for replacement of damaged salivary gland tissue caused by autoimmune disease or radiation therapy used to treat head and neck cancers, by inducing the proliferation, migration and differentiation of residual cells in the damaged salivary glands to promote tissue regeneration.

Finally, TGF- $\beta$ signaling components were shown to be upregulated after 7 days of SMG duct ligation, which correlated with upregulation of the fibrosis markers collagen 1 and fibronectin, responses that were inhibited by administration of the TGF- $\beta$ receptor 1 inhibitors SB431542 or GW788388. These data suggest that TGF- $\beta$ signaling contributes to duct ligation-induced changes in salivary epithelium that correlate with glandular fibrosis. 


\subsection{Future directions}

The research project presented in this dissertation could be further extended by pursuing the following tracks outlined below.

\subsubsection{Investigating the role of the P2X7R in salivary gland epithelial cells (SGECs) as nonprofessional antigen-presenting cells.}

The hallmark of SS is the infiltration of T and B cells into salivary glands, which is accompanied by the release of pro-inflammatory cytokines, including IL-1 $\beta$, IL-18, IL-6, IL-12, IL-22, TNF- $\alpha$ and IFN- $\gamma$, creating an inflammatory environment that surrounds the salivary gland epithelium ${ }^{3,7,8}$. These inflammatory conditions have been suggested to activate the SGECs to modulate the innate and adaptive immune responses responsible for the pathogenic features of $\mathrm{SS}^{40,43}$. Activated SGECs isolated from SS patients were reported to express constitutively immunoactive molecules, e.g., major histocompatibility complex (MHC I and II), costimulatory molecules and B cell activating factor (BAFF), in addition to the release of proinflammatory cytokines and chemokines in levels higher than the non-disease controls $^{7,40,43}$. These molecules were also upregulated in normal SGECs treated with IFN- $\gamma$ and TNF- $\alpha^{43}$. This suggests that SGECs play a role as a nonprofessional antigen-presenting cell that activates $\mathrm{T}$ cells and modulates the pathogenic features of $\mathrm{SS}^{40,43}$. P2X7R activation is involved in the production of TNF- $\alpha$ and IL-18 (IFN-y inducing factor) in addition to pro-inflammatory cytokines, e.g., IL-1 $\beta$, IL-6 and others $^{59,61,70-74,206}$, which are responsible for the inflammatory conditions seen in $\mathrm{SS}^{3,}$ ${ }^{7,8}$. Also, P2X7R activation induces the release of MHC II in a process-dependent 
manner upon inflammasome activation ${ }^{207}$. Hence, it would be interesting to determine the role of the P2X7R in activating salivary epithelial cells to act as nonprofessional antigen-presenting cells. This study would determine whether P2X7R activation contributes to the expression of immunoactive proteins in salivary epithelium that mediate SGEC interactions with immune cells. Also, this study would investigate the ability of SGECs to take-up and present antigens in response to P2X7R activation. Primary SMG cells isolated from WT and P2X7R ${ }^{-/-}$mice will be incubated with labelled soluble protein ovalbumin (OVA) antigen (OVA-FITC) at $37^{\circ} \mathrm{C}$, with or without eATP or BzATP activation (30-180 min). Fluorescence would be monitored by fluorescence microscopy. Then to examine the antigen presentation by SGEC, immunofluorescence double staining technique could be used. Primary SMG cells would be incubated with either the labelled antigen OVA $257-264-$ FITC (SIINFEKL) (complexes with MHC I) or $\mathrm{OVA}_{323-339}$-FITC (complexes with MHC II), with or without ATP or BzATP stimulation and fluorescence would be monitored using fluorescence microscopy. Also, it would be determined whether this response results in $\mathrm{T}$ cell activation and proliferation. This study would elucidate the role of the $\mathrm{P} 2 \mathrm{X} 7 \mathrm{R}$ in activating the salivary gland epithelial cells to act as nonprofessional antigen-presenting cells for T cells, thereby modulating innate and adaptive immune responses underlying the pathogenic features of SS.

\subsubsection{Investigating the genetics of P2X7R in SS}

Several single nucleotide polymorphisms (SNPs) are known in $P 2 X 7 R$ that are associated with an increase or decrease in receptor function ${ }^{63}$. The P2X7R SNPs 
mediate susceptibility to a variety of diseases, including tuberculosis ${ }^{68}$. Also, the gain of function mutation $P 2 X 7 R A 1405 G$ has been correlated with the development of SS in seropositive patients who do not carry the HLA-DR3 risk allele $^{69}$, the primary genetic risk factor in SS patients ${ }^{208}$. There are ten known $\mathrm{P} 2 \mathrm{X} 7 \mathrm{R}$ isoforms, namely $\mathrm{P} 2 \mathrm{X} 7 \mathrm{R}$ (B through $\mathrm{K}$ ), five of which are truncated variants lacking the C-terminus ${ }^{64,65}$. These isoforms tend to hetero-oligomerize with the full length P2X7R and hence regulate its function ${ }^{64,65}$. For example, P2X7J binds to full length P2X7R and negatively regulates P2X7R-induced apoptosis $^{66}$. Future studies would investigate the relationship between the $P 2 X 7 R$ SNPs and the expression of P2X7R variants and the development of SS. A better understanding of the genetics and physiology of the P2X7R and how this correlates with the pathogenesis of SS is necessary to improve P2X7R-targeted therapies. 


\section{References}

[1] Pedersen, A., Bardow, A., Jensen, S. B., and Nauntofte, B. (2002) Saliva and gastrointestinal functions of taste, mastication, swallowing and digestion, Oral Dis. 8, 117-129.

[2] Atkinson, J. C., Grisius, M., and Massey, W. (2005) Salivary hypofunction and xerostomia: diagnosis and treatment, Dent. Clin. North Am. 49, 309-326.

[3] Delaleu, N., Jonsson, R., and Koller, M. M. (2005) Sjögren's syndrome, Eur. J. Oral Sci. 113, 101-113.

[4] Ship, J. A., Pillemer, S. R., and Baum, B. J. (2002) Xerostomia and the geriatric patient, J. Am. Geriatr. Soc. 50, 535-543.

[5] Aziz, K. E., McCluskey, P. J., and Wakefield, D. (1997) Characterisation of follicular dendritic cells in labial salivary glands of patients with primary Sjogren syndrome: comparison with tonsillar lymphoid follicles, Ann. Rheum. Dis. 56, $140-143$.

[6] Zeher, M., Adany, R., Nagy, G., Gomez, R., and Szegedi, G. (1991) Macrophage containing factor XIII subunit a in salivary glands of patients with Sjogren's syndrome, J. Invest. Allerg. \& Clin. Immunol.: Off. )Organ of Intnal. Assoc. Asthmol. (INTERASMA) \& Soc. Latinamer. Alerg. e Inmunol. 1, 261-265.

[7] Fox, R. I., Kang, H.-I., Ando, D., Abrams, J., and Pisa, E. (1994) Cytokine mRNA expression in salivary gland biopsies of Sjögren's syndrome, J. Immunol 152, $5532-5539$. 
[8] Roescher, N., Tak, P. P., and Illei, G. G. (2010) Cytokines in Sjögren's syndrome: potential therapeutic targets, Ann. Rheum. Dis. 69, 945-948.

[9] Tapinos, N., Polihronis, M., Tzioufas, A., and Skopouli, F. (1998) Immunopathology of Sjogren's syndrome, In Ann. Med. Interne (Paris), 17-24.

[10] Haneji, N., Nakamura, T., Takio, K., Yanagi, K., Higashiyama, H., Saito, I., Noji, S., Sugino, H., and Hayashi, Y. (1997) Identification of $\alpha$-fodrin as a candidate autoantigen in primary Sjögren's syndrome, Science 276, 604-607.

[11] Miyazaki, K., Takeda, N., Ishimaru, N., Omotehara, F., Arakaki, R., and Hayashi, Y. (2005) Analysis of in vivo role of $\alpha$-fodrin autoantigen in primary Sjögren's syndrome, , Am. J. Physiol. 167, 1051-1059.

[12] Watanabe, T., Tsuchida, T., Kanda, N., Mori, K., Hayashi, Y., and Tamaki, K. (1999) Anti- $\alpha$-fodrin antibodies in Sjögren syndrome and lupus erythematosus, Arch. Dermatol. 135, 535-539.

[13] Bacman, S., Sterin-Borda, L., JosÉ Camusso, J., Arana, R., Hubscher, O., and Borda, E. (1996) Circulating antibodies against rat parotid gland M3 muscarinic receptors in primary Sjögren's syndrome, Clin. Exp. Immunol. 104, 454-459.

[14] Dawson, L., Stanbury, J., Venn, N., Hasdimir, B., Rogers, S., and Smith, P. (2006) Antimuscarinic antibodies in primary Sjögren's syndrome reversibly inhibit the mechanism of fluid secretion by human submandibular salivary acinar cells, Arthritis Rheum. 54, 1165-1173. 
[15] Müller, K., Oxholm, P., Mier-Madsen, M., Wiik, A. (1989) Circulating IgA- and IgM-rheumatoid factors in patients with primary Sjögren syndrome. Correlation to extraglandular manifestations, Scand. J. Rheumatol. 18, 29-31.

[16] Sisto, M., Lisi, S., Castellana, D., Scagliusi, P., D'Amore, M., Caprio, S., Scagliusi, A., Acquafredda, A., Panaro, M., and Mitolo, V. (2006) Autoantibodies from Sjögren's syndrome induce activation of both the intrinsic and extrinsic apoptotic pathways in human salivary gland cell line A-253, J. Autoimmun. 27, 38-49.

[17] Humphreys-Beher, M., Peck, A., Dang, H., and Talal, N. (1999) The role of apoptosis in the initiation of the autoimmune response in Sjögren's syndrome, Clin. Exp. Immunol. 116, 383-387.

[18] Nakken, B., Jonsson, R., Brokstad, K., Omholt, K., Nerland, A., Haga, H., and Halse, A. K. (2001) Associations of MHC class II alleles in Norwegian primary Sjögren's syndrome patients: implications for development of autoantibodies to the Ro52 autoantigen, Scand. J. Immunol. 54, 428-433.

[19] Miceli-Richard, C., Gestermann, N., Ittah, M., Comets, E., Loiseau, P., Puechal, X., Hachulla, E., Gottenberg, J. E., Lebon, P., and Becquemont, L. (2009) The CGGGG insertion/deletion polymorphism of the IRF5 promoter is a strong risk factor for primary Sjögren's syndrome, Arthritis Rheumat. 60, 1991-1997.

[20] Nordmark, G., Kristjansdottir, G., Theander, E., Appel, S., Eriksson, P., Vasaitis, L., Kvarnström, M., Delaleu, N., Lundmark, P., and Lundmark, A. (2011) Association of EBF1, FAM167A (C8orf13)-BLK and TNFSF4 gene variants with primary Sjogren's syndrome, Genes Immun. 12(2), 100-109 
[21] Markeljevic, J., Sarac, H., Bozina, N., Henigsberg, N., Simic, M., and Sain, L. C. (2015) Serotonin transporter gene polymorphisms: relation with platelet serotonin level in patients with primary Sjogren's syndrome, J. Neuroimmunol. 282, 104109.

[22] Ferro, F., Vagelli, R., Bruni, C., Cafaro, G., Marcucci, E., Bartoloni, E., and Baldini, C. (2016) One year in review 2016: Sjögren's syndrome, Clin. Exp. Rheumatol. $34,161-171$.

[23] Miceli-Richard, C., Wang-Renault, S. F., Boudaoud, S., Busato, F., Lallemand, C., Bethune, K., Belkhir, R., Nocturne, G., Mariette, X., and Tost, J. (2016) Overlap between differentially methylated DNA regions in blood B lymphocytes and genetic at-risk loci in primary Sjögren's syndrome, Ann. Rheum. Dis. 75, 933-940.

[24] Jeffries, M., Dozmorov, M., Tang, Y., Merrill, J. T., Wren, J. D., and Sawalha, A. H. (2011) Genome-wide DNA methylation patterns in $\mathrm{CD}^{+} \mathrm{T}$ cells from patients with systemic lupus erythematosus, Epigenetics 6, 593-601.

[25] Mavragani, C. P., Sagalovskiy, I., Guo, Q., Nezos, A., Kapsogeorgou, E. K., Lu, P., Liang Zhou, J., Kirou, K. A., Seshan, S. V., and Moutsopoulos, H. M. (2016) Expression of long interspersed nuclear element 1 retroelements and induction of type I interferon in patients with systemic autoimmune disease, Arthritis Rheumat. 68, 2686-2696.

[26] Fragkioudaki, S., Nezos, A., Souliotis, V. L., Chatziandreou, I., Saetta, A. A., Drakoulis, N., Tzioufas, A. G., Voulgarelis, M., Sfikakis, P. P., and Koutsilieris, 
M. (2017) MTHFR gene variants and non-MALT lymphoma development in primary Sjogren's syndrome, Sci. Rep. 7. 10.1038/s41598-017-07347-w.

[27] Spaan, M., Porola, P., Laine, M., Rozman, B., Azuma, M., and Konttinen, Y. T. (2009) Healthy human salivary glands contain a DHEA-sulphate processing intracrine machinery, which is deranged in primary Sjögren's syndrome, J. Cell. Mol. Med. 13, 1261-1270.

[28] Iwasa, A., Arakaki, R., Honma, N., Ushio, A., Yamada, A., Kondo, T., Kurosawa, E., Kujiraoka, S., Tsunematsu, T., and Kudo, Y. (2015) Aromatase controls Sjögren syndrome-like lesions through monocyte chemotactic protein-1 in target organ and adipose tissue-associated macrophages, Am. J. Pathol. 185, 151-161.

[29] Mavragani, C. P., and Moutsopoulos, H. M. (2014) Sjögren's syndrome, Annu. Rev. Pathol.: Mechan. Dis. 9, 273-285.

[30] Iwakiri, D., Zhou, L., Samanta, M., Matsumoto, M., Ebihara, T., Seya, T., Imai, S., Fujieda, M., Kawa, K., and Takada, K. (2009) Epstein-Barr virus (EBV)-encoded small RNA is released from EBV-infected cells and activates signaling from tolllike receptor 3, J. Exp. Med. 206, 2091-2099.

[31] Karaiskos, D., Mavragani, C. P., Makaroni, S., Zinzaras, E., Voulgarelis, M., Rabavilas, A., and Moutsopoulos, H. M. (2008) Stress, coping strategies and social support in patients with primary Sjogren's syndrome prior to disease onset: a retrospective case control study, Ann. Rheum. Dis. 62, 1204-1207.

[32] Tsifetaki, N., Kitsos, G., Paschides, C., Alamanos, Y., Eftaxias, V., Voulgari, P., Psilas, K., and Drosos, A. (2003) Oral pilocarpine for the treatment of ocular 
symptoms in patients with Sjögren's syndrome: a randomised 12 week controlled study, Ann. Rheum. Dis. 62, 1204-1207.

[33] Cummins, M. J., Papas, A., Kammer, G. M. and Fox, P. C. (2003) Treatment of primary sjögren's syndrome with low-dose human interferon alfa administered by the oromucosal route: Combined phase III results, Arthritis Care Res. (Hoboken) $49,585-593$.

[34] Fox, P. C. (2004) Salivary enhancement therapies, Caries Res. 38, 241-246.

[35] Arulkumaran, N., Unwin, R. J., and Tam, F. W. (2011) A potential therapeutic role for $\mathrm{P} 2 \mathrm{X} 7$ receptor (P2X7R) antagonists in the treatment of inflammatory diseases, Expert. Opin. Investig. Drugs 20, 897-915.

[36] Friedle, S. A., Curet, M. A., and Watters, J. J. (2010) Recent patents on novel P2X7 receptor antagonists and their potential for reducing central nervous system inflammation, Recent Pat. CNS Drug Discov. 5, 35-45.

[37] Mulder, D. J., Pooni, A., Mak, N., Hurlbut, D. J., Basta, S., and Justinich, C. J. (2011) Antigen presentation and MHC class II expression by human esophageal epithelial cells: role in eosinophilic esophagitis, Am. J. Pathol. 178, 744-753.

[38] Telega, G. W., Baumgart, D. C., and Carding, S. R. (2000) Uptake and presentation of antigen to T cells by primary colonic epithelial cells in normal and diseased states, Gastroenterology 119, 1548-1559.

[39] Bland, P., and Warren, L. (1986) Antigen presentation by epithelial cells of the rat small intestine. I. Kinetics, antigen specificity and blocking by anti-Ia antisera, Immunology 58, 1-7. 
[40] Moutsopoulos, H. (1994) Sjögren's Syndrome: autoimmune epithelitis, Clin. Immunol. Immunopathol. 72, 162-165.

[41] Abu-Helu, R. F., Dimitriou, I. D., Kapsogeorgou, E. K., Moutsopoulos, H. M., and Manoussakis, M. N. (2001) Induction of salivary gland epithelial cell injury in Sjogren's syndrome: in vitro assessment of T cell-derived cytokines and Fas protein expression, J. Autoimmun. 17, 141-153.

[42] Manoussakis, M. N., and Kapsogeorgou, E. K. (2007) The role of epithelial cells in the pathogenesis of Sjögren's syndrome, Clin. Rev. Allergy Immunol. 32, 225230.

[43] Tsunawaki, S., Nakamura, S., Ohyama, Y., Sasaki, M., Ikebe-Hiroki, A., Hiraki, A., Kadena, T., Kawamura, E., Kumamaru, W., and Shinohara, M. (2002) Possible function of salivary gland epithelial cells as nonprofessional antigen-presenting cells in the development of Sjögren's syndrome, J. Rheumatol. 29, 1884-1896.

[44] Van Lier, R. A., Brouwer, M., and Aarden, L. A. (1988) Signals involved in T cell activation. T cell proliferation induced through the synergistic action of anti-CD28 and anti-CD2 monoclonal antibodies, Eur. J. Immunol. 18, 167-172.

[45] Azuma, M., Cayabyab, M., Phillips, J., and Lanier, L. (1993) Requirements for CD28-dependent T cell-mediated cytotoxicity, J. Immunol 150, 2091-2101.

[46] Daridon, C., Devauchelle, V., Hutin, P., Berre, R. L., Martins-Carvalho, C., Bendaoud, B., Dueymes, M., Saraux, A., Youinou, P., and Pers, J. O. (2007) Aberrant expression of BAFF by B lymphocytes infiltrating the salivary glands of patients with primary Sjögren's syndrome, Arthritis Rheum. 56, 1134-1144. 
[47] Trautmann, A. (2009) Extracellular ATP in the immune system: more than just a “danger signal”, Sci Signal 2, 10.1126/scisignal.256pe6.

[48] Tsuda, M., Tozaki-Saitoh, H., and Inoue, K. (2010) Pain and purinergic signaling, Brain Res. Rev. 63, 222-232.

[49] Di Virgilio, F. (1998) ATP as a death factor, Biofactors 8, 301-303.

[50] Riteau, N., Gasse, P., Fauconnier, L., Gombault, A., Couegnat, M., Fick, L., Kanellopoulos, J., Quesniaux, V. F., Marchand-Adam, S., and Crestani, B. (2010) Extracellular ATP is a danger signal activating $\mathrm{P} 2 \mathrm{X} 7$ receptor in lung inflammation and fibrosis, Am. J. Respir. Crit. Care Med. 182, 774-783.

[51] Zimmermann, H. (2000) Extracellular metabolism of ATP and other nucleotides, Naunyn Schmiedebergs Arch. Pharmacol. 362, 299-309.

[52] Deaglio, S., and Robson, S. C. (2011) Ectonucleotidases as regulators of purinergic signaling in thrombosis, inflammation, and immunity, Adv. Pharmacol. 61, 301332.

[53] North, R. A. (2002) Molecular physiology of P2X receptors, Physiol. Rev. 82, 10131067

[54] Deplano, S., Cook, H. T., Russell, R., Franchi, L., Schneiter, S., Bhangal, G., Unwin, R. J., Pusey, C. D., Tam, F. W., and Behmoaras, J. (2013) P2X7 receptormediated Nlrp3-inflammasome activation is a genetic determinant of macrophage-dependent crescentic glomerulonephritis, J. Leukoc. Biol. 93, 127134. 
[55] Monif, M., Reid, C. A., Powell, K. L., Smart, M. L., and Williams, D. A. (2009) The P2X7 receptor drives microglial activation and proliferation: a trophic role for P2X7R pore, J. Neurosci. 29, 3781-3791.

[56] Di Virgilio, F. (2015) P2X receptors and inflammation, Curr. Med. Chem. 22, 866877.

[57] Lopez-Castejon, G., Theaker, J., Pelegrin, P., Clifton, A. D., Braddock, M., and Surprenant, A. (2010) P2X7 receptor-mediated release of cathepsins from macrophages is a cytokine-independent mechanism potentially involved in joint diseases, J. Immunol. 185, 2611-2619.

[58] Adinolfi, E., Pizzirani, C., Idzko, M., Panther, E., Norgauer, J., Di Virgilio, F., and Ferrari, D. (2005) P2X7 receptor: death or life?, Purinergic signal. 1, 219-227.

[59] Lister, M. F., Sharkey, J., Sawatzky, D. A., Hodgkiss, J. P., Davidson, D. J., Rossi, A. G., and Finlayson, K. (2007) The role of the purinergic P2X7 receptor in inflammation, J. Inflamm. (Lond) 10.1186/1476-9255-4-5.

[60] Steinberg, T. H., Newman, A. S., Swanson, J., and Silverstein, S. C. (1987) ATP ${ }^{4-}$ permeabilizes the plasma membrane of mouse macrophages to fluorescent dyes, J. Biol. Chem. 262, 8884-8888.

[61] Ferrari, D., Pizzirani, C., Adinolfi, E., Lemoli, R. M., Curti, A., Idzko, M., Panther, E., and Di Virgilio, F. (2006) The P2X7 receptor: a key player in IL-1 processing and release, J. Immunol. 176, 3877-3883. 
[62] Kim, M., Jiang, L. H., Wilson, H. L., North, R. A., and Surprenant, A. (2001) Proteomic and functional evidence for a P2X7 receptor signalling complex, The EMBO journal 20, 6347-6358.

[63] Surprenant, A., and North, R. A. (2009) Signaling at purinergic P2X receptors, Annu. Rev. Physiol. 71, 333-359.

[64] Cheewatrakoolpong, B., Gilchrest, H., Anthes, J. C., and Greenfeder, S. (2005) Identification and characterization of splice variants of the human P2X7 ATP channel, Biochem. Biophys. Res. Commun. 332, 17-27.

[65] Gorodeski, G. I. (2012) P2X7 receptors and epithelial cancers, Wiley Interdiscip. Rev.: Membr. Transp. and Signal. 1, 349-371.

[66] Feng, Y.-H., Li, X., Wang, L., Zhou, L., and Gorodeski, G. I. (2006) A truncated $\mathrm{P} 2 \mathrm{X} 7$ receptor variant $(\mathrm{P} 2 \mathrm{X} 7-\mathrm{j})$ endogenously expressed in cervical cancer cells antagonizes the full-length $\mathrm{P} 2 \mathrm{X} 7$ receptor through hetero-oligomerization, J. Biol. Chem. 281, 17228-17237.

[67] Sluyter, R., and Stokes, L. (2011) Significance of P2X7 receptor variants to human health and disease, Recent. Pat. DNA Gene Seq. 5, 41-54.

[68] Niño-Moreno, P., Portales-Pérez, D., Hernández-Castro, B., Portales-Cervantes, L., Flores-Meraz, V., Baranda, L., Gómez-Gómez, A., Acuña-Alonzo, V., Granados, J., and González-Amaro, R. (2007) P2X7 and NRAMP1/SLC11 A1 gene polymorphisms in Mexican mestizo patients with pulmonary tuberculosis, Clin. Exp. Immunol. 148, 469-477. 
[69] Lester, S., Stokes, L., Skarratt, K. K., Gu, B. J., Sivils, K. L., Lessard, C. J., Wiley, J. S., and Rischmueller, M. (2013) Epistasis with HLA DR3 implicates the P2X7 receptor in the pathogenesis of primary Sjögren's syndrome, Arthritis Res. Ther. 15, R71. 10.1186/ar4248

[70] Ferrari, D., Chiozzi, P., Falzoni, S., Dal Susino, M., Melchiorri, L., Baricordi, O., and Di Virgilio, F. (1997) Extracellular ATP triggers IL-1 beta release by activating the purinergic $\mathrm{P} 2 \mathrm{Z}$ receptor of human macrophages, J. Immunol. 159, $1451-1458$

[71] Bulanova, E., Budagian, V., Orinska, Z., Hein, M., Petersen, F., Thon, L., Adam, D., and Bulfone-Paus, S. (2005) Extracellular ATP induces cytokine expression and apoptosis through $\mathrm{P} 2 \mathrm{X} 7$ receptor in murine mast cells, J. Immunol. 174, 38803890.

[72] Solini, A., Chiozzi, P., Morelli, A., Fellin, R., and Di Virgilio, F. (1999) Human primary fibroblasts in vitro express a purinergic $\mathrm{P} 2 \mathrm{X} 7$ receptor coupled to ion fluxes, microvesicle formation and IL-6 release, J. Cell Sci. 112, 297-305.

[73] Shieh, C. H., Heinrich, A., Serchov, T., Calker, D., and Biber, K. (2014) P2X7-dependent, but differentially regulated release of IL-6, CCL2, and TNF- $\alpha$ in cultured mouse microglia, Glia. 10.1002/glia.22628

[74] Mehta, V. B., Hart, J., Wewers, M. D. (2001) ATP-stimulated release of interleukin (IL)-1beta and IL-18 requires priming by lipopolysaccharide and is independent of caspase-1 cleavage. . 276, 3820-3826., J. Biol. Chem. 276, 3820-3826. 
[75] Davide Ferrari, P. C., Falzoni, S., Hanau, S. and Di Virgilio. F. (1997) Purinergic modulation of interleukin-1 beta release from microglial Cells stimulated with bacterial endotoxin, J. Exp. Med. 185, 579-582.

[76] Chin, J., and Kostura, M. J. (1993) Dissociation of IL-1 beta synthesis and secretion in human blood monocytes stimulated with bacterial cell wall products, $J$. Immunol. 151, 5574-5585.

[77] Di Virgilio, F. (2007) Liaisons dangereuses: P2X7 and the inflammasome, Trends Pharmacol. Sci. 28, 465-472.

[78] Martinon, F., Burns, K., and Tschopp, J. (2002) The inflammasome: a molecular platform triggering activation of inflammatory caspases and processing of proIL$\beta$, Mol. Cell 10, 417-426.

[79] Meylan, E., Tschopp, J., and Karin, M. (2006) Intracellular pattern recognition receptors in the host response, Nature 442, 39-44.

[80] Petrilli, V., Papin, S., Dostert, C., Mayor, A., Martinon, F., and Tschopp, J. (2007) Activation of the NALP3 inflammasome is triggered by low intracellular potassium concentration, Cell Death Differ. 14, 1583-1589.

[81] Dinarello, C. A., Novick, D, Puren A. J., Fantuzzi G., Shapiro L., Muhl, H., Yoon, D., Reznikov, L. L., Kim Y. and Rubinstein, M. (1998) Overview of interleukin18: more than an interferon- $\gamma$ inducing factor, J. Leukoc. Biol. 63, 658-664.

[82] Ghayur, T., Banerjee, S., Hugunin, M., Butler, D., Herzog, L., Carter, A., Quintal, L., Sekut, L., Talanian, R., and Paskind, M. (1997) Caspase-1 processes IFN- $\gamma$ - 
inducing factor and regulates LPS-induced IFN- $\gamma$ production, Nature 386, 619623.

[83] Fontaine, V., Mohand-Said, S., Hanoteau, N., Fuchs, C., Pfizenmaier, K., and Eisel, U. (2002) Neurodegenerative and neuroprotective effects of tumor necrosis factor (TNF) in retinal ischemia: opposite roles of TNF receptor 1 and TNF receptor 2, J. Neurosci. 22, 1-7.

[84] Parvathenani, L. K., Tertyshnikova, S., Greco, C. R., Roberts, S. B., Robertson, B., and Posmantur, R. (2003) P2X7 mediates superoxide production in primary microglia and is up-regulated in a transgenic mouse model of Alzheimer's disease, J. Biol. Chem. 278, 13309-13317.

[85] Humphreys, B. D., and Dubyak, G. R. (1998) Modulation of P2X7 nucleotide receptor expression by pro-and anti-inflammatory stimuli in THP-1 monocytes, $J$. Leukoc. Biol. 64, 265-273.

[86] Lucattelli, M., Cicko, S., Müller, T., Lommatzsch, M., Cunto, G. D., Cardini, S., Sundas, W., Grimm, M., Zeiser, R., and Dürk, T. (2011) P2X7 receptor signaling in the pathogenesis of smoke-induced lung inflammation and emphysema, Am. J. Respir. Cell Mol. Biol. 44, 423-429.

[87] Chessell, I. P., Hatcher, J. P., Bountra, C., Michel, A. D., Hughes, J. P., Green, P., Egerton, J., Murfin, M., Richardson, J., and Peck, W. L. (2005) Disruption of the P2X7 purinoceptor gene abolishes chronic inflammatory and neuropathic pain, Pain 114, 386-396. 
[88] Woods, L. T., Camden, J. M., Batek, J. M., Petris, M. J., Erb, L., and Weisman, G. A. (2012) P2X7 receptor activation induces inflammatory responses in salivary gland epithelium, Am. J. Physiol. Cell Physiol. 303, C790-C801.

[89] Cesaro, A., Brest, P., Hofman, V., Hébuterne, X., Wildman, S., Ferrua, B., Marchetti, S., Doglio, A., Vouret-Craviari, V., and Galland, F. (2010) Amplification loop of the inflammatory process is induced by $\mathrm{P} 2 \mathrm{X} 7 \mathrm{R}$ activation in intestinal epithelial cells in response to neutrophil transepithelial migration, Am. J. Physiol. Gastrointest. Liver Physiol. 299, G32-G42.

[90] Qiu, Y., Li, W. H., Zhang, H. Q., Liu, Y., Tian, X. X., and Fang, W. G. (2014) P2X7 mediates ATP-driven invasiveness in prostate cancer cells, PLoS One 9, e114371.

[91] Giannuzzo, A., Saccomano, M., Napp, J., Ellegaard, M., Alves, F., and Novak, I. (2016) Targeting of the P2X7 receptor in pancreatic cancer and stellate cells, Int. J. Cancer 139, 2540-2552.

[92] Bae, J. Y., Lee, S. W., Shin, Y. H., Lee, J. H., Jahng, J. W., and Park, K. (2017) P2X7 receptor and NLRP3 inflammasome activation in head and neck cancer, Oncotarget 8, 48972-48982.

[93] Salvestrini, V., Orecchioni, S., Talarico, G., Reggiani, F., Mazzetti, C., Bertolini, F., Orioli, E., Adinolfi, E., Di Virgilio, F., and Pezzi, A. (2017) Extracellular ATP induces apoptosis through P2X7R activation in acute myeloid leukemia cells but not in normal hematopoietic stem cells, Oncotarget 8, 5895-5908.

[94] Baldini, C., Rossi, C., Ferro, F., Santini, E., Seccia, V., Donati, V., and Solini, A. (2013) The P2X7 receptor-inflammasome complex has a role in modulating the 
inflammatory response in primary Sjögren's syndrome, J. Intern. Med. 274, 480489.

[95] Halle, A., Hornung, V., Petzold, G. C., Stewart, C. R., Monks, B. G., Reinheckel, T., Fitzgerald, K. A., Latz, E., Moore, K. J., and Golenbock, D. T. (2008) The NALP3 inflammasome is involved in the innate immune response to amyloid- $\beta$, Nat. Immunol. 9, 857-865.

[96] Martinon, F., Pétrilli, V., Mayor, A., Tardivel, A., and Tschopp, J. (2006) Goutassociated uric acid crystals activate the NALP3 inflammasome, Nature 440, 237 241.

[97] Mariathasan, S., Newton, K., Monack, D. M., Vucic, D., French, D. M., Lee, W. P., Roose-Girma, M., Erickson, S., and Dixit, V. M. (2004) Differential activation of the inflammasome by caspase-1 adaptors ASC and Ipaf, Nature 430, 213-218.

[98] Cruz, C. M., Rinna, A., Forman, H. J., Ventura, A. L., Persechini, P. M., and Ojcius, D. M. (2007) ATP activates a reactive oxygen species-dependent oxidative stress response and secretion of proinflammatory cytokines in macrophages, J. Biol. Chem. 282, 2871-2879.

[99] Dostert, C., Pétrilli, V., Van Bruggen, R., Steele, C., Mossman, B. T., and Tschopp, J. (2008) Innate immune activation through Nalp3 inflammasome sensing of asbestos and silica, Science 320, 674-677.

[100] Zhou, R., Tardivel, A., Thorens, B., Choi, I., and Tschopp, J. (2010) Thioredoxininteracting protein links oxidative stress to inflammasome activation, Nat. Immunol. 11, 136-140. 
[101] Guarda, G., Dostert, C., Staehli, F., Cabalzar, K., Castillo, R., Tardivel, A., Schneider, P., and Tschopp, J. (2009) T cells dampen innate immune responses through inhibition of NLRP1 and NLRP3 inflammasomes, Nature 460, 269-273.

[102] Mayor, A., Martinon, F., De Smedt, T., Pétrilli, V., and Tschopp, J. (2007) A crucial function of SGT1 and HSP90 in inflammasome activity links mammalian and plant innate immune responses, Nat. Immunol. 8, 497-503.

[103] Kanneganti, T. D., Lamkanfi, M., Kim, Y.-G., Chen, G., Park, J. H., Franchi, L., Vandenabeele, P., and Núñez, G. (2007) Pannexin-1-mediated recognition of bacterial molecules activates the cryopyrin inflammasome independent of Tolllike receptor signaling, Immunity 26, 433-443.

[104] Hornung, V., Bauernfeind, F., Halle, A., Samstad, E. O., Kono, H., Rock, K. L., Fitzgerald, K. A., and Latz, E. (2008) Silica crystals and aluminum salts activate the NALP3 inflammasome through phagosomal destabilization, Nat. Immunol. 9, $847-856$

[105] Latz, E. (2010) NOX-free inflammasome activation, Blood 116, 1393-1394.

[106] Meissner, F., Seger, R. A., Moshous, D., Fischer, A., Reichenbach, J., and Zychlinsky, A. (2010) Inflammasome activation in NADPH oxidase defective mononuclear phagocytes from patients with chronic granulomatous disease, Blood 116, 1570-1573.

[107] Segal, B. H., Han, W., Bushey, J. J., Joo, M., Bhatti, Z., Feminella, J., Dennis, C. G., Vethanayagam, R. R., Yull, F. E., and Capitano, M. (2010) NADPH oxidase limits innate immune responses in the lungs in mice, PLoS One 5, e9631. 
[108] Muller, F. L., Roberts, A. G., Bowman, M. K., and Kramer, D. M. (2003) Architecture of the Qo site of the cytochrome bc 1 complex probed by superoxide production, Biochemistry 42, 6493-6499.

[109] Turrens, J. F. (2003) Mitochondrial formation of reactive oxygen species, $J$. Physiol. 552, 335-344.

[110] Heid, M. E., Keyel, P. A., Kamga, C., Shiva, S., Watkins, S. C., and Salter, R. D. (2013) Mitochondrial reactive oxygen species induces NLRP3-dependent lysosomal damage and inflammasome activation, J. Immunol. 191, 5230-5238.

[111] Zhou, R., Yazdi, A. S., Menu, P., and Tschopp, J. (2011) A role for mitochondria in NLRP3 inflammasome activation, Nature 469, 221-225.

[112] Kim, S., Kim, D., Kim, S., Lee, H., Lee, K., Cho, S., and Lee, Y. (2014) NLRP3 inflammasome activation by mitochondrial ROS in bronchial epithelial cells is required for allergic inflammation, Cell Death Dis. 5, e1498.

[113] Gupta, S. (2000) Molecular steps of cell suicide: an insight into immune senescence, J. Clin. Immunol. 20, 229-239.

[114] Virgilio, F. D., Chiozzi, P., Falzoni, S., Ferrari, D., Sanz, J. M., Venketaraman, V., and Baricordi, O. R. (1998) Cytolytic P2X purinoceptors, Cell Death Differ. 5, 191-199.

[115] Tsukimoto, M., Harada, H., Ikari, A., and Takagi, K. (2005) Involvement of chloride in apoptotic cell death induced by activation of ATP-sensitive P2X7 purinoceptor, J. Biol. Chem. 280, 2653-2658. 
[116] Tsukimoto, M., Maehata, M., Harada, H., Ikari, A., Takagi, K., and Degawa, M. (2006) P2X7 receptor-dependent cell death is modulated during murine T cell maturation and mediated by dual signaling pathways, J. Immunol. 177, 28422850.

[117] Verhoef, P. A., Estacion, M., Schilling, W., Dubyak. G.R. (2003) P2X7 receptordependent blebbing and the activation of Rho-effector kinases, caspases, and IL-1 beta release. , J. Immunol. 170, 5728-5738.

[118] Noguchi, T., Ishii, K., Fukutomi, H., Naguro, I., Matsuzawa, A., Takeda, K., and Ichijo, H. (2008) Requirement of reactive oxygen species-dependent activation of ASK1-p38 MAPK pathway for extracellular ATP-induced apoptosis in macrophage, J. Biol. Chem. 283, 7657-7665.

[119] Hwang, S. M., Koo, N. Y., Choi, S. Y., Chun, G. S., Kim, J. S., and Park, K. (2009) P2X7 receptor-mediated membrane blebbing in salivary epithelial cells, Korean J. Physiol. Pharmacol. 13, 175-179.

[120] Wang, Q., Wang, L., Feng, Y. H., Li, X., Zeng, R., and Gorodeski, G. I. (2004) P2X7 receptor-mediated apoptosis of human cervical epithelial cells, Am. J. Physiol. Cell Physiol. 287, C1349-C1358.

[121] Kong, Q., Wang, M., Liao, Z., Camden, J. M., Yu, S., Simonyi, A., Sun, G. Y., Gonzalez, F. A., Erb, L., and Seye, C. I. (2005) P2X7 nucleotide receptors mediate caspase-8/9/3-dependent apoptosis in rat primary cortical neurons, Purinergic signal. 1, 337-347. 
[122] Gu, B. J., Saunders, B. M., Petrou, S., and Wiley, J. S. (2011) P2X7 is a scavenger receptor for apoptotic cells in the absence of its ligand, extracellular ATP, $J$. Immunol 187, 2365-2375.

[123] Baricordi, O. R., Ferrari, D., Melchiorri, L., Chiozzi, P., Hanau, S., Chiari, E., Rubini, M., and Di Virgilio, F. (1996) An ATP-activated channel is involved in mitogenic stimulation of human T lymphocytes, Blood 87, 682-690.

[124] Baricordi, O. R., Melchiorri, L., Adinolfi, E., Falzoni, S., Chiozzi, P., Buell, G., and Di Virgilio, F. (1999) Increased proliferation rate of lymphoid cells transfected with the P2X7 ATP receptor, J. Biol. Chem. 274, 33206-33208.

[125] Choy, E. H., and Panayi, G. S. (2001) Cytokine pathways and joint inflammation in rheumatoid arthritis, N. Engl. J. Med. 344, 907-916.

[126] Caporali, F., Capecchi, P. L., Gamberucci, A., Lazzerini, P. E., Pompella, G., Natale, M., Lorenzini, S., Selvi, E., Galeazzi, M., and Pasini, F. L. (2008) Human rheumatoid synoviocytes express functional P2X7 receptors, J. Mol. Med. 86, 937-949.

[127] Feldmann, M., Brennan, F. M., and Maini, R. N. (1996) Role of cytokines in rheumatoid arthritis, Annu. Rev. Immunol. 14, 397-440.

[128] Di Virgilio, F. (2013) The therapeutic potential of modifying inflammasomes and NOD-like receptors, Pharmacol. Rev. 65, 872-905.

[129] Kirou, K. A., Lee, C., George, S., Louca, K., Peterson, M. G., and Crow, M. K. (2005) Activation of the interferon- $\alpha$ pathway identifies a subgroup of systemic 
lupus erythematosus patients with distinct serologic features and active disease, Arthritis Rheumatol. 52, 1491-1503.

[130] Turner, C. M., Tam, F. W., Lai, P.-C., Tarzi, R. M., Burnstock, G., Pusey, C. D., Cook, H. T., and Unwin, R. J. (2006) Increased expression of the pro-apoptotic ATP-sensitive P2X7 receptor in experimental and human glomerulonephritis, Nephrol. Dial. Transplant. 22, 386-395.

[131] Taylor, S. R., Turner, C. M., Elliott, J. I., McDaid, J., Hewitt, R., Smith, J., Pickering, M. C., Whitehouse, D. L., Cook, H. T., and Burnstock, G. (2009) P2X7 deficiency attenuates renal injury in experimental glomerulonephritis, J. Am. Soc. Nephrol. 20, 1275-1281.

[132] Kahlenberg, J. M., Yalavarthi, S., Zhao, W., Hodgin, J. B., Reed, T. J., Tsuji, N. M., and Kaplan, M. J. (2014) An essential role of caspase 1 in the induction of murine lupus and its associated vascular damage, Arthritis Rheumatol. 66, 152162.

[133] De Marchi, E., Orioli, E., Dal Ben, D., and Adinolfi, E. (2016) Chapter two-P2X7 receptor as a therapeutic target, Adv. Protein Chem. Struct. Biol. 104, 39-79.

[134] Keystone, E. C., Wang, M. M., Layton, M., Hollis, S., McInnes, I. B., and Team, D. S. (2011) Clinical evaluation of the efficacy of the P2X7 purinergic receptor antagonist AZD9056 on the signs and symptoms of rheumatoid arthritis in patients with active disease despite treatment with methotrexate or sulphasalazine, Ann. Rheum. Dis., 71, 1630-1635. 
[135] Bartlett, R., Stokes, L., and Sluyter, R. (2014) The P2X7 receptor channel: recent developments and the use of P2X7 antagonists in models of disease, Pharmacol. Rev. 66, 638-675.

[136] Melvin, J. E., Yule, D., Shuttleworth, T., and Begenisich, T. (2005) Regulation of fluid and electrolyte secretion in salivary gland acinar cells, Annu. Rev. Physiol. 67, 445-469.

[137] Nakamoto, T., Brown, D. A., Catalán, M. A., Gonzalez-Begne, M., Romanenko, V. G., and Melvin, J. E. (2009) Purinergic P2X7 receptors mediate ATP-induced saliva secretion by the mouse submandibular gland, J. Biol. Chem. 284, 48154822.

[138] Novak, I., Jans, I. M., and Wohlfahrt, L. (2010) Effect of P2X7 receptor knockout on exocrine secretion of pancreas, salivary glands and lacrimal glands, J. Physiol $588,3615-3627$.

[139] Pochet, S., Garcia-Marcos, M., Seil, M., Otto, A., Marino, A., and Dehaye, J. P. (2007) Contribution of two ionotropic purinergic receptors to ATP responses in submandibular gland ductal cells, Cell. Signal. 19, 2155-2164.

[140] Turner, J. T., Weisman, G. A., and Camden, J. M. (1997) Upregulation of P2Y 2 nucleotide receptors in rat salivary gland cells during short-term culture, Am. $J$. Physiol. Cell Physiol. 273, C1100-C1107.

[141] Schrader, A. M., Camden, J. M., and Weisman, G. A. (2005) P2Y ${ }_{2}$ nucleotide receptor up-regulation in submandibular gland cells from the NOD. B10 mouse model of Sjögren's syndrome, Arch. Oral Biol. 50, 533-540. 
[142] Baker, O. J., Camden, J. M., Rome, D. E., Seye, C. I., and Weisman, G. A. (2008) $\mathrm{P}_{2} \mathrm{Y}_{2}$ nucleotide receptor activation up-regulates vascular cell adhesion molecular-1 expression and enhances lymphocyte adherence to a human submandibular gland cell line, Mol. Immunol. 45, 65-75.

[143] El-Sayed, F. G., Camden, J. M., Woods, L. T., Khalafalla, M. G., Petris, M. J., Erb, L. and Weisman, G. A. (2014) $\mathrm{P}_{2} \mathrm{Y}_{2}$ nucleotide receptor activation enhances the aggregation and self-organization of dispersed salivary epithelial cells, Am. $J$. Physiol. Cell Physiol. 307, C83-C96.

[144] Ahn, J. S., Camden, J. M., Schrader, A. M., Redman, R. S., and Turner, J. T. (2000) Reversible regulation of $\mathrm{P}_{2} \mathrm{Y}_{2}$ nucleotide receptor expression in the ductligated rat submandibular gland, Am. J. Physiol. Cell Physiol. 279, C286-C294.

[145] Weinger, I., Klepeis, V. E., and Trinkaus-Randall, V. (2005) Tri-nucleotide receptors play a critical role in epithelial cell wound repair, Purinergic Signal. 1, 281-292

[146] Beldi, G., Enjyoji, K., Wu, Y., Miller, L., Banz, Y., Sun, X., and Robson, S. C. (2008) The role of purinergic signaling in the liver and in transplantation: effects of extracellular nucleotides on hepatic graft vascular injury, rejection and metabolism, Front. biosci.: a journal and virtual library 13, 2588-2603.

[147] Degagné, E., Grbic, D. M., Dupuis, A.-A., Lavoie, E. G., Langlois, C., Jain, N., Weisman, G. A., Sévigny, J., and Gendron, F. P. (2009) P2 $Y_{2}$ receptor transcription is increased by NF- $\mathrm{kB}$ and stimulates cyclooxygenase- 2 expression and PGE2 released by intestinal epithelial cells, J. Immunol. 183, 4521-4529. 
[148] Ayata, C. K., Ganal, S. C., Hockenjos, B., Willim, K., Vieira, R. P., Grimm, M., Robaye, B., Boeynaems, J. M., Di Virgilio, F., and Pellegatti, P. (2012) Purinergic $\mathrm{P}_{2} \mathrm{Y}_{2}$ receptors promote neutrophil infiltration and hepatocyte death in mice with acute liver injury, Gastroenterology 143, 1620-1629.

[149] Peterson, T. S., Thebeau, C. N., Ajit, D., Camden, J. M., Woods, L. T., Wood, W. G., Petris, M. J., Sun, G. Y., Erb, L., and Weisman, G. A. (2013) Up-regulation and activation of the $\mathrm{P} 2 \mathrm{Y}_{2}$ nucleotide receptor mediate neurite extension in IL-1 $\beta$-treated mouse primary cortical neurons, J. Neurochem. 125, 885-896.

[150] Kayes, T. D., Weisman, G. A., Camden, J. M., Woods, L. T., Bredehoeft, C., Downey, E. F., Cole, J., and Braley-Mullen, H. (2016) New murine model of early onset autoimmune thyroid disease/hypothyroidism and autoimmune exocrinopathy of the salivary gland, J. Immunol. 197, 2119-2130.

[151] Yu, S., Sharp, G. C., and Braley-Mullen, H. (2002) Dual roles for IFN- $\gamma$, but not for IL-4, in spontaneous autoimmune thyroiditis in NOD. H-2h4 mice, $J$. Immunol. 169, 3999-4007.

[152] Tai, X., Cowan, M., Feigenbaum, L., and Singer, A. (2005) CD28 costimulation of developing thymocytes induces Foxp3 expression and regulatory $\mathrm{T}$ cell differentiation independently of interleukin 2, Nat. Immunol. 6, 152-162.

[153] Tincani, A., Andreoli, L., Cavazzana, I., Doria, A., Favero, M., Fenini, M. G., Franceschini, F., Lojacono, A., Nascimbeni, G., and Santoro, A. (2013) Novel aspects of Sjögren's syndrome in 2012, BMC Med. 11, 93. 10.1186/1741-7015$11-93$ 
[154] Burgess, L. K., and Dardick, I. (1998) Cell population changes during atrophy and regeneration of rat parotid gland, Oral Surg. Oral Med. Oral Pathol. Oral Radiol. Endod. 85, 699-706.

[155] Takahashi, S., Schoch, E., and Walker, N. I. (1998) Origin of acinar cell regeneration after atrophy of the rat parotid induced by duct obstruction, Int. J. Exp. Pathol. 79, 293-301.

[156] Takahashi, S., Schoch, E., and Walker, N. I. (1998) Origin of acinar cell regeneration after atrophy of the rat parotid induced by duct obstruction, Int. $j$. exp. pathol. 79, 293-301.

[157] Man, Y. G., Ball, W. D., Marchetti, L., and Hand, A. R. (2001) Contributions of intercalated duct cells to the normal parenchyma of submandibular glands of adult rats, Anat. Rec. 263, 202-214.

[158] Takahashi, S., Nakamura, S., Suzuki, R., Islam, N., Domon, T., Yamamoto, T., and Wakita, M. (2000) Apoptosis and mitosis of parenchymal cells in the ductligated rat submandibular gland, Tissue cell 32, 457-463.

[159] Zaia, A. A., Della Coletta, R., Almeida, O. P., and Line, S. R. (1996) Expression of collagen and elastic fibers in duct-ligated submandibular glands of mice, Eur. J. Oral Sci. 104, 627-629.

[160] Kolliputi, N., Shaik, R. S., and Waxman, A. B. (2010) The inflammasome mediates hyperoxia-induced alveolar cell permeability, J. Immunol. 184, 58195826. 
[161] Pelegrin, P., and Surprenant, A. (2006) Pannexin-1 mediates large pore formation and interleukin-1 $\beta$ release by the ATP-gated $\mathrm{P} 2 \mathrm{X} 7$ receptor, EMBO J. 25, 50715082

[162] Pelegrin, P., and Surprenant, A. (2007) Pannexin-1 couples to maitotoxin- and nigericin-induced interleukin-1beta release through a dye uptake-independent pathway, J. Biol. Chem. 282, 2386-2394.

[163] Riteau, N., Baron, L., Villeret, B., Guillou, N., Savigny, F., Ryffel, B., Rassendren, F., Le Bert, M., Gombault, A., and Couillin, I. (2012) ATP release and purinergic signaling: a common pathway for particle-mediated inflammasome activation, Cell Death Dis. 3, e403.

[164] Adinolfi, E., Kim, M., Young, M. T., Di Virgilio, F., and Surprenant, A. (2003) Tyrosine phosphorylation of HSP90 within the P2X7 receptor complex negatively regulates P2X7 receptors, J. Biol. Chem. 278, 37344-37351.

[165] Fox, P. C. (2004) Salivary enhancement therapies, Caries Res 38, 241-246.

[166] Weisman, G. A., De, B. K., Friedberg, I., Pritchard, R. S., and Heppel, L. A. (1984) Cellular responses to external ATP which precede an increase in nucleotide permeability in transformed cells, J. Cell. Physiol. 119, 211-219.

[167] Surprenant, A., Rassendren, F., Kawashima, E., North, R., and Buell, G. (1996) The cytolytic $\mathrm{P} 2 \mathrm{Z}$ receptor for extracellular ATP identified as a $\mathrm{P} 2 \mathrm{X}$ receptor (P2X7), Science 272, 735-738. 
[168] Wilson, H. L., Wilson, S. A., Surprenant, A., and North, R. A. (2002) Epithelial membrane proteins induce membrane blebbing and interact with the P2X7 receptor C terminus, J. Biol. Chem. 277, 34017-34023.

[169] Rathinam, V. A., and Fitzgerald, K. A. (2016) Inflammasome complexes: emerging mechanisms and effector functions, Cell 165, 792-800.

[170] Müller, T., Vieira, R. P., Grimm, M., Dürk, T., Cicko, S., Zeiser, R., Jakob, T., Martin, S. F., Blumenthal, B., and Sorichter, S. (2011) A potential role for P2X7R in allergic airway inflammation in mice and humans, Am. J. Respir. Cell Mol. Biol. 44, 456-464.

[171] McGaraughty, S., Chu, K., Namovic, M., Donnelly-Roberts, D., Harris, R., Zhang, X. F., Shieh, C. C., Wismer, C., Zhu, C., and Gauvin, D. (2007) P2X7-related modulation of pathological nociception in rats, Neuroscience 146, 1817-1828.

[172] Feng, L., Chen, Y., Ding, R., Fu, Z., Yang, S., Deng, X., and Zeng, J. (2015) P2X7R blockade prevents NLRP3 inflammasome activation and brain injury in a rat model of intracerebral hemorrhage: involvement of peroxynitrite, $J$. Neuroinflammation 12, 1. 10.1186/s12974-015-0409-2

[173] Alves, L. A., Bezerra, R. J. S., Faria, R. X., Ferreira, L. G. B., and da Silva Frutuoso, V. (2013) Physiological roles and potential therapeutic applications of the P2X7 receptor in inflammation and pain, Molecules 18, 10953-10972.

[174] Karmakar, M., Katsnelson, M. A., Dubyak, G. R., and Pearlman, E. (2016) Neutrophil P2X7 receptors mediate NLRP3 inflammasome-dependent IL-1 $\beta$ secretion in response to ATP, Nat. Commun 7. 10.1038/ncomms10555 
[175] Couillin, I., Gombault, A., and Baron, L. (2013) ATP release and purinergic signaling in NLRP3 inflammasome activation, Front. Immunol. 3, 414. 10.3389/fimmu.2012.00414

[176] Kahlenberg, J. M., and Dubyak, G. R. (2004) Mechanisms of caspase-1 activation by P2X7 receptor-mediated K ${ }^{+}$release, Am. J. Physiol. Cell Physiol. 286, C1100C1108.

[177] Juliana, C., Fernandes-Alnemri, T., Wu, J., Datta, P., Solorzano, L., Yu, J. W., Meng, R., Quong, A. A., Latz, E., and Scott, C. P. (2010) Anti-inflammatory compounds parthenolide and Bay 11-7082 are direct inhibitors of the inflammasome, J. Biol. Chem. 285, 9792-9802.

[178] Coll, R. C., Robertson, A. A., Chae, J. J., Higgins, S. C., Muñoz-Planillo, R., Inserra, M. C., Vetter, I., Dungan, L. S., Monks, B. G., and Stutz, A. (2015) A small-molecule inhibitor of the NLRP3 inflammasome for the treatment of inflammatory diseases, Nature medicine 21, 248-255.

[179] Perregaux, D. G., and Gabel, C. A. (1998) Human monocyte stimulus-coupled IL$1 \beta$ posttranslational processing: modulation via monovalent cations, Am. J. of Physiol. Cell Physiol. 275, C1538-C1547.

[180] Muñoz-Planillo, R., Kuffa, P., Martínez-Colón, G., Smith, B. L., Rajendiran, T. M., and Núñez, G. (2013) K ${ }^{+}$efflux is the common trigger of NLRP3 inflammasome activation by bacterial toxins and particulate matter, Immunity $38,1142-1153$. 
[181] Niethammer, P., Grabher, C., Look, A. T., and Mitchison, T. J. (2009) A tissuescale gradient of hydrogen peroxide mediates rapid wound detection in zebrafish, Nature 459, 996-999.

[182] Bolwell, G. P. (1999) Role of active oxygen species and NO in plant defence responses, Curr. Opin. Plant Biol. 2, 287-294.

[183] Cloonan, S. M., and Choi, A. M. (2012) Mitochondria: commanders of innate immunity and disease?, Curr. Opin. Immunol. 24, 32-40.

[184] Scroggins, B. T., and Neckers, L. (2007) Post-translational modification of heatshock protein 90: impact on chaperone function, Expert Opin. Drug Discov. 2, $1403-1414$.

[185] Thiel, M., Wolfs, M. J., Bauer, S., Wenning, A. S., Burckhart, T., Schwarz, E. C., Scott, A. M., Renner, C., and Hoth, M. (2010) Efficiency of T-cell costimulation by CD80 and CD86 cross-linking correlates with calcium entry, Immunology 129, $28-40$.

[186] Delaleu, N., Mydel, P., Brun, J. G., Jonsson, M. V., Alimonti, A., and Jonsson, R. (2016) Sjögren's syndrome patients with ectopic germinal centers present with a distinct salivary proteome, Rheumatology. 10.1093/rheumatology/kew013

[187] Coskun, M. (2014) Intestinal epithelium in inflammatory bowel disease, Front. Med. 1, 24. 10.3389/fmed.2014.00024

[188] Shimoda, S., Harada, K., Niiro, H., Yoshizumi, T., Soejima, Y., Taketomi, A., Maehara, Y., Tsuneyama, K., Nakamura, M., and Komori, A. (2008) Biliary 
epithelial cells and primary biliary cirrhosis: the role of liver-infiltrating mononuclear cells, Hepatology 47, 958-965.

[189] Bläsche, R., Ebeling, G., Perike, S., Weinhold, K., Kasper, M., and Barth, K. (2012) Activation of P2X7R and downstream effects in bleomycin treated lung epithelial cells, Int. J. Biochem. Cell Biol. 44, 514-524.

[190] Witte, E., Kokolakis, G., Witte, K., Warszawska, K., Friedrich, M., Christou, D., Kirsch, S., Sterry, W., Volk, H.-D., and Sabat, R. (2016) Interleukin-29 induces epithelial production of CXCR3A ligands and T-cell infiltration, J. Mol. Med. 94, $391-400$

[191] Barrera, M., Bahamondes, V., Sepulveda, D., Quest, A., Castro, I., Cortés, J., Aguilera, S., Urzúa, U., Molina, C., and Pérez, P. (2013) Sjögren's syndrome and the epithelial target: a comprehensive review, J. Autoimmun. 42, 7-18.

[192] Abais, J. M., Xia, M., Zhang, Y., Boini, K. M., and Li, P. L. (2015) Redox regulation of NLRP3 inflammasomes: ROS as trigger or effector?, Antioxid. Redox Signal. 22, 1111-1129.

[193] Akundi, R. S., Huang, Z., Eason, J., Pandya, J. D., Zhi, L., Cass, W. A., Sullivan, P. G., and Büeler, H. (2011) Increased mitochondrial calcium sensitivity and abnormal expression of innate immunity genes precede dopaminergic defects in Pink1-deficient mice, PLoS One 6, e16038.

[194] Joana da Costa, P., Santiago, A. P. S., Amâncio, R. T., Galina, A., Oliveira, M. F., and Bozza, F. A. (2008) Sepsis induces brain mitochondrial dysfunction, Crit. Care Med. 36, 1925-1932. 
[195] Dinarello, C. A. (2011) Interleukin-1 in the pathogenesis and treatment of inflammatory diseases, Blood 117, 3720-3732.

[196] Dinarello, C. A. (2009) Immunological and inflammatory functions of the interleukin-1 family, Annu. Rev. Immunol. 27, 519-550.

[197] Kalinski, P. (2012) Regulation of immune responses by prostaglandin E2, J. Immunol. 188, 21-28.

[198] Sharma, J., Al-Omran, A., and Parvathy, S. (2007) Role of nitric oxide in inflammatory diseases, Inflammopharmacology 15, 252-259.

[199] Jonsson, M. V., Delaleu, N., Brokstad, K. A., Berggreen, E., and Skarstein, K. (2006) Impaired salivary gland function in NOD mice: association with changes in cytokine profile but not with histopathologic changes in the salivary gland, Arthritis Rheum. 54, 2300-2305.

[200] Lee, Y. A., Choi, H. M., Lee, S. H., Yang, H. I., Yoo, M. C., Hong, S. J., and Kim, K. S. (2012) Synergy between adiponectin and interleukin-1 $\beta$ on the expression of interleukin-6, interleukin-8, and cyclooxygenase-2 in fibroblast-like synoviocytes, Exp. Mol. Med. 44, 440-447.

[201] Kagami, H., Wang, S., and Hai, B. (2008) Restoring the function of salivary glands, Oral Dis. 14, 15-24.

[202] Bookman, A. A., Shen, H., Cook, R. J., Bailey, D., McComb, R. J., Rutka, J. A., Slomovic, A. R., and Caffery, B. (2011) Whole stimulated salivary flow: correlation with the pathology of inflammation and damage in minor salivary 
gland biopsy specimens from patients with primary Sjögren's syndrome but not patients with sicca, Arthritis Rheumatol. 63, 2014-2020.

[203] Liu, Y. (2006) Renal fibrosis: new insights into the pathogenesis and therapeutics, Kidney Int. 69, 213-217.

[204] Tatler, A. L., and Jenkins, G. (2012) TGF- $\beta$ activation and lung fibrosis, Proc. Am. Thorac. Soc. 9, 130-136.

[205] Mallat, A., and Lotersztajn, S. (2013) Cellular mechanisms of tissue fibrosis. 5. Novel insights into liver fibrosis, Am. J. Physiol. Cell Physiol. 305, C789-C799.

[206] Dinarello, C. (2002) The IL-1 family and inflammatory diseases, Clin. Exp. Rheumatol. 20, S1-S13.

[207] Qu, Y., Ramachandra, L., Mohr, S., Franchi, L., Harding, C. V., Nunez, G., and Dubyak, G. R. (2009) P2X7 receptor-stimulated secretion of MHC class IIcontaining exosomes requires the ASC/NLRP3 inflammasome but is independent of caspase-1, J. Immunol. 182, 5052-5062.

[208] Cruz-Tapias, P., Rojas-Villarraga, A., Maier-Moore, S., and Anaya, J.-M. (2012) HLA and Sjögren's syndrome susceptibility. A meta-analysis of worldwide studies, Autoimm. rev. 11, 281-287. 


\title{
Appendix I
}

\section{$\mathrm{P}_{2} \mathrm{Y}_{2}$ nucleotide receptor activation enhances the aggregation and self-organization of dispersed salivary epithelial cells}

As found in: El-Sayed, F.G., Camden, J.M., Woods, L.T., Khalafalla, M.G., Petris, M.J., Erb, L. and Weisman, G.A., 2014. P2Y 2 nucleotide receptor activation enhances the aggregation and self-organization of dispersed salivary epithelial cells. American Journal of Physiology-Cell Physiology, 307(1), pp.C83-C96.

\begin{abstract}
Hyposalivation resulting from salivary gland dysfunction leads to poor oral health and greatly reduces the quality of life of patients. Current treatments for hyposalivation are limited. However, regenerative medicine to replace dysfunctional salivary glands represents a revolutionary approach. The ability of dispersed salivary epithelial cells or salivary gland-derived progenitor cells to self-organize into acinar-like spheres or branching structures that mimic the native tissue holds promise for cell-based reconstitution of a functional salivary gland. However, the mechanisms involved in salivary epithelial cell aggregation and tissue reconstitution are not fully understood. This study investigated the role of the $\mathrm{P} 2 \mathrm{Y}_{2}$ nucleotide receptor $\left(\mathrm{P} 2 \mathrm{Y}_{2} \mathrm{R}\right)$, a $\mathrm{G}$ protein-coupled receptor that is upregulated following salivary gland damage and disease, in salivary gland reconstitution. In vitro results with the rat parotid acinar Par-C10 cell line indicate that $\mathrm{P} 2 \mathrm{Y}_{2} \mathrm{R}$ activation with the selective agonist UTP enhances the self-organization of dispersed salivary epithelial cells into acinar-like spheres. Other results indicate that the $\mathrm{P} 2 \mathrm{Y}_{2} \mathrm{R}$-mediated response is dependent on epidermal growth factor receptor activation via the metalloproteases ADAM10/ADAM17 or the $\alpha_{5} \beta_{1}$ integrin/Cdc42 signaling pathway, which leads to activation of the MAPKs JNK and ERK1/2. Ex vivo data using primary submandibular gland cells from wild-type and $P 2 Y_{2} R^{-/-}$mice confirmed that
\end{abstract}


UTP-induced migratory responses required for acinar cell self-organization are mediated by the $\mathrm{P} 2 \mathrm{Y}_{2} \mathrm{R}$. Overall, this study suggests that the $\mathrm{P} 2 \mathrm{Y}_{2} \mathrm{R}$ is a promising target for salivary gland reconstitution and identifies the involvement of two novel components of the $\mathrm{P} 2 \mathrm{Y}_{2} \mathrm{R}$ signaling cascade in salivary epithelial cells, the $\alpha_{5} \beta_{1}$ integrin and the Rho GTPase Cdc42.

Keywords: salivary gland reconstitution, $\mathrm{P} 2 \mathrm{Y}_{2}$ nucleotide receptor, EGF receptor, $\alpha_{5} \beta_{1}$ integrin, Cdc42 Rho GTPase, extracellular ATP

\section{Introduction}

Salivary glands are exocrine glands composed of multiple secretory end pieces called acini, which secrete saliva into the oral cavity via a system of branched ductal cells, including intercalated ducts, striated ducts, and a main excretory duct (52). Saliva performs many protective and physiological functions by providing the oral cavity with water and electrolytes along with essential proteins, including lubricants, antibacterial, antifungal, antiviral, and remineralization agents, digestive enzymes, and growth factors $(25,31,52)$. Accordingly, hyposalivation due to salivary gland dysfunction resulting from the autoimmune disease Sjögren's syndrome (SS) or irradiation therapy for head and neck cancers leads to a significant deterioration of oral health and seriously decreases the quality of life of these patients $(2,4)$. Current treatments for hyposalivation are limited to saliva substitutes in the form of gels or sprays and medications, such as the muscarinic receptor agonists pilocarpine and cevimeline, which induce saliva secretion from residual salivary gland cells. However, these treatments are largely ineffective due to their transient nature or systemic side effects that are poorly tolerated by many patients ( 3 , 
106). Therefore, the development of new therapeutic approaches to treat salivary hypofunction is a necessity. Experimental approaches for restoring salivary gland function have been considered, including gene therapy to augment the expression of proteins involved in saliva secretion $(28,82,104)$. An alternative approach to regain the function of salivary glands is to induce the proliferation, migration, and differentiation of residual cells in the damaged salivary glands to promote tissue regeneration (59). This approach can be further applied to bioengineer artificial salivary glands that closely resemble the native organ in both structure and function (59).

Reconstitution studies, using salivary gland tissue isolated from embryonic mice (118) and humans (90) or human salivary gland progenitor (SGP) cells (84), have demonstrated the ability of dissociated cells to migrate towards each other and self-organize into acinar-like aggregates with structural features and differentiation markers that resemble the native gland. Cellular mechanisms and components that enhance the formation of these acinar-like aggregates would likely be important factors in salivary gland reconstitution and regeneration. In this study, we investigated the role in salivary gland reconstitution/regeneration of the $\mathrm{P} 2 \mathrm{Y}_{2}$ nucleotide receptor $\left(\mathrm{P} 2 \mathrm{Y}_{2} \mathrm{R}\right)$ for extracellular ATP and UTP, since previous findings have suggested roles for the $\mathrm{P}_{2} \mathrm{Y}_{2} \mathrm{R}$ in corneal epithelia wound healing by inducing cell migration (119), liver regeneration by promoting hepatocyte proliferation (8), inflammatory bowel disease by enhancing epithelial repair (27), intestinal reepithelialization following experimental colitis (26), and reduction of infarct size following myocardial infarction (20). In addition, the $\mathrm{P} 2 \mathrm{Y}_{2} \mathrm{R}$ is upregulated upon disruption of salivary gland tissue homeostasis (113) and in salivary glands of the NOD.B10 mouse model of SS-like autoimmune exocrinopathy (99). In a 
classic model of salivary gland regeneration, $\mathrm{P} 2 \mathrm{Y}_{2} \mathrm{R}$ expression and activity increase due to tissue atrophy caused by a 3-day ductal ligation in rat submandibular gland (SMG), whereas $\mathrm{P} 2 \mathrm{Y}_{2} \mathrm{R}$ expression and activity levels and glandular morphology resemble unligated controls 14 days after deligation (1). Collectively, these findings suggest that $\mathrm{P} 2 \mathrm{Y}_{2} \mathrm{R}$ upregulation plays a role in salivary gland regeneration.

The $\mathrm{P} 2 \mathrm{Y}_{2} \mathrm{R}$ has structural motifs that enable interactions with diverse signaling pathways, such as Src homology 3 binding domains that mediate transactivation of growth factor receptors (76) and an Arg-Gly-Asp (RGD) domain that binds directly to $\alpha_{V} \beta_{3 / 5}$ integrins to activate the Rho and Rac GTPases and cytoskeletal rearrangements $(6,34,74)$. $\mathrm{P}_{2} \mathrm{Y}_{2} \mathrm{R}$ activation also has been shown to induce downstream activation of MAPKs, including JNK $(29,110)$ and ERK1/2 $(13,29,94)$, in several cell types. The $\mathrm{P}_{2} \mathrm{Y}_{2} \mathrm{R}$ also has been shown to activate metalloproteases that induce epidermal growth factor (EGF) receptor (EGFR) and ErbB3 phosphorylation in human salivary gland (HSG) cells (94). $\mathrm{P} 2 \mathrm{Y}_{2} \mathrm{R}$ interactions and signaling pathways enable extracellular ATP and UTP to regulate numerous physiological processes, such as cell proliferation, migration, and differentiation $(6,12,14,34,87,117,119,125)$.

On the basis of the role of the $\mathrm{P} 2 \mathrm{Y}_{2} \mathrm{R}$ in the regulation of intracellular signaling pathways that are crucial to tissue repair, we investigated whether the $\mathrm{P} 2 \mathrm{Y}_{2} \mathrm{R}$ plays a similar role in the salivary gland using in vitro and ex vivo approaches. Our goals were to test whether $\mathrm{P} 2 \mathrm{Y}_{2} \mathrm{R}$ activation enhances the aggregation and self-organization of dispersed salivary epithelial cells into acinar-like aggregates and to determine the underlying mechanisms. We found that $\mathrm{P} 2 \mathrm{Y}_{2} \mathrm{R}$-mediated formation of acinar-like spheres involves the 
transactivation of the EGFR through activation of the metalloproteases

ADAM10/ADAM17 and the $\alpha_{5} \beta_{1}$ integrin/Cdc42 Rho GTPase signaling pathway, leading to downstream activation of MAPKs.

In the following studies, we used the rat parotid acinar (Par-C10) cell line, an established in vitro model of salivary gland differentiation and function $(7,112)$. Par-C10 cells express endogenous $\mathrm{P} 2 \mathrm{Y}_{2} \mathrm{Rs}$, but not $\mathrm{P} 2 \mathrm{Y}_{4} \mathrm{R}$ (unpublished observations) or $\mathrm{P} 2 \mathrm{Y}_{6} \mathrm{R}$ (112). Therefore, $\mathrm{P} 2 \mathrm{Y}_{2} \mathrm{R}$ is the only $\mathrm{P} 2 \mathrm{Y}$ or $\mathrm{P} 2 \mathrm{X}$ receptor subtype that responds to UTP in these cells (112). Unlike the majority of salivary cell lines, including HSG cells, Par-C10 cells are able to differentiate on Matrigel into three-dimensional (3D) acinar-like spheres that display characteristics similar to differentiated acini in salivary glands, including cell polarization and tight junction formation, which are required to maintain the transepithelial potential difference and responsiveness to muscarinic receptor agonists (7). In addition, we used primary SMG cells isolated from wild-type and $P 2 Y_{2} R^{-/}$mice to corroborate the results obtained with Par-C10 cells.

\section{MATERIALS AND METHODS}

\section{Reagents.}

All reagents were purchased from Sigma-Aldrich (St. Louis, MO) unless otherwise noted.

\section{Par-C10 cell culture.}

Par-C10 cells transfected with cDNA encoding the green fluorescent protein (GFP)tagged human $\mathrm{P} 2 \mathrm{Y}_{2} \mathrm{R}\left(\mathrm{GFP}-\mathrm{hP} 2 \mathrm{Y}_{2} \mathrm{R}\right)(\underline{7})$ were cultured in a 1:1 mixture of DMEM- 
Ham's F-12 medium (Life Technologies, Grand Island, NY) supplemented with 2.5\% (vol/vol) fetal bovine serum (FBS) (Life Technologies), insulin ( $5 \mu \mathrm{g} / \mathrm{ml})$, transferrin (5 $\mu \mathrm{g} / \mathrm{ml})$, selenite $(5 \mathrm{ng} / \mathrm{ml})$, retinoic acid $(0.1 \mu \mathrm{M})$, EGF $(80 \mathrm{ng} / \mathrm{ml})$ (Calbiochem, Billerica, MA), triiodothyronine (2 $\mathrm{nM})$, hydrocortisone $(1.1 \mu \mathrm{M})$, glutamine $(5 \mathrm{mM})$, gentamicin $(50 \mu \mathrm{g} / \mathrm{ml})$, cholera toxin $(8.4 \mathrm{ng} / \mathrm{ml})$, and G418 $(0.5 \mathrm{mg} / \mathrm{ml})$ (Mediatech, Manassas, VA) and maintained at $37^{\circ} \mathrm{C}$ in a humidified atmosphere of $5 \% \mathrm{CO}_{2}$ and $95 \%$ air.

\section{Mice.}

C57BL/6 (wild-type) and $P 2 Y_{2} R^{-/-}$mice on a C57BL/6 background were purchased from Jackson Laboratories (Bar Harbor, ME) and bred at the Christopher S. Bond Life Sciences Center Animal Facility of the University of Missouri, Columbia, MO. Animals were housed in vented cages with 12:12-h light-dark cycles and received food and water ad libitum. All animals were handled using protocols approved by the Institutional Animal Care and Use Committee (IACUC) of the University of Missouri.

\section{Preparation of dispersed cell aggregates from mouse SMG.}

Dispersed cell aggregates from the SMGs of wild-type C57BL/6 and $P 2 Y_{2} R^{-/-}$mice were prepared, as previously described (94). Briefly, the mice were anesthetized with isoflurane and the SMGs were removed. The glands were finely minced and incubated in dispersion medium consisting of DMEM-Ham's F-12 medium (1:1), $0.2 \mathrm{mM} \mathrm{CaCl}_{2}, 1 \%$ (wt/vol) bovine serum albumin (BSA), $50 \mathrm{U} / \mathrm{ml}$ collagenase (Worthington Biochemical, Freehold, NJ), and $400 \mathrm{U} / \mathrm{ml}$ hyaluronidase at $37^{\circ} \mathrm{C}$ for 40 min with aeration $(95 \%$ air 
and $5 \% \mathrm{CO}_{2}$ ). Cell aggregates in dispersion medium were suspended by pipetting at 20, 30 , and 40 min of the incubation period. The dispersed cell aggregates were washed with enzyme-free assay buffer (in mM: $120 \mathrm{NaCl}, 4 \mathrm{KCl}, 1.2 \mathrm{KH}_{2} \mathrm{PO}_{4}, 1.2 \mathrm{MgSO}_{4}, 1 \mathrm{CaCl}_{2}$, 10 glucose, 15 HEPES, pH 7.4) containing 1\% (vol/vol) FBS, filtered through nylon mesh, and cultured in DMEM-Ham's F-12 medium (1:1) containing 2.5\% (vol/vol) FBS and the following supplements: retinoic acid $(0.1 \mu \mathrm{M})$, EGF $(80 \mathrm{ng} / \mathrm{ml})$, triiodothyronine (2 $\mathrm{nM})$, hydrocortisone $(1.1 \mu \mathrm{M})$, glutamine $(5 \mathrm{mM})$, insulin $(5 \mu \mathrm{g} / \mathrm{ml})$, transferrin $(5$ $\mu \mathrm{g} / \mathrm{ml})$, selenite $(5 \mathrm{ng} / \mathrm{ml})$, gentamicin $(50 \mu \mathrm{g} / \mathrm{ml})$, and cholera toxin $(8.4 \mathrm{ng} / \mathrm{ml})$. The cells were cultured at $37^{\circ} \mathrm{C}$ in a humidified atmosphere of $95 \%$ air and $5 \% \mathrm{CO}_{2}$.

\section{Migration assay.}

Par-C10 single-cell suspensions in DMEM/Ham's F-12 medium (1:1) containing 0.1\% $(\mathrm{vol} / \mathrm{vol})$ FBS were seeded $\left(2 \times 10^{5}\right.$ cells/well $)$ on a 24 -well plate coated with growth factor reduced (GFR) Matrigel (BD Biosciences, San Jose, CA) and incubated at $37^{\circ} \mathrm{C}$ in a humidified atmosphere of $5 \% \mathrm{CO}_{2}$ and $95 \%$ air for $4 \mathrm{~h}$. Then, the cell culture plate was mounted on a Nikon Eclipse Ti-E microscope equipped with a digital camera, a motorized $\mathrm{x}-\mathrm{y}$ stage, an automatic shutter, and an in vivo incubation chamber $\left(37^{\circ} \mathrm{C}, 5 \%\right.$ $\mathrm{CO}_{2}$, and $95 \%$ air). Within each well, a field of cells was located with a $\times 10$ objective and marked for monitoring over the duration of the experiment using Nikon NIS-Elements imaging software. The exposure time was kept constant for all positions and all time points. Cells were treated with or without UTP $(100 \mu \mathrm{M})$ or EGF $(100 \mathrm{ng} / \mathrm{ml})$. In inhibitor studies, cells were pretreated with EGFR inhibitor AG1478 $(1 \mu \mathrm{M})(\mathrm{Cell}$ Signaling Technology, Beverly, MA), ADAM10/ADAM17 inhibitor TAPI-2 (10 $\mu \mathrm{M})$ 
(Peptides International, Louisville, KY), $\alpha_{5} \beta_{1}$ integrin blocking antibody $(100 \mu \mathrm{g} / \mathrm{ml})$ (Biolegend, San Diego, CA), Cdc42 inhibitor ML141 (10 $\mu \mathrm{M})$ (Tocris Bioscience, Minneapolis, MN), RhoA inhibitor SR3677 (10 $\mu$ M) (Tocris Bioscience), MEK/ERK pathway inhibitor U0126 (10 $\mu \mathrm{M})($ Cell Signaling Technology) or JNK inhibitor SP600125 (10 $\mu \mathrm{M})$ (Tocris Bioscience) for $2 \mathrm{~h}$ before UTP, EGF, or vehicle (basal) treatment. Unless otherwise noted, inhibitors at the concentrations employed had no effect on the responses measured under basal conditions. Transmitted light images of cells were obtained every $10 \mathrm{~min}$ for the time indicated. Cellular aggregation was monitored by manually counting the number of aggregation events, where one aggregation event was defined as the coalescence/fusion of two or more cells at the same time point. ZO-1 tight junction protein was detected in Par-C10 cell aggregates formed after $36 \mathrm{~h}$ using immunofluorescence as previously described (7).

For primary SMG cells isolated from wild-type and $P 2 Y_{2} R^{-/-}$mice, SMGs were enzymatically dispersed and incubated for 3 days $\left(37^{\circ} \mathrm{C}, 5 \% \mathrm{CO}_{2}\right.$, and $95 \%$ air $)$ to allow the $\mathrm{P} 2 \mathrm{Y}_{2} \mathrm{R}$ to upregulate. After 3 days, cells were serum-starved overnight and on day 4, cells were seeded on GFR-Matrigel for $8 \mathrm{~h}$, treated with or without UTP, and monitored by time-lapse live cell imaging, as described above. In inhibitor studies, cells were pretreated with EGFR inhibitor AG1478 $(1 \mu \mathrm{M})($ Cell Signaling Technology) for $2 \mathrm{~h}$ before UTP or vehicle (basal) treatment. Primary cell migration was assessed by measuring the distance traveled from the origin, total distance traveled, and average velocity using the tracking software provided with the NIS-Elements imaging software. 


\section{SDS-PAGE and Western blot analysis.}

Par-C10 cells $\left(2 \times 10^{5}\right.$ cells/well) were seeded on 24 -well culture dishes, grown to $70 \%$ confluence, and then incubated overnight in DMEM-Ham's F-12 medium (1:1) without serum. When indicated, the cells were pretreated with or without inhibitors for $2 \mathrm{~h}$ at $37^{\circ} \mathrm{C}$ before stimulation with agonists for the indicated times. Then, the medium was removed and $100 \mu \mathrm{l}$ of $2 \times$ Laemmli lysis buffer [20 $\mathrm{mM} \mathrm{NaH}_{2} \mathrm{PO}_{4}, \mathrm{pH} 7.0,20 \%$ (vol/vol) glycerol, 4\% (wt/vol) SDS, 0.01\% (wt/vol) bromophenol blue, and $100 \mathrm{mM}$ dithiothreitol] were added. The samples were sonicated for $5 \mathrm{~s}$ with a Branson Sonifier 250 (microtip; output level, 5; duty cycle, $50 \%$ ), heated at $95^{\circ} \mathrm{C}$ for $5 \mathrm{~min}$, and subjected to SDS-PAGE on $7.5 \%$ (wt/vol) polyacrylamide gels. The proteins resolved on the gel were transferred to nitrocellulose membranes and blocked for $1 \mathrm{~h}$ with $5 \%$ (wt/vol) nonfat dry milk in Tris-buffered saline containing $0.1 \%$ (vol/vol) Tween 20 (TBST). The blots were incubated overnight at $4{ }^{\circ} \mathrm{C}$ in blocking solution or TBST with the following rabbit polyclonal antibodies used at 1:1,000 dilutions: anti-phospho-EGFR (Tyr1068) (Cell Signaling Technology), anti-phospho-JNK (Thr183/Tyr185) (Cell Signaling Technology), anti-phospho-ERK1/2 (Thr202/Tyr204) (Cell Signaling Technology) or anti-ERK1/2 (Santa Cruz Biotechnology, Santa Cruz, CA) as a loading control. The membranes were washed three times with TBST and incubated with horseradish peroxidase-linked goat anti-rabbit IgG antibody (1:2,000 dilution; Santa Cruz Biotechnology) at room temperature for $1 \mathrm{~h}$. The membranes were washed three times with TBST and incubated with enhanced chemiluminescence reagent, and the protein bands detected on X-ray film were quantified using a computer-driven scanner and Quantity One software (Bio-Rad, Hercules, CA). The intensities of phosphorylated 
protein bands in cells treated with agonists or other agents were normalized to total ERK1/2 and are expressed as a percentage of normalized data from untreated controls.

\section{Cdc42 activation assay.}

A Cdc42 activation assay kit (Cell Biolabs, San Diego, CA) was used to assess Cdc42 activity according to the manufacturer's instructions. Briefly, Par-C10 cells were cultured in 100-mm culture dishes and grown to $70 \%$ confluence. Then, cells were starved overnight in serum-free DMEM-Ham's F-12 medium (1:1) before being stimulated with UTP $(100 \mu \mathrm{M})$ for the indicated times. Cell lysates were collected using $1 \times$ assay/lysis buffer (125 mM HEPES, pH 7.5, $750 \mathrm{mM} \mathrm{NaCl}, 5 \% \mathrm{NP}-40,50 \mathrm{mM} \mathrm{MgCl} 2,5 \mathrm{mM}$ EDTA, $10 \%$ glycerol) and incubated for $1 \mathrm{~h}$ at $4^{\circ} \mathrm{C}$ with p21-activated kinase-1 $\mathrm{p} 21$ binding domain (PAK1 PBD) agarose beads, which bind the GTP-bound form of Cdc42. GTP-bound Cdc42 was analyzed by Western analysis using mouse monoclonal anti-rat Cdc42 antibody (1:1,000 dilution; Cell Biolabs). The membranes were washed three times with TBST and incubated with horseradish peroxidase-linked goat anti-mouse IgG antibody (1:2,000 dilution) at room temperature for $1 \mathrm{~h}$. The membranes were washed three times with TBST and incubated with enhanced chemiluminescence reagent, and the protein bands were detected on X-ray film.

\section{Reverse transcription and real-time $\mathrm{PCR}$ analysis of $\mathrm{P}_{2} \mathrm{Y}_{2} \mathrm{R}$ mRNA expression.}

Total RNA was isolated using the RNeasy Plus Mini Kit (Qiagen, Valencia, CA) from SMG aggregates cultured for $0,24,48$, or $72 \mathrm{~h}$ at $37^{\circ} \mathrm{C}$ in $5 \% \mathrm{CO}_{2}$ and $95 \%$ air. cDNA was synthesized from $1 \mu \mathrm{g}$ of purified RNA using the Advantage RT for PCR kit 
(Clontech Laboratories, Mountain View, CA). Ten percent of the synthesized cDNA was used as a template in $25 \mu \mathrm{l}$ real-time PCR reactions, and samples were run in duplicate for the $P 2 Y_{2} R$ target and the endogenous $18 S$ RNA control. The relative levels of $P 2 Y_{2} R$ and $18 S$ RNA in each sample were determined and are expressed as a ratio of $P 2 Y_{2} R$ to 18S RNA (normalized to 1) using Applied Biosystems software.

\section{Intracellular free $\mathrm{Ca}^{2+}$ concentration measurements.}

Changes in the intracellular free $\mathrm{Ca}^{2+}$ concentration $\left(\left[\mathrm{Ca}^{2+}\right]_{\mathrm{i}}\right)$ in SMG cell aggregates were quantified as previously described (99). Briefly, dispersed SMG aggregates from wild-type or $P 2 Y_{2} R^{-/-}$mice were cultured for $72 \mathrm{~h}$ and loaded with $2 \mu \mathrm{M}$ fura 2-AM (Calbiochem) for $30 \mathrm{~min}$ at $37^{\circ} \mathrm{C}$ in assay buffer (in mM: $120 \mathrm{NaCl}, 4 \mathrm{KCl}, 1.2 \mathrm{KH}_{2} \mathrm{PO}_{4}$, 1.2 $\mathrm{MgSO}_{4}, 1 \mathrm{CaCl}_{2}, 10$ glucose, 15 HEPES, $\mathrm{pH}$ 7.4) containing $0.1 \%$ (wt/vol) BSA. Then, the SMG aggregates were washed and adhered to chambered coverslips coated with Cell-Tak (BD Biosciences) for an additional $30 \mathrm{~min}$ in the absence of fura 2-AM. SMG aggregates were stimulated with UTP $(100 \mu \mathrm{M})$, and changes in the $340 / 380 \mathrm{~nm}$ excitation ratio (505 $\mathrm{nm}$ emission) were monitored using an InCyt dual-wavelength fluorescence imaging system (Intracellular Imaging, Cincinnati, OH). Fluorescence ratios were converted to $\left[\mathrm{Ca}^{2+}\right]_{\mathrm{i}}(\mathrm{nM})$ using a standard curve created with known concentrations of $\mathrm{Ca}^{2+}$. 


\section{Statistical analysis.}

The quantitative results are presented as the means $\pm \mathrm{SE}$ of data from three or more experiments. Two-tailed $t$-test or ANOVA followed by Bonferroni or Dunnett's test was performed, as indicated, where $P<0.05$ represents a significant difference.

\section{RESULTS}

\section{$P 2 Y_{2} R$ activation enhances Par-C10 cell aggregation and the formation of acinar-}

\section{like spheres.}

When plated on extracellular matrices, such as Matrigel, dispersed salivary epithelial cells isolated from embryonic mice (118) or adult humans (90) as well as cultured ParC10 (7) and HSG (49) cells migrate towards each other and self-organize into aggregates that display structural and/or functional features similar to the native salivary gland. Since activation of the $\mathrm{P} 2 \mathrm{Y}_{2} \mathrm{R}$ has been shown to enhance the migration of a variety of cell types $(6,117,125)$, including epithelial cells $(13,68)$, we investigated whether $\mathrm{P} 2 \mathrm{Y}_{2} \mathrm{R}$ activation enhances the migration, aggregation, and self-organization of salivary epithelial cells. Par-C10 single-cell suspensions seeded on GFR-Matrigel-coated 24-well plates $\left(2 \times 10^{5}\right.$ cells/well $)$ were treated with or without UTP $(100 \mu \mathrm{M})$, and cells were monitored for $36 \mathrm{~h}$ by time-lapse live cell imaging (Fig. Appendix I-1A), as described in materials and methods. During the first $2 \mathrm{~h}$ of the time course, UTP-treated single ParC10 cells showed enhanced migratory responses, as indicated by the distance that single cells traveled from the origin (Fig. Appendix I-1B), the total distance that cells migrated (Fig. Appendix I-1C), and the increase in the cell velocity (Fig. Appendix I-1D). After 2 
h, single Par-C10 cells began to form aggregates that were quantified, as described in materials and methods, where one aggregation event represents the coalescence/fusion of two or more cells at the same time point. UTP-treated Par-C10 cells exhibited enhanced aggregation (Fig. Appendix I-1, $A$ and $E$, and Supplemental Movies S1 and S2; Supplemental Material for this article is available online at the journal website) with $100 \%$ forming acinar-like spheres that display lumen formation and an organized distribution of the tight junction protein ZO-1 (Fig. Appendix I-1F) at the end of $36 \mathrm{~h}$. Although untreated (basal) Par-C10 cells can aggregate and express ZO-1, they did not form differentiated acinar-like spheres until $\sim 72 \mathrm{~h}$ in culture (data not shown), as previously described (7). Notably, the majority of aggregation events took place in the first $12 \mathrm{~h}$ after addition of UTP (Fig. Appendix I-1G). Therefore, subsequent experiments investigating aggregation events were performed for $12 \mathrm{~h}$.

\section{Inhibition of EGFR decreases UTP-induced Par-C10 cell aggregation.}

EGFR regulates a wide variety of cellular responses, including cell migration and differentiation $(47,57)$. In HSG cells, the $\mathrm{P} 2 \mathrm{Y}_{2} \mathrm{R}$ has been shown to activate EGFR (94). To determine whether UTP-induced enhancement of Par-C10 cell aggregation is dependent on EGFR activation, cells were pretreated with AG1478 $(1 \mu \mathrm{M})$, a potent EGFR inhibitor, $2 \mathrm{~h}$ prior to UTP stimulation. The results show that EGFR inhibition decreased UTP-induced Par-C10 cell aggregation by 69\% (Fig. Appendix I-2A) and, as expected, completely inhibited EGF-induced enhancement of Par-C10 cell aggregation (Fig. Appendix I-2A). EGFR inhibition also prevented UTP- and EGF-induced phosphorylation of the EGFR (Fig. Appendix I-2B). 


\section{Inhibition of ADAM10/ADAM17 metalloproteases decreases UTP-induced Par-C10 cell aggregation and EGFR phosphorylation.}

In $\mathrm{HSG}$ cells, the $\mathrm{P} 2 \mathrm{Y}_{2} \mathrm{R}$ has been shown to activate EGFR via ADAM10 and ADAM17 metalloproteases (94) that promote shedding of EGF-like ligands, such as neuregulin, which bind to and activate members of the EGFR family. To determine whether ADAM10/ADAM17 are involved in the UTP-induced enhancement of Par-C10 cell aggregation, cells were pretreated with the selective ADAM10/ADAM17 inhibitor TAPI$2(10 \mu \mathrm{M})$, which partially (52\%) decreased UTP-induced Par-C10 cell aggregation (Fig. Appendix I-3A), whereas ADAM10/ADAM17 inhibition did not affect the EGF-induced increase in aggregation (Fig. Appendix I-3A). Consistent with the role of metalloproteases in the $\mathrm{P} 2 \mathrm{Y}_{2} \mathrm{R}$-mediated generation of EGFR agonists (94), ADAM10/ADAM17 inhibition decreased UTP-induced, but not EGF-induced, phosphorylation of the EGFR (Fig. Appendix I-3B). The partial loss of UTP-induced ParC10 cell aggregation by ADAM10/ADAM17 inhibition suggests that other $\mathrm{P}_{2} \mathrm{Y}_{2} \mathrm{R}$ mediated signaling pathways contribute to the cell aggregation response.

\section{Inhibition of the $\alpha_{5} \beta_{1}$ integrin/Cdc42 signaling pathway decreases UTP-induced Par-C10 cell aggregation and EGFR phosphorylation.}

The $\mathrm{P} 2 \mathrm{Y}_{2} \mathrm{R}$ contains an extracellular-oriented RGD sequence that interacts with RGDbinding integrins $(35)$ to activate Rho GTPases that regulate cell migration $(6,117)$. The RGD-binding $\alpha_{5} \beta_{1}$ integrin has been shown to regulate SMG branching morphogenesis (96) and stimulate migration of a variety of cell types $(16,22,42,51,69,73,115)$. To test whether UTP-induced Par-C10 cell migration and aggregation require activation of 
$\alpha_{5} \beta_{1}$ integrin, cells were pretreated with $\alpha_{5} \beta_{1}$ integrin function-blocking antibody (100 $\mathrm{mg} / \mathrm{ml}$ ) prior to addition of $100 \mu \mathrm{M} \mathrm{UTP}$. Results indicate that inhibition of $\alpha_{5} \beta_{1}$ integrin function decreased UTP-induced aggregation by $49 \%$, but had no effect on the EGFinduced response (Fig. Appendix I-4A). Integrin-dependent activation of the Rho GTPases Cdc42, Rac1, and RhoA has been shown to modulate cytoskeletal reorganization and cell migration, where there is a reciprocal relationship between Cdc42/Rac1 and RhoA activities $(32,75,97)$. Our results show that stimulation of ParC10 cells with $100 \mu \mathrm{M}$ UTP activates Cdc42 in a time-dependent manner (Fig. Appendix I- $4 B$, top $)$. Inhibition of Cdc42 with the selective antagonist ML141 $(10 \mu \mathrm{M})$ inhibited UTP-induced aggregation by $90 \%$ (Fig. Appendix I-4B, bottom) and inhibited the UTPinduced phosphorylation of EGFR to a similar extent (Fig. Appendix I-4D), but it had no effect on EGF-induced responses, which are independent of metalloproteases (Fig. Appendix I-3) and $\alpha_{5} \beta_{1}$ integrin/Cdc42 (Figs. Appendix I-4, $A, B$, and $D$ ). However, inhibition of RhoA with SR3677 $(10 \mu \mathrm{M})$ significantly increased basal cell aggregation by almost twofold and had no additional effect on the UTP- or the EGF-induced enhancement of Par-C10 cell aggregation (Fig. Appendix I-4C). Inhibition of Rac1 using NSC23766 $(100 \mu \mathrm{M})$ did not affect UTP-induced or basal Par-C10 cell aggregation (data not shown). These data suggest that the $\mathrm{P} 2 \mathrm{Y}_{2} \mathrm{R}$-mediated activation of the $\alpha_{5} \beta_{1}$ integrin/Cdc42 signaling pathway enhances the self-organization of Par-C10 cells into acinar-like spheres through the activation of the EGFR pathway. Moreover, these data show that RhoA plays an inhibitory role in the basal aggregation of dispersed Par-C10 cells. 
UTP-induced Par-C10 cell aggregation depends on the activation of JNK and ERK1/2.

The activation of the EGFR leads to downstream activation of the MAPKs ERK1/2 and JNK, a response shown to modulate cell migration (18). Initially, we determined that $\mathrm{P} 2 \mathrm{Y}_{2} \mathrm{R}$ activation with $100 \mu \mathrm{M}$ UTP stimulates the time-dependent phosphorylation of JNK and ERK1/2 in Par-C10 cells (Fig. Appendix I-5A). Inhibition of JNK with $10 \mu \mathrm{M}$ SP600125 or ERK1/2 with $10 \mu \mathrm{M}$ U0126, a MEK inhibitor, decreased UTP-induced ParC10 cell aggregation (Fig. Appendix I-5B), suggesting that JNK and ERK1/2 are regulators of Par-C10 acinar-like sphere formation. The EGFR pathway is apparently involved in the regulation of JNK- and ERK1/2-dependent Par-C10 cell aggregation induced by $100 \mu \mathrm{M}$ UTP, since inhibition of the EGFR with $1 \mu \mathrm{M}$ AG1478 (Fig. Appendix I-5C) significantly reduced UTP-induced JNK and ERK1/2 phosphorylation.

\section{UTP stimulates the migration of primary murine SMG cells from wild-type but not $\mathbf{P}_{2} \mathbf{R}^{-1-}$ mice.}

To test whether the UTP-induced salivary epithelial cell migration and aggregation are mediated by the $\mathrm{P} 2 \mathrm{Y}_{2} \mathrm{R}, \mathrm{SMGs}$ from wild-type and $\mathrm{P} 2 \mathrm{Y}_{2} \mathrm{R}^{-/-}$mice were isolated, enzymatically dispersed, and cultured for 3 days to allow for upregulation of the $\mathrm{P} 2 \mathrm{Y}_{2} \mathrm{R}$, as previously described (113). Similar to primary rat SMG cell aggregates (113), $\mathrm{P} 2 \mathrm{Y}_{2} \mathrm{R}$ mRNA expression is upregulated with time in cells cultured from wild-type mice (Fig. Appendix I-6A), consistent with an increase in the $\left[\mathrm{Ca}^{2+}\right]_{\mathrm{i}}$ induced by UTP in these cells (Fig. Appendix I-6B), responses not seen in SMG cell aggregates from $P 2 Y_{2} R^{-/-}$mice (data not shown). UTP $(100 \mu \mathrm{M})$ stimulated the migration of SMG cell aggregates from 
wild-type but not $P 2 Y_{2} R^{-/-}$mice (Fig. Appendix I-6C). UTP-induced migration of wildtype primary SMG cells occurred only during the first $4 \mathrm{~h}$, as indicated by the distance that cell aggregates traveled from the origin (Fig. Appendix I-6D), the total distance that cell aggregates migrated (Fig. Appendix I-6E), and an increase in the velocity of the cell aggregates (Fig. Appendix I-6F). A lack of these responses in SMG from $\mathrm{P}_{2} \mathrm{Y}_{2} \mathrm{R}^{-/-}$mice (Fig. Appendix I-6, $C-F$ ) confirms that UTP-induced SMG cell migration is mediated by $\mathrm{P}_{2} \mathrm{Y}_{2} \mathrm{R}$ activation. Furthermore, inhibition of EGFR with $1 \mu \mathrm{M}$ AG1478 impaired the UTP-induced migratory responses in wild-type primary SMG cells (Fig. Appendix I-7), corroborating our findings using Par-C10 cells that the $\mathrm{P} 2 \mathrm{Y}_{2} \mathrm{R}$-induced responses are dependent on EGFR activation.

\section{DISCUSSION}

Recent progress has been made in the development of strategies for regeneration and engineering of a variety of tissues, including skin $(79,92)$, corneal epithelium (43), cartilage (85), bone $(10,11)$, bladder (77), and lacrimal (48) and salivary glands (83). Determining the capacity of dispersed cells or tissue fragments to reassemble into native structures and the underlying mechanisms involved should provide novel insights to improve tissue regeneration approaches. The capacity of dispersed salivary epithelial cells or salivary gland-derived progenitor cells to reassemble into acinar-like spheres or branching structures has been previously assessed $(84,90,118)$, but little is known about the signaling events involved in these differentiation processes. In the present study, we determined that the $\mathrm{P} 2 \mathrm{Y}_{2}$ nucleotide receptor $\left(\mathrm{P} 2 \mathrm{Y}_{2} \mathrm{R}\right)$, known to be upregulated during salivary gland damage and disease $(1,99,113)$, plays a role in the aggregation and self- 
organization of dispersed salivary epithelial cells into acinar-like spheres. Our in vitro data using the rat parotid acinar (Par-C10) cell line show that $\mathrm{P}_{2} \mathrm{Y}_{2} \mathrm{R}$ activation by UTP significantly enhances the migration, aggregation, and self-organization of dispersed ParC10 cells into acinar-like spheres (Fig. Appendix I-1, $A-E$, and Supplemental Movies S1 and S2) that display structural features and differentiation markers similar to those of acini in the native gland (Fig. Appendix I-1F), as previously described (7). In addition, our ex vivo data show that $P 2 Y_{2} R$ deletion prevents the UTP-induced migration of primary murine SMG cell aggregates (Fig. Appendix I-6), demonstrating that UTPinduced migratory responses of salivary epithelial cells are primarily mediated by $\mathrm{P} 2 \mathrm{Y}_{2} \mathrm{R}$ activation.

In this paper, we demonstrate that UTP-induced enhancement of dispersed salivary epithelial cell aggregation occurs by two distinct signaling pathways coupled to activation of the $\mathrm{P} 2 \mathrm{Y}_{2} \mathrm{R}: 1$ ) the activation of metalloproteases (i.e., ADAM10/ADAM17) and 2) the activation of the $\alpha_{5} \beta_{1}$ integrin/Cdc42 Rho GTPase pathway, major signaling pathways that activate various physiological processes $(5,95,101,108,109,116,123$, 128). Both of these signaling pathways activate EGFR, which leads to the downstream activation of JNK and ERK1/2 that we demonstrate increases UTP-induced aggregation of Par-C10 cells. A schematic outlining these $\mathrm{P} 2 \mathrm{Y}_{2} \mathrm{R}$-mediated signaling pathways involved in salivary epithelial cell migration and aggregation is shown in Fig. Appendix I-8.

It is well-established that the EGFR and its signaling pathways are critical for stimulating cell migration and the regeneration of a variety of tissues $(30,37,57,58,81,91)$. In 
salivary tissue reconstitution studies, exogenous EGF has been shown to be crucial for the self-organization of dispersed salivary gland-derived progenitor cells into branching structures (84). Several studies have shown that $\mathrm{P} 2 \mathrm{Y}_{2} \mathrm{R}$ activation enhances epithelial cell migration, thereby accelerating wound healing and tissue regeneration $(9,12-14,26,62$, $68)$ in part due to transactivation of the EGFR $(12,14,62,68)$. Our group has previously shown that the $\mathrm{P} 2 \mathrm{Y}_{2} \mathrm{R}$ mediates transactivation of the EGFR in HSG cells through metalloprotease-dependent neuregulin release (94). In the present study, we demonstrate that the ADAM10/ADAM17/EGFR signaling pathway is required for $\mathrm{P} 2 \mathrm{Y}_{2} \mathrm{R}$-mediated aggregation of salivary epithelial cells (Figs. Appendix I-2, -3 and -8), suggesting $\mathrm{P}_{2} \mathrm{Y}_{2} \mathrm{R}$ as a potential therapeutic target for promoting salivary gland regeneration or the ex vivo bioengineering of salivary glands, which represent promising alternative approaches to replace the current ineffective therapies for hyposalivation resulting from SS or irradiation therapy for head and neck cancers.

In addition to metalloprotease-dependent activation of the EGFR, the $\mathrm{P} 2 \mathrm{Y}_{2} \mathrm{R}$ can activate EGFR through the $\alpha_{5} \beta_{1}$ integrin/Cdc42 signaling pathway (Fig. Appendix I-4). Our group has previously shown that the $\mathrm{P} 2 \mathrm{Y}_{2} \mathrm{R}$ contains an RGD motif in its first extracellular loop that enables receptor interaction with RGD-binding $\alpha_{\mathrm{V}} \beta_{3 / 5}$ integrins to stimulate cell migration $(6,26,64,117)$. However, $\mathrm{P}_{2} \mathrm{Y}_{2} \mathrm{R}$ interactions with other RGD-binding integrins have not been previously reported. In this study, we show for the first time that the $\alpha_{5} \beta_{1}$ integrin, a known mediator of SMG branching morphogenesis (96), cell migration, and tissue regeneration $(16,40-42,51,66,67,69,73,78,88,115,121,127)$, also plays a role in $\mathrm{P} 2 \mathrm{Y}_{2} \mathrm{R}$-mediated salivary epithelial cell aggregation (Fig. Appendix I$4 A$ ). We also have shown that the $\mathrm{P} 2 \mathrm{Y}_{2} \mathrm{R} / \alpha_{\mathrm{V}}$ integrin interaction leads to the activation of 
Rac (6), a Rho GTPase critical for regulating cell migration $(39,44-46,93,98)$, epithelial morphogenesis $(44,114)$, and salivary acinar formation $(23)$. In this study, we found no evidence that Rac1 is required for $\mathrm{P} 2 \mathrm{Y}_{2} \mathrm{R}$-mediated salivary epithelial cell aggregation (data not shown), but rather Cdc42, another Rho GTPase known to regulate cell migration $(38,39,44-46,93,98)$ and tissue regeneration $(89,126)$, regulates the aggregatory response to $\mathrm{P} 2 \mathrm{Y}_{2} \mathrm{R}$ activation (Fig. Appendix I-4B). Previous reports from our lab have linked $\mathrm{P} 2 \mathrm{Y}_{2} \mathrm{R}$-mediated cell migration to the activation of the Rho GTPase RhoA, as well as $\operatorname{Rac} 1(6,64,74,103)$. Interestingly, RhoA inhibition in Par-C10 salivary epithelial cells increased basal cell aggregation by almost twofold and had no additional effect on the UTP- or EGF-induced enhancement of cell aggregation (Fig. Appendix I-4C), suggesting that RhoA GTPase is a negative regulator of migratory responses in these cells. A reciprocal relationship between Cdc42 and RhoA has recently been described for mammary epithelial acinar morphogenesis (32). In contrast, another study has shown that inhibition of RhoA does not affect acinus formation by HSG cells (23).

It is well-established that MAPKs, including JNK and ERK1/2, regulate cell proliferation, migration, and differentiation $(15,18,21,36,63,72,86,102,120)$, processes important for salivary gland morphogenesis $(60,70)$ and regeneration of a wide variety of tissues $(19,24,50,53,54,56,65,71,80,100,105,107,111,122,124)$. The $\mathrm{P} 2 \mathrm{Y}_{2} \mathrm{R}$-mediated activation of ERK1/2 has been reported in HSG cells (94), corneal epithelial cells (13), and human coronary artery endothelial cells (HCAEC) (29). However, the ability of the $\mathrm{P} 2 \mathrm{Y}_{2} \mathrm{R}$ to activate JNK has only been reported for HCAEC (29) and primary rat hepatocytes (110). Our data indicate that the $\mathrm{P} 2 \mathrm{Y}_{2} \mathrm{R}$ agonist UTP 
activates JNK and ERK1/2 (Fig. Appendix I- 5A) through the canonical EGFR pathway (Fig. Appendix I-5C) to enhance salivary epithelial cell aggregation and self-organization (Fig. Appendix I-5B).

Growth factor receptors and integrins represent major signaling pathways that interact at different levels to regulate various physiological processes $(33,55)$. The present study indicates that the P2 $Y_{2} \mathrm{R}$ transactivates the EGFR through the $\alpha_{5} \beta_{1}$ integrin/Cdc42 signaling pathway as well as the activation of the metalloproteases ADAM10/ADAM17, enabling extracellular nucleotides to enhance the aggregation and self-organization of dispersed salivary epithelial cells into acinar-like spheres on GFR-Matrigel by increasing the activities of the MAPKs JNK and ERK1/2. Further work is needed to investigate whether other $\mathrm{P} 2 \mathrm{Y}_{2} \mathrm{R}$ signaling pathways are involved in acinar-like sphere formation, such as the activation of the MAPK p38 that has been reported to promote the regeneration of salivary glands (24), skeletal muscle (17), and sciatic nerve (61) and to regulate corneal epithelial wound healing (105). Other potential $\mathrm{P} 2 \mathrm{Y}_{2} \mathrm{R}$ signaling pathways involved in salivary epithelial cell migration include the activation of phosphatidylinositol-3-kinase (PI3-K)/protein kinase B (Akt) (117) and the $\mathrm{G}_{\mathrm{o}}$ signaling pathway (6). Understanding the signaling events responsible for the aggregation and selforganization of dispersed salivary epithelial cells into acinar-like spheres should provide insights into novel approaches for the bioengineering of salivary glands (83) and should lead to better regenerative/replacement strategies for salivary glands damaged in human autoimmune diseases or as an unintended side effect of radiation treatments for head and neck cancers. 


\section{GRANTS}

This project was supported by NIH/NIDCR Grant DE-007389. The content is solely the responsibility of the authors and does not necessarily represent the official views of the National Institute of Dental and Craniofacial Research or the National Institutes of Health or the National Institutes of Health.

\section{DISCLOSURES}

No conflicts of interest, financial or otherwise, are declared by the author(s).

\section{AUTHOR CONTRIBUTIONS}

F.G.E., J.M.C., L.T.W., L.E., and G.A.W. conceived and designed the research; F.G.E. and J.M.C. performed experiments; F.G.E. and J.M.C. analyzed data; F.G.E., J.M.C., L.T.W., M.G.K., M.J.P., L.E., and G.A.W. interpreted results of experiments; F.G.E. and J.M.C. prepared figures; F.G.E. and J.M.C. drafted manuscript; F.G.E., J.M.C., L.T.W., M.G.K., M.J.P., L.E., and G.A.W. edited and revised manuscript; F.G.E., J.M.C., L.T.W., M.G.K., M.J.P., L.E., and G.A.W. approved final version of manuscript. 


\section{FIGURES}

Fig. Appendix I-1. UTP enhances Par-C10 cell aggregation and the formation of acinar-like spheres on growth factor reduced (GFR) Matrigel. $A$ : Par-C10 single-cell suspensions were cultured on GFR-Matrigel for $4 \mathrm{~h}$, then treated with or without UTP $(100 \mu \mathrm{M})$ and monitored by time-lapse live cell imaging for $36 \mathrm{~h}$, as described in materials and methods. $B-D$ : the migration of single Par-C10 cells was monitored for $2 \mathrm{~h}$, and the distance migrated from the origin $(B)$, total distance traveled $(C)$, and average velocity of single cells $(D)$ were quantified with the tracking software provided with NISElements imaging software. The data represent the means \pm SE of results from at least 3 experiments. ${ }^{*} P<0.05$, significant increase over basal levels (two-tailed $t$-test). $E$ : quantification of the number of aggregation events in response to UTP (100 $\mu \mathrm{M})$ after 36 h. F: after 36 h, UTP-treated Par-C10 cell aggregates formed acinar-like spheres that display lumen formation and an organized distribution of the tight junction protein ZO-1 (red) detected by immunofluorescence using rabbit anti-ZO-1 antibody, as previously described (7), features not observed in the Par-C10 cell aggregates formed under basal conditions. $G$ : quantification of the aggregation events from $0-12 \mathrm{~h}, 12-24 \mathrm{~h}$, and 24-36 $\mathrm{h}$ indicates that the majority of aggregation events take place in the first $12 \mathrm{~h}$ with or without UTP treatment. The data shown represent the means $\pm \mathrm{SE}$ of results from at least 3 experiments. ${ }^{*} P<0.05$, significant increase over basal levels (two-tailed $t$-test). 
A

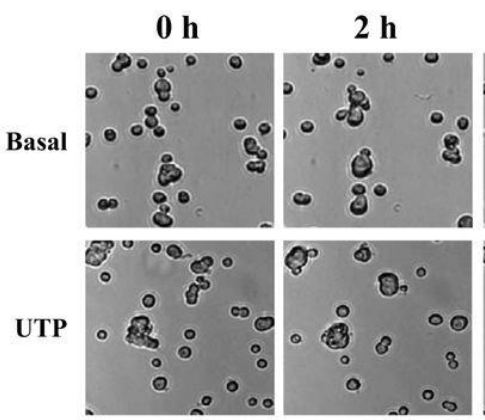

$6 \mathrm{~h}$

$12 \mathrm{~h}$

24 h

$36 \mathrm{~h}$
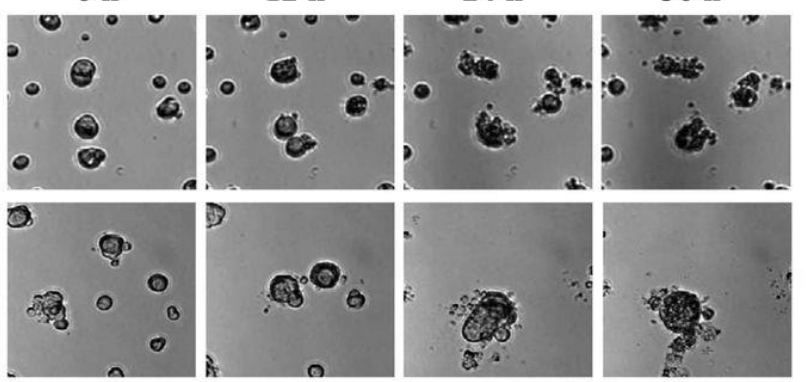

B

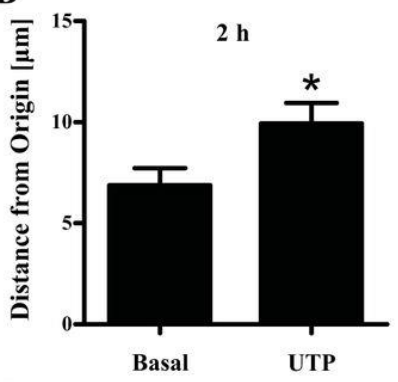

C
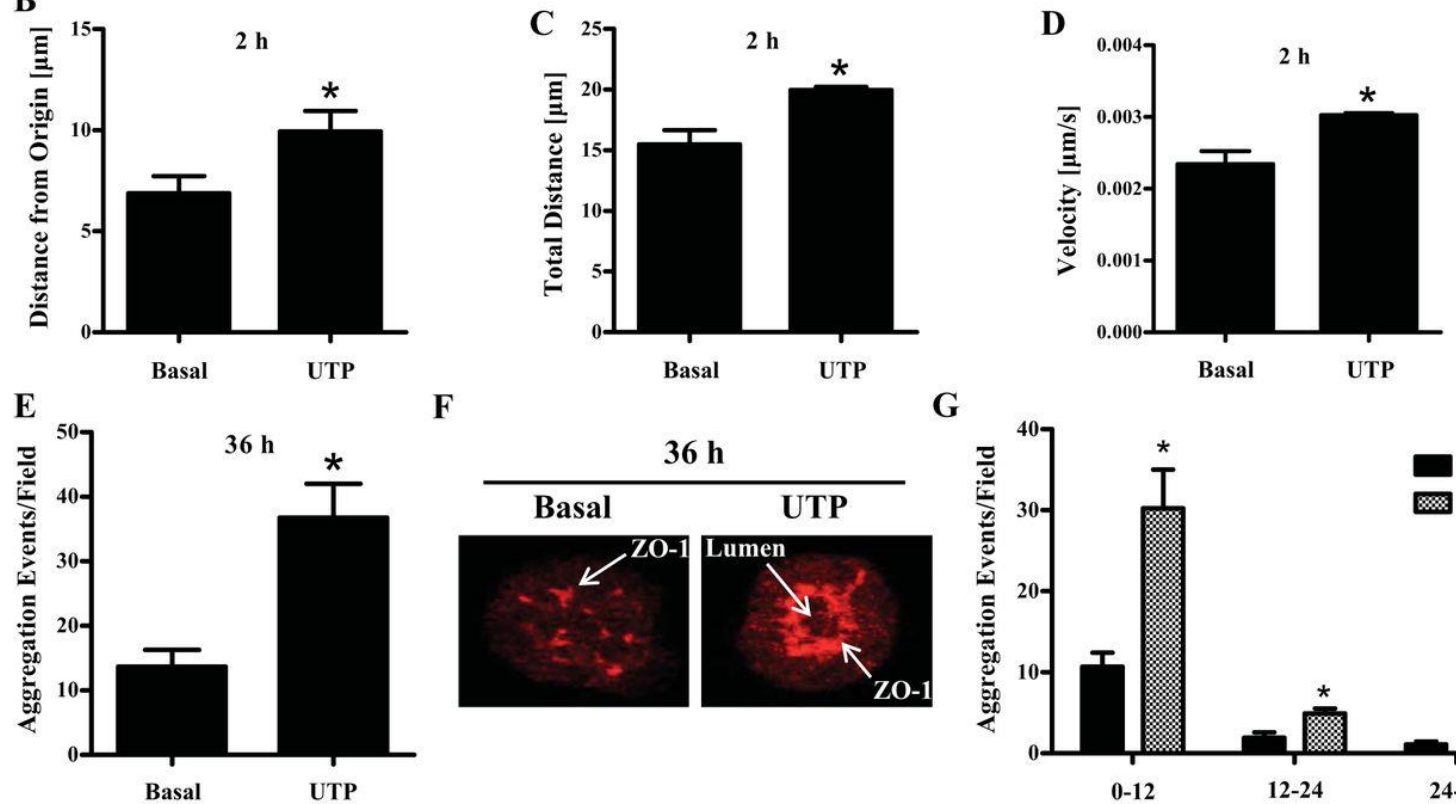

F

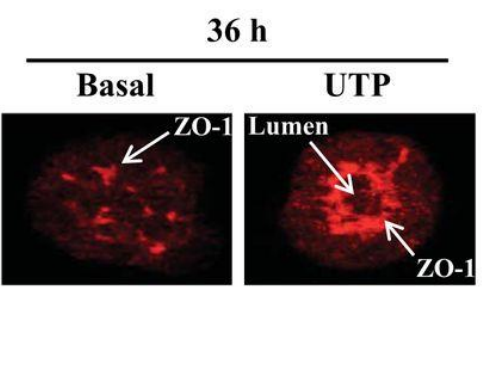

G

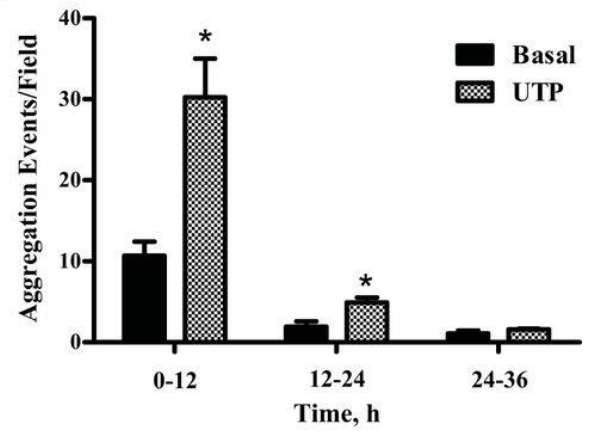


Fig. Appendix I-2. Inhibition of epidermal growth factor (EGF) receptor (EGFR) activation decreases UTP-induced enhancement of Par-C10 cell aggregation. A: ParC10 single-cell suspensions plated on GFR-Matrigel for $4 \mathrm{~h}$ were pretreated with or without the EGFR inhibitor AG1478 $(1 \mu \mathrm{M})$ for $2 \mathrm{~h}$, then incubated with or without UTP $(100 \mu \mathrm{M})$ or EGF $(100 \mathrm{ng} / \mathrm{ml})$. Par-C10 cell aggregates were monitored by time-lapse live cell imaging for $12 \mathrm{~h}$. The data are expressed as percentages of the maximal number of aggregation events induced by UTP or EGF in the absence of AG1478 and represent the means \pm SE of results from at least 3 experiments. ${ }^{* *} P<0.01, * * * P<0.001$, significant difference from the UTP- or EGF-induced response (two-tailed $t$-test). $B$ : ParC10 cells were serum-starved overnight, pretreated with or without AG1478 $(1 \mu \mathrm{M})$ for 2 $\mathrm{h}$, and then treated with or without UTP $(100 \mu \mathrm{M})$ or EGF $(100 \mathrm{ng} / \mathrm{ml})$. Five minutes after UTP or EGF addition, protein extracts were prepared from Par-C10 cell aggregates and EGFR phosphorylation (Y1068) was determined by Western analysis. Representative blots are shown (top). Quantification of protein levels in blots (bottom) was performed using Quantity One software, as described in materials and methods. The data are expressed as the percentage increase in EGFR phosphorylation induced by UTP or EGF, compared with untreated controls, and represent the means \pm SE of results from at least 3 experiments. ${ }^{*} P<0.05, * * * P<0.01$, significant difference from the UTP- or EGFinduced response (two-tailed $t$-test). 

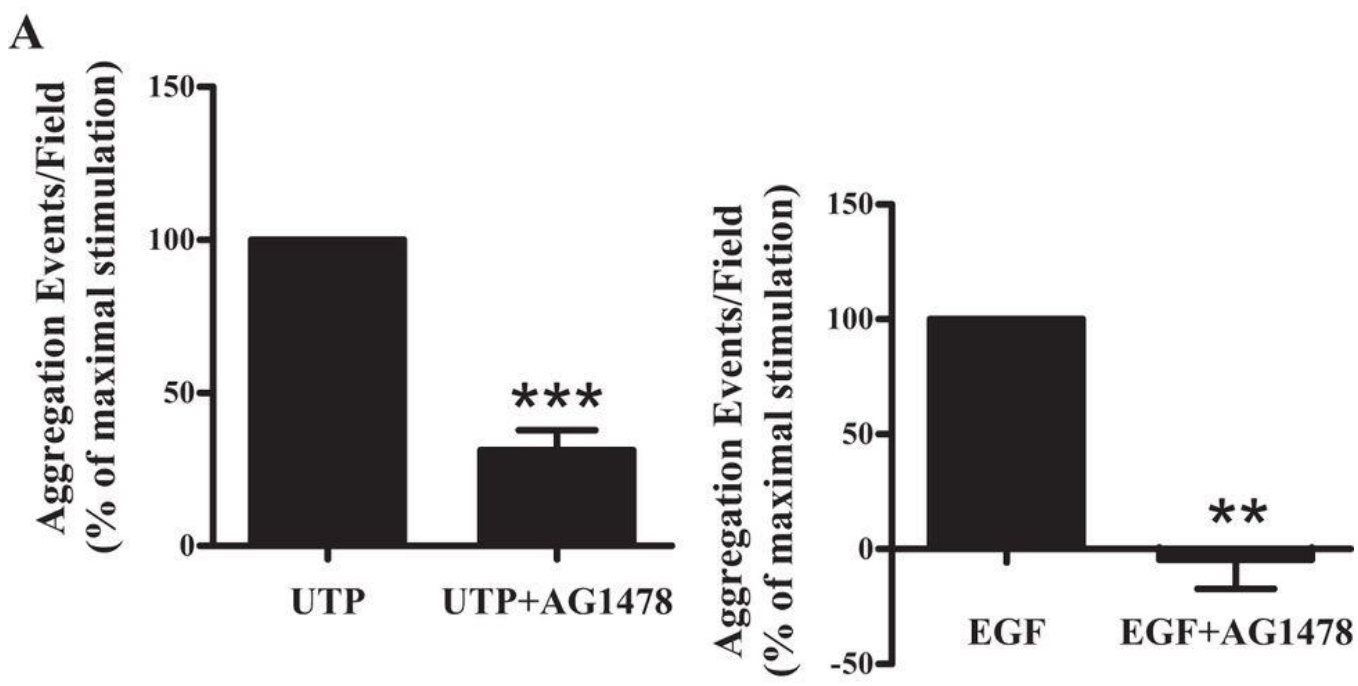

B

$$
\begin{aligned}
& \text { +AG1478 }
\end{aligned}
$$

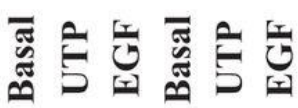

p-EGFR

(Y1068)

ERK1/2
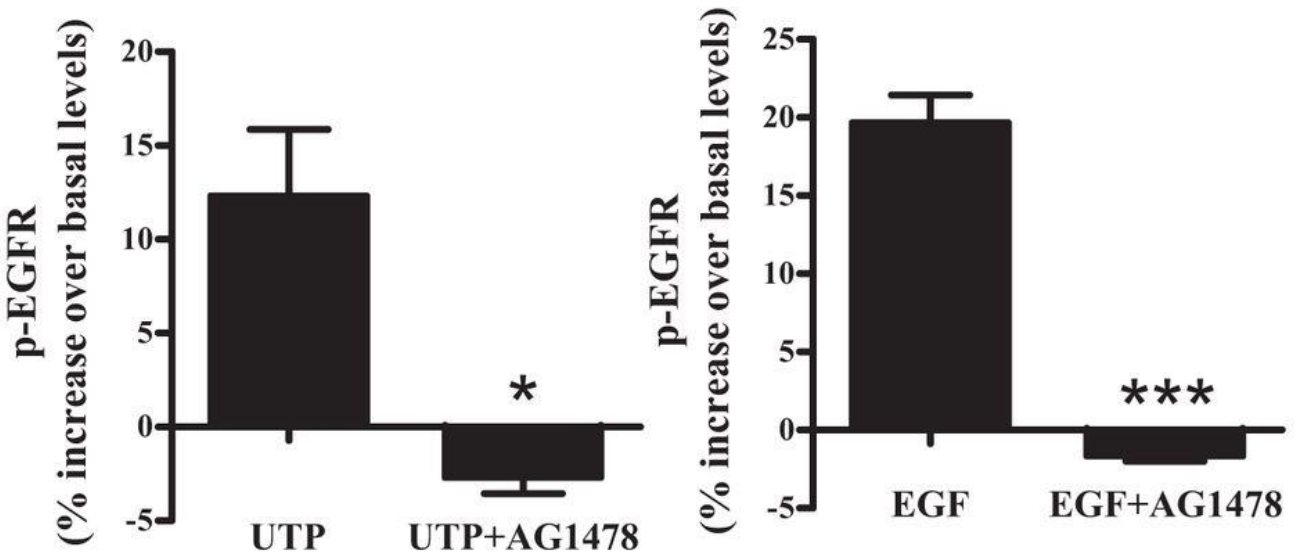
Fig. Appendix I-3. Inhibition of metalloproteases ADAM10/ADAM17 decreases UTP-induced enhancement of Par-C10 cell aggregation and EGFR phosphorylation. A: Par-C10 single-cell suspensions plated on GFR-Matrigel for $4 \mathrm{~h}$ were pretreated with or without the ADAM10/ADAM17 inhibitor TAPI-2 $(10 \mu \mathrm{M})$ for $2 \mathrm{~h}$, then incubated with or without UTP $(100 \mu \mathrm{M})$ or EGF $(100 \mathrm{ng} / \mathrm{ml})$. Par-C10 cell aggregates were monitored by time-lapse live cell imaging for $12 \mathrm{~h}$. The data are expressed as percentages of the maximal number of aggregation events induced by UTP or EGF in the absence of TAPI- 2 and represent the means \pm SE of results from at least 3 experiments. $* * * P<$ 0.001, significant difference from the UTP- or EGF-induced response (two-tailed $t$-test). $B$ : Par-C10 cells were serum-starved overnight, pretreated with or without TAPI-2 (10 $\mu \mathrm{M})$ for $2 \mathrm{~h}$, and then treated with or without UTP $(100 \mu \mathrm{M})$ or EGF $(100 \mathrm{ng} / \mathrm{ml})$. Five minutes after UTP or EGF addition, protein extracts were prepared from Par-C10 cell aggregates and EGFR phosphorylation (Y1068) was determined by Western analysis. Representative blots are shown (top), where a black line represents noncontiguous lanes from the same gel. Quantification of protein levels in blots (bottom) was performed using Quantity One software, as described in materials and methods. The data are expressed as the percentage increase in EGFR phosphorylation induced by UTP or EGF, compared with untreated controls, and represent the means \pm SE of results from at least 3 experiments. $* * P<0.01$, significant difference from the UTP- or EGF-induced response (two-tailed $t$-test). 
A
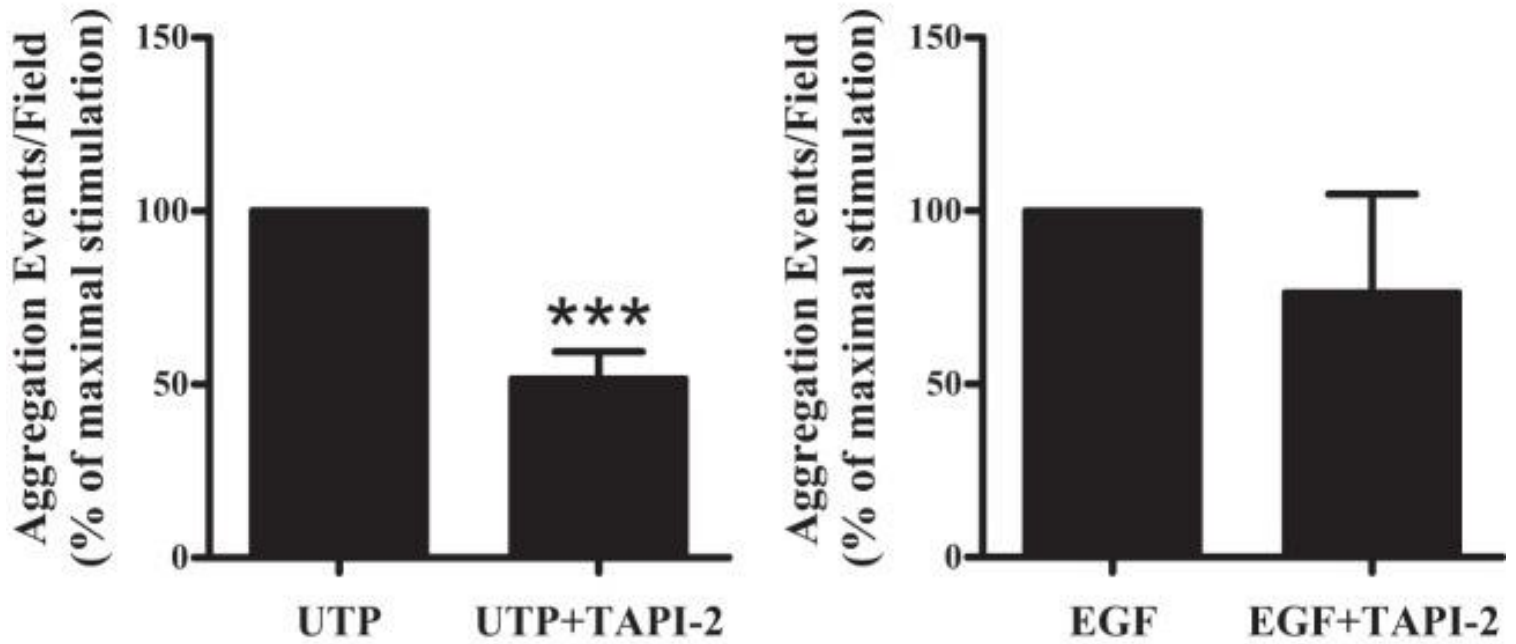

B

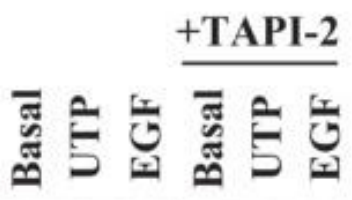

p-EGFR

(Y1068)

ERK1/2
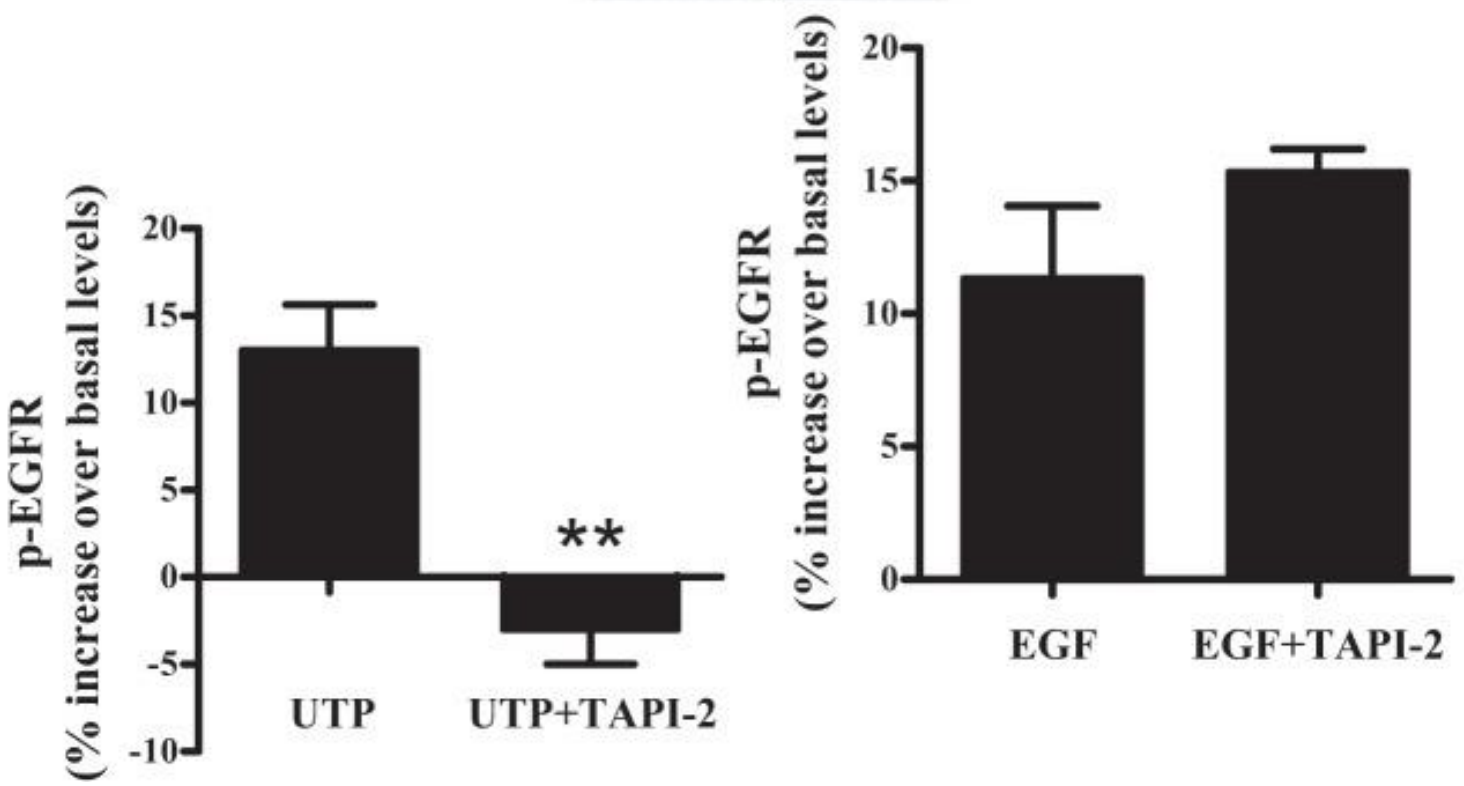
Fig. Appendix I-4. Inhibition of the $\alpha_{5} \beta_{1} / \mathrm{Cdc} 42$ signaling pathway decreases UTPinduced Par-C10 cell aggregation and EGFR phosphorylation, whereas RhoA inhibition increases basal cell aggregation. Par-C10 single-cell suspensions were plated on GFRMatrigel for $4 \mathrm{~h}$, pretreated for $2 \mathrm{~h}$ with or without $\alpha_{5} \beta_{1}$ integrin function-blocking antibody $(100 \mu \mathrm{g} / \mathrm{ml})(A)$, the Cdc42 inhibitor ML141 $(10 \mu \mathrm{M})(B$, bottom $)$, or the RhoA inhibitor SR3677 $(10 \mu \mathrm{M})(C)$. Cells were then treated with or without UTP $(100 \mu \mathrm{M})$ or EGF (100 ng/ml), as indicated, and cell aggregation was monitored by time-lapse live cell imaging for an additional $12 \mathrm{~h}$. The data are expressed as percentages of the maximal number of aggregation events induced by UTP or EGF $(A$ and $B)$ or the total number of aggregation events $(C)$. The data represent the means $\pm \mathrm{SE}$ of results from at least 3 experiments. $A$ and $B: * P<0.05, * * P<0.01$, significant difference from the UTP- or EGF-induced response (two-tailed $t$-test). $C$ : two-way ANOVA was performed followed by the Bonferroni test. ${ }^{*} P<0.05$, ${ }^{* *} P<0.01$, significant difference in the number of aggregation events between SR3677-treated and untreated cells under basal conditions or SR3677-treated cells stimulated with or without UTP or EGF, as indicated. B, top: GTP binding by $\mathrm{Cdc} 42$ was determined in serum-starved Par-C10 cells treated with or without UTP $(100 \mu \mathrm{M})$ for 1,5 , or $10 \mathrm{~min}$, as described in materials and methods. $D$ : Par-C10 cells were serum-starved overnight, pretreated with or without the Cdc42 inhibitor ML141 $(10 \mu \mathrm{M})$ for $2 \mathrm{~h}$, and then treated with or without UTP $(100 \mu \mathrm{M})$ or EGF (100 $\mathrm{ng} / \mathrm{ml}$ ) for $5 \mathrm{~min}$. EGFR phosphorylation (Y1068) was determined by Western analysis. A representative blot is shown (top), where a black line represents noncontiguous lanes from the same gel. Quantification of protein levels in blots (bottom) was performed using Quantity One software, as described in materials and methods. The data are expressed as 
the percentage increase in EGFR phosphorylation induced by UTP, compared with untreated controls, and represent the means \pm SE of results from at least 3 experiments. ${ }^{*} P<0.05$, significant difference from the UTP-induced response (two-tailed $t$-test).

A

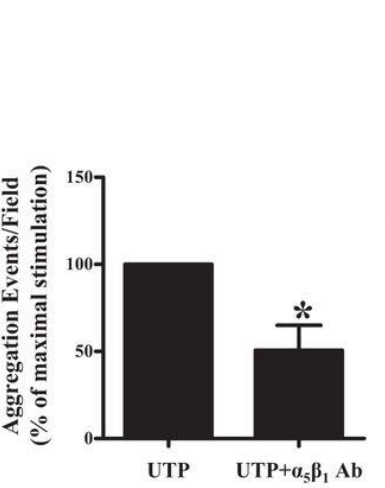

C

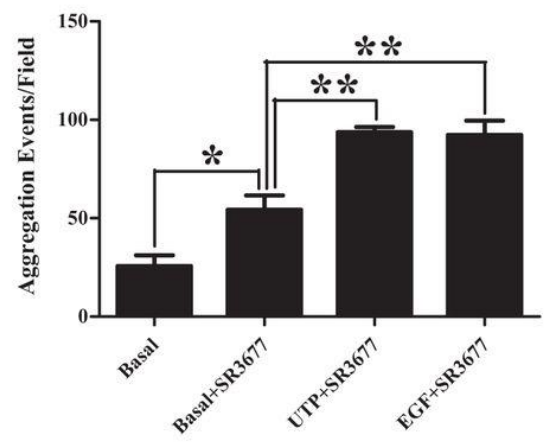

B
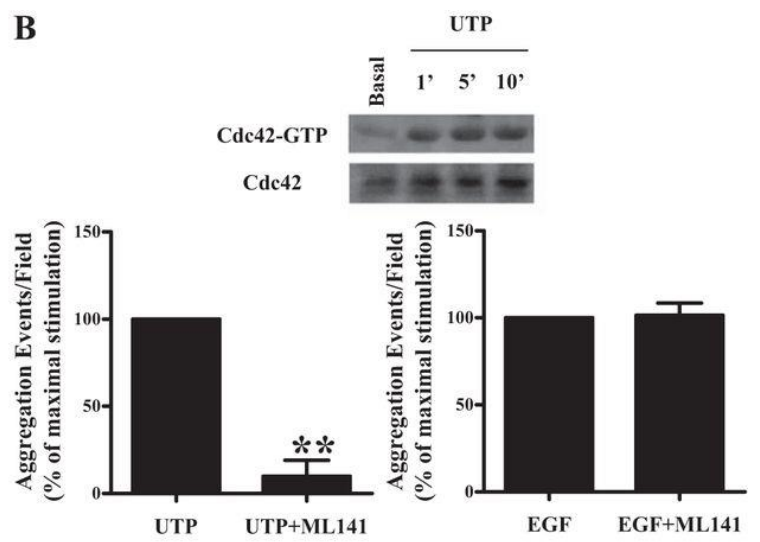

D
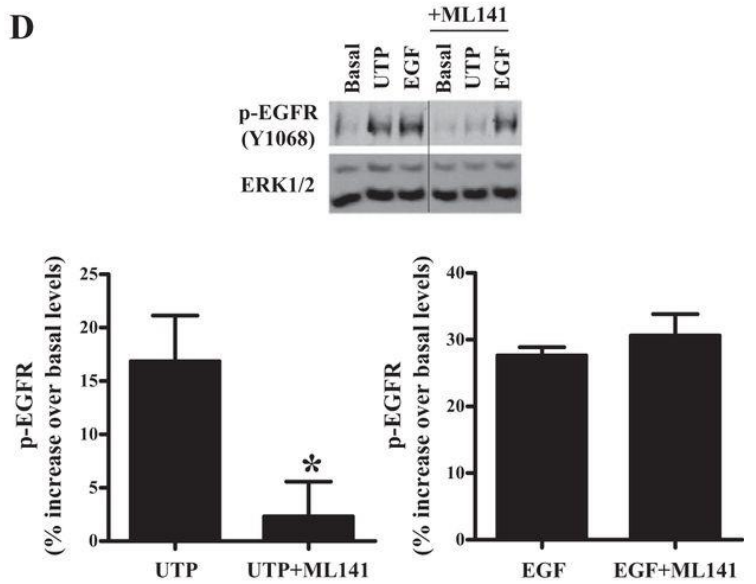
Fig. Appendix I-5. UTP-induced enhancement of Par-C10 cell aggregation is dependent on the activation of JNK and ERK1/2 by the EGFR. $A$ : Par-C10 cells were serum-starved overnight and treated with or without $100 \mu \mathrm{M}$ UTP for 1, 5, 10, or 15 min. Protein extracts were subjected to SDS-PAGE, and p-JNK (Thr183/Tyr185), p-ERK1/2 (Thr202/Tyr204), and ERK1/2 (loading control) were detected by Western analysis. $B$ : Par-C10 single-cell suspensions plated on GFR-Matrigel for $4 \mathrm{~h}$ were pretreated with or without the JNK inhibitor SP600125 $(10 \mu \mathrm{M})$ or the MEK/ERK inhibitor U0126 $(10 \mu \mathrm{M})$ for $2 \mathrm{~h}$. Cells were then treated with or without UTP $(100 \mu \mathrm{M})$, and cell aggregation was monitored by time-lapse live cell imaging for $12 \mathrm{~h}$. The data are expressed as percentages of the maximal number of aggregation events induced by UTP and represent the means \pm SE of results from at least 3 experiments. ${ }^{*} P<<0.01$, $* * * P<0.001$, significant difference from the UTP-induced response (two-tailed $t$-test). $C$ : Par-C10 cells were pretreated for $2 \mathrm{~h}$ with or without the EGFR inhibitor AG1478 $(1 \mu \mathrm{M})$ then treated with or without UTP $(100 \mu \mathrm{M})$ for 5 min. Protein extracts were subjected to SDS-PAGE, and p-JNK (Thr183/Tyr185), p-ERK1/2 (Thr202/Tyr204), and ERK1/2 (loading control) were detected by Western analysis (representative blots are shown on the left, where a black line represents noncontiguous lanes from the same gel). Quantification of protein levels was performed (right), as described in materials and methods. The data are expressed as the percentage increase in JNK (Thr183/Tyr185) and ERK1/2 (Thr202/Tyr204) phosphorylation induced by UTP, compared with untreated control, and represent the means $\pm \mathrm{SE}$ of results from at least 3 experiments. ${ }^{*} P<0.05$, $* * P<0.01$, significant difference from the UTP-induced response (two-tailed $t$-test). 

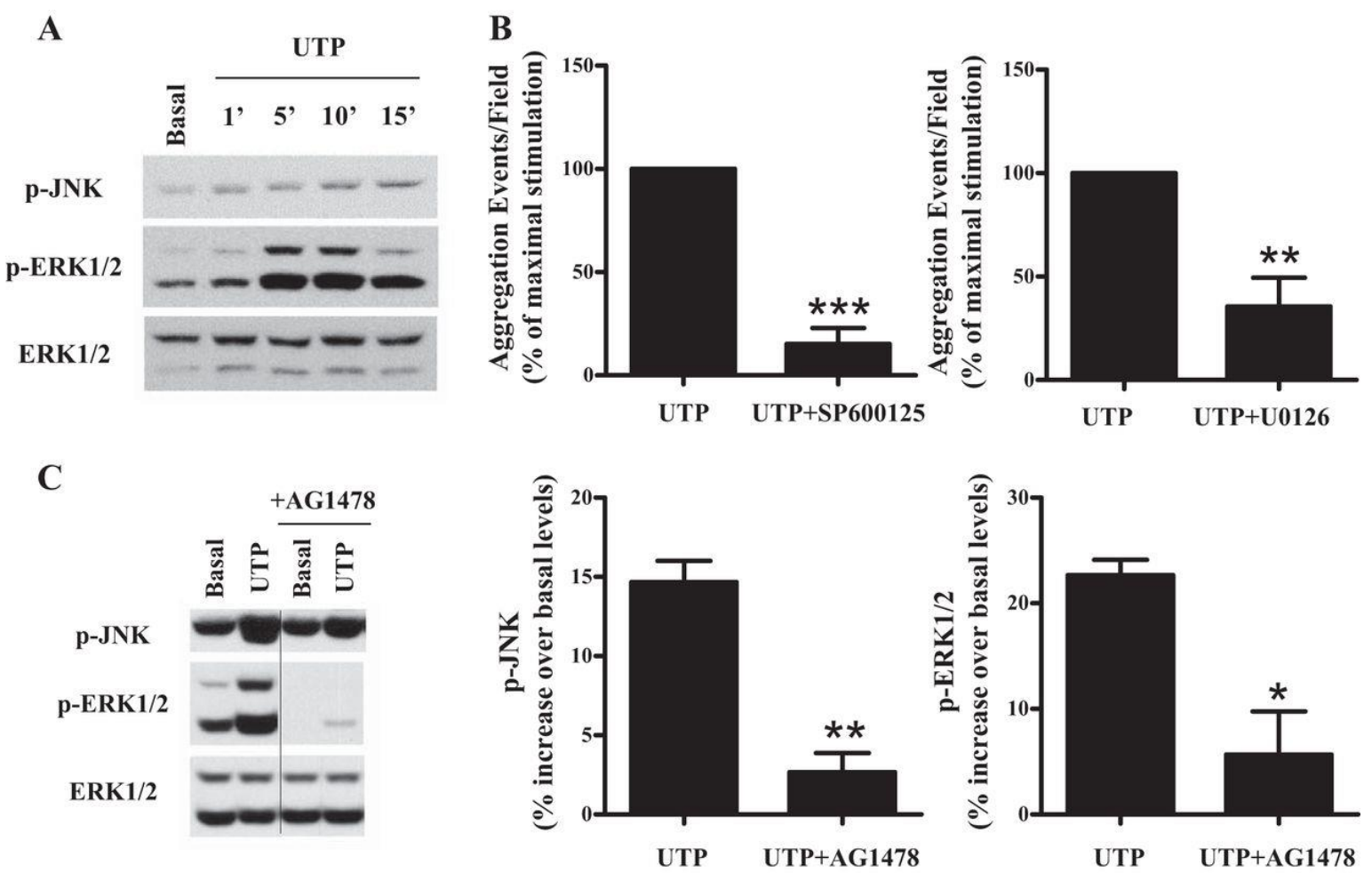
Fig. Appendix I-6. $\mathrm{P}_{2} \mathrm{Y}_{2}$ receptor $\left(\mathrm{P} 2 \mathrm{Y}_{2} \mathrm{R}\right)$ mediates UTP-induced migration of primary submandibular gland (SMG) cell aggregates. $A$ : $\mathrm{P} 2 \mathrm{Y}_{2} \mathrm{R}$ mRNA was isolated from SMG cell aggregates from wild-type and $\mathrm{P}_{2} \mathrm{Y}_{2} \mathrm{R}^{-/-}$mice after $0,24,48$, or $72 \mathrm{~h}$ in culture, as described in materials and methods. The data are expressed as fold increase in $\mathrm{P} 2 \mathrm{Y}_{2} \mathrm{R}$ mRNA levels over the 0 time point and represent the means of $\pm \mathrm{SE}$ of results from 4 experiments. ${ }^{*} P<0.05, * * * P<0.001$, significant increase in $\mathrm{P} 2 \mathrm{Y}_{2} \mathrm{R}$ mRNA expression, compared with the 0 time point (one-way ANOVA followed by Dunnett's test). $B$ : changes in the intracellular free $\mathrm{Ca}^{2+}$ concentration $\left(\left[\mathrm{Ca}^{2+}\right]_{\mathrm{i}}\right)$ induced by $100 \mu \mathrm{M}$ UTP in SMG cell aggregates at 0 and $72 \mathrm{~h}$ in culture were determined, as described in materials and methods. The data represent the means \pm SE of results from 7 experiments. *** $P<0.001$, significant difference from the 0 time point (two-tailed $t$-test). $C$ : primary SMGs isolated from wild-type and $\mathrm{P} 2 \mathrm{Y}_{2} \mathrm{R}^{-/-}$mice were enzymatically dispersed and incubated for 3 days $\left(37^{\circ} \mathrm{C}, 5 \% \mathrm{CO}_{2}\right.$, and $95 \%$ air) to enable upregulation of the $\mathrm{P} 2 \mathrm{Y}_{2} \mathrm{R}$. After 3 days, cells were serum-starved overnight, seeded on GFR-Matrigel for $8 \mathrm{~h}$, and treated with or without $100 \mu \mathrm{M}$ UTP. Cell aggregates of similar size were monitored by time-lapse live cell imaging for $24 \mathrm{~h}$, and the point of origin (arrow) and the migration path (red line) are indicated. $D-F$ : quantification of the distance migrated from the origin $(D)$, the total distance traveled $(E)$, and the average velocity $(F)$ of aggregates throughout the first $4 \mathrm{~h}$ of the time course was performed with the tracking software provided with NIS-Elements imaging software. The data represent the means \pm SE of results from at least 3 experiments. ${ }^{*} P<0.05$, significant increase over basal levels (two-tailed $t$-test). 
A

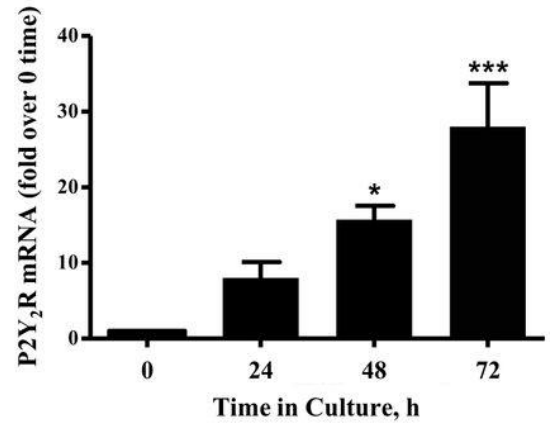

C

$24 \mathrm{~h}$

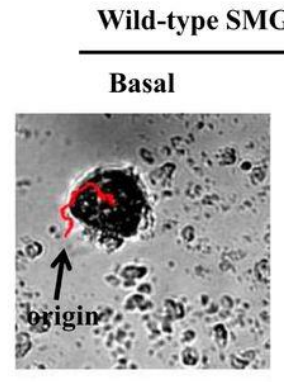

B

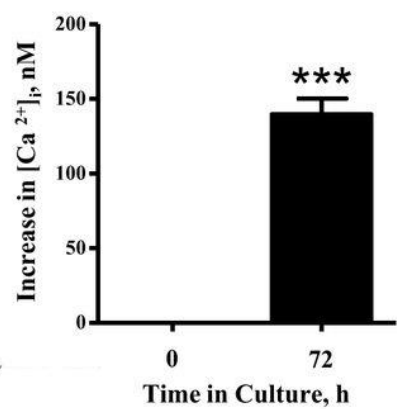

Time in Culture, $\mathrm{h}$

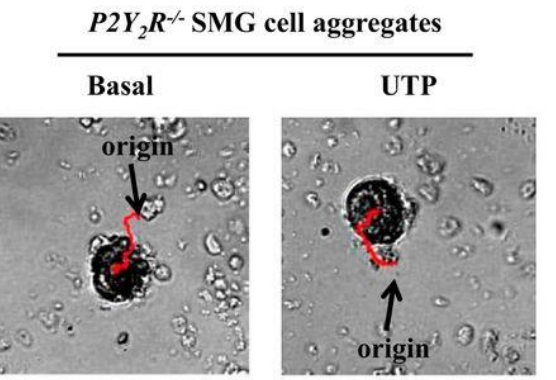

D

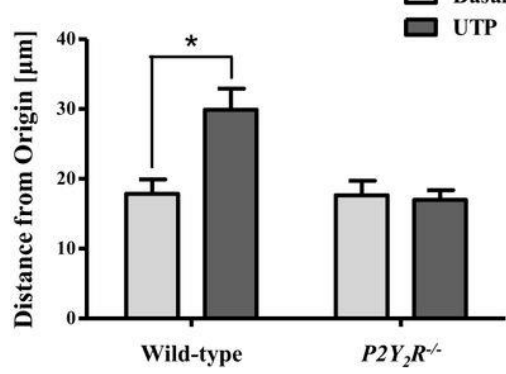

$\mathbf{E}$

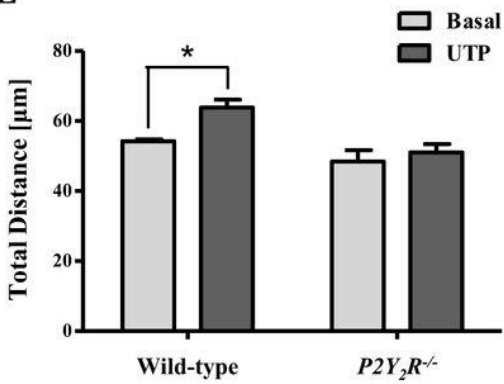

$\mathbf{F}$

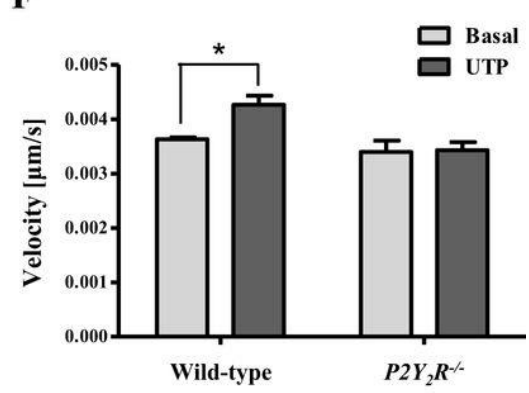


Fig. Appendix I-7. P2Y ${ }_{2} R$-induced migration of primary SMG cell aggregates is dependent on EGFR. Primary SMGs isolated from wild-type and $P 2 \mathrm{Y}_{2} R^{-/-}$mice were enzymatically dispersed and incubated for 3 days $\left(37^{\circ} \mathrm{C}, 5 \% \mathrm{CO}_{2}\right.$, and $95 \%$ air $)$ to enable upregulation of the $\mathrm{P} 2 \mathrm{Y}_{2} \mathrm{R}$. After 3 days, cells were serum-starved overnight, seeded on GFR-Matrigel for $8 \mathrm{~h}$, and pretreated for $2 \mathrm{~h}$ with or without the EGFR inhibitor AG1478 $(1 \mu \mathrm{M})$. Cells were then treated with or without UTP $(100 \mu \mathrm{M})$. Cell aggregates of similar size were monitored by time-lapse live cell imaging. Quantification of the distance migrated from the origin $(A)$, the total distance traveled $(B)$, and the average velocity $(C)$ of aggregates during the first $4 \mathrm{~h}$ of the time course was performed with the tracking software provided with NIS-Elements imaging software. The data represent the means \pm SE of results from at least 3 experiments. ${ }^{*} P<0.05$, significant decrease from basal levels (two-tailed $t$-test).
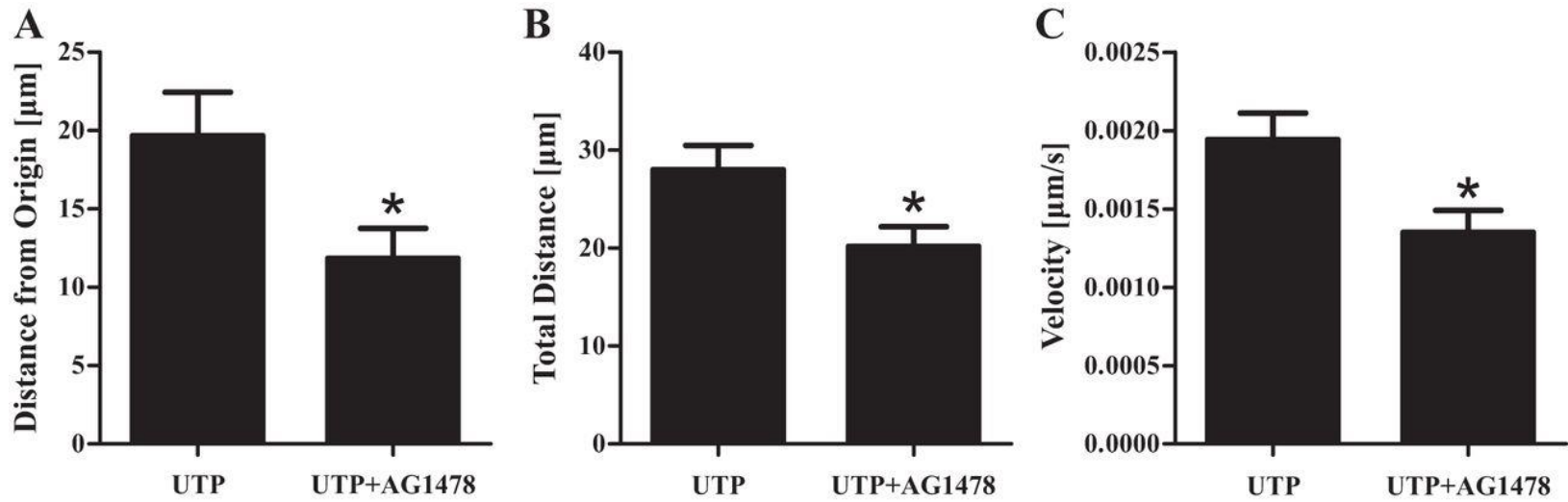
Fig. Appendix I-8. Proposed mechanisms for $\mathrm{P}_{2} \mathrm{Y}_{2} \mathrm{R}$-mediated enhancement of salivary epithelial cell aggregation and formation of acinar-like spheres. The $\mathrm{P} 2 \mathrm{Y}_{2} \mathrm{R}$ enhances the aggregation of dispersed salivary epithelial cells into acinar-like spheres through the activation of the EGFR and subsequent downstream activation of JNK and ERK1/2. P2Y ${ }_{2} \mathrm{R}$ mediates EGFR activation through two distinct pathways: the first pathway involves $\mathrm{P} 2 \mathrm{Y}_{2} \mathrm{R}$-mediated activation of matrix metalloproteases (i.e., ADAM10/ADAM17), which cleave membrane-bound EGFR ligands (94) leading to the activation of the EGFR, and the second pathway involves $\mathrm{P} 2 \mathrm{Y}_{2} \mathrm{R}$-mediated activation of the Arg-Gly-Asp (RGD) binding $\alpha_{5} \beta_{1}$ integrin, which leads to activation of the Rho GTPase Cdc42 that also activates the EGFR. RhoA activation has an inhibitory effect on the basal aggregation of dispersed Par-C10 salivary epithelial cells. $\mathrm{P} 2 \mathrm{Y}_{2} \mathrm{R}, \mathrm{P} 2 \mathrm{Y}_{2}$ receptor; ADAM, a disintegrin and metalloproteinase; GFR, growth factor receptor; NRG, neuregulin; EGFR, epidermal growth factor receptor; RhoA, Ras homolog gene family member A; Cdc42, cell division control protein 42 homolog. 


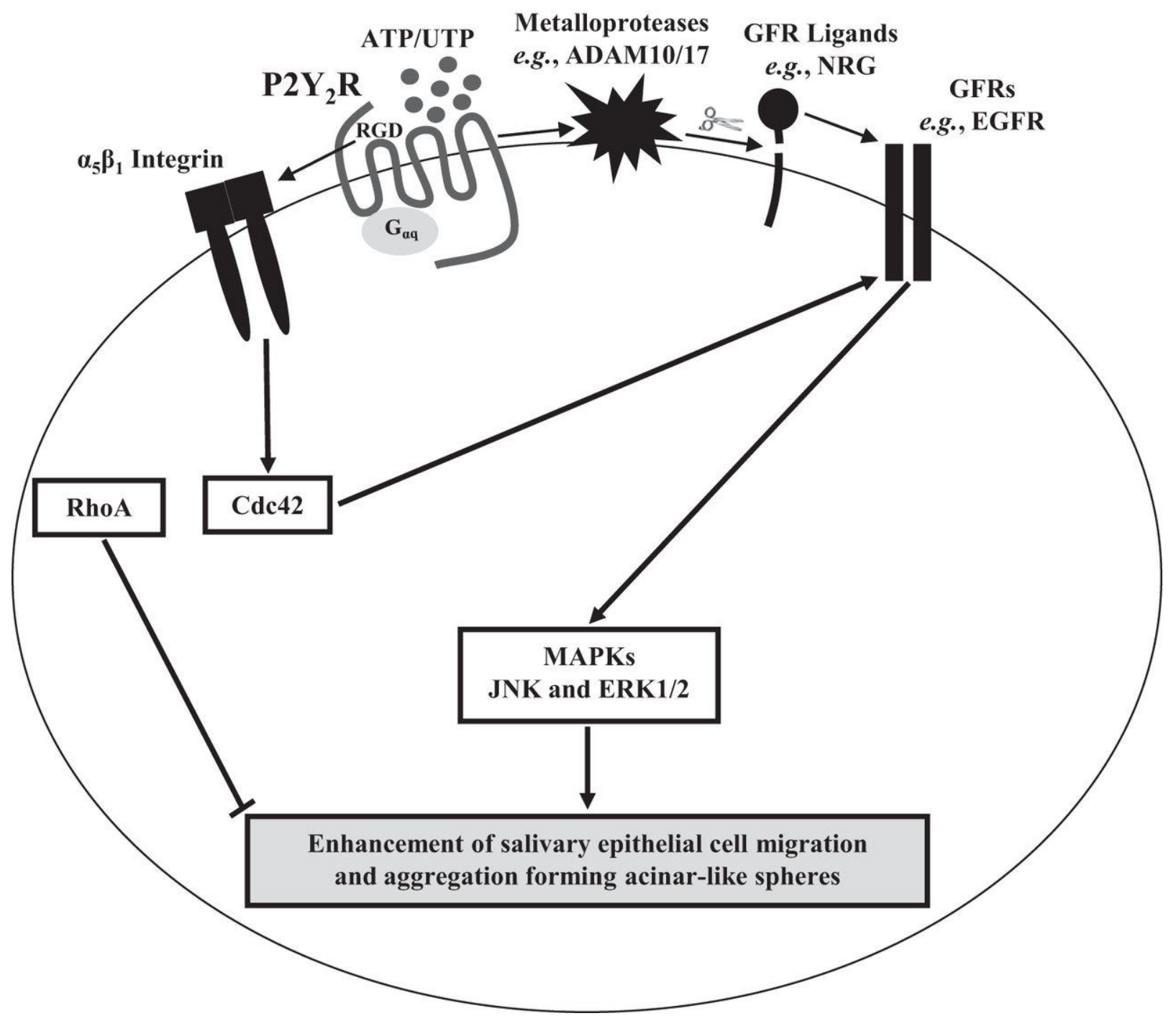




\section{REFERENCES}

1. Ahn JS, Camden JM, Schrader AM, Redman RS, Turner JT. Reversible regulation of $\mathrm{P} 2 \mathrm{Y}_{2}$ nucleotide receptor expression in the duct-ligated rat submandibular gland. Am J Physiol Cell Physiol 279: C286-C294, 2000.

2. Atkinson J, Fox P. Salivary gland dysfunction. Clin Geriatr Med 8: 499-511, 1992.

3. Atkinson JC, Baum BJ. Salivary enhancement: current status and future therapies. J Dent Educ 65: 1096-1101, 2001.

4. Atkinson JC, Wu AJ. Salivary gland dysfunction: causes, symptoms, treatment. J Am Dent Assoc 125: 409-416, 1994.

5. Auer KL, Contessa J, Brenz-Verca S, Pirola L, Rusconi S, Cooper G, Abo A, Wymann MP, Davis RJ, Birrer M. The Ras/Rac1/Cdc42/SEK/JNK/c-Jun cascade is a key pathway by which agonists stimulate DNA synthesis in primary cultures of rat hepatocytes. Mol Biol Cell 9: 561-573, 1998.

6. Bagchi S, Liao Z, Gonzalez FA, Chorna NE, Seye CI, Weisman GA, Erb L. The P2Y 2 nucleotide receptor interacts with $\alpha_{V}$ integrins to activate $G_{o}$ and induce cell migration. J Biol Chem 280: 39050-39057, 2005.

7. Baker OJ, Schulz DJ, Camden JM, Liao Z, Peterson TS, Seye CI, Petris MJ, Weisman GA. Rat parotid gland cell differentiation in three-dimensional culture. Tissue Eng Part C Methods 16: 1135-1144, 2010.

8. Beldi G, Enjyoji K, Wu Y, Miller L, Banz Y, Sun X, Robson SC. The role of purinergic signaling in the liver and in transplantation: effects of extracellular nucleotides on hepatic graft vascular injury, rejection and metabolism. Front Biosci 13: 2588-2603, 2008. 
9. Belete HA, Hubmayr RD, Wang S, Singh RD. The role of purinergic signaling on deformation induced injury and repair responses of alveolar epithelial cells. PLos One 6: e27469, 2011.

10. Bhumiratana S, Vunjak-Novakovic G. Concise review: personalized human bone grafts for reconstructing head and face. Stem Cells Transl Med 1: 64-69, 2012.

11. Boeckel DG, Shinkai RSA, Grossi ML, Teixeira ER. Cell culture-based tissue engineering as an alternative to bone grafts in implant dentistry: a literature review. J Oral Implantol 38 Spec No: 538-545, 2012.

12. Boucher I, Kehasse A, Marcincin M, Rich C, Rahimi N, Trinkaus-Randall V. Distinct activation of epidermal growth factor receptor by UTP contributes to epithelial cell wound repair. Am J Pathol 178: 1092-1105, 2011.

13. Boucher I, Rich C, Lee A, Marcincin M, Trinkaus-Randall V. The P2Y2 receptor mediates the epithelial injury response and cell migration. Am J Physiol Cell Physiol 299: C411-C421, 2010.

14. Boucher I, Yang L, Mayo C, Klepeis V, Trinkaus-Randall V. Injury and nucleotides induce phosphorylation of epidermal growth factor receptor: MMP and HB-EGF dependent pathway. Exp Eye Res 85: 130-141, 2007.

15. Cargnello M, Roux PP. Activation and function of the MAPKs and their substrates, the MAPK-activated protein kinases. Microbiol Mol Biol Rev 75: 50-83, 2011.

16. Caswell PT, Spence HJ, Parsons M, White DP, Clark K, Cheng KW, Mills GB, Humphries MJ, Messent AJ, Anderson KI, McCaffrey MW, Ozanne BW, Norman JC. Rab25 associates with $\alpha_{5} \beta_{1}$ integrin to promote invasive migration in threedimensional microenvironments. Dev Cell 13: 496-510, 2007. 
17. Chen SE, Jin B, Li YP. TNF- $\alpha$ regulates myogenesis and muscle regeneration by activating p38 MAPK. Am J Physiol Cell Physiol 292: C1660-C1671, 2007.

18. Chen Z, Gibson TB, Robinson F, Silvestro L, Pearson G, Xu BE, Wright A, Vanderbilt C, Cobb MH. MAP kinases. Chem Rev 101: 2449-2476, 2001.

19. Chierzi S, Ratto GM, Verma P, Fawcett JW. The ability of axons to regenerate their growth cones depends on axonal type and age, and is regulated by calcium, cAMP and ERK. Eur J Neurosci 21: 2051-2062, 2005.

20. Cohen R, Shainberg A, Hochhauser E, Cheporko Y, Tobar A, Birk E, Pinhas L, Leipziger J, Don J, Porat E. UTP reduces infarct size and improves mice heart function after myocardial infarct via $\mathrm{P}_{2} \mathrm{Y}_{2}$ receptor. Biochem Pharmacol 82: 1126$1133,2011$.

21. Coso OA. Signaling from the small GTP-binding proteins Rac1 and Cdc42 to the cJun N-terminal kinase/stress-activated protein kinase pathway. A role for mixed lineage kinase 3/protein-tyrosine kinase 1, a novel member of the mixed lineage kinase family. J Biol Chem 271: 27225-27228, 1996.

22. Cox EA, Sastry SK, Huttenlocher A. Integrin-mediated adhesion regulates cell polarity and membrane protrusion through the Rho family of GTPases. Mol Biol Cell 12: 265-277, 2001.

23. Crema VO, Hamassaki DE, Santos MF. Small Rho GTPases are important for acinus formation in a human salivary gland cell line. Cell Tissue Res 325: 493-500, 2006.

24. Dang H, Elliott JJ, Lin AL, Zhu B, Katz MS, Yeh CK. Mitogen-activated protein kinase upregulation and activation during rat parotid gland atrophy and 
regeneration: role of epidermal growth factor and $\beta 2$-adrenergic receptors.

Differentiation 76: 546-557, 2008.

25. De Almeida PDV, Gregio A, Machado M, De Lima A, Azevedo LR. Saliva composition and functions: a comprehensive review. J Contemp Dent Pract 9: 72 80, 2008.

26. Degagné E, Degrandmaison J, Grbic DM, Vinette V, Arguin G, Gendron FP. P2Y 2 receptor promotes intestinal microtubule stabilization and mucosal re-epithelization in experimental colitis. J Cell Physiol 228: 99-109, 2013.

27. Degagné E, Grbic DM, Dupuis AA, Lavoie EG, Langlois C, Jain N, Weisman GA, Sévigny J, Gendron FP. P2Y 2 receptor transcription is increased by NF- $\mathrm{kB}$ and stimulates cyclooxygenase-2 expression and PGE2 released by intestinal epithelial cells. J Immunol 183: 4521-4529, 2009.

28. Delporte C, O'Connell BC, He X, Lancaster HE, O'Connell AC, Agre P, Baum BJ. Increased fluid secretion after adenoviral-mediated transfer of the aquaporin-1 cDNA to irradiated rat salivary glands. Proc Natl Acad Sci USA 94: 3268-3273, 1997.

29. Ding L, Ma W, Littmann T, Camp R, Shen J. The $\mathrm{P}_{2} \mathrm{Y}_{2}$ nucleotide receptor mediates tissue factor expression in human coronary artery endothelial cells. J Biol Chem 286: 27027-27038, 2011.

30. Dise RS, Frey MR, Whitehead RH, Polk DB. Epidermal growth factor stimulates Rac activation through Src and phosphatidylinositol 3-kinase to promote colonic epithelial cell migration. Am J Physiol Gastrointest Liver Physiol 294: G276-G285, 2008. 
31. Dodds MW, Johnson DA, Yeh CK. Health benefits of saliva: a review. J Dent 33: 223-233, 2005.

32. Duan L, Chen G, Virmani S, Ying G, Raja SM, Chung BM, Rainey MA, Dimri M, Ortega-Cava CF, Zhao X, Clubb RJ, Tu C, Reddi AL, Naramura M, Band V, Band H. Distinct roles for Rho versus Rac/Cdc42 GTPases downstream of Vav2 in regulating mammary epithelial acinar architecture. J Biol Chem 285: 1555-1568, 2010.

33. Eliceiri BP. Integrin and growth factor receptor crosstalk. Circ Res 89: 1104-1110, 2001.

34. Erb L, Liao Z, Seye CI, Weisman GA. P2 receptors: intracellular signaling. Pflügers Arch 452: 552-562, 2006.

35. Erb L, Liu J, Ockerhausen J, Kong Q, Garrad RC, Griffin K, Neal C, Krugh B, Santiago-Pérez LI, González FA. An RGD sequence in the $\mathrm{P} 2 \mathrm{Y}_{2}$ receptor interacts with $\alpha_{v} \beta_{3}$ integrins and is required for $G_{0}$-mediated signal transduction. J Cell Biol 153: 491-502, 2001.

36. Fanger GR, Johnson NL, Johnson GL. MEK kinases are regulated by EGF and selectively interact with Rac/Cdc42. EMBO J 16: 4961-4972, 1997.

37. Frey MR, Golovin A, Polk DB. Epidermal growth factor-stimulated intestinal epithelial cell migration requires Src family kinase-dependent p38 MAPK signaling. J Biol Chem 279: 44513-44521, 2004.

38. Friesland A, Zhao Y, Chen YH, Wang L, Zhou H, Lu Q. Small molecule targeting Cdc42-intersectin interaction disrupts Golgi organization and suppresses cell motility. Proc Natl Acad Sci USA 110: 1261-1266, 2013. 
39. Fukata M, Nakagawa M, Kaibuchi K. Roles of Rho-family GTPases in cell polarisation and directional migration. Curr Opin Cell Biol 15: 590-597, 2003.

40. Gardiner NJ. Integrins and the extracellular matrix: key mediators of development and regeneration of the sensory nervous system. Dev Neurobiol 71: 1054-1072, 2011.

41. Giros A, Grgur K, Gossler A, Costell M. $\alpha_{5} \beta_{1}$ integrin-mediated adhesion to fibronectin is required for axis elongation and somitogenesis in mice. PLos One 6: e22002, 2011.

42. Gleeson LM, Chakraborty C, McKinnon T, Lala PK. Insulin-like growth factorbinding protein 1 stimulates human trophoblast migration by signaling through $\alpha_{5} \beta_{1}$ integrin via mitogen-activated protein kinase pathway. J Clin Endocrinol Metab 86: 2484-2493, 2001.

43. Griffith M, Polisetti N, Kuffova L, Gallar J, Forrester J, Vemuganti GK, Fuchsluger TA. Regenerative approaches as alternatives to donor allografting for restoration of corneal function. Ocul Surf 10: 170-183, 2012.

44. Hall A. Rho family GTPases. Biochem Soc Trans 40: 1378-1382, 2012.

45. Hall A. Rho GTPases and the actin cytoskeleton. Science 279: 509-514, 1998.

46. Hanna S, El-Sibai M. Signaling networks of Rho GTPases in cell motility. Cell Signal 25: 1955-1961, 2013.

47. Herbst RS. Review of epidermal growth factor receptor biology. Int J Radiat Oncol Biol Phys 59: 21-26, 2004.

48. Hirayama M, Ogawa M, Oshima M, Sekine Y, Ishida K, Yamashita K, Ikeda K, Shimmura S, Kawakita T, Tsubota K, Tsuji T. Functional lacrimal gland 
regeneration by transplantation of a bioengineered organ germ. Nat Commun 4: 2497, 2013.

49. Hoffman MP, Kibbey MC, Letterio JJ, Kleinman HK. Role of laminin-1 and TGF$\beta 3$ in acinar differentiation of a human submandibular gland cell line (HSG). J Cell Sci 109: 2013-2021, 1996.

50. Hollis ER, 2nd, Jamshidi P, Low K, Blesch A, Tuszynski MH. Induction of corticospinal regeneration by lentiviral trkB-induced ERK activation. Proc Natl Acad Sci USA 106: 7215-7220, 2009.

51. Hotchkiss KA, Ashton AW, Schwartz EL. Thymidine phosphorylase and 2deoxyribose stimulate human endothelial cell migration by specific activation of the integrins $\alpha_{5} \beta_{1}$ and $\alpha_{v} \beta_{3}$. J Biol Chem 278: 19272-19279, 2003.

52. Humphrey SP, Williamson RT. A review of saliva: normal composition, flow, and function. J Prosthet Dent 85: 162-169, 2001

53. Iimuro Y, Fujimoto J. TLRs, NF-אB, JNK, and liver regeneration. Gastroenterol Res Pract 2010: 598109, 2010.

54. Ishizuka S, Yano T, Hagiwara K, Sone M, Nihei H, Ozasa H, Horikawa S. Extracellular signal-regulated kinase mediates renal regeneration in rats with myoglobinuric acute renal injury. Biochem Biophys Res Commun 254: 88-92, 1999.

55. Ivaska J, Heino J. Cooperation between integrins and growth factor receptors in signaling and endocytosis. Annu Rev Cell Dev Biol 27: 291-320, 2011. 
56. Javelaud D, Laboureau J, Gabison E, Verrecchia F, Mauviel A. Disruption of basal JNK activity differentially affects key fibroblast functions important for wound healing. J Biol Chem 278: 24624-24628, 2003.

57. Jorissen R. Epidermal growth factor receptor: mechanisms of activation and signalling. Exp Cell Res 284: 31-53, 2003.

58. Joslin EJ, Opresko LK, Wells A, Wiley HS, Lauffenburger DA. EGF-receptormediated mammary epithelial cell migration is driven by sustained ERK signaling from autocrine stimulation. J Cell Sci 120: 3688-3699, 2007.

59. Kagami H, Wang S, Hai B. Restoring the function of salivary glands. Oral Dis 14: 15-24, 2008.

60. Kashimata M, Sayeed S, Ka A, Onetti-Muda A, Sakagami H, Faraggiana T, Gresik EW. The ERK-1/2 signaling pathway is involved in the stimulation of branching morphogenesis of fetal mouse submandibular glands by EGF. Dev Biol 220: 183196, 2000.

61. Kato N, Matsumoto M, Kogawa M, Atkins GJ, Findlay DM, Fujikawa T, Oda H, Ogata M. Critical role of p38 MAPK for regeneration of the sciatic nerve following crush injury in vivo. J Neuroinflammation 10: 1, 2013.

62. Kehasse A, Rich CB, Lee A, McComb ME, Costello CE, Trinkaus-Randall V. Epithelial wounds induce differential phosphorylation changes in response to purinergic and EGF receptor activation. Am J Pathol 183: 1841-1852, 2013.

63. Keshet Y, Seger R. The MAP kinase signaling cascades: a system of hundreds of components regulates a diverse array of physiological functions. Methods Mol Biol 661: 3-38, 2010. 
64. Kim HJ, Ajit D, Peterson TS, Wang Y, Camden JM, Gibson Wood W, Sun GY, Erb L, Petris M, Weisman GA. Nucleotides released from $A \beta_{1-42}$-treated microglial cells increase cell migration and $A \beta_{1-42}$ uptake through $\mathrm{P} 2 \mathrm{Y}_{2}$ receptor activation. $\mathrm{J}$ Neurochem 121: 228-238, 2012.

65. Kim M, McGinnis W. Phosphorylation of Grainy head by ERK is essential for wound-dependent regeneration but not for development of an epidermal barrier. Proc Natl Acad Sci USA 108: 650-655, 2011.

66. Kiwanuka E, Andersson L, Caterson EJ, Junker JP, Gerdin B, Eriksson E. CCN2 promotes keratinocyte adhesion and migration via integrin $\alpha_{5} \beta_{1}$. Exp Cell Res 319: 2938-2946, 2013.

67. Klein S, de Fougerolles AR, Blaikie P, Khan L, Pepe A, Green CD, Koteliansky V, Giancotti FG. $\alpha_{5} \beta_{1}$ integrin activates an NF-kB-dependent program of gene expression important for angiogenesis and inflammation. Mol Cell Biol 22: $5912-$ 5922, 2002.

68. Klepeis VE, Weinger I, Kaczmarek E, Trinkaus-Randall V. P2Y receptors play a critical role in epithelial cell communication and migration. J Cell Biochem 93: 1115-1133, 2004.

69. Koivisto L, Grenman R, Heino J, Larjava H. Integrins $\alpha_{5} \beta_{1}, \alpha_{v} \beta_{1}$, and $\alpha_{v} \beta_{6}$ collaborate in squamous carcinoma cell spreading and migration on fibronectin. Exp Cell Res 255: 10-17, 2000.

70. Koyama N, Kashimata M, Sakashita H, Sakagami H, Gresik EW. EGF-stimulated signaling by means of PI3K, PLC $\gamma 1$, and PKC isozymes regulates branching 
morphogenesis of the fetal mouse submandibular gland. Dev Dyn 227: 216-226, 2003.

71. Kunduzova OR, Bianchi P, Pizzinat N, Escourrou G, Seguelas MH, Parini A, Cambon C. Regulation of JNK/ERK activation, cell apoptosis, and tissue regeneration by monoamine oxidases after renal ischemia-reperfusion. FASEB J 16: 1129-1131, 2002.

72. Levi NL, Hanoch T, Benard O, Rozenblat M, Harris D, Reiss N, Naor Z, Seger R. Stimulation of Jun N-terminal kinase (JNK) by gonadotropin-releasing hormone in pituitary $\alpha \mathrm{T} 3-1$ cell line is mediated by protein kinase $\mathrm{C}$, c-Src, and Cdc42. Mol Endocrinol 12: 815-824, 1998.

73. Li R, Maminishkis A, Zahn G, Vossmeyer D, Miller SS. Integrin $\alpha_{5} \beta_{1}$ mediates attachment, migration, and proliferation in human retinal pigment epithelium: relevance for proliferative retinal disease. Invest Ophthalmol Vis Sci 50: 59885996, 2009.

74. Liao Z, Seye CI, Weisman GA, Erb L. The P2 $\mathrm{Y}_{2}$ nucleotide receptor requires interaction with $\alpha_{V}$ integrins to access and activate $\mathrm{G}_{12}$. J Cell Sci 120: 1654-1662, 2007.

75. Lim L. Networking of Rho GTPases in regulating morphology: the role of effectors and regulators. Biol Cell 91: 546-548, 1999.

76. Liu J, Liao Z, Camden J, Griffin KD, Garrad RC, Santiago-Perez LI, Gonzalez FA, Seye CI, Weisman GA, Erb L. Src homology 3 binding sites in the $\mathrm{P}_{2} \mathrm{Y}_{2}$ nucleotide receptor interact with Src and regulate activities of Src, proline-rich tyrosine kinase 2, and growth factor receptors. J Biol Chem 279: 8212-8218, 2004. 
77. Ludlow JW, Kelley RW, Bertram TA. The future of regenerative medicine: urinary system. Tissue Eng Part B Rev 18: 218-224, 2012.

78. Ly DP, Corbett SA. The integrin $\alpha_{5} \beta_{1}$ regulates $\alpha_{v} \beta_{3}$-mediated extracellular signalregulated kinase activation. J Surg Res 123: 200-205, 2005.

79. Ma L, Gao C, Mao Z, Zhou J, Shen J, Hu X, Han C. Collagen/chitosan porous scaffolds with improved biostability for skin tissue engineering. Biomaterials 24: 4833-4841, 2003.

80. Napoli I, Noon LA, Ribeiro S, Kerai AP, Parrinello S, Rosenberg LH, Collins MJ, Harrisingh MC, White IJ, Woodhoo A, Lloyd AC. A central role for the ERKsignaling pathway in controlling Schwann cell plasticity and peripheral nerve regeneration in vivo. Neuron 73: 729-742, 2012.

81. Natarajan A, Wagner B, Sibilia M. The EGF receptor is required for efficient liver regeneration. Proc Natl Acad Sci USA 104: 17081-17086, 2007.

82. O'Connell AC, Baccaglini L, Fox PC, O'Connell BC, Kenshalo D, Oweisy H, Hoque A, Sun D, Herscher LL, Braddon VR. Safety and efficacy of adenovirus-mediated transfer of the human aquaporin-1 cDNA to irradiated parotid glands of non-human primates. Cancer Gene Ther 6: 505-513, 1999.

83. Ogawa M, Oshima M, Imamura A, Sekine Y, Ishida K, Yamashita K, Nakajima K, Hirayama M, Tachikawa T, Tsuji T. Functional salivary gland regeneration by transplantation of a bioengineered organ germ. Nat Commun 4: 2498, 2013.

84. Okumura K, Shinohara M, Endo F. Capability of tissue stem cells to organize into salivary rudiments. Stem Cells Int 2012: 502136, 2012. 
85. Oldershaw RA. Cell sources for the regeneration of articular cartilage: the past, the horizon and the future. Int J Exp Pathol 93: 389-400, 2012.

86. Pearson G, Robinson F, Gibson TB, Xu B, Karandikar M, Berman K, Cobb MH. Mitogen-activated protein (MAP) kinase pathways: regulation and physiological functions. Endocr Rev 22: 153-183, 2001.

87. Peterson TS, Camden JM, Wang Y, Seye CI, Wood WG, Sun GY, Erb L, Petris MJ, Weisman GA. P2Y 2 nucleotide receptor-mediated responses in brain cells. Mol Neurobiol 41: 356-366, 2010.

88. Pickering JG, Chow LH, Li S, Rogers KA, Rocnik EF, Zhong R, Chan B. $\alpha_{5} \beta_{1}$ integrin expression and luminal edge fibronectin matrix assembly by smooth muscle cells after arterial injury. Am J Pathol 156: 453-465, 2000.

89. Pothula S, Bazan HE, Chandrasekher G. Regulation of Cdc42 expression and signaling is critical for promoting corneal epithelial wound healing. Invest Ophthalmol Vis Sci 54: 5343-5352, 2013.

90. Pradhan S, Liu C, Zhang C, Jia X, Farach-Carson MC, Witt RL. Lumen formation in three-dimensional cultures of salivary acinar cells. Otolaryngol Head Neck Surg 142: 191-195, 2010.

91. Prenzel N, Fischer O, Streit S, Hart S, Ullrich A. The epidermal growth factor receptor family as a central element for cellular signal transduction and diversification. Endocr Relat Cancer 8: 11-31, 2001.

92. Priya SG, Jungvid H, Kumar A. Skin tissue engineering for tissue repair and regeneration. Tissue Eng Part B Rev 14: 105-118, 2008. 
93. Raftopoulou M, Hall A. Cell migration: Rho GTPases lead the way. Dev Biol 265: 23-32, 2004.

94. Ratchford AM, Baker OJ, Camden JM, Rikka S, Petris MJ, Seye CI, Erb L, Weisman GA. P2Y 2 nucleotide receptors mediate metalloprotease-dependent phosphorylation of epidermal growth factor receptor and ErbB3 in human salivary gland cells. J Biol Chem 285: 7545-7555, 2010.

95. Rul W, Zugasti O, Roux P, Peyssonnaux C, Eychene A, Franke TF, Lenormand P, Fort P, Hibner U. Activation of ERK, controlled by Rac1 and Cdc42 via Akt, is required for anoikis. Ann NY Acad Sci 973: 145-148, 2002.

96. Sakai T, Larsen M, Yamada KM. Fibronectin requirement in branching morphogenesis. Nature 423: 876-881, 2003.

97. Sander EE, Jean P, van Delft S, van der Kammen RA, Collard JG. Rac downregulates Rho activity: reciprocal balance between both GTPases determines cellular morphology and migratory behavior. J Cell Biol 147: 1009-1022, 1999. 98. Schmitz AA, Govek EE, Bottner B, Van Aelst L. Rho GTPases: signaling, migration, invasion. Exp Cell Res 261: 1-12, 2000.

99. Schrader AM, Camden JM, Weisman GA. P2Y 2 nucleotide receptor upregulation in submandibular gland cells from the NOD. B10 mouse model of Sjögren's syndrome. Arch Oral Biol 50: 533-540, 2005.

100. Schwabe RF, Bradham CA, Uehara T, Hatano E, Bennett BL, Schoonhoven R, Brenner DA. c-Jun-N-terminal kinase drives cyclin D1 expression and proliferation during liver regeneration. Hepatology 37: 824-832, 2003. 
101. Schwartz MA, Shattil SJ. Signaling networks linking integrins and Rho family GTPases. Trends Biochem Sci 25: 388-391, 2000.

102. Seger R, Krebs EG. The MAPK signaling cascade. FASEB J 9: 726-735, 1995.

103. Seye CI, Yu N, Gonzalez FA, Erb L, Weisman GA. The P2 $\mathrm{Y}_{2}$ nucleotide receptor mediates vascular cell adhesion molecule-1 expression through interaction with VEGF receptor-2 (KDR/Flk-1). J Biol Chem 279: 35679-35686, 2004.

104. Shan Z, Li J, Zheng C, Liu X, Fan Z, Zhang C, Goldsmith CM, Wellner RB, Baum BJ, Wang S. Increased fluid secretion after adenoviral-mediated transfer of the human aquaporin-1 cDNA to irradiated miniature pig parotid glands. Mol Ther 11: 444-451, 2005.

105. Sharma GD, He J, Bazan HE. p38 and ERK1/2 coordinate cellular migration and proliferation in epithelial wound healing: evidence of crosstalk activation between MAP kinase cascades. J Biol Chem 278: 21989-21997, 2003.

106. Ship J. Diagnosing, managing, and preventing salivary gland disorders. Oral Dis 8: 77-89, 2002.

107. Spence JR, Madhavan M, Aycinena JC, Del Rio-Tsonis K. Retina regeneration in the chick embryo is not induced by spontaneous Mitf downregulation but requires FGF/FGFR/MEK/ERK dependent upregulation of Pax6. Mol Vis 13: 57-65, 2007.

108. Su JL, Lin MT, Hong CC, Chang CC, Shiah SG, Wu CW, Chen ST, Chau YP, Kuo ML. Resveratrol induces FasL-related apoptosis through Cdc42 activation of ASK1/JNK-dependent signaling pathway in human leukemia HL-60 cells. Carcinogenesis 26: 1-10, 2005. 
109. Szczur K, Xu H, Atkinson S, Zheng Y, Filippi MD. Rho GTPase Cdc42 regulates directionality and random movement via distinct MAPK pathways in neutrophils. Blood 108: 4205-4213, 2006.

110. Thevananther S, Sun H, Li D, Arjunan V, Awad SS, Wyllie S, Zimmerman TL, Goss JA, Karpen SJ. Extracellular ATP activates c-jun N-terminal kinase signaling and cell cycle progression in hepatocytes. Hepatology 39: 393-402, 2004.

111. Tonges L, Planchamp V, Koch JC, Herdegen T, Bahr M, Lingor P. JNK isoforms differentially regulate neurite growth and regeneration in dopaminergic neurons in vitro. J Mol Neurosci 45: 284-293, 2011.

112. Turner JT, Redman RS, Camden JM, Landon LA, Quissell DO. A rat parotid gland cell line, Par-C10, exhibits neurotransmitter-regulated transepithelial anion secretion. Am J Physiol Cell Physiol 275: C367-C374, 1998.

113. Turner JT, Weisman GA, Camden JM. Upregulation of $\mathrm{P}_{2} \mathrm{Y}_{2}$ nucleotide receptors in rat salivary gland cells during short-term culture. Am J Physiol Cell Physiol 273: C1100-C1107, 1997.

114. Van Aelst L, Symons M. Role of Rho family GTPases in epithelial morphogenesis. Genes Dev 16: 1032-1054, 2002.

115. Veevers-Lowe J, Ball SG, Shuttleworth A, Kielty CM. Mesenchymal stem cell migration is regulated by fibronectin through $\alpha_{5} \beta_{1}$-integrin-mediated activation of PDGFR- $\beta$ and potentiation of growth factor signals. J Cell Sci 124: 1288-1300, 2011. 
116. Wang L, Yang L, Burns K, Kuan CY, Zheng Y. Cdc42GAP regulates c-Jun Nterminal kinase (JNK)-mediated apoptosis and cell number during mammalian perinatal growth. Proc Natl Acad Sci USA 102: 13484-13489, 2005.

117. Wang M, Kong Q, Gonzalez FA, Sun G, Erb L, Seye C, Weisman GA. P2Y 2 nucleotide receptor interaction with $\alpha_{\mathrm{V}}$ integrin mediates astrocyte migration. $\mathbf{J}$ Neurochem 95: 630-640, 2005.

118. Wei C, Larsen M, Hoffman MP, Yamada KM. Self-organization and branching morphogenesis of primary salivary epithelial cells. Tissue Eng 13: 721-735, 2007.

119. Weinger I, Klepeis VE, Trinkaus-Randall V. Tri-nucleotide receptors play a critical role in epithelial cell wound repair. Purinergic Signal 1: 281-292, 2005.

120. Wu WS, Wu JR, Hu CT. Signal crosstalks for sustained MAPK activation and cell migration: the potential role of reactive oxygen species. Cancer Metastasis Rev 27: 303-314, 2008.

121. Yanagida H, Tanaka J, Maruo S. Immunocytochemical localization of a cell adhesion molecule, integrin $\alpha_{5} \beta_{1}$, in nerve growth cones. J Orthop Sci 4: 353-360, 1999.

122. Yano T, Yano Y, Yuasa M, Horikawa S, Ozasa H, Okada S, Otani S, Hagiwara K. The repetitive activation of extracellular signal-regulated kinase is required for renal regeneration in rat. Life Sci 62: 2341-2347, 1998.

123. Yeh CK, Ghosh PM, Dang H, Liu Q, Lin AL, Zhang BX, Katz MS. $\beta$-Adrenergicresponsive activation of extracellular signal-regulated protein kinases in salivary cells: role of epidermal growth factor receptor and cAMP. Am J Physiol Cell Physiol 288: C1357-C1366, 2005. 
124. Yin J, Yu FS. ERK1/2 mediate wounding- and G-protein-coupled receptor ligandsinduced EGFR activation via regulating ADAM17 and HB-EGF shedding. Invest Ophthalmol Vis Sci 50: 132-139, 2009.

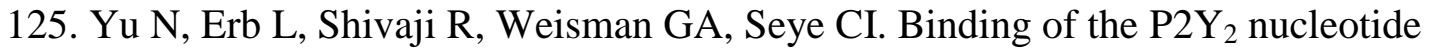
receptor to filamin A regulates migration of vascular smooth muscle cells. Circ Res 102: 581-588, 2008.

126. Yuan H, Zhang H, Wu X, Zhang Z, Du D, Zhou W, Zhou S, Brakebusch C, Chen Z. Hepatocyte-specific deletion of Cdc42 results in delayed liver regeneration after partial hepatectomy in mice. Hepatology 49: 240-249, 2009.

127. Zech T, Calaminus SD, Caswell P, Spence HJ, Carnell M, Insall RH, Norman J, Machesky LM. The Arp2/3 activator WASH regulates $\alpha_{5} \beta_{1}$-integrin-mediated invasive migration. J Cell Sci 124: 3753-3759, 2011.

128. Zhong B, Jiang K, Gilvary DL, Epling-Burnette PK, Ritchey C, Liu J, Jackson RJ, Hong-Geller E, Wei S. Human neutrophils utilize a Rac/Cdc42-dependent MAPK pathway to direct intracellular granule mobilization toward ingested microbial pathogens. Blood 101: 3240-3248, 2003. 


\title{
Appendix II
}

Increased Expression of TGF- $\beta$ Signaling Components in a Mouse Model of Fibrosis Induced by Submandibular Gland Duct Ligation

As found in: Woods, L.T., Camden, J.M., El-Sayed, F.G., Khalafalla, M.G., Petris, M.J., Erb, L. and Weisman, G.A., 2015. Increased expression of TGF- $\beta$ signaling components in a mouse model of fibrosis induced by submandibular gland duct ligation. PLoS One, 10(5), p.e0123641.

\begin{abstract}
Transforming growth factor- $\beta$ (TGF- $\beta$ ) is a multi-functional cytokine with a welldescribed role in the regulation of tissue fibrosis and regeneration in the liver, kidney and lung. Submandibular gland (SMG) duct ligation and subsequent deligation in rodents is a classical model for studying salivary gland damage and regeneration. While previous studies suggest that TGF- $\beta$ may contribute to salivary gland fibrosis, the expression of TGF- $\beta$ signaling components has not been investigated in relation to mouse SMG duct ligation-induced fibrosis and regeneration following ductal deligation. Following a 7 day SMG duct ligation, TGF- $\beta 1$ and TGF- $\beta 3$ were significantly upregulated in the SMG, as were TGF- $\beta$ receptor 1 and downstream Smad family transcription factors in salivary acinar cells, but not in ductal cells. In acinar cells, duct ligation also led to upregulation of snail, a Smad-activated E-cadherin repressor and regulator of epithelial-mesenchymal transition, whereas in ductal cells upregulation of E-cadherin was observed while snail expression was unchanged. Upregulation of these TGF- $\beta$ signaling components correlated with upregulation of fibrosis markers collagen 1 and fibronectin, responses that were inhibited by administration of the TGF- $\beta$ receptor 1 inhibitors SB431542 or
\end{abstract}


GW788388. After SMG regeneration following a 28 day duct deligation, TGF- $\beta$ signaling components and epithelial-mesenchymal transition markers returned to levels similar to non-ligated controls. The results from this study indicate that increased TGF- $\beta$ signaling contributes to duct ligation-induced changes in salivary epithelium that correlate with glandular fibrosis. Furthermore, the reversibility of enhanced TGF- $\beta$ signaling in acinar cells of duct-ligated mouse SMG after deligation indicates that this is an ideal model for studying TGF- $\beta$ signaling mechanisms in salivary epithelium as well as mechanisms of fibrosis initiation and their resolution.

\section{Introduction}

The salivary glands are exocrine glands that secrete saliva into the oral cavity where components of saliva aid in digestion and prevent oral infection [1]. In humans, the majority of saliva is secreted from the parotid, submandibular and sublingual glands with minor contributions from numerous, small accessory glands. For saliva production, activation of muscarinic receptors on the basolateral membrane of acinar cells results in fluid secretion into the ductal lumen where the ion content is modulated as saliva travels along a series of collecting ducts into the main secretory duct which empties into the oral cavity [1]. Salivary dysfunction can significantly decrease quality of life and leads to dry mouth, oral infection and poor nutrition [2]. Two primary causes of salivary dysfunction in humans are Sjögren's syndrome (SS), an autoimmune disease characterized by lymphocytic infiltration of the salivary gland and production of autoantibodies, and $\gamma$ radiation-induced dysfunction, an unintended consequence of treatment for head and neck cancers [3, 4]. Current treatments for salivary hypofunction (i.e., xerostomia) include administration of sialogogues and saliva substitutes; however, these approaches 
are limited to treating the symptom and not the cause of xerostomia [5]. New strategies to treat xerostomia are being investigated to regenerate salivary glands and restore normal levels of saliva secretion $[6,7]$. Understanding the underlying mechanisms of salivary gland inflammation in SS and radiation therapy that result in tissue damage could reveal novel targets to prevent salivary gland degeneration and promote restoration of functional tissue.

Salivary gland duct ligation and subsequent deligation is a well-studied animal model of salivary gland inflammation (ligation) and regeneration (deligation) [8-14]. In this model, the main excretory duct of the submandibular gland (SMG) is surgically occluded and after a set period of time ( 1-30 days) the process is reversed. Within 24 hours of duct ligation, immune cells begin to infiltrate the gland and acinar cells begin to atrophy, lose expression of acinar proteins and eventually undergo apoptosis [8, 10, 11, 15-17]. Ductal cells, subsets of which have been proposed to be salivary progenitor cells that can regenerate the gland, remain intact and proliferative during ligation $[11,18,19]$. Additionally, ligation causes salivary glands to become fibrotic [20]. Interestingly, once the gland is deligated, it begins to regenerate and regains saliva production $[12,14,21]$. Studies in rats have demonstrated that SMGs regenerate histologically and functionally upon deligation, even after $>30$ days of duct ligation [21]. The ability of the SMG to recover from severe inflammatory and fibrotic events following ligation has made duct ligation a useful experimental approach for investigating mechanisms underlying salivary gland inflammation and regeneration. 
Previous studies with liver, lung and kidney have elucidated a key role for transforming growth factor- $\beta$ (TGF- $\beta$ ) in regulating fibrosis and tissue regeneration [22-25]. Three isoforms of TGF- $\beta$ have been identified and denoted as TGF- $\beta 1$, TGF- $\beta 2$ and TGF- $\beta 3$. These cytokines are unique in their mechanism of latent activation [26]. TGF- $\beta$ is produced as a proprotein that is proteolytically cleaved into TGF- $\beta$ and the latency associated peptide (LAP). Following cleavage, TGF- $\beta$ and LAP remain covalently bound and LAP forms disulfide bonds with the latent TGF- $\beta$ binding protein (LTBP). This Large Latent Complex (LLC), consisting of TGF- $\beta$, LAP and LTBP, is then secreted from the cell [26]. The release of active TGF- $\beta$ from the LLC occurs through proteolytic cleavage by matrix metalloproteases, disruption of non-covalent interactions by thrombospondin-1 and interaction of LAP with integrins [27-29]. Once TGF- $\beta$ is released, activation of the canonical TGF- $\beta$ signaling pathway occurs through binding of TGF- $\beta$ to TGF- $\beta$ receptor 2 (TGF- $\beta$ R2), which then dimerizes with TGF- $\beta$ receptor 1 (TGF- $\beta$ R1) leading to intracellular phosphorylation and activation of the transcription factors Smad2 and Smad3 [30]. Along with Smad4, these transcription factors induce cellular responses to extracellular TGF- $\beta$ by activating several DNA-binding transcription factors including Snai1 (Snail) and Snai2 (Slug) [31]. Snail and Slug have been well-described as mediators of TGF- $\beta$-induced epithelial-mesenchymal transition (EMT) [32-34]. Non-canonical TGF- $\beta$ signaling pathways also have been shown to contribute to TGF- $\beta$-induced EMT, specifically through the activation of TGF- $\beta$ activated kinase 1 (TAK1) and TAK-1-binding protein (TAB1) [35, 36].

EMT is a cellular mechanism by which epithelial cells dedifferentiate from their epithelial status to a mesenchymal-like phenotype [37]. This process has been suggested 
to play a major role in the metastasis of cancer cells, tissue fibrosis and regeneration [3840]. During EMT, epithelial proteins such as E-cadherin and zona occludens-1 (ZO-1) are downregulated while mesenchymal proteins such as vimentin and $\alpha$-smooth muscle actin ( $\alpha$-SMA) and fibrotic proteins such as fibronectin and collagen 1 are upregulated [41]. The cells undergoing EMT then become mesenchymal-like, increasing their capacity for migration and redifferentiation. Snail functions in EMT by repressing the expression of epithelial E-cadherin $[32,42,43]$. Given the importance of TGF- $\beta$ signaling to EMT and fibrosis and considering previous reports on the role of TGF- $\beta$ in liver and kidney regeneration, we explored whether expression of TGF- $\beta$ and its downsteam signaling proteins is altered in the SMG ligation/deligation model of salivary gland inflammation and regeneration. Our results demonstrate increased expression of components of the TGF- $\beta$ signaling pathway in salivary gland epithelium during SMG duct ligation and, interestingly, this response is more pronounced in acinar cells compared to ductal cells. Furthermore, we found increased expression of E-cadherin and fibrosis markers during SMG ligation that, along with proteins in the TGF- $\beta$ signaling cascade, return to normal levels following deligation, which correlates with restoration of normal tissue architecture. We further demonstrate that treatment of mice with the TGF- $\beta$ R1 inhibitors SB431542 or GW788388 significantly reduces the upregulation of the fibrosis markers collagen 1 and fibronectin caused by SMG duct ligation. Thus, this study demonstrates that the SMG ligation/deligation model is an excellent system for investigating reversible TGF- $\beta$-mediated signaling mechanisms in epithelium as well as mechanisms of fibrogenesis and fibrosis resolution. 


\section{Materials and Methods}

\section{Reagents}

TRIzol Reagent, AlexaFluor 594 goat anti-rabbit IgG antibody, AlexaFluor 594 donkey anti-rabbit IgG antibody, AlexaFluor 488 donkey anti-goat IgG antibody and Hoechst 33258 nuclear stain were purchased from Life Technologies (Grand Island, NY). Rabbit anti-aquaporin-5 polyclonal antibody (178615) was purchased from EMD Millipore (Billerica, MA). Rat anti-CD45 monoclonal antibody (30-F11) was purchased from Biolegend (San Diego, CA). Rabbit anti-TGF- $\beta 1 / 2 / 3$ polyclonal antibody (3771), rabbit anti-Smad2/3 monoclonal antibody (D7G7), rabbit anti-phospho-Smad2/3 monoclonal antibody (D27F4) and rabbit anti-E-cadherin monoclonal antibody (24E10) were purchased from Cell Signaling Technology (Danvers, MA). Rabbit anti-Snail polyclonal antibody (NBP1-19529) was purchased from Novus Biologicals (Littleton, CO). Rabbit anti-TGF- $\beta$ R1 polyclonal antibody (H-100), goat anti-aquaporin-5 polyclonal antibody (G-19) and horseradish peroxidase-conjugated goat anti-rabbit IgG antibody were purchased from Santa Cruz Biotechnology (Santa Cruz, CA). The TGF- $\beta$ R1 inhibitors SB431542 and GW788388 were purchased from Tocris Bioscience (Bristol, United Kingdom). All other reagents were purchased from Sigma-Aldrich (St. Louis, MO), unless stated otherwise.

\section{Animals and ethics}

C57BL/6 mice were purchased from Jackson Laboratories (Bar Harbor, ME) and bred at the Christopher S. Bond Life Sciences Center Animal Facility of the University of Missouri, Columbia, MO. Animals were housed in vented cages with $12 \mathrm{~h}$ light/dark 
cycles and received food and water ad libitum. Age-matched 6-8 week old male mice were utilized for all experiments. All surgeries were performed following anesthesia by intraperitoneal injection with Avertin ( $0.75 \mathrm{mg} / \mathrm{g}$ mouse weight). Euthanasia was performed by terminal anesthesia followed by cervical dislocation and all efforts were made to minimize suffering. The protocol for this study was approved by the University of Missouri Animal Care and Use Committee (Protocol Number: 7880).

\section{Ligation and deligation of the SMG main excretory duct}

Unilateral ligation of the SMG main excretory duct was performed as previously described [9]. Briefly, mice were anesthetized by intraperitoneal injection with Avertin ( $0.75 \mathrm{mg} / \mathrm{g}$ mouse weight) and the main excretory duct on one side of the neck was dissected and separated from surrounding connective tissue under a surgical stereoscope. The duct was ligated using surgical sutures with particular care taken to avoid ligation of surrounding blood vessels and nerves. The incision was closed using surgical clamps and the mice were allowed to recover. After 7 days, mice were either subjected to SMG deligation or anesthetized with isoflurane in a chamber and euthanized by cervical dislocation. For SMG deligation, mice were anesthetized (as above) and, following careful dissection of the neck, the surgical suture was removed from the SMG duct and the incision was closed using surgical clamps. Following 28 days of recovery, mice were anesthetized and euthanized (as above). Then, 7 day-ligated glands with or without a 28 day deligation and contralateral control glands were excised and processed for real-time PCR (RT-PCR), Western analysis or immunofluorescence as described below. For TGF$\beta$ R1 inhibitor studies, mice received intraperitoneal injection of SB431542 $(20 \mathrm{mg} / \mathrm{kg}$ 
mouse weight in DMSO), GW788388 (2 mg/kg mouse weight in DMSO) or DMSO only as a vehicle control directly after SMG duct ligation and 4 days post-ligation. Seven day ligated and contralateral control glands with or without inhibitors were then collected and processed for RT-PCR analysis, as described below.

\section{Real-time PCR}

Ligated, deligated and contralateral control glands were homogenized in TRIzol reagent. Following a $5 \mathrm{~min}$ incubation at room temperature, chloroform $(0.2 \mathrm{ml} / \mathrm{ml}$ TRIzol $)$ was added and samples were incubated for $5 \mathrm{~min}$ at room temperature. Samples were centrifuged at $12,000 \mathrm{x} \mathrm{g}$ for $15 \mathrm{~min}$ at $4^{\circ} \mathrm{C}$ and RNA isolation from the resulting aqueous phase was performed using the RNeasy Plus Mini Kit (Qiagen, Valencia, CA). cDNA was prepared from $1 \mu \mathrm{g}$ of purified RNA using RNA to cDNA EcoDry Premix (Clontech Laboratories, Mountain View, CA). Specific Taqman primers for mouse $T G F-\beta 1, T G F$ ß2, TGF-ß3, TAK1 (MAP3K7), TAB1, Snail (Snai1), Slug (Snai2), fibronectin (Fn1), collagen 1 (Colla1), E-cadherin (Cdh1) and $18 S$ were purchased from Applied Biosystems (Foster City, CA) and used for RT-PCR on an Applied Biosystems 7500 Real-Time PCR machine. For data analysis, mRNA expression of target genes was normalized to $18 \mathrm{~S}$ ribosomal RNA as an internal control.

\section{SDS-PAGE and western blot analysis}

Ligated, deligated and contralateral control SMGs were homogenized in Tissue Protein Extraction Reagent (Thermo Scientific, Rockford, IL) containing protease inhibitor cocktail (Sigma-Aldrich). Samples were centrifuged at $10,000 \mathrm{x}$ g for $5 \mathrm{~min}$ to pellet 
cellular debris, supernatants were collected and the protein concentration was measured using a Nanodrop 1000 spectrophotometer. Following protein concentration normalization, samples were combined 1:1 with 2X Laemmli Buffer (20 mM sodium phosphate, $\mathrm{pH} 7.0,20 \%$ (v/v) glycerol, 4\% (w/v) SDS, $0.01 \%(\mathrm{w} / \mathrm{v})$ bromophenol blue and $100 \mathrm{mM}$ DTT) and subjected to Western blot analysis, as previously described [8]. Briefly, samples containing $50 \mu \mathrm{g}$ total protein were subjected to $7.5 \%$ (w/v) SDS-PAGE and transferred to nitrocellulose membranes. As a loading control, membranes were stained with Ponceau S solution $(0.1 \%(\mathrm{w} / \mathrm{v})$ Ponceau $\mathrm{S}$ in $5 \%(\mathrm{v} / \mathrm{v})$ acetic acid) for $5 \mathrm{~min}$ followed by 2 washes in 5\% (v/v) acetic acid. Membranes were then washed in Trisbuffered saline (pH 7.4) containing 0.1\% (v/v) Tween-20 (TBST), blocked for $1 \mathrm{~h}$ with $5 \%(\mathrm{w} / \mathrm{v})$ non-fat dry milk in TBST and incubated with rabbit anti-pro-TGF- $\beta 1 / 2 / 3$ (diluted 1:1,000 in TBST), rabbit anti-Smad2/3 antibody (diluted 1:1,000 in TBST) or rabbit anti-phospho-Smad2/3 antibody (diluted 1:1,000 in TBST) for $16 \mathrm{~h}$ at $4{ }^{\circ} \mathrm{C}$. Membranes were then washed in TBST and incubated with horseradish peroxidaseconjugated goat anti-rabbit IgG antibody (1:2,000 dilution in TBST) at room temperature for $1 \mathrm{~h}$. Protein bands were visualized using enhanced chemiluminescence reagent (Thermo Scientific) and detected on X-ray film.

\section{Immunofluorescence and brightfield microscopy}

Immunofluorescence microscopy was performed as previously described [8]. Briefly, ligated, deligated and contralateral control SMGs were snap frozen in 2-methylbutane cooled with liquid nitrogen. Glands were then equilibrated to $-20^{\circ} \mathrm{C}$, cut into $8 \mu \mathrm{m}$ sections using a Leica CM1900 cryostat and adhered to microscope slides. Sections were 
then fixed with 4\% (v/v) paraformaldehyde in PBS, pH 7.4, for 20 min, washed three times in PBS and incubated in blocking buffer (5\% (v/v) goat serum, $10 \mu \mathrm{M}$ digitonin in PBS) for $2 \mathrm{~h}$ at room temperature. Sections were then incubated for $16 \mathrm{~h}$ at $4^{\circ} \mathrm{C}$ with rabbit primary antibodies specific for aquaporin-5, CD45, TGF- $\beta$ R1, Smad2/3, phosphoSmad2/3, Snail or E-cadherin (diluted 1:250 in blocking buffer). Primary antibody specificity for aquaporin-5 [44], CD45 [45], TGF- $\beta$ R1 [46], Smad2/3 and phosphoSmad2/3 [47], Snail [48] and E-cadherin [49] was determined, as cited, and sections incubated with only secondary antibody served as negative controls where no fluorescence was observed. Following three washes in PBS, sections were incubated with AlexaFluor 594 goat anti-rabbit IgG, AlexaFluor 488 goat anti-rabbit IgG or AlexaFluor 594 goat anti-rat $\operatorname{IgG}$ (diluted 1:1,000 in blocking buffer) for $1 \mathrm{~h}$ at room temperature. Sections were then washed three times in PBS and stained with the nuclear dye Hoechst 33258 (diluted 1:5,000 in PBS) for 5 min at room temperature. Following three washes in PBS, slides were mounted and dried. For dual-immunofluorescence analysis, goat serum in blocking buffer was replaced with donkey serum and, following a $2 \mathrm{~h}$ incubation in blocking buffer, SMG sections were treated with goat anti-aquaporin-5 antibody (diluted 1:250 in blocking buffer) and the indicated rabbit primary antibody for $16 \mathrm{~h}$ at $4^{\circ} \mathrm{C}$. Then, AlexaFluor 594 donkey anti-rabbit IgG and AlexaFluor 488 donkey anti-goat IgG secondary antibodies (both diluted 1:1000 in blocking buffer) were added to washed sections for $1 \mathrm{~h}$ at room temperature. Fluorescence was visualized using a Nikon Ti-E inverted microscope equipped with appropriate filters.

For brightfield microscopy, ligated, deligated and contralateral control SMGs were placed in $4 \%(\mathrm{v} / \mathrm{v})$ paraformaldehyde in PBS at $4^{\circ} \mathrm{C}$ for $24 \mathrm{~h}$ followed by $70 \%(\mathrm{v} / \mathrm{v})$ 
ethanol for $24 \mathrm{~h}$ at $4^{\circ} \mathrm{C}$. Samples were then sent to IDEXX RADIL (Columbia, MO) where glands were embedded in paraffin, cut into $5 \mu \mathrm{m}$ sections and subjected to hematoxylin and eosin or Masson's trichrome staining. Hematoxylin and eosin-stained slides were visualized on an AMG EVOS XL Core brightfield microscope and Masson's trichrome-stained slides were visualized on an Olympus Vanox AHBT3 brightfield microscope at the University of Missouri Molecular Cytology Core Facility. Low magnification images of whole SMG sections were generated from multiple $4 \mathrm{X}$ magnification images stitched together with Leica LAS3.1 imaging software.

\section{Statistical analysis}

Quantitative results are presented as means \pm S.E.M. of data from three or more independent experiments. Statistical significance was defined as $P<0.05$ as calculated by one-way ANOVA with repeated measures post-test where appropriate or by a two tailed t-test, using GraphPad Prism software.

\section{Results}

\section{Regeneration of duct-ligated SMG following deligation}

The SMG excretory duct ligation/deligation model has long been used for the study of salivary gland inflammation and regeneration $[8-10,14]$. The SMG is composed primarily of ductal and acinar cells that can easily be distinguished by morphology and/or expression of cell-specific markers (Fig. Appendix II-1). Following 7 days of SMG duct ligation, expression of the acinar cell marker aquaporin-5 (AQP5), an apical membrane water channel, is dramatically reduced as acinar cells atrophy (Fig . Appendix II-1A vs. 
1B) $[17,50]$. Additionally, SMG duct ligation leads to enhanced immune cell infiltration, as judged by expression of the pan-immune cell marker CD45 (Fig . Appendix II-1E) [8, 10], and the loss of ductal secretory granules (Fig . Appendix II-1H). Once the SMG excretory duct is deligated the gland begins to regenerate and, after a 28 day recovery period, expression of the acinar cell marker AQP5 returns to levels (Fig. Appendix II-1C) comparable to control glands (Fig. Appendix II-1A). Additionally, the number of immune cells returns to levels (Fig . Appendix II-F) comparable to control glands (Fig. Appendix II-1D). Ductal secretory granules also return after deligation (Fig. Appendix II-1I) and duct morphology resembles unligated control glands (Fig. Appendix II-1G).

\section{Reversible upregulation of TGF- $\beta$ isoforms and TGF- $\beta$ R1 occurs in the SMG following excretory duct ligation and deligation}

TGF- $\beta$ signaling has been shown to regulate tissue fibrosis and regeneration in a number of tissues including liver, lung and kidney [22-25]. However, a role for TGF- $\beta$ signaling in response to SMG duct ligation and deligation has not been defined. Western analysis using an antibody that recognizes all three TGF- $\beta$ isoforms shows substantial TGF- $\beta$ upregulation in response to a 7 day duct ligation. After duct deligation and a 28 day recovery, the levels of pro-TGF- $\beta 1 / 2 / 3$ return to levels comparable to control glands (Fig. Appendix II- 2A). RT-PCR analysis of cDNA prepared from whole SMGs shows that expression of mRNA to TGF- $\beta 1$ and TGF- $\beta 3$, but not TGF- $\beta 2$, is significantly increased in the SMG following 7 days of duct ligation, as compared to control glands (Fig. Appendix II-2B). Furthermore, TGF- $\beta 1$ and TGF- $\beta 3$ upregulation in response to duct ligation was fully reversible upon duct deligation and a 28 day recovery period, where 
expression levels of these cytokines returned to control levels (Fig. Appendix II- 2B). In addition to TGF- $\beta 1$ and TGF- $\beta 3$, TGF- $\beta$ R1 expression was significantly increased following SMG duct ligation, as compared to control glands, and returned to control levels 28 days after deligation (Fig. Appendix II- 2C). Dual-immunofluorescence staining of TGF- $\beta$ R1 and the acinar marker AQP5 revealed that the expression of TGF- $\beta$ R1 in the ligated SMG was restricted to acinar cells, similar to control glands.

\section{Reversible upregulation of canonical and non-canonical TGF- $\beta$ signaling pathways in response to excretory duct ligation and deligation}

Canonical TGF- $\beta$ signaling occurs following the binding of TGF- $\beta$ to its cognate receptor to induce the phosphorylation and activation of the intracellular transcription factors Smad2 and Smad3, which then translocate to the nucleus to activate downstream targets of the TGF- $\beta$ signaling cascade $[30,51]$. Utilizing an antibody that recognizes both Smad2 and Smad3, Western analysis indicates that the expression of Smad2/3 in whole gland lysates from control SMGs is highly upregulated following 7 days of duct ligation (Fig. Appendix II- 3A). The level of $\operatorname{Smad} 2 / 3$ activation, as measured by the amount of phosphorylated-Smad2/3 (p-Smad2/3) in whole gland lysates, was also highly increased following SMG duct ligation (Fig. Appendix II- 3A). After duct deligation and a 28 day recovery, the levels of Smad2/3 and p-Smad2/3 return to levels comparable to control glands (Fig. Appendix II- 3A). Immunofluorescence analysis revealed that the increased expression of Smad2/3 (Fig. Appendix II- 3B) and p-Smad2/3 (Fig. Appendix II- 3C) induced by SMG duct ligation is localized to acinar cells, a response that was reversed upon deligation and a 28 day recovery (Fig. Appendix II- 3B and 3C), similar to TGF- $\beta$ 
R1 expression patterns (Fig. Appendix II- 2B). Dual-immunofluorescence staining of pSmad2/3 and AQP5 revealed that the expression of p-Smad2/3 following a 7 day duct ligation colocalized with Hoechst nuclear stain in acinar cells (Fig. Appendix II- 3C).

In addition to canonical signaling through the activation of Smad transcription factors, non-canonical TGF- $\beta$ signaling occurs through the activation of the mitogen-activated protein kinase-3 (MAP3K) TAK1 and the TAK1-binding protein TAB1 [52]. RT-PCR analysis reveals significant upregulation of both TAK1 and TAB1 mRNA expression following 7 days of SMG duct ligation and expression returned to levels comparable to unligated control glands following deligation and a 28 day recovery (Fig. Appendix II$3 \mathrm{D})$.

\section{Reversible upregulation of Snail and Slug in response to duct ligation and deligation}

Smad $2 / 3$ phosphorylation and translocation to the nucleus mediates TGF- $\beta$-induced cellular responses through transcriptional activation of other DNA-binding transcription factors, including Snail (Snai1) and Slug (Snai2) [53]. The transcription repressor Snail is a primary target for regulation through direct binding of $\operatorname{Smad} 2 / 3$ to the Snail promoter $[54,55]$. Following 7 days of SMG duct ligation, both Snail and Slug mRNA expression in whole SMGs was significantly increased, as compared to control glands, and expression was reversed to control levels after ductal deligation and a 28 day recovery (Fig. Appendix II- 4A and 4B). Immunofluorescence analysis of Snail localization following SMG duct ligation and deligation revealed a similar pattern to Smad2/3 and TGF- $\beta$ R1, with Snail upregulation primarily restricted to acinar cells (Fig. Appendix II- 
4C). Dual-immunofluorescence analysis confirmed the colocalization of Snail and AQP5 following a 7 day duct ligation (Fig. Appendix II- 4D).

\section{Reversible upregulation of E-cadherin in response to SMG duct ligation and deligation}

Previous reports have described a role for TGF- $\beta$ in EMT and Snail has been shown to be a primary effector in this pathway by repressing E-cadherin expression [32, 41]. Because our data show that upregulation of the transcriptional repressor Snail occurs after SMG duct ligation (Fig. Appendix II- 4) and E-cadherin expression is suppressed by Snail during EMT [32], we investigated whether E-cadherin expression is altered in response to SMG ligation and deligation. Interestingly, following 7 days of duct ligation, E-cadherin mRNA expression was significantly upregulated (Fig. Appendix II- 5A), despite the finding that TGF- $\beta$ signaling molecules and Snail expression were increased following SMG duct ligation (Figs. Appendix II- 2-4). Immunofluorescence analysis of E-cadherin localization after SMG duct ligation revealed that E-cadherin was highly upregulated in ductal cells, suggesting that ductal cells maintain epithelial integrity (Fig. Appendix II5B). It seems likely that upregulation of E-cadherin in ductal cells (Fig. Appendix II- 5B) is responsible for the overall upregulation of E-cadherin in whole gland cell lysates (Fig. Appendix II- 5A). Following deligation and a 28 day recovery, the expression of Ecadherin returned to levels comparable to control glands (Fig. Appendix II- 5A and 5B). 


\section{Glandular fibrosis resulting from SMG duct ligation is resolved following ductal deligation}

Previous studies have demonstrated that SMG duct ligation can increase collagen deposition and glandular fibrosis [20]. Additionally, conditional overexpression of TGF$\beta 1$ in the salivary glands leads to glandular fibrosis [56]. To investigate fibrosis progression and resolution in the murine duct ligation/deligation model, SMG ducts were ligated for 7 days followed by deligation and a 28 day recovery. After 7 days of duct ligation, collagen deposition assayed by Masson's Trichrome staining (blue) was substantially increased around blood vessels and large collecting ducts of SMG as well as within the interlobular stroma (Fig. Appendix II-6B), as compared to control SMG (Fig. Appendix II-6A). Analysis at higher magnification revealed that duct ligation also caused extensive collagen deposition in the interstitial areas around acinar cells and ductal cells (Fig. Appendix II-6E), as compared to control SMG (Fig. Appendix II-6D), suggesting that active extracellular matrix (ECM) production and deposition occurred in these regions of the SMG. Following ductal deligation and a 28 day recovery (Fig. Appendix II-6C and 6F), glandular fibrosis was resolved and collagen deposition around blood vessels, collecting ducts and interstitial areas resembled control glands (Fig. Appendix II6A and 6D). RT-PCR analysis of cDNA prepared from whole SMGs revealed significant upregulation of collagen 1 and fibronectin mRNA after a 7 day duct ligation that returned to control levels after deligation and a 28 day recovery (Fig. Appendix II-6G). 


\section{Treatment with TGF- $\beta$ R1 inhibitors attenuates upregulation of fibrosis markers in response to SMG duct ligation}

The small molecule TGF- $\beta$ R1 inhibitors SB431542 and GW788388 have been shown to reduce TGF- $\beta$-mediated signaling and tissue fibrosis in mouse models of kidney, liver and lung fibrosis [57-60]. To determine whether TGF- $\beta$ R1 inhibition reduces 7 day duct ligation-induced SMG fibrosis, mice were treated with SB431542 (20 mg/kg mouse weight), GW788388 (2 mg/kg mouse weight) or DMSO directly after SMG duct ligation and on day 4 post-ligation. RT-PCR analysis of 7 day ligated and contralateral unligated glands revealed significant attenuation of duct ligation-induced collagen 1 and fibronectin mRNA upregulation following treatment with either SB431542 or GW788388, as compared to DMSO-treated ligated glands (Fig. Appendix II- 7).

\section{Discussion}

TGF- $\beta$ participates in diverse biological processes including development, inflammation, fibrosis, tissue regeneration and EMT [23, 25, 41, 61, 62]. In salivary glands, previous studies have shown that TGF- $\beta$ isoforms can modulate branching morphogenesis during salivary gland development [63]. Additionally, in vitro studies have shown that TGF- $\beta$ signaling modulates the formation of acinar units by primary murine SMG cells and the human salivary gland (HSG) cell line $[64,65]$, suggesting that TGF- $\beta$ plays a role in regeneration of salivary acini in vivo. Overexpression of TGF- $\beta 1$ in murine salivary glands has been shown to significantly disrupt salivary gland development and function, likely due to glandular atrophy and fibrosis [56]. Conversely, inhibition of TGF- $\beta$ signaling in the salivary gland through conditional knockout of TGF- $\beta$ R1 also leads to 
salivary dysfunction through the development of multifocal lymphocytic inflammation of the salivary glands [66]. Global knockout of TGF- $\beta 1$ in mice leads to a severe inflammatory phenotype characterized by lymphocytic infiltration of the heart, lung and salivary glands and premature death within 4 weeks of age [67]. Further investigation has revealed that TGF- $\beta 1^{-/-}$mice develop nuclear autoantibodies, glandular atrophy, loss of acinar cells and significant inflammatory lesions in the salivary gland, all of which are traits similar to the human autoimmune disorder Sjögren's syndrome $[68,69]$. While attempts to determine TGF- $\beta$ levels in salivary glands of SS patients have yielded conflicting data $[70,71]$, studies have shown that TGF- $\beta$ expression increases in patients suffering from chronic obstructive sialadenitis, a human condition caused by obstruction of the SMG excretory duct $[72,73]$. Because the rodent model of SMG duct ligation closely mimics obstructive sialadenitis [74], the findings presented in this paper have clinical relevance.

Tissue fibrosis is typically associated with chronic inflammation where molecular signals from unrepaired injured tissue stimulate resident fibroblasts, epithelial cells (through EMT) or bone marrow-derived fibrocytes to differentiate into myofibroblasts $[75,76]$. Overproduction and deposition of ECM components, such as collagen 1 and fibronectin, progressively replace normal parenchyma and disrupt tissue morphology and function [75]. In vitro studies have shown that TGF- $\beta$ stimulates the production of collagen and fibronectin, key proteins in the development of fibrosis [77, 78]. In vivo, TGF- $\beta$ also has been shown to stimulate fibrogenesis in animal models of liver, lung and kidney fibrosis [79-81]. Salivary gland fibrosis following radiation exposure during treatment of head and neck cancers contributes to long term hyposalivation in patients $[82,83]$ and 
increased TGF- $\beta$ expression has been reported in patients suffering from radiationinduced xerostomia [84]. Additionally, TGF- $\beta$ has been shown to initiate fibrosis following radiation treatment of the skin [85], suggesting that TGF- $\beta$ may contribute to radiation-induced salivary gland fibrosis. The results from this study show that significant collagen deposition and upregulation of collagen 1 and fibronectin mRNA (Figs.

Appendix II- 6-7) in the SMG following duct ligation occurs concurrently with increased expression of TGF- $\beta$ signaling components (Figs. Appendix II-2-4). Moreover, ligationinduced SMG fibrosis is attenuated following administration of the TGF- $\beta$ R1 inhibitors SB431542 and GW788388 (Fig. Appendix II-7). These small molecule TGF- $\beta$ R1 inhibitors have been shown to inhibit TGF- $\beta$ signaling through competitive antagonism of TGF- $\beta$ R1 kinase activity, thereby preventing phosphorylation and activation of Smad transcription factors $[86,87]$ suggesting that this canonical TGF- $\beta$ signaling pathway plays a major role in duct-ligation induced fibrosis. The remarkable ability of the ductligated SMG to regenerate following deligation makes this an ideal model to investigate the molecular pathways involved in fibrosis resolution. Identifying mechanisms that modulate the expression or function of proteins which aid in fibrosis resolution (i.e., matrix metalloproteases (MMPs), tissue inhibitors of metalloproteases (TIMPs) and hepatocyte growth factor (HGF) [88-90]) in the murine duct-ligated SMG could help develop strategies to reduce salivary gland fibrosis in humans that occurs in chronic obstructive sialadenitis or following radiation treatment for head and neck cancer.

In addition to its role in stimulating myofibroblasts during fibrosis, TGF- $\beta$ has significant effects on epithelial cells. TGF- $\beta$ signaling in epithelial cells has been shown to induce migration, reduce proliferation and stimulate apoptosis [91-93]. Interestingly, the data 
presented in this paper suggest that TGF- $\beta$ signaling is very active in salivary acinar cells during duct ligation (Figs. Appendix II-2-4). Previous studies have demonstrated the presence of TGF- $\beta$ in saliva where it is hypothesized to function in maintaining immune homeostasis in the oral cavity and esophagus [94, 95]. Furthermore, immunohistochemical studies have shown that TGF- $\beta$ is localized to ductal cells in the salivary glands of humans and mice under normal and pathological circumstances [65, 70, 71]. Our data suggest that TGF- $\beta$ R1 is primarily expressed in salivary acinar cells (Fig. Appendix II-2C) and these cells also demonstrate upregulation of molecules in the TGF- $\beta$ signaling cascade following ductal ligation (Figs. Appendix II-3 and 4). Perhaps ductal cells secrete TGF- $\beta$ during normal salivary gland function which then accumulates in the lumen after the gland is ligated, whereupon elevated TGF- $\beta$ levels activate the upregulated TGF- $\beta$ R1 on salivary acinar cells. Previous studies have shown that some subsets of ductal cells proliferate in response to SMG duct ligation while acinar cells downregulate expression of AQP5 and eventually undergo apoptosis $[11,15,19]$. Thus, the altered expression of TGF- $\beta$ R 1 in salivary acinar cells may be a contributing factor to the known responses of salivary epithelium to SMG duct ligation.

The ability of TGF- $\beta$ to induce the transition of epithelial cells into a mesenchymal phenotype has been extensively studied both in vitro [41, 65, 96-99] and in vivo [100104], and is widely regarded as a necessary process in embryogenesis [105]. However, the in vivo significance of post-embryogenesis EMT has been debated [106-108]. In exocrine glands, EMT has been shown to play a role in the repair of lacrimal glands following IL-1-induced injury [109] and, in the pancreas, EMT induces the formation of insulin-secreting beta cells from pancreatic acinar cells $[110,111]$. Other studies have 
provided in vivo evidence of TGF- $\beta$-induced EMT in the kidney, liver and lungs [100, 103, 104]. During EMT, epithelial cells downregulate the expression of proteins necessary for epithelial function, such as the cell adhesion molecule E-cadherin and the tight junction proteins ZO-1 and claudin, and upregulate proteins that contribute to mesenchymal function, such as the intermediate fiber vimentin and $\alpha$-smooth muscle actin $[37,41]$. TGF- $\beta$ induces EMT through the phosphorylation and activation of Smad family transcription factors that then induce the upregulation of other transcriptional regulators, such as the zinc-finger transcription repressors Snail and Slug [32, 33, 54]. Snail is a well-described repressor of E-cadherin expression [32, 42, 43] and overexpression of Snail induces EMT in several types of epithelial cells [32]. TGF- $\beta$ induced TAK1 activation, which is thought to occur through TAK1/TAB1 interaction with TNF receptor-associated factor 6 (TRAF6) and downstream NF-kB activation, has been shown to regulate EMT in both human lung epithelial and peritoneal-derived mesothelial cells $[35,36,112]$. Our results show increased Smad2/3 and TAK1/TAB1 expression (Fig. Appendix II-3) as well as upregulation of Snail and Slug expression following ductal ligation (Fig. Appendix II-4), which suggests that TGF- $\beta$ signaling is increased in salivary epithelial cells during injury. Of particular interest is the differential expression pattern of Snail in response to duct ligation where ductal cells appear to have low expression levels of Snail, whereas acinar cells have much higher expression levels (Fig. Appendix II-4C and 4D). This acinar localization of Snail is in agreement with Smad2/3 localization (Fig. Appendix II-3B and 3C), both of which are likely the result of the upregulation and localization of TGF- $\beta$ R1 in acinar cells caused by SMG duct ligation (Fig. Appendix II-2C). If TGF- $\beta$-induced EMT occurs in duct-ligated SMG, one 
would expect to find E-cadherin downregulation in the gland [32]. However, our results show significant upregulation of E-cadherin following a 7 day SMG duct ligation (Fig. Appendix II-5A). It seems likely that upregulation of E-cadherin in ductal and not acinar cells (Fig. Appendix II-5B) is responsible for the overall upregulation of E-cadherin in whole gland cell lysates (Fig. Appendix II-5A). Interestingly, previous studies have shown that E-cadherin expression increases in kidney tubules following ureteral ligation [113]. Taken together, these data suggest that during SMG duct ligation, salivary epithelium (acinar and ductal cells) have diverse responses which could be driven in part by differential capacities for TGF- $\beta$ signaling. Whereas salivary acinar cells upon SMG duct ligation exhibit decreased expression of AQP5 (Fig. Appendix II-1) [17] and cellular atrophy (Fig. Appendix II-1) [50] and increased expression of TGF- $\beta$ signaling molecules (Figs. Appendix II-2-4), ductal cells exhibit increased E-cadherin expression (Fig. Appendix II-5) and proliferation [18, 19]. Perhaps the increase in E-cadherin expression in ductal cells is a protective response. Previous studies have demonstrated a role for Ecadherin in cell survival, where conditional knockout of E-cadherin in alveolar epithelial cells in the mammary gland led to significant apoptosis and glandular dysfunction [114, 115]. Whether salivary acinar cells actually undergo EMT during duct ligation remains to be determined, however, it seems likely that TGF- $\beta$ signaling contributes to the observed changes in acinar cell morphology that occur upon duct ligation.

The results from this study provide evidence of a role for TGF- $\beta$ during mature salivary gland damage and regeneration. We show significant upregulation of TGF- $\beta 1$ and TGF$\beta 3$ as well as TGF- $\beta$ R1 in response to SMG duct ligation (Fig. Appendix II-2). Furthermore, we provide evidence for active TGF- $\beta$ signaling in salivary acinar epithelial 
cells caused by duct ligation, as indicated by increases in the expression and phosphorylation of Smad2/3 and the expression of its downstream target Snail (Figs. Appendix II-3 and 4). This study also provides evidence that SMG duct ligation causes fibrosis (Fig. Appendix II-6), concurrent with enhanced TGF- $\beta$ signaling in acinar cells (Figs. Appendix II-2-4) that can be attenuated following administration of small molecule TGF- $\beta$ R1 inhibitors (Fig. Appendix II-7). We also describe the reversibility of these cellular responses upon ductal deligation and recovery, thereby demonstrating the capacity of the SMG to regenerate following damage and fibrosis. Although it has classically been used to study inflammatory and regenerative pathways, SMG duct ligation-induced damage appears to be an ideal model for investigating mechanisms that initiate and resolve salivary gland fibrosis. The observed differential responses of salivary acinar and ductal cells to TGF- $\beta$ also indicate that this model should be useful for in vivo studies of TGF- $\beta$ signaling in epithelial cells. Further insights into TGF- $\beta$ signaling in duct-ligated SMG could identify novel therapeutic targets for salivary gland fibrosis associated with obstructive sialoadenitis and radiation-induced damage to the salivary gland in humans.

\section{Author Contributions}

Conceived and designed the experiments: LTW JMC GAW. Performed the experiments: LTW JMC. Analyzed the data: LTW JMC FGES MGK MJP LE GAW. Wrote the paper: LTW JMC FGES MGK MJP LE GAW. 


\section{Figures}

Fig. Appendix II-1. Submandibular gland ductal ligation followed by deligation results in reversible acinar cell atrophy, immune cell infiltration and glandular fibrosis. (A, D, G) Control SMG, (B, E, H) 7 day duct-ligated SMG and (C, F, I) 7 day duct-ligated SMG followed by deligation and recovery for 28 days were subjected to immunofluorescence staining with (A-C) antibodies to the acinar cell marker AQP5 (green) and Hoechst nuclear stain (blue), (D-F) antibodies to the pan-immune cell marker CD45 (red) and Hoechst nuclear stain (blue) and (G-I) hematoxylin and eosin. Results indicate that ligation of the main SMG excretory duct induces (B) loss of acinar cells, (E) substantial immune cell infiltration and $(\mathrm{H})$ atrophy of acinar cells (white arrow) and loss of secretory granules (pink) within ductal cells (black arrow) that is reversed by subsequent deligation $(\mathrm{C}, \mathrm{F}, \mathrm{I})$. Images are representative of results from at least 3 independent experiments and scale bar $=20 \mu \mathrm{m}$. 

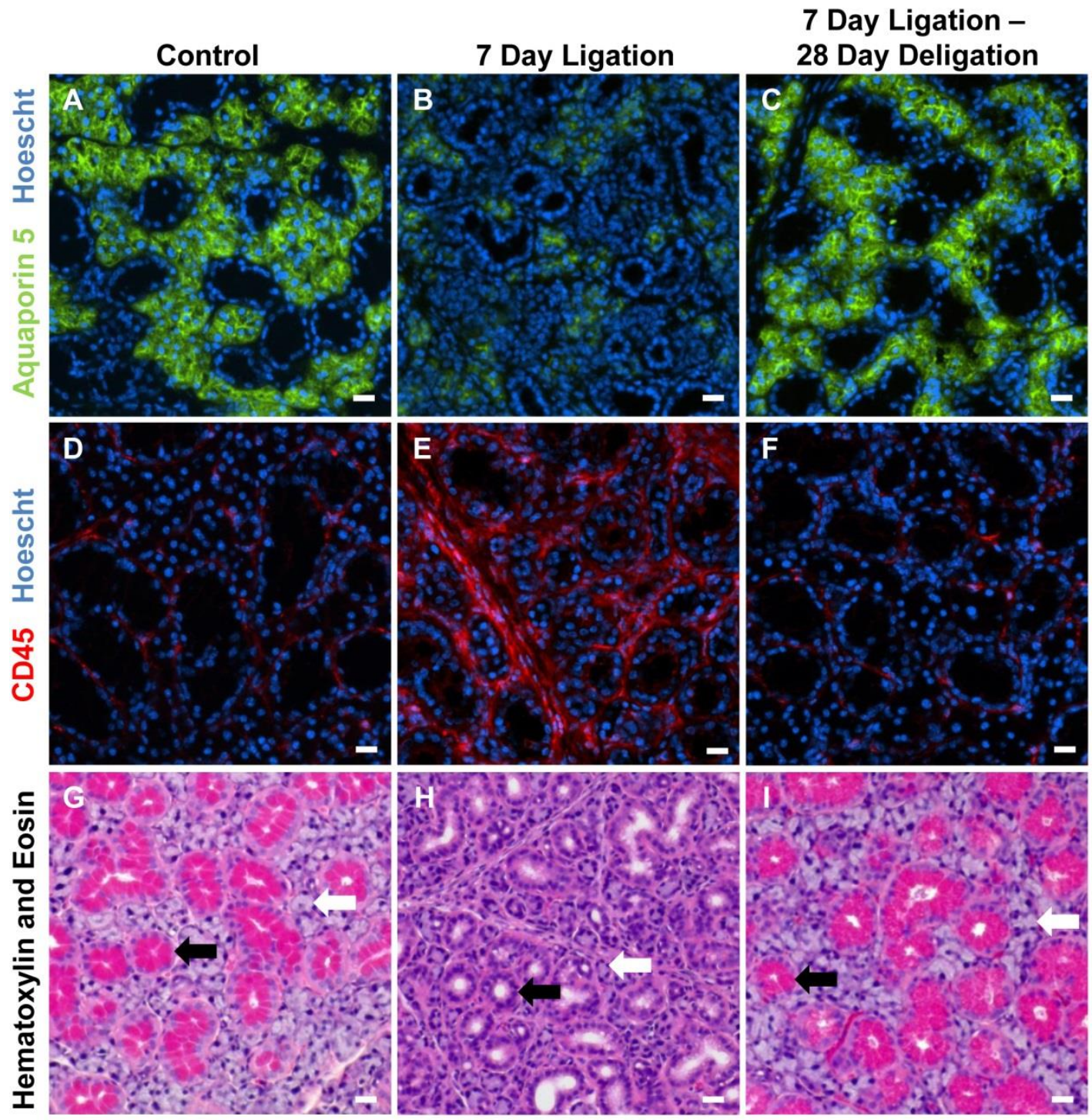
Fig. Appendix II-2. Upregulation of TGF- $\beta 1$, TGF- $\beta 3$ and TGF- $\beta$ R1 in response to SMG duct ligation is reversible upon deligation. (A) Western analysis of whole gland lysates shows upregulation of pro-TGF- $\beta 1 / 2 / 3$ expression (top) in response to 7 day SMG duct ligation that is reversible following deligation and recovery for 28 days. Ponceau $\mathrm{S}$ staining (bottom) shows equal amounts of total protein in each well. (B) RT-PCR analysis of cDNA prepared from whole SMGs shows significant upregulation of TGF- $\beta 1$ and TGF- $\beta 3$, but not TGF- $\beta 2$, mRNA expression after 7 days of SMG excretory duct ligation (grey bars), as compared to contralateral control glands (white bars). When ducts were ligated for 7 days then deligated for 28 days (black bars), expression levels of TGF$\beta 1$ and TGF- $\beta 3$ mRNA return to control levels, whereas TGF- $\beta 2$ mRNA levels remain unchanged. Data represent means \pm S.E.M. $(n=7$ for control and 7 day ligation, $n=5$ for 7 day ligation, deligation and a 28 day recovery), where $* P<0.05$ and $* * P<0.01$ indicate significant differences in mRNA expression, as compared to control. (C) Dualimmunofluorescence analysis of $8 \mu \mathrm{m}$ frozen SMG sections for control, 7 day ligation and 7 day ligation followed by deligation and recovery for 28 days reveals that TGF- $\beta$ R1 (red) expression is upregulated primarily in acinar cells (marked by residual AQP5 expression; green) after a 7 day SMG duct ligation, whereas little staining is visible in ductal cells. After a 7 day duct ligation followed by deligation and a 28 day recovery, TGF- $\beta$ R1 expression levels are similar to control. Hoechst nuclear stain in blue and scale bar $=20 \mu \mathrm{m}$. Images are representative of results from at least 3 independent experiments. 
A

7 Day 7 Day Ligation -
Control Ligation 28 Day Deligation

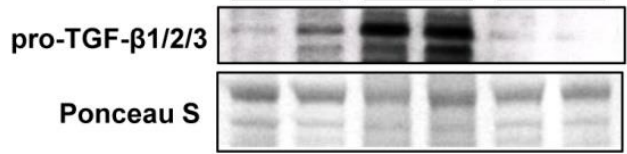

B

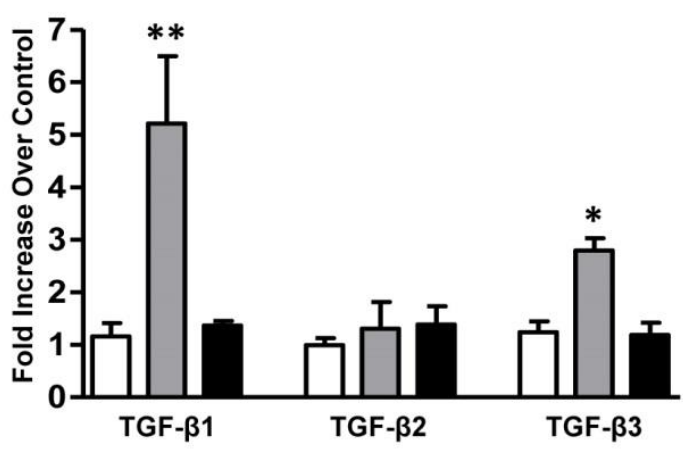

C

Control

7 Day Ligation

7 Day Ligation -
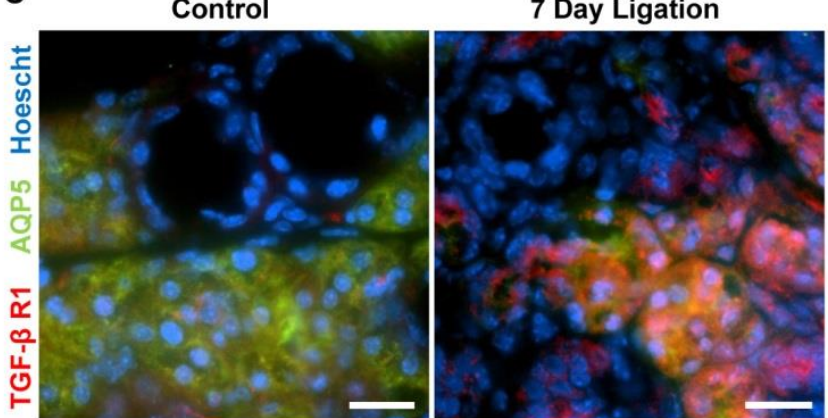

28 Day Deligation

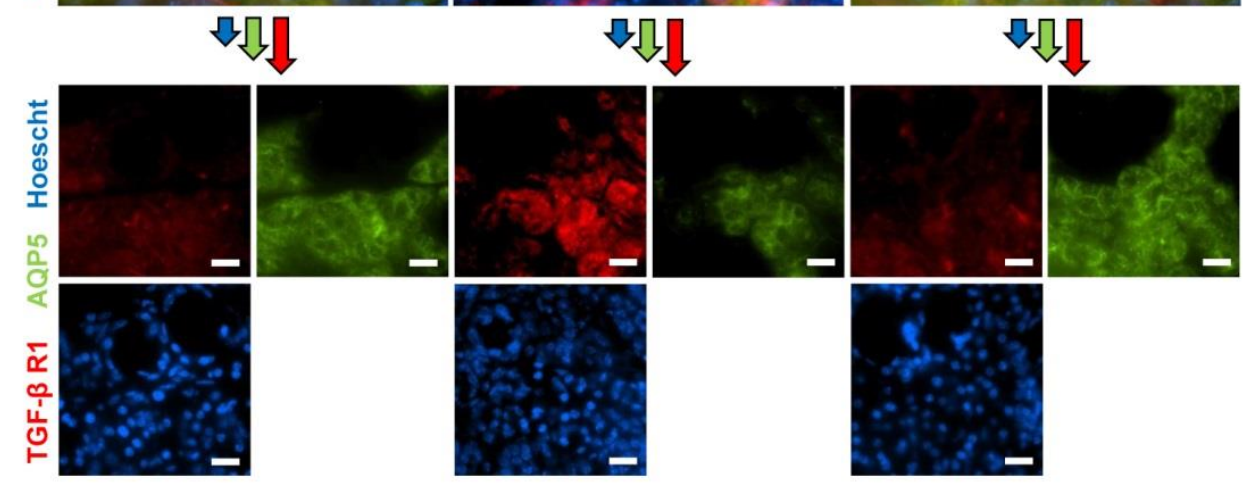


Fig. Appendix II-3. Upregulation of Smad2/3, TAK1 and TAB1 in response to SMG duct ligation is reversible upon duct deligation. (A) Western blot analysis of whole gland lysates from unligated control SMG, SMG after a 7 day duct ligation or a 7 day ligation followed by deligation and a 28 day recovery. Duct ligation increases Smad2/3 expression (top) and phospho-Smad2/3 levels (middle) that return to control levels after deligation and recovery. Ponceau S staining (bottom) shows equal amounts of total protein in each well. Immunofluorescence analysis revealed that increases in (B) Smad2/3 (red) expression and (C) p-Smad2/3 (red) levels after a 7 day duct ligation are restricted to acinar cells (marked by residual AQP5 expression; green), where $\mathrm{p}-\mathrm{Smad} 2 / 3$ is localized to the nucleus, as determined by colocalization with Hoechst nuclear stain (blue). Smad2/3 and p-Smad2/3 returned to control levels after deligation of SMG ducts and recovery. Images are representative of results from at least 3 independent experiments and scale bar $=20 \mu \mathrm{m}$. (D) RT-PCR analysis of whole gland lysates shows increased TAK1 and TAB1 mRNA expression following a 7 day duct ligation, which was reversed to control levels following deligation and a 28 day recovery. Data represent means \pm S.E.M. $(n=6$ for control, $n=8$ for 7 day ligation, $n=5$ for 7 day ligation, deligation and a 28 day recovery), where $* P<0.05$ and $* * P<0.01$ indicate significant differences in mRNA expression, as compared to control SMG. 

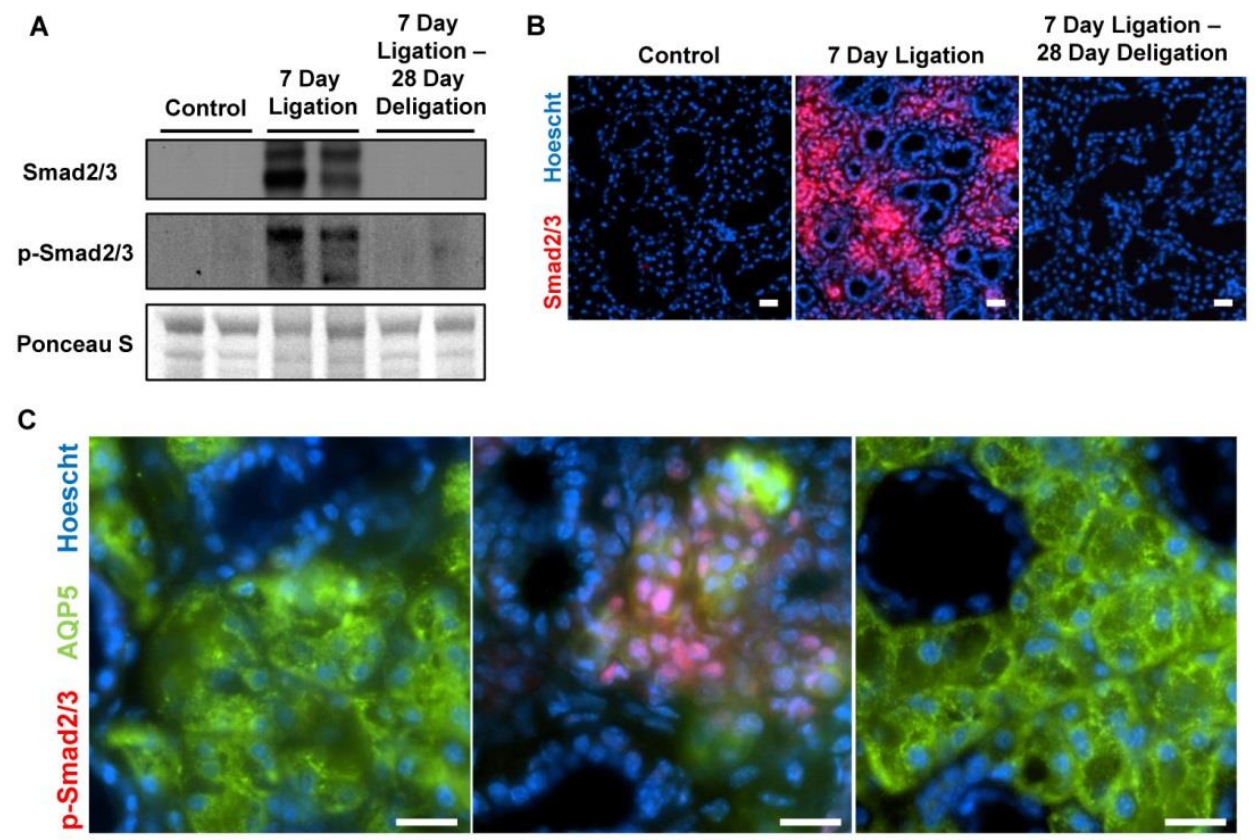

Control

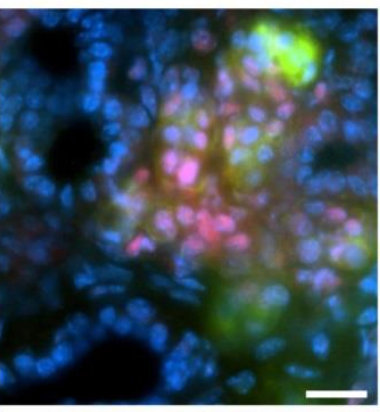

7 Day Ligation

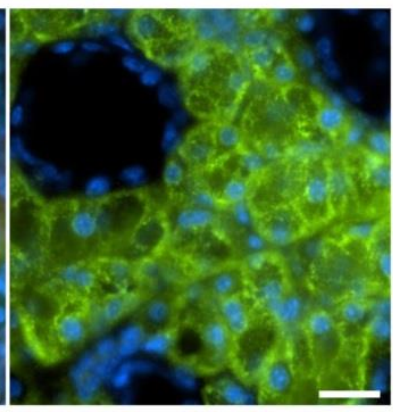

7 Day Ligation 28 Day Deligation
D

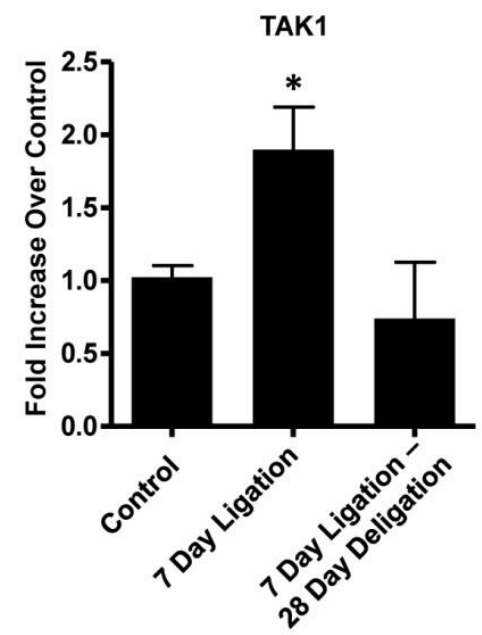

TAB1

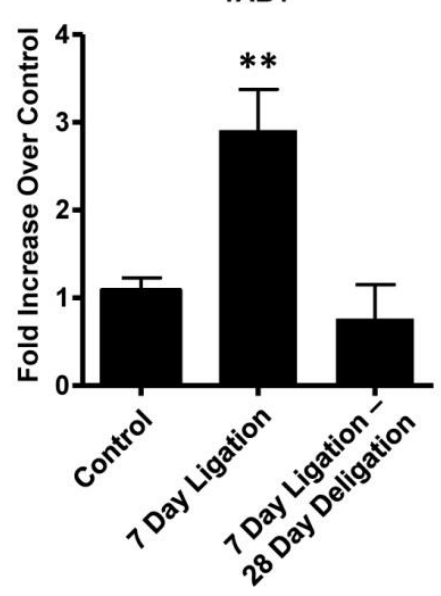


Fig. Appendix II-4. Upregulation of Snail and Slug in response to SMG duct ligation is reversible upon duct deligation. RT-PCR analysis of cDNA prepared from whole SMGs shows significant upregulation of (A) Snail and (B) Slug mRNA after a 7 day duct ligation, which is reversed to control levels after deligation and a 28 day recovery. Data represent means \pm S.E.M. $(n=4$ for control, $n=8$ for 7 day ligation, $n=5$ for 7 day ligation, deligation and a 28 day recovery), where $* * * P<0.001$ and $* P<0.05$ indicate significant differences in mRNA expression, as compared to control SMG. (C) Immunofluorescence analysis reveals that Snail (red) expression is primarily upregulated in acinar cells after a 7 day duct ligation, and returns to control levels after deligation and recovery. (D) Dual-immunofluorescence staining confirmed the colocalization of Snail (red) with the acinar marker AQP5 (green) following a 7 day duct ligation. Hoechst nuclear stain in blue and scale bar $=20 \mu \mathrm{m}$. Images are representative of results from at least 3 independent experiments. 

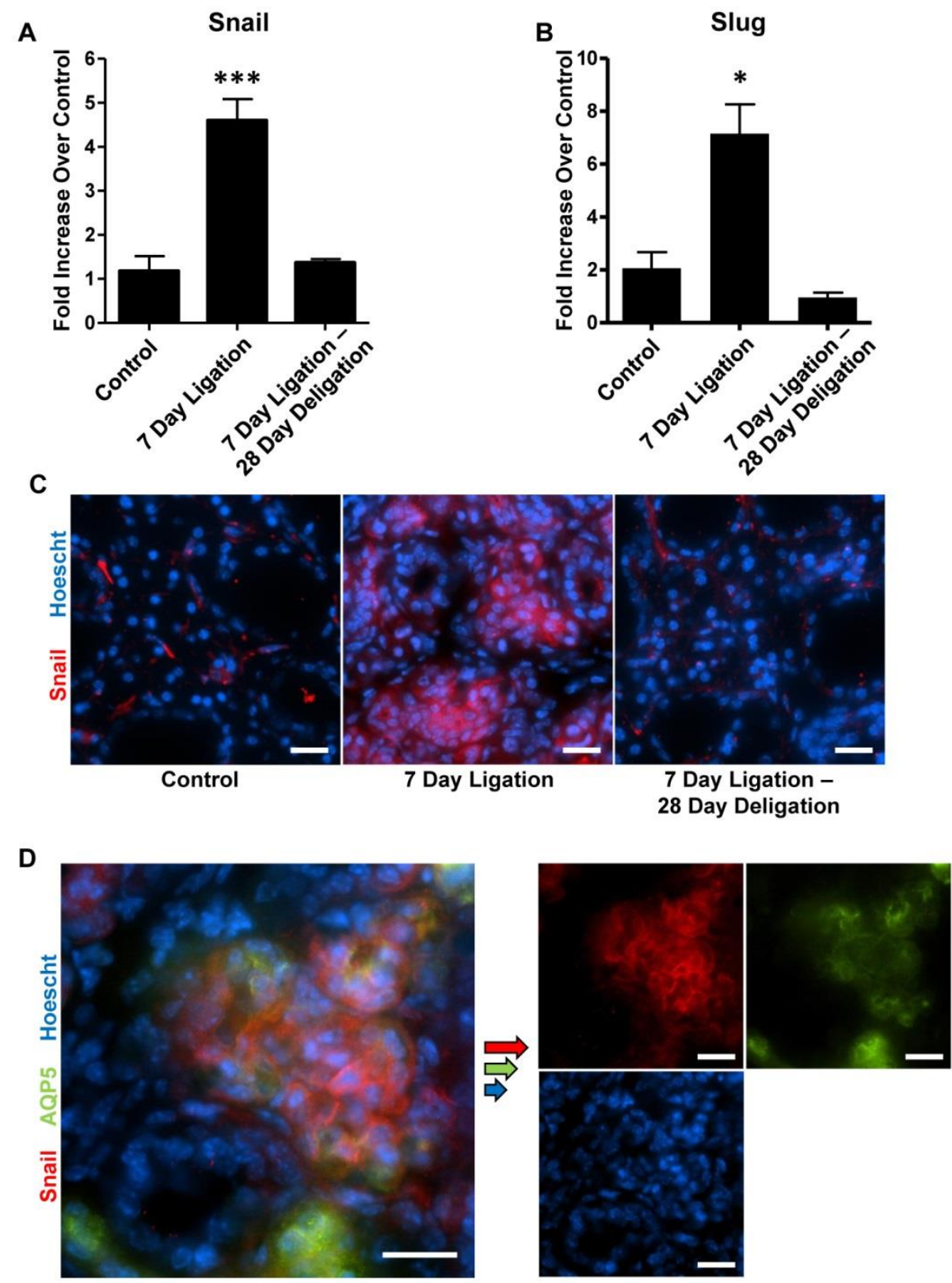

7 Day Ligation 
Fig. Appendix II-5. E-cadherin upregulation in response to SMG duct ligation is reversible after duct deligation. (A) RT-PCR analysis of cDNA prepared from whole SMGs shows significant upregulation of E-cadherin mRNA after a 7 day duct ligation (grey bar), which is reversed to control levels (white bar) after deligation and a 28 day recovery (black bar). Data represent means \pm S.E.M. $(n=8$ for control, $n=7$ for 7 day ligation, $\mathrm{n}=5$ for 7 day ligation, deligation and a 28 day recovery), where $* * * P<0.001$ indicates a significant difference in mRNA expression, as compared to control SMG. (B) Immunofluorescence analysis reveals that E-cadherin (red) was significantly upregulated in SMG ducts after a 7 day ligation, and returned to control levels after deligation and recovery. Hoechst nuclear stain in blue and scale bar $=20 \mu \mathrm{m}$. Images are representative of results from at least 3 independent experiments. 


\section{A EMT Markers}

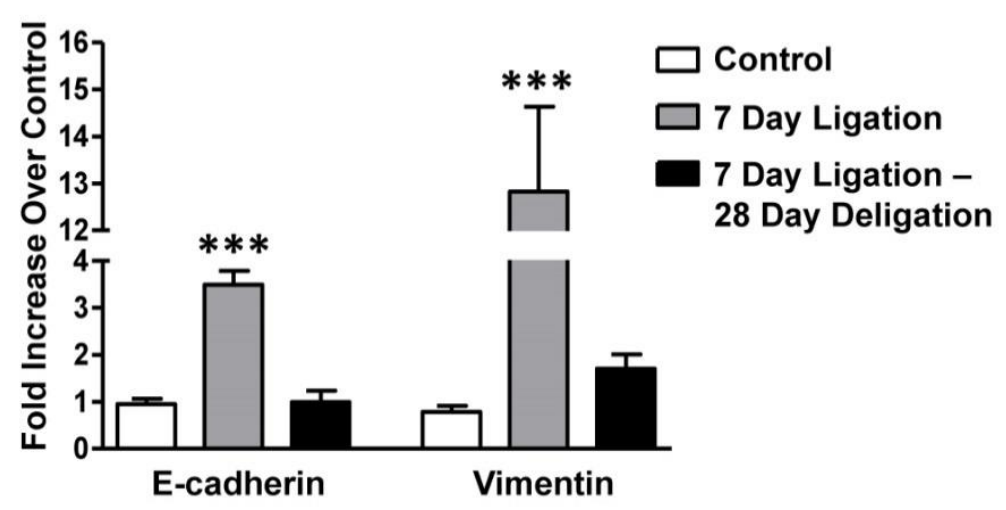

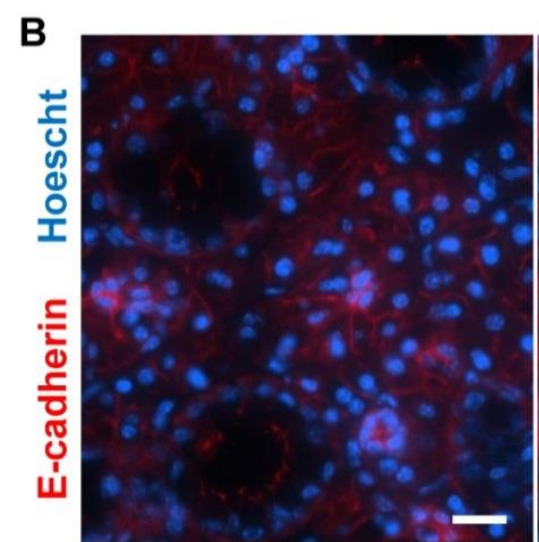

Control

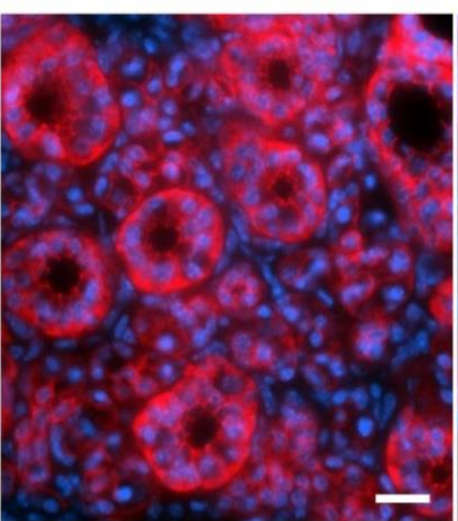

7 Day Ligation

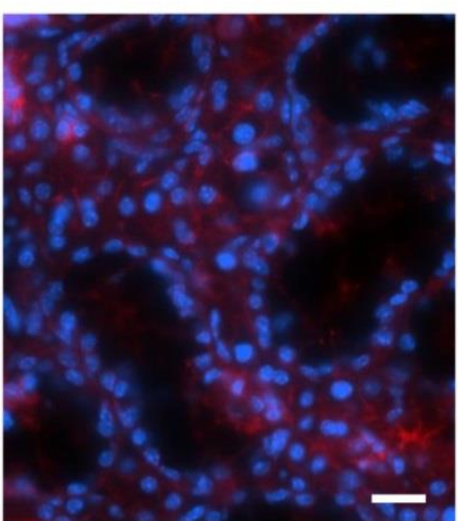

7 Day Ligation 28 Day Deligation 
Fig. Appendix II-6. Glandular fibrosis following SMG duct ligation is resolved following deligation. SMGs from unligated controls (A, D), after a 7 day duct ligation $(\mathrm{B}, \mathrm{E})$ or a 7 day ligation followed by deligation and a 28 day recovery $(\mathrm{C}, \mathrm{F})$ were subjected to Masson's trichrome staining to analyze collagen deposition (blue). A 7 day duct ligation resulted in blue staining of collagen fibers around blood vessels and large saliva collecting ducts (B), as compared to controls (A). At 400X magnification, heavy deposition of collagen fibers can be seen in the interstitial area around acinar and ductal cells after a 7 day duct ligation (E), as compared to controls (D). Following ductal deligation and a 28 day recovery $(\mathrm{C}, \mathrm{F})$, collagen deposition returns to levels similar to control SMGs (A, D). Images are representative of results from at least 3 independent experiments. (A-C) scale bar $=1,000 \mu \mathrm{m},(\mathrm{D}-\mathrm{F})$ scale bar $=20 \mu \mathrm{m}$. (G) RT-PCR analysis of cDNA prepared from whole SMGs shows extensive upregulation of collagen 1 and fibronectin mRNAs after a 7 day duct ligation (grey bars), which is reversed to control levels (white bars) after deligation and a 28 day recovery (black bars). Data represent means \pm S.E.M. $(n=8$ for control, $n=7$ for 7 day ligation, $n=5$ for 7 day ligation, deligation and a 28 day recovery), where $* * * P<0.001$ indicates a significant difference in mRNA expression, as compared to control SMGs. 


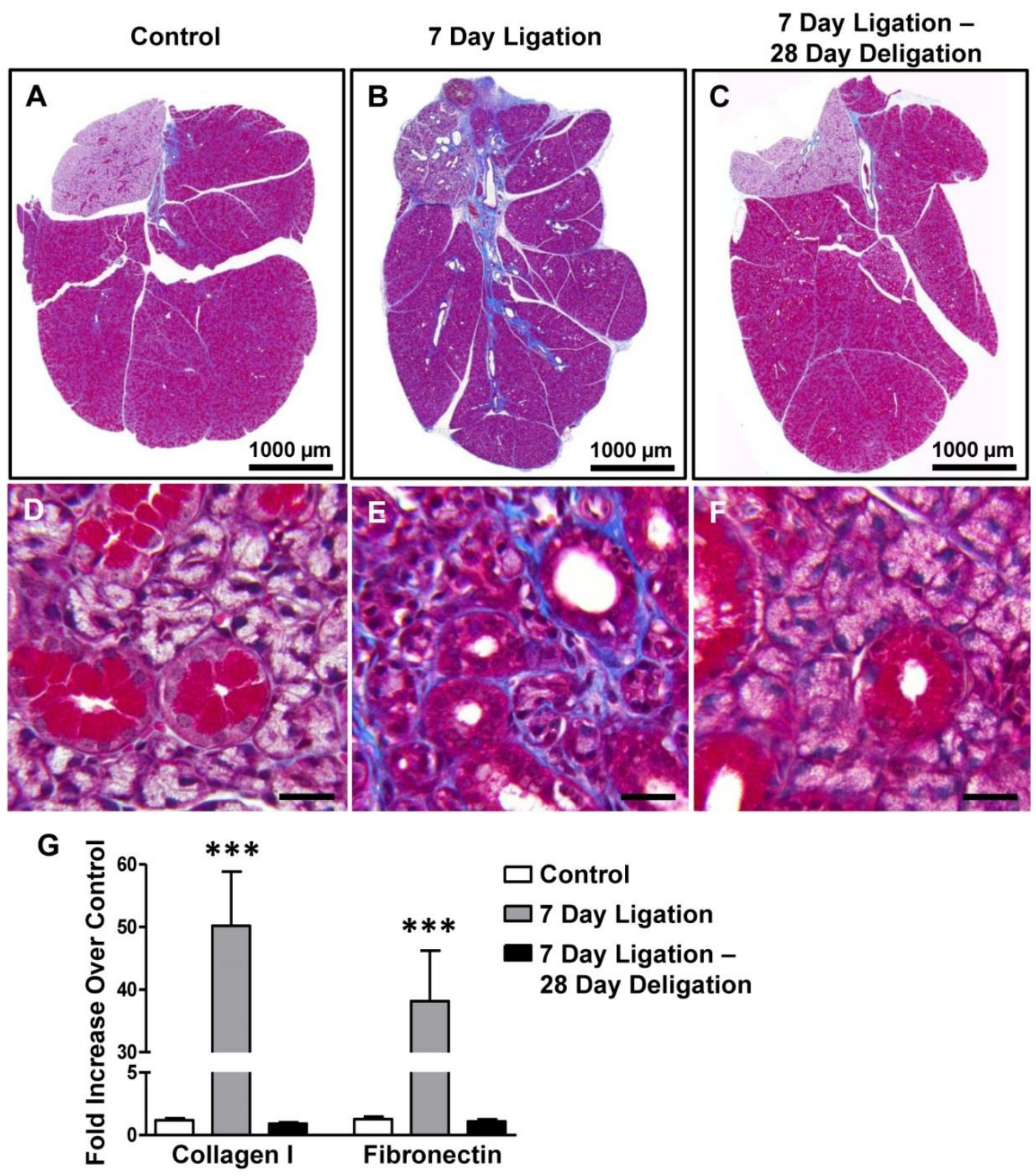


Fig. Appendix II-7. TGF- $\beta$ R1 inhibitors SB431542 and GW788388 attenuate duct ligation-induced upregulation of fibrosis markers. RT-PCR analysis of 7 day ligated and contralateral unligated control SMGs shows significant attenuation of 7 day duct ligation-induced collagen 1 and fibronectin mRNA upregulation in mice treated with either SB431542 (20 mg/kg mouse weight) or GW788388 (2 mg/kg mouse weight), as compared to DMSO-treated controls. Data represent means \pm S.E.M. $(n=6$ for DMSO, $n$ $=6$ for SB431542, $\mathrm{n}=5$ for GW788388), where $* P<0.05$ and $* * * P<0.001$ indicate significant differences in mRNA expression, as compared to DMSO-treated controls.

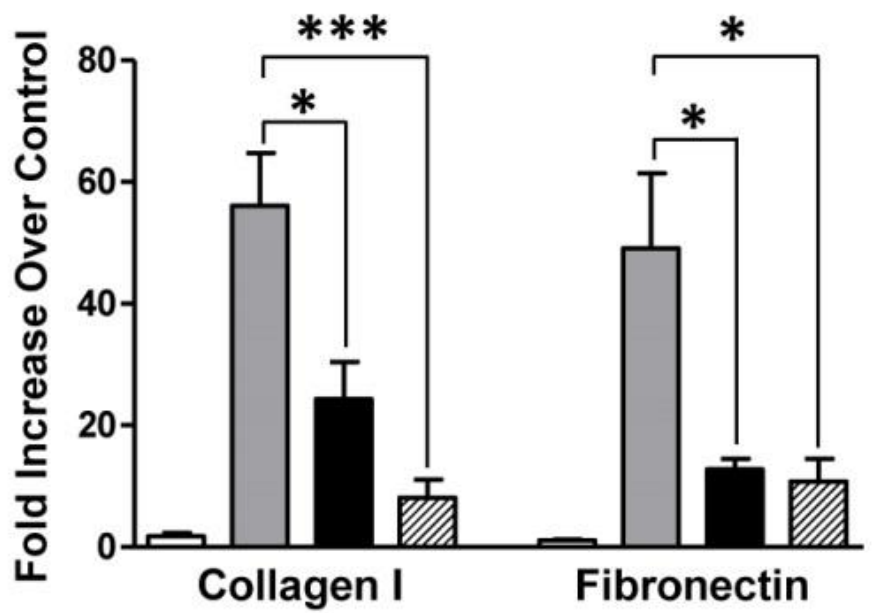
Control
7 Day Ligation + DMSO
7 Day Ligation + SB 431542
שת 7 Day Ligation + GW 788388 


\section{References}

1. Pedersen AM, Bardow A, Jensen SB, Nauntofte B. Saliva and gastrointestinal functions of taste, mastication, swallowing and digestion. Oral diseases. 2002;8(3):117-29. Epub 2002/07/11. pmid:12108756.

2. Atkinson JC, Grisius M, Massey W. Salivary hypofunction and xerostomia: diagnosis and treatment. Dental clinics of North America. 2005;49(2):309-26. Epub 2005/03/10. pmid:15755407.

3. Brito-Zeron P, Siso-Almirall A, Bove A, Kostov BA, Ramos-Casals M. Primary Sjogren syndrome: an update on current pharmacotherapy options and future directions. Expert opinion on pharmacotherapy. 2013;14(3):279-89. Epub 2013/01/26. pmid:23346917.

4. Fox PC. Acquired salivary dysfunction. Drugs and radiation. Annals of the New York Academy of Sciences. 1998;842:132-7. Epub 1998/05/26. pmid:9599303.

5. . Vissink A, Mitchell JB, Baum BJ, Limesand KH, Jensen SB, Fox PC, et al. Clinical management of salivary gland hypofunction and xerostomia in head-andneck cancer patients: successes and barriers. International journal of radiation oncology, biology, physics. 2010;78(4):983-91. Epub 2010/10/26. pmid:20970030; PubMed Central PMCID: PMC2964345.

6. . Lombaert IM, Brunsting JF, Wierenga PK, Faber H, Stokman MA, Kok T, et al. Rescue of salivary gland function after stem cell transplantation in irradiated glands. PloS one. 2008;3(4):e2063. Epub 2008/05/01. pmid:18446241; PubMed Central PMCID: PMC2329592. 
7. Ogawa M, Oshima M, Imamura A, Sekine Y, Ishida K, Yamashita K, et al. Functional salivary gland regeneration by transplantation of a bioengineered organ germ. Nature communications. 2013;4:2498. Epub 2013/10/03. pmid:24084982; PubMed Central PMCID: PMC3806330.

8. Woods LT, Camden JM, Batek JM, Petris MJ, Erb L, Weisman GA. P2X7 receptor activation induces inflammatory responses in salivary gland epithelium. American journal of physiology Cell physiology. 2012;303(7):C790-801. Epub 2012/08/10. pmid:22875784; PubMed Central PMCID: PMC3469598.

9. Ahn JS, Camden JM, Schrader AM, Redman RS, Turner JT. Reversible regulation of $\mathrm{P} 2 \mathrm{Y}_{2}$ nucleotide receptor expression in the duct-ligated rat submandibular gland. American journal of physiology Cell physiology. 2000;279(2):C286-94. Epub 2000/07/27. pmid:10912994.

10. pathology. 1979;8(5):293-304. Epub 1979/10/01. pmid:119842.

11. Takahashi S, Schoch E, Walker NI. Origin of acinar cell regeneration after atrophy of the rat parotid induced by duct obstruction. International journal of experimental pathology. 1998;79(5):293-301. Epub 1999/04/08. pmid:10193312; PubMed Central PMCID: PMC3220221.

12. Burgess KL, Dardick I. Cell population changes during atrophy and regeneration of rat parotid gland. Oral surgery, oral medicine, oral pathology, oral radiology, and endodontics. 1998;85(6):699-706. Epub 1998/06/25. pmid:9638704.

13. . Arany S, Catalan MA, Roztocil E, Ovitt CE. Ascl3 knockout and cell ablation models reveal complexity of salivary gland maintenance and regeneration. 
Developmental biology. 2011;353(2):186-93. Epub 2011/03/08. pmid:21377457; PubMed Central PMCID: PMC3093111.

14. Cotroneo E, Proctor GB, Carpenter GH. Regeneration of acinar cells following ligation of rat submandibular gland retraces the embryonic-perinatal pathway of cytodifferentiation. Differentiation; research in biological diversity. 2010;79(2):120-30. Epub 2010/01/09. pmid:20056310; PubMed Central PMCID: PMC2841285.

15. Scott J, Liu P, Smith PM. Morphological and functional characteristics of acinar atrophy and recovery in the duct-ligated parotid gland of the rat. Journal of dental research. 1999;78(11):1711-9. Epub 1999/11/27. pmid:10576167.

16. . Redman RS. On approaches to the functional restoration of salivary glands damaged by radiation therapy for head and neck cancer, with a review of related aspects of salivary gland morphology and development. Biotechnic \& histochemistry: official publication of the Biological Stain Commission. 2008;83(3):103-30. Epub 2008/10/02. pmid:18828044; PubMed Central PMCID: PMC2740375.

17. Cotroneo E, Proctor GB, Paterson KL, Carpenter GH. Early markers of regeneration following ductal ligation in rat submandibular gland. Cell and tissue research. 2008;332(2):227-35. Epub 2008/03/13. pmid:18335244; PubMed Central PMCID: PMC2493059.

18. . Man YG, Ball WD, Marchetti L, Hand AR. Contributions of intercalated duct cells to the normal parenchyma of submandibular glands of adult rats. The Anatomical record. 2001;263(2):202-14. Epub 2001/05/22. pmid:11360236. 
19. . Takahashi S, Nakamura S, Suzuki R, Islam N, Domon T, Yamamoto T, et al. Apoptosis and mitosis of parenchymal cells in the duct-ligated rat submandibular gland. Tissue \& cell. 2000;32(6):457-63. Epub 2001/02/24. pmid:11197228.

20. Zaia AA, Della Coletta R, Almeida OP, Line SR. Expression of collagen and elastic fibers in duct-ligated submandibular glands of mice. European journal of oral sciences. 1996;104(5-6):627-9. Epub 1996/10/01. pmid:9021337.

21. Tamarin A. Submaxillary gland recovery from obstruction. I. Overall changes and electron microscopic alterations of granular duct cells. Journal of ultrastructure research. 1971;34(3):276-87. Epub 1971/02/01. pmid:4926049.

22. Liu Y. Renal fibrosis: new insights into the pathogenesis and therapeutics. Kidney international. 2006;69(2):213-7. Epub 2006/01/13. pmid:16408108.

23. Tatler AL, Jenkins G. TGF- $\beta$ activation and lung fibrosis. Proceedings of the American Thoracic Society. 2012;9(3):130-6. Epub 2012/07/18. pmid:22802287.

24. Mallat A, Lotersztajn S. Cellular mechanisms of tissue fibrosis. 5. Novel insights into liver fibrosis. American journal of physiology Cell physiology. 2013;305(8):C789-99. Epub 2013/08/02. pmid:23903700.

25 . growth factor- $\beta$ signaling and expansion of progenitor cells in regenerating liver. Hepatology. 2010;51(4):1373-82. Epub 2010/02/05. pmid:20131405; PubMed Central PMCID: PMC3001243.

26. . Annes JP, Munger JS, Rifkin DB. Making sense of latent TGF- $\beta$ activation. Journal of cell science. 2003;116(Pt 2):217-24. Epub 2002/12/17. pmid:12482908. 
27. Yu Q, Stamenkovic I. Cell surface-localized matrix metalloproteinase-9 proteolytically activates TGF- $\beta$ and promotes tumor invasion and angiogenesis. Genes \& development. 2000;14(2):163-76. Epub 2000/02/01. pmid:10652271; PubMed Central PMCID: PMC316345.

28. Murphy-Ullrich JE, Poczatek M. Activation of latent TGF- $\beta$ by thrombospondin1: mechanisms and physiology. Cytokine \& growth factor reviews. 2000;11(12):59-69. Epub 2000/03/10. pmid:10708953.

29. Munger JS, Huang X, Kawakatsu H, Griffiths MJ, Dalton SL, Wu J, et al. The integrin $\alpha_{v} \beta_{6}$ binds and activates latent TGF- $\beta 1$ : a mechanism for regulating pulmonary inflammation and fibrosis. Cell. 1999;96(3):319-28. Epub 1999/02/20. pmid:10025398.

30. Moustakas A, Souchelnytskyi S, Heldin CH. Smad regulation in TGF- $\beta$ signal transduction. Journal of cell science. 2001;114(Pt 24):4359-69. Epub 2002/01/17. pmid:11792802.

31. Brandl M, Seidler B, Haller F, Adamski J, Schmid RM, Saur D, et al. IKK $\alpha$ controls canonical TGF- $\beta$-SMAD signaling to regulate genes expressing SNAIL and SLUG during EMT in panc1 cells. Journal of cell science. 2010;123(Pt 24):4231-9. Epub 2010/11/18. pmid:21081648.

32. . Cano A, Perez-Moreno MA, Rodrigo I, Locascio A, Blanco MJ, del Barrio MG, et al. The transcription factor snail controls epithelial-mesenchymal transitions by repressing E-cadherin expression. Nature cell biology. 2000;2(2):76-83. Epub 2000/02/03. pmid:10655586. 
33. Wang Y, Shi J, Chai K, Ying X, Zhou BP. The Role of Snail in EMT and Tumorigenesis. Current cancer drug targets. 2013;13(9):963-72. Epub 2013/10/31. pmid:24168186.

34. Medici D, Hay ED, Olsen BR. Snail and Slug promote epithelial-mesenchymal transition through $\beta$-catenin-T-cell factor-4-dependent expression of transforming growth factor- $\beta 3$. Molecular biology of the cell. 2008;19(11):4875-87. Epub 2008/09/19. pmid:18799618; PubMed Central PMCID: PMC2575183.

35. Gardner A, Fisher AJ, Richter C, Johnson GE, Moisey EJ, Brodlie M, et al. The critical role of TAK1 in accentuated epithelial to mesenchymal transition in obliterative bronchiolitis after lung transplantation. The American journal of pathology. 2012;180(6):2293-308. Epub 2012/04/25. pmid:22525462; PubMed Central PMCID: PMC3366074.

36. Strippoli R, Benedicto I, Perez Lozano ML, Pellinen T, Sandoval P, LopezCabrera M, et al. Inhibition of transforming growth factor-activated kinase 1 (TAK1) blocks and reverses epithelial to mesenchymal transition of mesothelial cells. PloS one. 2012;7(2):e31492. Epub 2012/03/03. pmid:22384029; PubMed Central PMCID: PMC3288041.

37. Kalluri R, Weinberg RA. The basics of epithelial-mesenchymal transition. The Journal of clinical investigation. 2009;119(6):1420-8. Epub 2009/06/03. pmid:19487818; PubMed Central PMCID: PMC2689101.

38. Thiery JP. Epithelial-mesenchymal transitions in tumour progression. Nature reviews Cancer. 2002;2(6):442-54. Epub 2002/08/22. pmid:12189386. 
39. Kalluri R, Neilson EG. Epithelial-mesenchymal transition and its implications for fibrosis. The Journal of clinical investigation. 2003;112(12):1776-84. Epub 2003/12/18. pmid:14679171; PubMed Central PMCID: PMC297008.

40. . Xue ZF, Wu XM, Liu M. Hepatic regeneration and the epithelial to mesenchymal transition. World journal of gastroenterology: WJG. 2013;19(9):1380-6. Epub 2013/03/30. pmid:23538893; PubMed Central PMCID: PMC3602497.

41. Xu J, Lamouille S, Derynck R. TGF- $\beta$-induced epithelial to mesenchymal transition. Cell research. 2009;19(2):156-72. Epub 2009/01/21. pmid:19153598.

42. Peinado H, Ballestar E, Esteller M, Cano A. Snail mediates E-cadherin repression by the recruitment of the Sin3A/histone deacetylase 1 (HDAC1)/HDAC2 complex. Molecular and cellular biology. 2004;24(1):306-19. Epub 2003/12/16. pmid:14673164; PubMed Central PMCID: PMC303344.

43. Batlle E, Sancho E, Franci C, Dominguez D, Monfar M, Baulida J, et al. The transcription factor snail is a repressor of E-cadherin gene expression in epithelial tumour cells. Nature cell biology. 2000;2(2):84-9. Epub 2000/02/03. pmid:10655587.

44. Wong AP, Keating A, Lu WY, Duchesneau P, Wang X, Sacher A, et al. Identification of a bone marrow-derived epithelial-like population capable of repopulating injured mouse airway epithelium. The Journal of clinical investigation. 2009;119(2):336-48. Epub 2009/01/24. pmid:19164856; PubMed Central PMCID: PMC2631300. 
45. Khan SQ, Guo L, Cimbaluk DJ, Elshabrawy H, Faridi MH, Jolly M, et al. A Small Molecule $\beta_{2}$ Integrin Agonist Improves Chronic Kidney Allograft Survival by Reducing Leukocyte Recruitment and Accompanying Vasculopathy. Frontiers in medicine. 2014;1:45. Epub 2015/01/17. pmid:25593918; PubMed Central PMCID: PMC4291902.

46. . Mu Y, Sundar R, Thakur N, Ekman M, Gudey SK, Yakymovych M, et al. TRAF6 ubiquitinates TGF- $\beta$ type I receptor to promote its cleavage and nuclear translocation in cancer. Nature communications. 2011;2:330. Epub 2011/06/02. pmid:21629263; PubMed Central PMCID: PMC3113296.

47. . Liu X, Xiong C, Jia S, Zhang Y, Chen YG, Wang Q, et al. Araf kinase antagonizes Nodal-Smad 2 activity in mesendoderm development by directly phosphorylating the Smad2 linker region. Nature communications. 2013;4:1728. Epub 2013/04/18. pmid:23591895; PubMed Central PMCID: PMC3644095.

48. Huang XY, Zhang C, Cai JB, Shi GM, Ke AW, Dong ZR, et al. Comprehensive multiple molecular profile of epithelial mesenchymal transition in intrahepatic cholangiocarcinoma patients. PloS one. 2014;9(5):e96860. Epub 2014/05/13. pmid:24816558; PubMed Central PMCID: PMC4016113.

49. Sampson VB, David JM, Puig I, Patil PU, de Herreros AG, Thomas GV, et al. Wilms' tumor protein induces an epithelial-mesenchymal hybrid differentiation state in clear cell renal cell carcinoma. PloS one. 2014;9(7):e102041. Epub 2014/07/16. pmid:25025131; PubMed Central PMCID: PMC4099076.

50. . Silver N, Proctor GB, Arno M, Carpenter GH. Activation of mTOR coincides with autophagy during ligation-induced atrophy in the rat submandibular gland. 
Cell death \& disease. 2010;1:e14. Epub 2010/10/05. pmid:20890458; PubMed Central PMCID: PMC2948542.

51. Shi Y, Massague J. Mechanisms of TGF- $\beta$ signaling from cell membrane to the nucleus. Cell. 2003;113(6):685-700. Epub 2003/06/18. pmid:12809600.

52. Kim SI, Kwak JH, Na HJ, Kim JK, Ding Y, Choi ME. Transforming growth factor- $\beta$ (TGF- $\beta 1$ ) activates TAK1 via TAB1-mediated autophosphorylation, independent of TGF- $\beta$ receptor kinase activity in mesangial cells. The Journal of biological chemistry. 2009;284(33):22285-96. Epub 2009/06/27. pmid:19556242; PubMed Central PMCID: PMC2755952.

53. Massague J, Seoane J, Wotton D. Smad transcription factors. Genes \& development. 2005;19(23):2783-810. Epub 2005/12/03. pmid:16322555.

54. Cho HJ, Baek KE, Saika S, Jeong MJ, Yoo J. Snail is required for transforming growth factor- $\beta$-induced epithelial-mesenchymal transition by activating PI3 kinase/Akt signal pathway. Biochemical and biophysical research communications. 2007;353(2):337-43. Epub 2006/12/26. pmid:17187756.

55. Hoot KE, Lighthall J, Han G, Lu SL, Li A, Ju W, et al. Keratinocyte-specific Smad2 ablation results in increased epithelial-mesenchymal transition during skin cancer formation and progression. The Journal of clinical investigation. 2008;118(8):2722-32. Epub 2008/07/12. pmid:18618014; PubMed Central PMCID: PMC2447925.

56. . Hall BE, Zheng C, Swaim WD, Cho A, Nagineni CN, Eckhaus MA, et al. Conditional overexpression of TGF- $\beta 1$ disrupts mouse salivary gland development and function. Laboratory investigation; a journal of technical 
methods and pathology. 2010;90(4):543-55. Epub 2010/02/10. pmid:20142803; PubMed Central PMCID: PMC2847636.

57. Bonniaud P, Margetts PJ, Kolb M, Schroeder JA, Kapoun AM, Damm D, et al. Progressive transforming growth factor $\beta 1$-induced lung fibrosis is blocked by an orally active ALK5 kinase inhibitor. American journal of respiratory and critical care medicine. 2005;171(8):889-98. Epub 2004/11/26. pmid:15563636.

58. Petersen M, Thorikay M, Deckers M, van Dinther M, Grygielko ET, Gellibert F, et al. Oral administration of GW788388, an inhibitor of TGF- $\beta$ type I and II receptor kinases, decreases renal fibrosis. Kidney international. 2008;73(6):70515. Epub 2007/12/14. pmid:18075500.

59. Gellibert F, de Gouville AC, Woolven J, Mathews N, Nguyen VL, Bertho-Ruault C, et al. Discovery of 4-\{4-[3-(pyridin-2-yl)-1H-pyrazol-4-yl]pyridin-2-yl $\}$-N(tetrahydro-2H- pyran-4-yl)benzamide (GW788388): a potent, selective, and orally active transforming growth factor- $\beta$ type I receptor inhibitor. Journal of medicinal chemistry. 2006;49(7):2210-21. Epub 2006/03/31. pmid:16570917.

60. Segawa S, Goto D, Yoshiga Y, Sugihara M, Hayashi T, Chino Y, et al. Inhibition of transforming growth factor- $\beta$ signalling attenuates interleukin (IL)-18 plus IL2-induced interstitial lung disease in mice. Clinical and experimental immunology. 2010;160(3):394-402. Epub 2010/01/22. pmid:20089076; PubMed Central PMCID: PMC2883110.

61. . Wu MY, Hill CS. TGF- $\beta$ superfamily signaling in embryonic development and homeostasis. Developmental cell. 2009;16(3):329-43. Epub 2009/03/18. pmid:19289080. 
62. Sanjabi S, Zenewicz LA, Kamanaka M, Flavell RA. Anti-inflammatory and proinflammatory roles of TGF- $\beta$, IL-10, and IL-22 in immunity and autoimmunity. Current opinion in pharmacology. 2009;9(4):447-53. Epub 2009/06/02. pmid:19481975; PubMed Central PMCID: PMC2755239.

63. Jaskoll T, Choy HA, Melnick M. Glucocorticoids, TGF- $\beta$, and embryonic mouse salivary gland morphogenesis. Journal of craniofacial genetics and developmental biology. 1994;14(4):217-30. Epub 1994/10/01. pmid:7883868.

64. Hoffman MP, Kibbey MC, Letterio JJ, Kleinman HK. Role of laminin-1 and TGF- $\beta 3$ in acinar differentiation of a human submandibular gland cell line (HSG). Journal of cell science. 1996;109 (Pt 8):2013-21. Epub 1996/08/01. pmid:8856497.

65. . Janebodin K, Buranaphatthana W, Ieronimakis N, Hays AL, Reyes M. An in vitro culture system for long-term expansion of epithelial and mesenchymal salivary gland cells: role of TGF- $\beta 1$ in salivary gland epithelial and mesenchymal differentiation. BioMed research international. 2013;2013:815895. Epub 2013/07/11. pmid:23841093; PubMed Central PMCID: PMC3690740.

66. . Nandula SR, Amarnath S, Molinolo A, Bandyopadhyay BC, Hall B, Goldsmith $\mathrm{CM}$, et al. Female mice are more susceptible to developing inflammatory disorders due to impaired transforming growth factor- $\beta$ signaling in salivary glands. Arthritis and rheumatism. 2007;56(6):1798-805. Epub 2007/05/29. pmid: 17530708 . 
67. Christ M, McCartney-Francis NL, Kulkarni AB, Ward JM, Mizel DE, Mackall CL, et al. Immune dysregulation in TGF- $\beta 1$-deficient mice. J Immunol. 1994;153(5):1936-46. Epub 1994/09/01. pmid:8051399.

68. McCartney-Francis NL, Mizel DE, Redman RS, Frazier-Jessen M, Panek RB, Kulkarni AB, et al. Autoimmune Sjogren's-like lesions in salivary glands of TGF$\beta 1$-deficient mice are inhibited by adhesion-blocking peptides. J Immunol. 1996;157(3):1306-12. Epub 1996/08/01. pmid:8757639.

69. Dang H, Geiser AG, Letterio JJ, Nakabayashi T, Kong L, Fernandes G, et al. SLE-like autoantibodies and Sjogren's syndrome-like lymphoproliferation in TGF- $\beta$ knockout mice. J Immunol. 1995;155(6):3205-12. Epub 1995/09/15. pmid:7673733.

70. Mason GI, Hamburger J, Bowman S, Matthews JB. Salivary gland expression of transforming growth factor- $\beta$ isoforms in Sjogren's syndrome and benign lymphoepithelial lesions. Molecular pathology: MP. 2003;56(1):52-9. Epub 2003/02/01. pmid:12560464; PubMed Central PMCID: PMC1187290.

71. Kizu Y, Sakurai H, Katagiri S, Shinozaki N, Ono M, Tsubota K, et al. Immunohistological analysis of tumour growth factor- $\beta 1$ expression in normal and inflamed salivary glands. Journal of clinical pathology. 1996;49(9):728-32. Epub 1996/09/01. pmid:9038756; PubMed Central PMCID: PMC500721.

72. Teymoortash A, Tiemann M, Schrader C, Hartmann O, Werner JA. Transforming growth factor- $\beta$ in chronic obstructive sialadenitis of human submandibular gland. Archives of oral biology. 2003;48(2):111-6. Epub 2003/03/19. pmid:12642229. 
73. Cauli A, Yanni G, Pitzalis C, Challacombe S, Panayi GS. Cytokine and adhesion molecule expression in the minor salivary glands of patients with Sjogren's syndrome and chronic sialoadenitis. Annals of the rheumatic diseases. 1995;54(3):209-15. Epub 1995/03/01. pmid:7748018; PubMed Central PMCID: PMC1005558.

74. . Harrison JD, Badir MS. Chronic submandibular sialadenitis: ultrastructure and phosphatase histochemistry. Ultrastructural pathology. 1998;22(6):431-7. Epub 1999/01/19. pmid:9891921.

75. . Wynn TA. Cellular and molecular mechanisms of fibrosis. The Journal of pathology. 2008;214(2):199-210. Epub 2007/12/29. pmid:18161745; PubMed Central PMCID: PMC2693329.

76. Farris AB, Colvin RB. Renal interstitial fibrosis: mechanisms and evaluation. Current opinion in nephrology and hypertension. 2012;21(3):289-300. Epub 2012/03/28. pmid:22449945; PubMed Central PMCID: PMC3354760.

77. Ignotz RA, Massague J. Transforming growth factor- $\beta$ stimulates the expression of fibronectin and collagen and their incorporation into the extracellular matrix. The Journal of biological chemistry. 1986;261(9):4337-45. Epub 1986/03/25. pmid:3456347.

78. Chen SJ, Yuan W, Mori Y, Levenson A, Trojanowska M, Varga J. Stimulation of type I collagen transcription in human skin fibroblasts by TGF- $\beta$ : involvement of Smad 3. The Journal of investigative dermatology. 1999;112(1):49-57. Epub 1999/01/14. pmid:9886263. 
79. Yang L, Inokuchi S, Roh YS, Song J, Loomba R, Park EJ, et al. Transforming growth factor- $\beta$ signaling in hepatocytes promotes hepatic fibrosis and carcinogenesis in mice with hepatocyte-specific deletion of TAK1.

Gastroenterology. 2013;144(5):1042-54 e4. Epub 2013/02/09. pmid:23391818; PubMed Central PMCID: PMC3752402.

80. . Sime PJ, Xing Z, Graham FL, Csaky KG, Gauldie J. Adenovector-mediated gene transfer of active transforming growth factor- $\beta 1$ induces prolonged severe fibrosis in rat lung. The Journal of clinical investigation. 1997;100(4):768-76. Epub 1997/08/15. pmid:9259574; PubMed Central PMCID: PMC508247.

81. Meng XM, Huang XR, Xiao J, Chen HY, Zhong X, Chung AC, et al. Diverse roles of TGF- $\beta$ receptor II in renal fibrosis and inflammation in vivo and in vitro. The Journal of pathology. 2012;227(2):175-88. Epub 2011/12/23. pmid:22190171.

82. . Cooper JS, Fu K, Marks J, Silverman S. Late effects of radiation therapy in the head and neck region. International journal of radiation oncology, biology, physics. 1995;31(5):1141-64. Epub 1995/03/30. pmid:7713779.

83. Grundmann O, Mitchell GC, Limesand KH. Sensitivity of salivary glands to radiation: from animal models to therapies. Journal of dental research. 2009;88(10):894-903. Epub 2009/09/29. pmid:19783796; PubMed Central PMCID: PMC2882712.

84. Hakim SG, Ribbat J, Berndt A, Richter P, Kosmehl H, Benedek GA, et al. Expression of Wnt-1, TGF- $\beta$ and related cell-cell adhesion components following radiotherapy in salivary glands of patients with manifested radiogenic xerostomia. 
Radiotherapy and oncology: journal of the European Society for Therapeutic Radiology and Oncology. 2011. Epub 2011/09/03. pmid:21885141.

85. Martin M, Lefaix J, Delanian S. TGF- $\beta 1$ and radiation fibrosis: a master switch and a specific therapeutic target? International journal of radiation oncology, biology, physics. 2000;47(2):277-90. Epub 2000/05/10. pmid:10802350.

86. Callahan JF, Burgess JL, Fornwald JA, Gaster LM, Harling JD, Harrington FP, et al. Identification of novel inhibitors of the transforming growth factor- $\beta 1$ (TGF31) type 1 receptor (ALK5). Journal of medicinal chemistry. 2002;45(5):9991001. Epub 2002/02/22. pmid:11855979.

87. . Muraoka-Cook RS, Shin I, Yi JY, Easterly E, Barcellos-Hoff MH, Yingling JM, et al. Activated type I TGF- $\beta$ receptor kinase enhances the survival of mammary epithelial cells and accelerates tumor progression. Oncogene. 2006;25(24):340823. Epub 2005/09/28. pmid:16186809.

88. Yoshiji H, Kuriyama S, Yoshii J, Ikenaka Y, Noguchi R, Nakatani T, et al. Tissue inhibitor of metalloproteinases-1 attenuates spontaneous liver fibrosis resolution in the transgenic mouse. Hepatology. 2002;36(4 Pt 1):850-60. Epub 2002/09/26. pmid:12297832.

89. . Zhou X, Hovell CJ, Pawley S, Hutchings MI, Arthur MJ, Iredale JP, et al. Expression of matrix metalloproteinase-2 and -14 persists during early resolution of experimental liver fibrosis and might contribute to fibrolysis. Liver international: official journal of the International Association for the Study of the Liver. 2004;24(5):492-501. Epub 2004/10/16. pmid:15482348. 
90. Xia JL, Dai C, Michalopoulos GK, Liu Y. Hepatocyte growth factor attenuates liver fibrosis induced by bile duct ligation. The American journal of pathology. 2006;168(5):1500-12. Epub 2006/05/03. pmid:16651617; PubMed Central PMCID: PMC1606599.

91. Hagimoto N, Kuwano K, Inoshima I, Yoshimi M, Nakamura N, Fujita M, et al. TGF- $\beta 1$ as an enhancer of Fas-mediated apoptosis of lung epithelial cells. $\mathbf{J}$ Immunol. 2002;168(12):6470-8. Epub 2002/06/11. pmid:12055267.

92. Boland S, Boisvieux-Ulrich E, Houcine O, Baeza-Squiban A, Pouchelet M, Schoevaert D, et al. TGF- $\beta 1$ promotes actin cytoskeleton reorganization and migratory phenotype in epithelial tracheal cells in primary culture. Journal of cell science. 1996;109 (Pt 9):2207-19. Epub 1996/09/01. pmid:8886972.

93. . Moses HL. TGF- $\beta$ regulation of epithelial cell proliferation. Molecular reproduction and development. 1992;32(2):179-84. Epub 1992/06/01. pmid:1637556.

94. Rezaie A, Khalaj S, Shabihkhani M, Nikfar S, Zamani MJ, Mohammadirad A, et al. Study on the correlations among disease activity index and salivary transforming growth factor- $\beta 1$ and nitric oxide in ulcerative colitis patients. Annals of the New York Academy of Sciences. 2007;1095:305-14. Epub 2007/04/04. pmid:17404043.

95. of transforming growth factor- $\beta$ in the oral cavity and esophagus of mice and its expression by mast cells in these tissues. The American journal of pathology. 2009;174(6):2137-49. Epub 2009/05/02. pmid:19406991; PubMed Central PMCID: PMC2684179. 
96. of TGF- $\beta$ on renal tubular epithelial cells by blocking Smad2 activation. Journal of the American Society of Nephrology: JASN. 2002;13(6):1464-72. Epub 2002/06/01. pmid:12039975

97. Bhowmick NA, Ghiassi M, Bakin A, Aakre M, Lundquist CA, Engel ME, et al. Transforming growth factor- $\beta 1$ mediates epithelial to mesenchymal transdifferentiation through a RhoA-dependent mechanism. Molecular biology of the cell. 2001;12(1):27-36. Epub 2001/02/13. pmid:11160820; PubMed Central PMCID: PMC30565.

98. . Miettinen PJ, Ebner R, Lopez AR, Derynck R. TGF- $\beta$ induced transdifferentiation of mammary epithelial cells to mesenchymal cells: involvement of type I receptors. The Journal of cell biology. 1994;127(6 Pt 2):2021-36. Epub 1994/12/01. pmid:7806579; PubMed Central PMCID: PMC2120317.

99. Tirino V, Camerlingo R, Bifulco K, Irollo E, Montella R, Paino F, et al. TGF- $\beta 1$ exposure induces epithelial to mesenchymal transition both in CSCs and nonCSCs of the A549 cell line, leading to an increase of migration ability in the $\mathrm{CD}_{133}{ }^{+}$A549 cell fraction. Cell death \& disease. 2013;4:e620. Epub 2013/05/04. pmid:23640462; PubMed Central PMCID: PMC3674353.

100. Iwano M, Plieth D, Danoff TM, Xue C, Okada H, Neilson EG. Evidence that fibroblasts derive from epithelium during tissue fibrosis. The Journal of clinical investigation. 2002;110(3):341-50. Epub 2002/08/07. pmid:12163453; PubMed Central PMCID: PMC151091. 
101. Rees JR, Onwuegbusi BA, Save VE, Alderson D, Fitzgerald RC. In vivo and in vitro evidence for transforming growth factor- $\beta 1$-mediated epithelial to mesenchymal transition in esophageal adenocarcinoma. Cancer research. 2006;66(19):9583-90. Epub 2006/10/05. pmid:170186

102. Rastaldi MP, Ferrario F, Giardino L, Dell'Antonio G, Grillo C, Grillo P, et al. Epithelial-mesenchymal transition of tubular epithelial cells in human renal biopsies. Kidney international. 2002;62(1):137-46. Epub 2002/06/26. pmid:12081572.

103. Kim KK, Kugler MC, Wolters PJ, Robillard L, Galvez MG, Brumwell AN, et al. Alveolar epithelial cell mesenchymal transition develops in vivo during pulmonary fibrosis and is regulated by the extracellular matrix. Proceedings of the National Academy of Sciences of the United States of America. 2006;103(35):13180-5. Epub 2006/08/23. pmid:16924102; PubMed Central PMCID: PMC1551904.

104. Zeisberg M, Yang C, Martino M, Duncan MB, Rieder F, Tanjore H, et al. Fibroblasts derive from hepatocytes in liver fibrosis via epithelial to mesenchymal transition. The Journal of biological chemistry. 2007;282(32):23337-47. Epub 2007/06/15. pmid:17562716.

105. Nakaya Y, Sheng G. Epithelial to mesenchymal transition during gastrulation: an embryological view. Development, growth \& differentiation. 2008;50(9):75566. Epub 2008/12/03. pmid:19046163. 
106. Tarin D, Thompson EW, Newgreen DF. The fallacy of epithelial mesenchymal transition in neoplasia. Cancer research. 2005;65(14):5996-6000; discussion -1. Epub 2005/07/19. pmid:16024596.

107. Kriz W, Kaissling B, Le Hir M. Epithelial-mesenchymal transition (EMT) in kidney fibrosis: fact or fantasy? The Journal of clinical investigation. 2011;121(2):468-74. Epub 2011/03/04. pmid:21370523; PubMed Central PMCID: PMC3026733.

108. Fragiadaki M, Mason RM. Epithelial-mesenchymal transition in renal fibrosisevidence for and against. International journal of experimental pathology. 2011;92(3):143-50. Epub 2011/05/11. pmid:21554437; PubMed Central PMCID: PMC3101487.

109. You S, Avidan O, Tariq A, Ahluwalia I, Stark PC, Kublin CL, et al. Role of epithelial-mesenchymal transition in repair of the lacrimal gland after experimentally induced injury. Investigative ophthalmology \& visual science. 2012;53(1):126-35. Epub 2011/10/26. pmid:22025566; PubMed Central PMCID: PMC3292353.

110. Gershengorn MC, Hardikar AA, Wei C, Geras-Raaka E, Marcus-Samuels B, Raaka BM. Epithelial-to-mesenchymal transition generates proliferative human islet precursor cells. Science. 2004;306(5705):2261-4. Epub 2004/11/27. pmid: 15564314. 
111. Minami K, Okuno M, Miyawaki K, Okumachi A, Ishizaki K, Oyama K, et al. Lineage tracing and characterization of insulin-secreting cells generated from adult pancreatic acinar cells. Proceedings of the National Academy of Sciences of the United States of America. 2005;102(42):15116-21. Epub 2005/10/08. pmid:16210247; PubMed Central PMCID: PMC1257737.

112. Sorrentino A, Thakur N, Grimsby S, Marcusson A, von Bulow V, Schuster N, et al. The type I TGF- $\beta$ receptor engages TRAF6 to activate TAK1 in a receptor kinase-independent manner. Nature cell biology. 2008;10(10):1199-207. Epub 2008/09/02. pmid:18758450.

113. Docherty NG, Calvo IF, Quinlan MR, Perez-Barriocanal F, McGuire BB, Fitzpatrick JM, et al. Increased E-cadherin expression in the ligated kidney following unilateral ureteric obstruction. Kidney international. 2009;75(2):20513. Epub 2008/09/27. pmid:18818685. 114. Day ML, Zhao X, Vallorosi CJ, Putzi M, Powell CT, Lin C, et al. E-cadherin mediates aggregation-dependent survival of prostate and mammary epithelial cells through the retinoblastoma cell cycle control pathway. The Journal of biological chemistry. 1999;274(14):965664. Epub 1999/03/27. pmid:10092652.

115. Boussadia O, Kutsch S, Hierholzer A, Delmas V, Kemler R. E-cadherin is a survival factor for the lactating mouse mammary gland. Mechanisms of development. 2002;115(1-2):53-62. Epub 2002/06/07. pmid:12049767. 


\section{VITA}

Mahmoud Galal Khalafalla was born September 18th, 1981, in Wurzburg, Germany. After graduating from high school in his hometown, Mahmoud joined the School of Pharmacy, Cairo University, Egypt and received a B.S. degree in Pharmaceutical Sciences in 2003. In the fall of 2011, Mahmoud started his Ph.D. program in the Department of Biochemistry at the University of Missouri, USA, under the supervision of Dr. Gary A. Weisman. 